\title{
FLEXURAL BEHAVIOR OF INTERLOCKING COMPRESSED EARTH BLOCK SHEAR WALLS SUBJECTED TO IN-PLANE LOADING
}

\author{
A Thesis \\ Presented to the Faculty of \\ California Polytechnic State University, \\ San Luis Obispo
}

\begin{abstract}
In Partial Fulfillment
of the Requirements for the Degree of

Master of Science in Civil and Environmental Engineering
\end{abstract}

by

Bradley James Stirling

July 2011 
(C) 2011

\section{BRADLEY JAMES STIRLING}

ALL RIGHTS RESERVED

ii 


\section{COMMITTEE MEMBERSHIP}

TITLE: $\quad$ Flexural Behavior of Interlocking Compressed Earth Block Shear Walls Subjected to In-plane Loading
AUTHOR:
Bradley James Stirling

DATE SUBMITTED:

July 2011

COMMITTEE CHAIR: $\quad$ Bing Qu, Assistant Professor

COMMITTEE MEMBER: Daniel Jansen, Associate Professor

COMMITTEE MEMBER: $\quad$ Peter Laursen, Assistant Professor 


\title{
ABSTRACT \\ Flexural Behavior of Interlocking Compressed Earth \\ Block Shear Walls Subjected to In-Plane Loading
}

\author{
Bradley James Stirling
}

This thesis investigates the flexural behavior of interlocking compressed earth block (ICEB) shear walls. In-plane cyclic tests were conducted to evaluate the performance of three flexure dominant large scale ICEB specimens: a slim wall with a 2:1 height to width aspect ratio, a flanged wall, and a wall with an opening at the center. Following the experimental investigation, two types of analyses were conducted for calculating the ultimate strength of flexure dominant ICEB walls: a nonlinear static analysis model assuming lumped plasticity and a plastic analysis model. In addition, incremental dynamic analysis was conducted to address the seismic performance of flexure dominant ICEB buildings. Based on the database from the incremental dynamic analysis, the collapse potential of demonstration ICEB buildings were compared for the countries of interest.

Keywords: interlocking compressed earth block, flexural behavior, cyclic testing; nonlinear analysis. 


\section{ACKNOWLEDGEMENTS}

The completion of this project would not have been possible without the help and support of countless individuals who dedicated their time, expertise, and support for which I am extremely grateful.

A special thanks to my fellow students who have helped make this project a success, in particular, David Bland and Clayton Proto for the countless hours dedicated to forming the groundwork for this project. Your friendship and dedication to this project have been extraordinary. Also thank you to the students of CE 557 who helped in the seismic analysis of the project, with a particular thanks to Anthony Trgovcich for his help interfacing Matlab with structural analysis software used in this thesis.

I cannot thank my advisor Bing Qu enough for the amount of time and hard work he has dedicated to ensuring that this project was a success. Your continuous guidance, enthusiasm and encouragement have helped take this project from concept phase to completion. It has been both an honor and pleasure to work with you. I would also like to thank Dan Jansen for his guidance throughout the testing process and insight into the proper specimen instrumentation. Your professionalism and commitment to excellence are appreciated. Much thanks to Peter Laursen for the insight shared into masonry construction and analysis that accompanied this project.

To my friends and family who have seen me thought all the ups and downs of this project, thank you! Your love and encouragement have helped me in ways you cannot fathom and will forever be remembered and appreciated. 


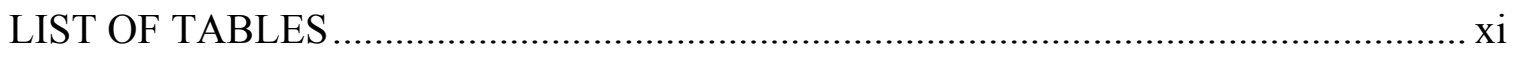

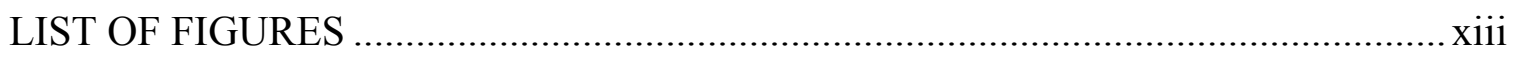

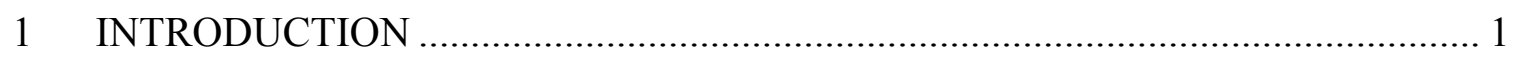

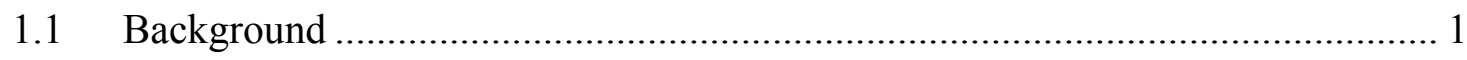

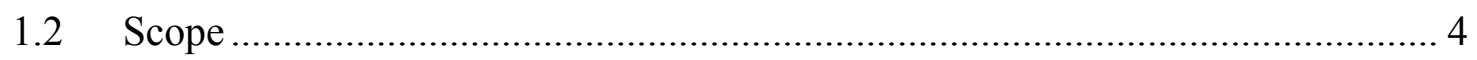

1.3 Organizational of Contents....................................................................... 5

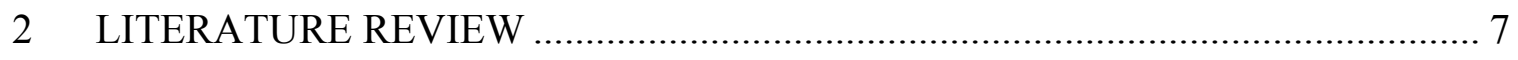

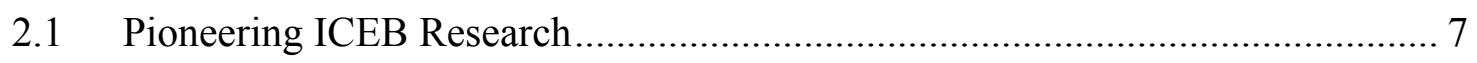

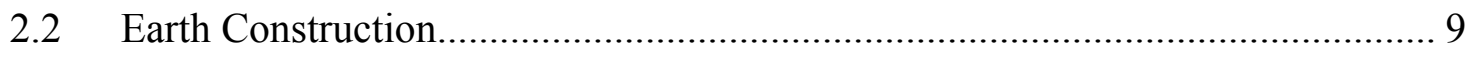

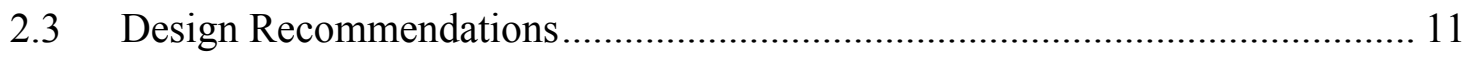

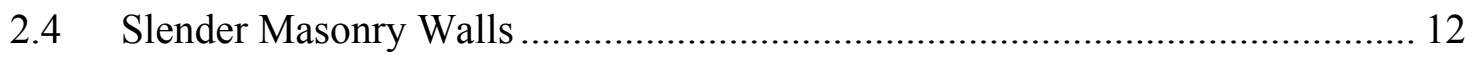

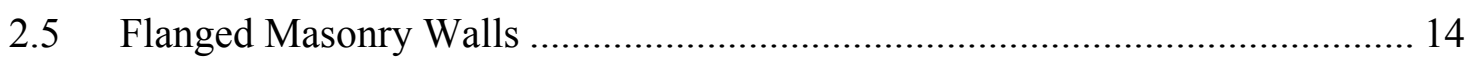

2.6 Masonry Shear Walls with Opening ............................................................ 15

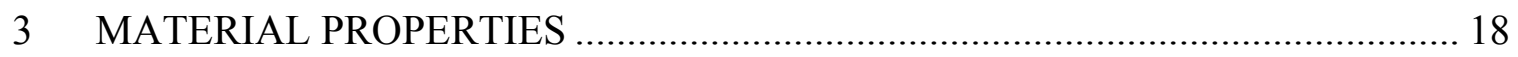

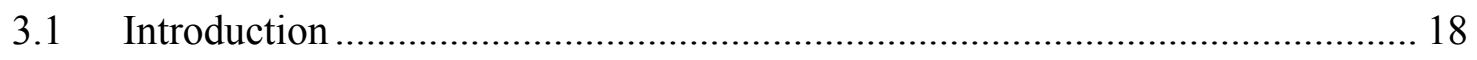

3.2 Interlocking Compressed Earth Blocks.......................................................... 18

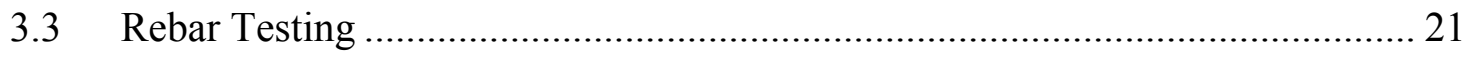

3.4 Masonry Prism Testing ............................................................................ 22

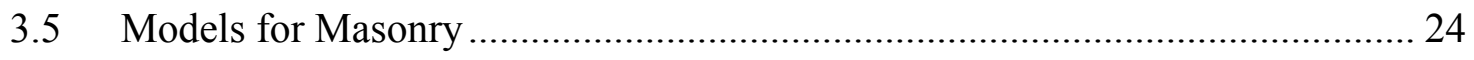

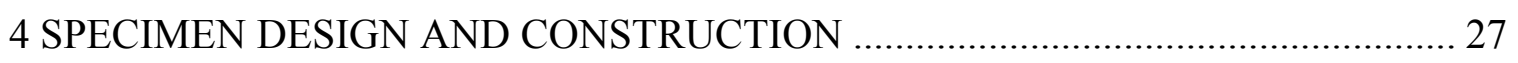




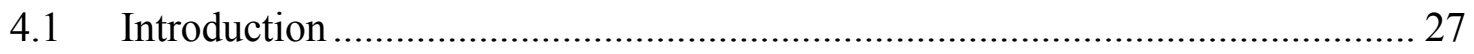

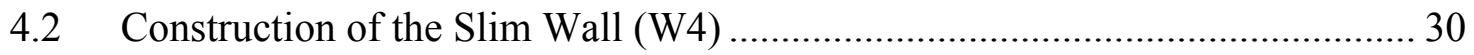

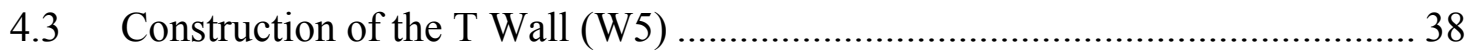

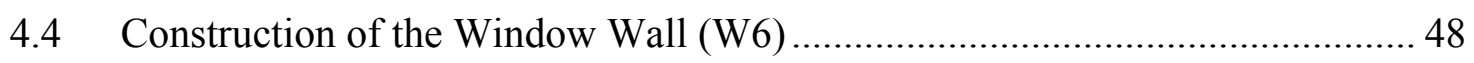

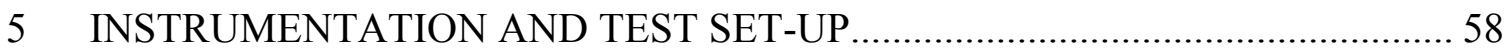

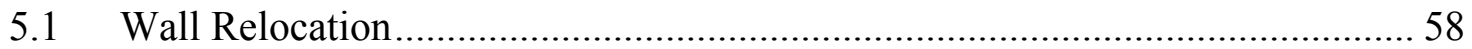

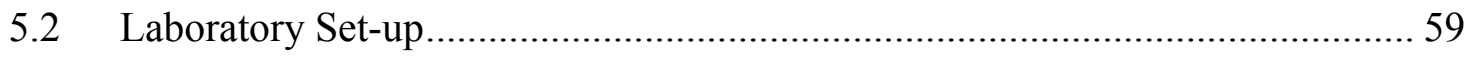

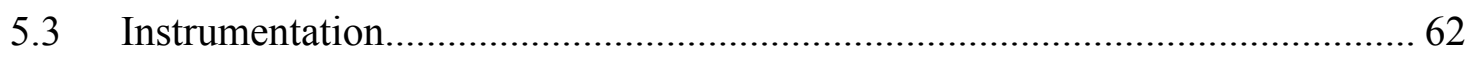

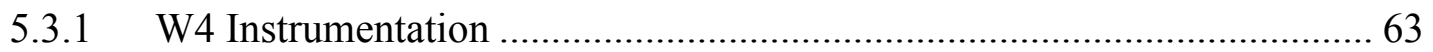

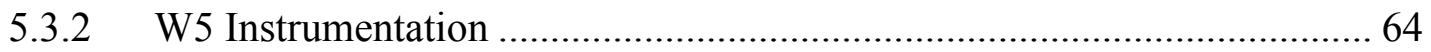

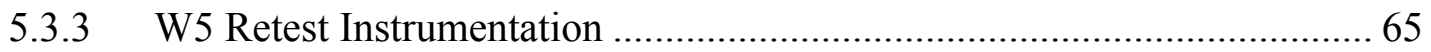

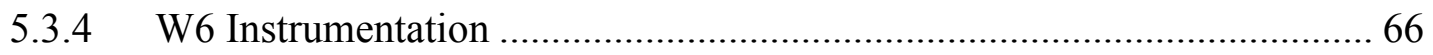

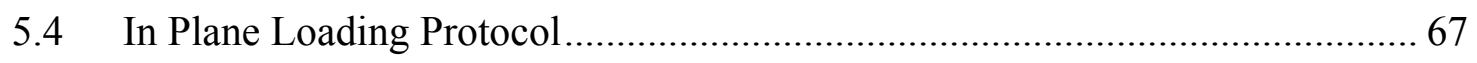

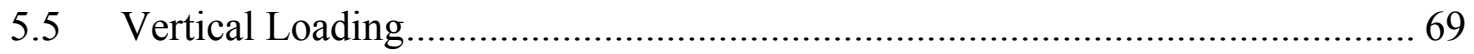

6 OBSERVATIONS FROM THE TESTS .................................................. 70

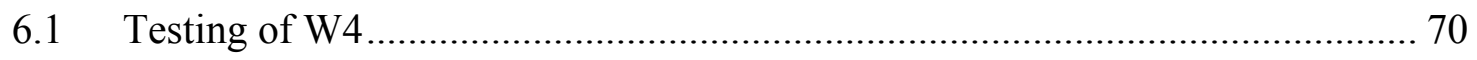

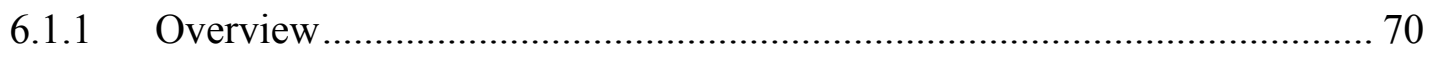

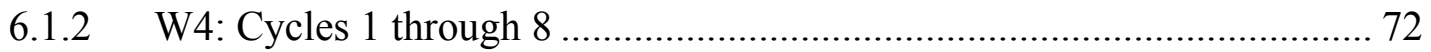

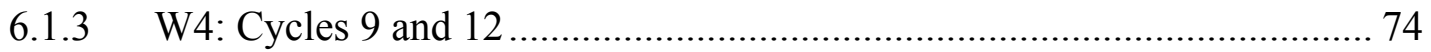

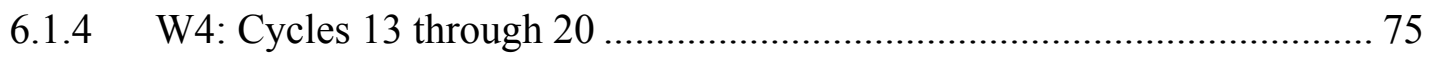

vii 


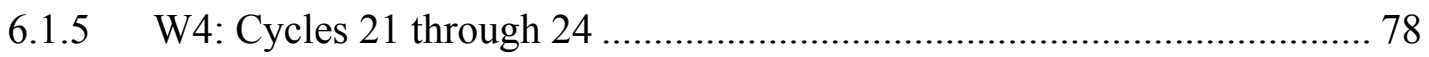

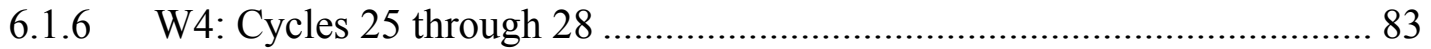

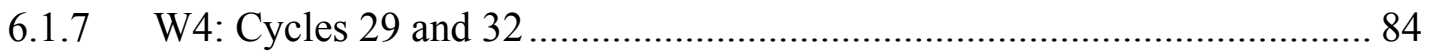

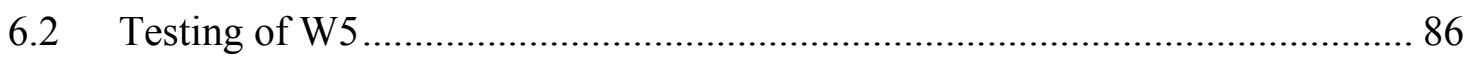

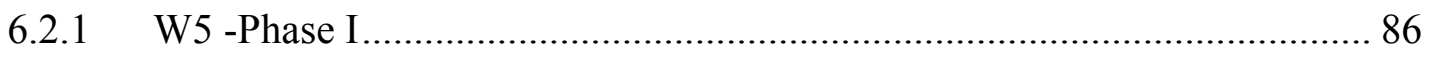

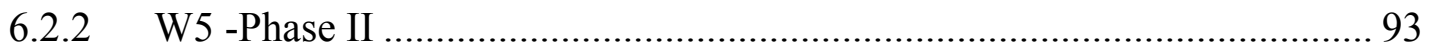

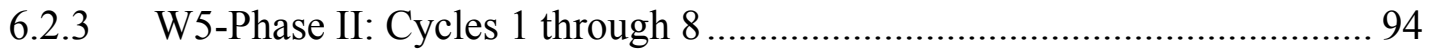

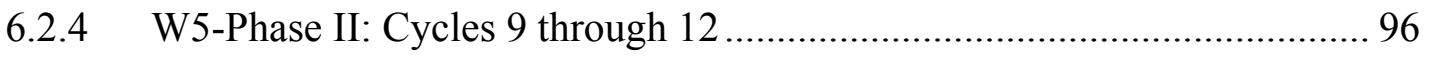

6.2.5 W5-Phase II: Cycles 13 Through 16................................................ 98

6.2.6 W5-Phase II: Cycles 17 through 20 ............................................... 100

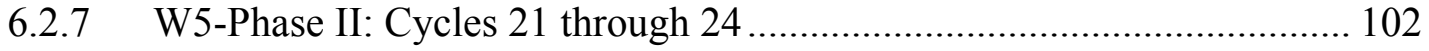

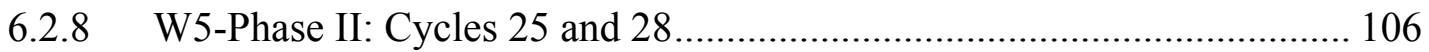

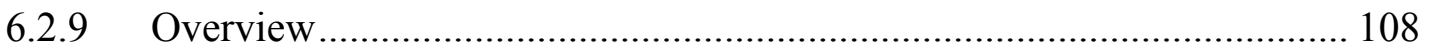

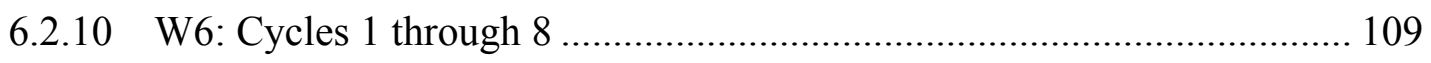

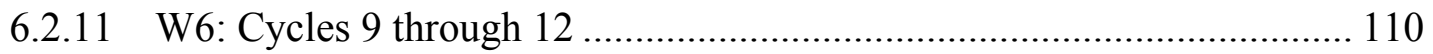

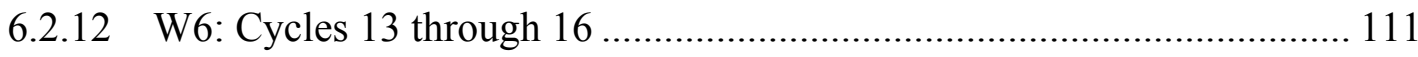

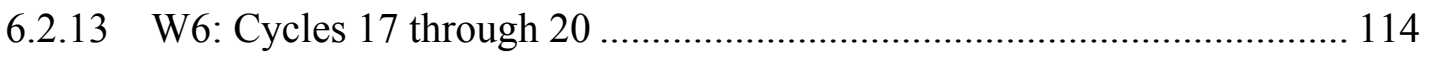

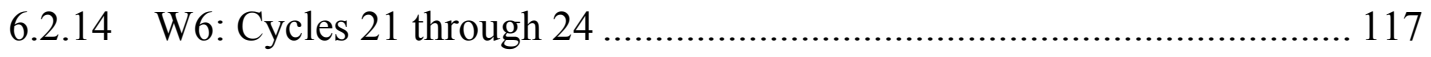

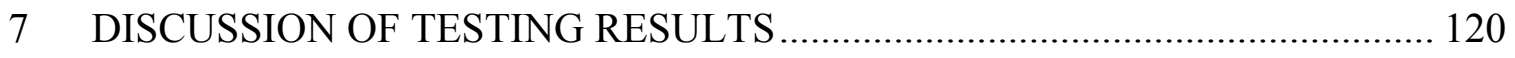

7.1 Hysteretic Curves ............................................................................ 120 


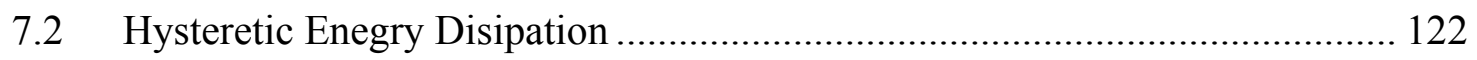

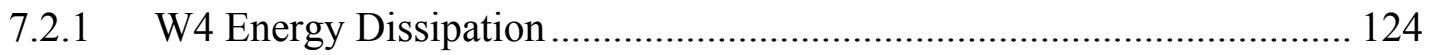

7.2.2 W5 Energy Dissipation .................................................................. 125

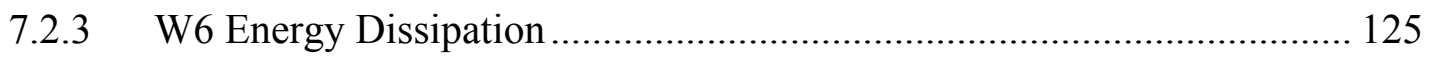

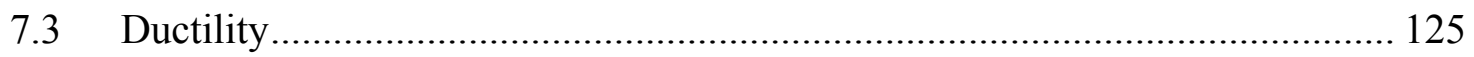

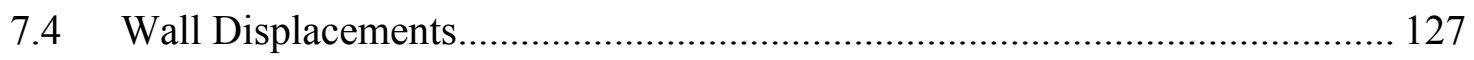

7.4.1 W4

7.4.2 W5

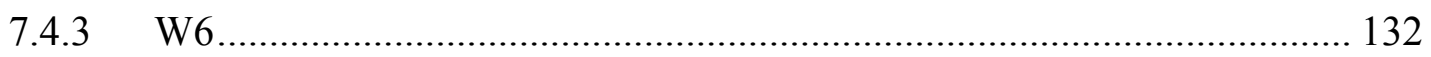

7.5 Plastic Moment Resistance and Lateral Strength of Specimens ....................... 133

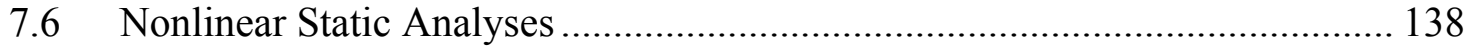

8 SEISMIC PERFORMANCE OF FLEXURE DOMINANT ICEB WALLS ......... 143

8.1 Description and Validation of the Computer Model........................................ 143

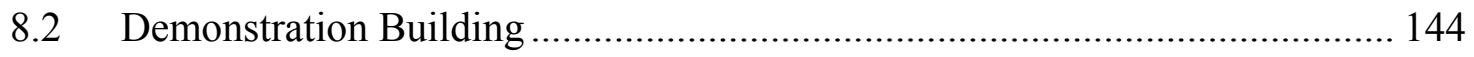

8.2.1 Geometries and Materials of the Demonstration Buildings....................... 145

8.2.2 Determination of Fundamental Period.................................................... 146

8.3 Incremental dynamic analysis ..................................................................... 149

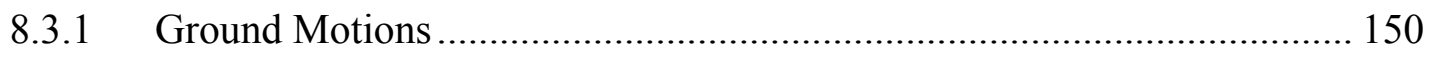

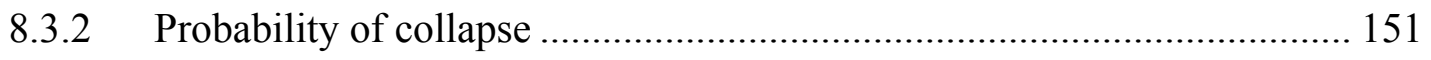

8.4 Discussion of ICEB structures at different sites........................................... 154 
9 CONCLUDING REMARKS AND FUTURE WORK

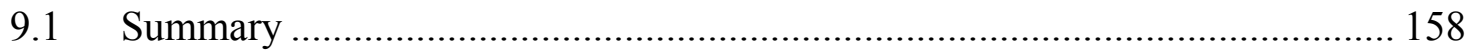

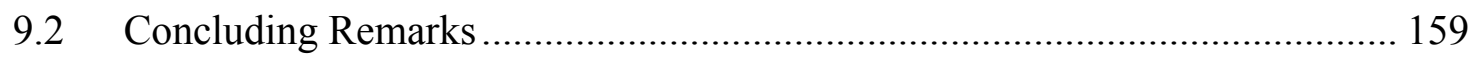

9.2.1 Findings from Experimental Results ....................................................... 159

9.2.2 Findings from Analytical Results ........................................................ 160

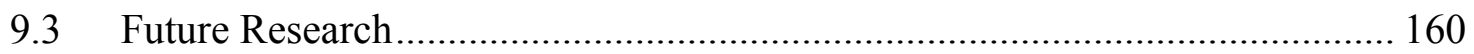

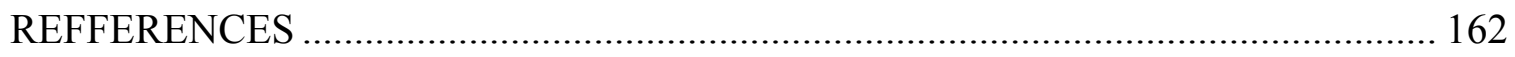

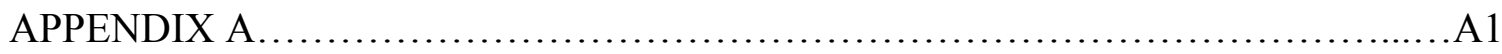

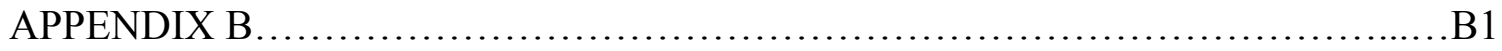

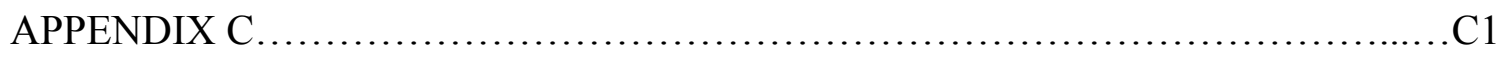




\section{LIST OF TABLES}

Table 3-1: ICEB mixture proportion for an 8 block mix (Proto et al., 2010)................... 20

Table 3-2: ICEB produced for specimen construction ............................................ 20

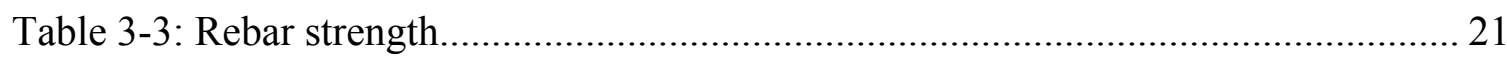

Table 3-4: Average Prism Compressive Strength...................................................... 24

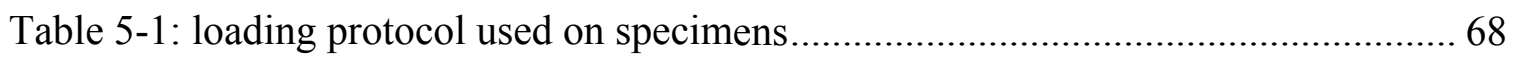

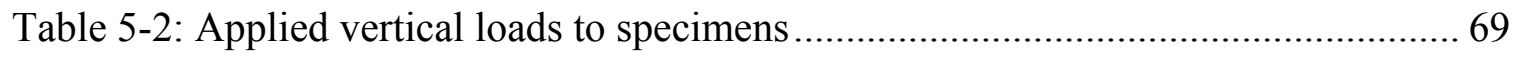

Table 7-1 Maximum displacement and forces of specimens ................................. 121

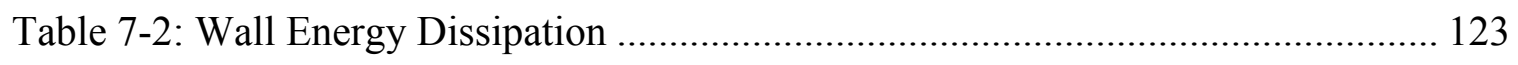

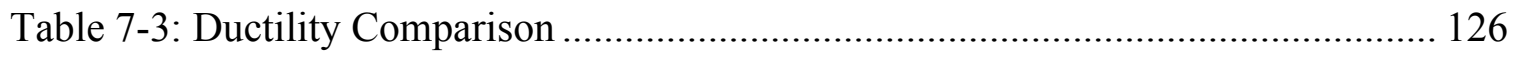

Table 7-4: Instrument distances for W4 and W5 retest ......................................... 131

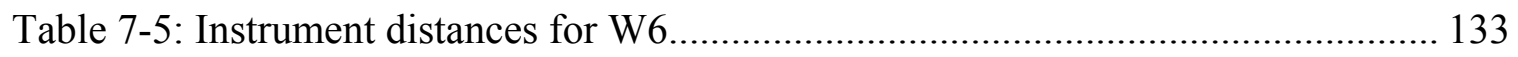

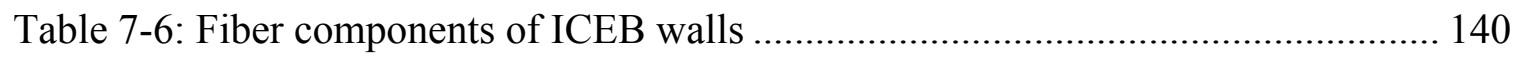

Table 8-1: Properties of demonstration buildings.................................................. 148

Table 8-2: PSA values for 50\% collapse probability ........................................... 154

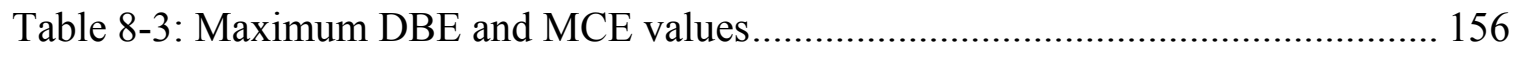

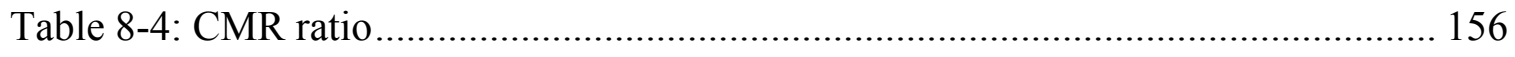

Table A-1: ICEB prism compressive strength..................................

Table A-2: ICEB compressive strength................................ A-2

Table A-3: Rebar tensile test data.........................................

Table A-4: Grout and Mortar Proportions . ................................. A-4

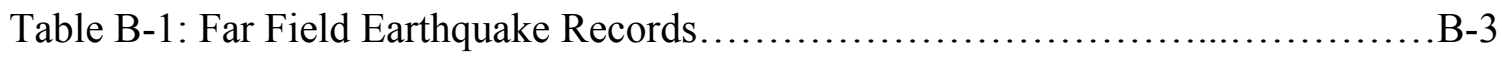


Table B-2: Near Field Earthquake Records............................... B-4

Table C-1: Thailand Seismic Design Factors....................................

Table C-2: Seismic Factor for each Zone.................................

Table C-3: Structural Factor for Different Type Buildings..........................

Table C-4: Resonance Coefficient as a function of Soil Type......................

Table C-5: Seismic Importance factor based on Structure use........................

Table C-6: Summary of Spectral Acceleration values of the sites in Thailand......... C-5

Table C-7: Indonesia Seismic Design Factors..................................

Table C-8: Importance factors for Buildings in Indonesia..........................

Table C-9: Structural factor for Indonesian Building ..............................

Table C-10: Location based design factors....................................... 


\section{LIST OF FIGURES}

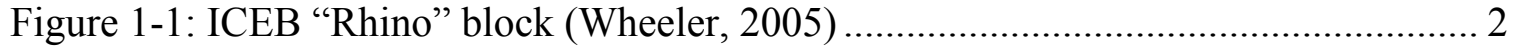

Figure 1-2: Soeng Thai BP6 Block press........................................................................ 2

Figure 1-3: Various forms of ICEBs used in building construction ............................... 3

Figure 2-1: Compressed Earth Blocks produced by Aurum press 3000 ......................... 9

Figure 2-2: Failure Mechanism for Shear walls with openings .................................. 17

Figure 3-1: The six types of blocks used in wall construction ................................... 19

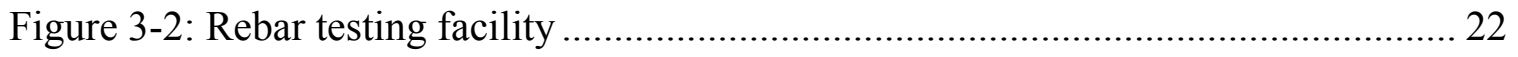

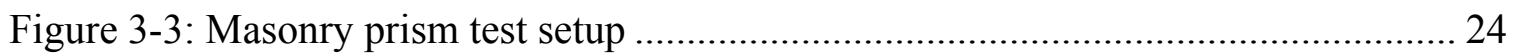

Figure 3-4: Stress vs. Strain Data from Masonry Prism Tests...................................... 26

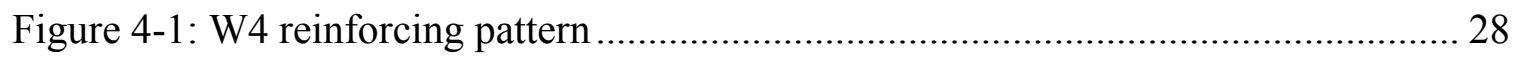

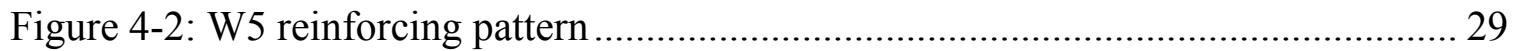

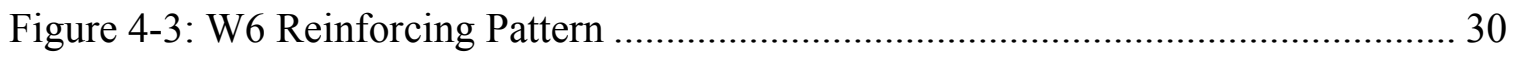

Figure 4-4: Rebar Anchored Footing of W4 …................................................... 32

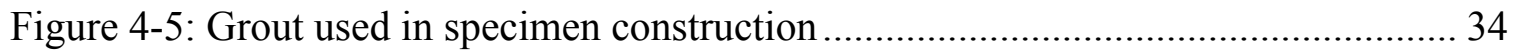

Figure 4-6: Plywood confinements for grout keys ................................................ 36

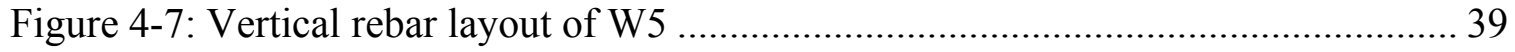

Figure 4-8: Modification of end blocks for reinforcement ................................... 40

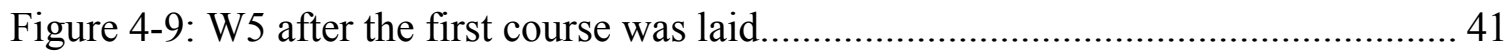

Figure 4-10: Course 1 of W5 with shear reinforcement placed.................................. 42

Figure 4-11: Cobraand Peacock Pattern for intersecting Walls ................................ 43

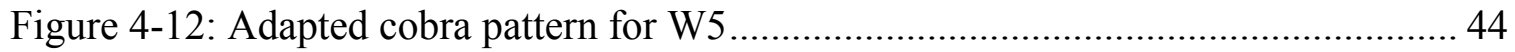

xiii 
Figure 4-13: Courses 1 through 5 of W5 after grouting, .......................................... 45

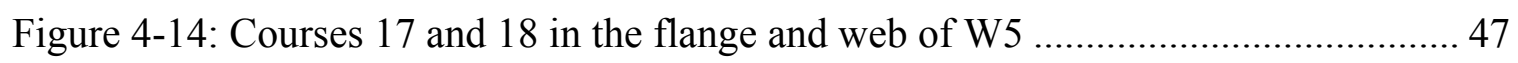

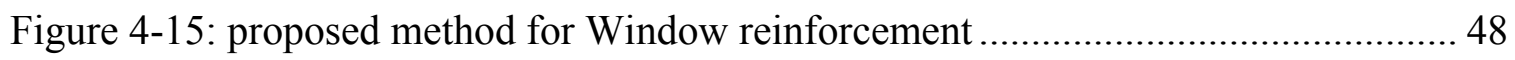

Figure 4-16: Revised method for window reinforcement to prevent corner tearing ........ 48

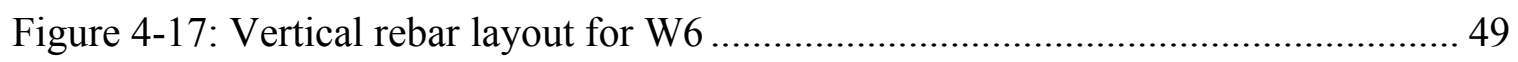

Figure 4-18: Transverse reinforcement hooked around vertical rebar of W6 ................ 51

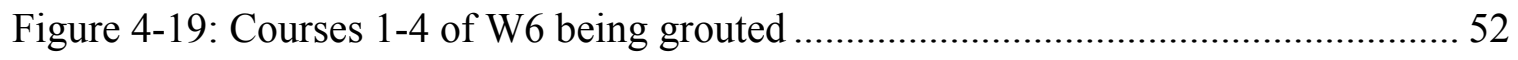

Figure 4-20: Schematic of the timber frame for the window..................................... 54

Figure 4-21: shear reinforcement design of W6 header............................................. 55

Figure 4-22: Setting the shear reinforcement for the lintel of W6 ...............................56

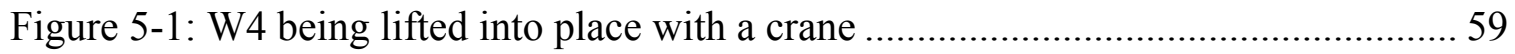

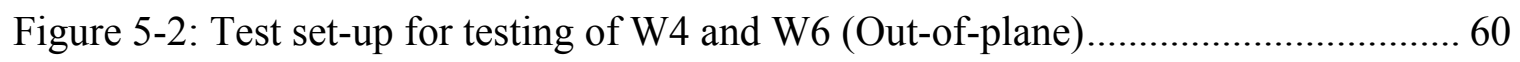

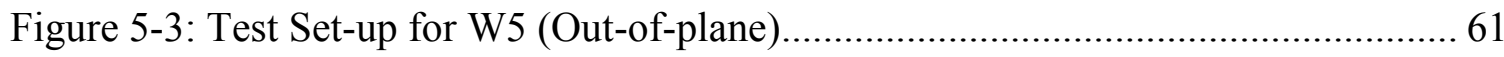

Figure 5-4: Steel loading beam used for load transfer from the actuator to wall ............ 62

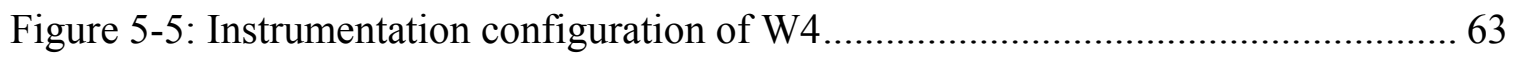

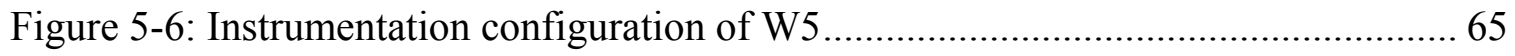

Figure 5-7: Instrumentation configuration of W5 after reinforced concrete retrofit ........ 66

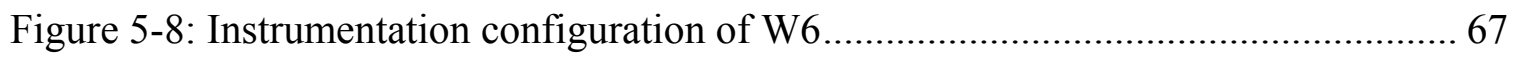

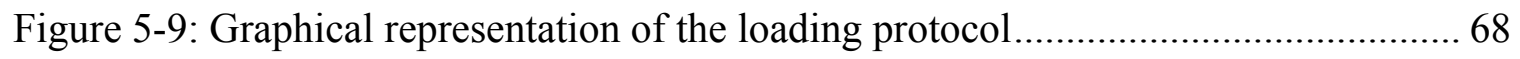

Figure 6-1: W4 footing slip vs. lateral displacement of actuator................................ 70

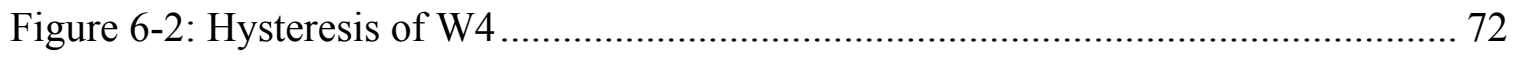

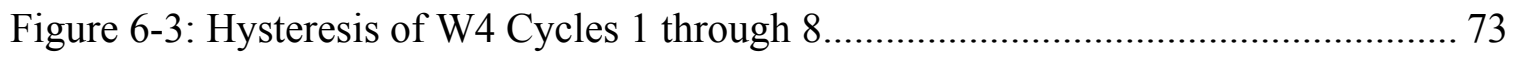

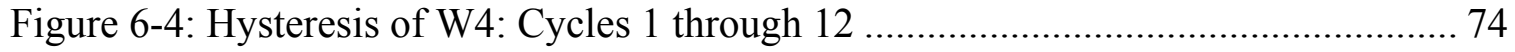


Figure 6-5: Cracking at the base of W4 during Cycle 10 .......................................... 75

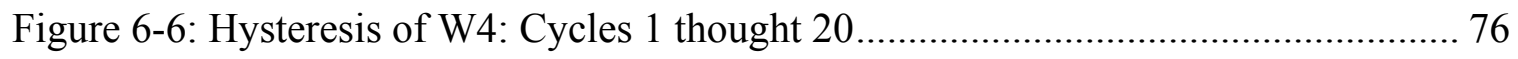

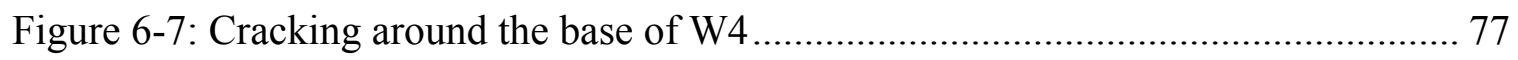

Figure 6-8: W4 cracking around the grout channel and the loading beam..................... 78

Figure 6-9: Shearing between courses of W4 and the mortar in the footing ................... 79

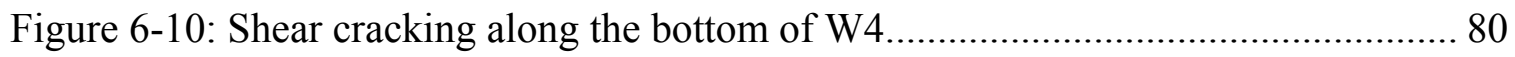

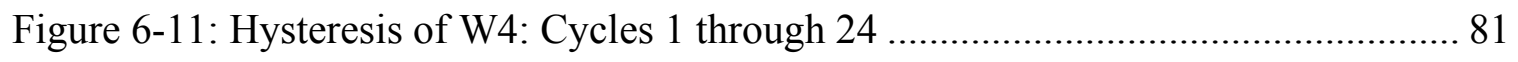

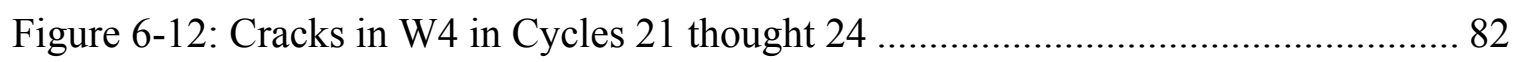

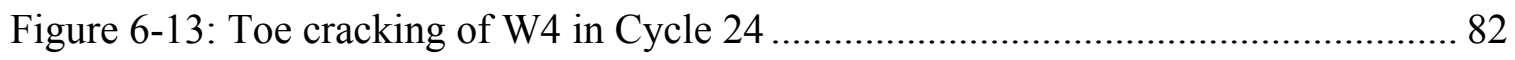

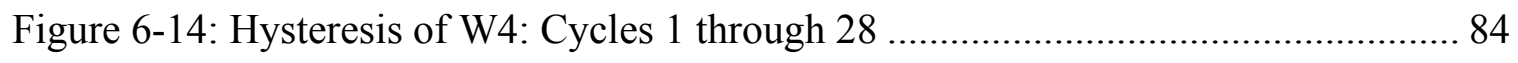

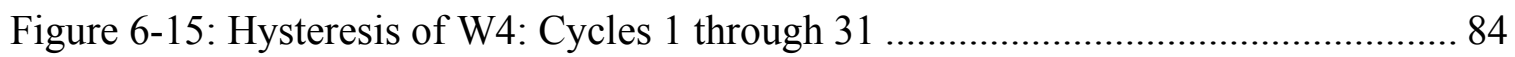

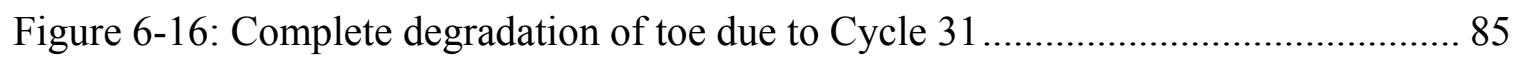

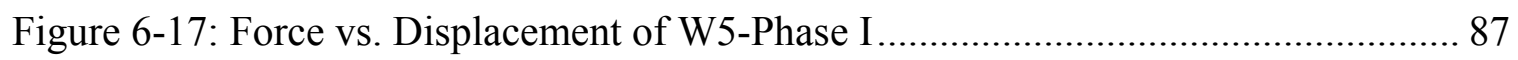

Figure 6-18: Damages in W5 Web resulting from mechanical failure of actuator........... 88

Figure 6-19: Compression failure at the intersection of the web and flange .................. 89

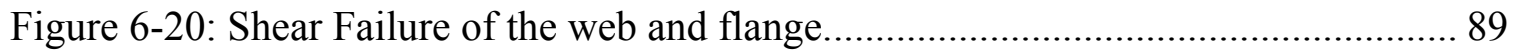

Figure 6-21: Repair of the web of W5 before reinforced concrete was cast .................. 91

Figure 6-22: Repair of the flange of W5 before reinforced concrete was cast ............... 91

Figure 6-23: Web of W5 after removal of the reinforced concrete formwork ............... 92

Figure 6-24: Flange of W5 after removal of the reinforced concrete formwork ............. 93

Figure 6-25: Hysteresis of W5-Phase II.......................................................... 94

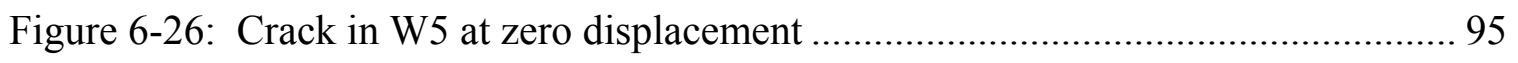

Figure 6-27: Crack in the W5 at maximum displacement of cycle 8 ........................... 95 
Figure 6-28: Hysteresis of W5- Phase II: Cycles 1 thought $8 \ldots \ldots \ldots \ldots \ldots \ldots \ldots \ldots \ldots \ldots \ldots \ldots . . . . . . . \ldots 6$

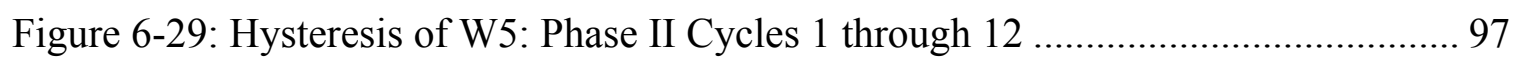

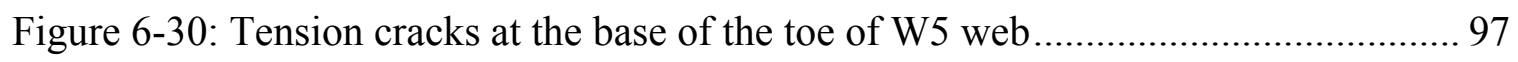

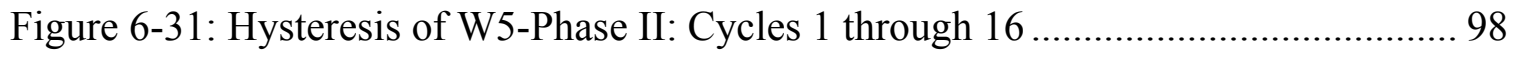

Figure 6-32: Spalling of the outer grout channel of the W5 web during Cycle 16.......... 99

Figure 6-33: Cracking of W5 web at zero displacement after Cycle 16...................... 100

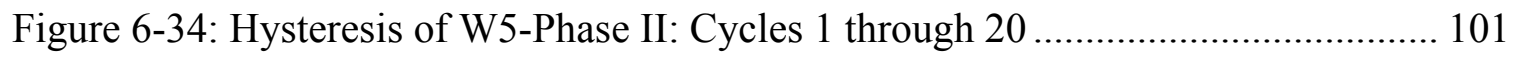

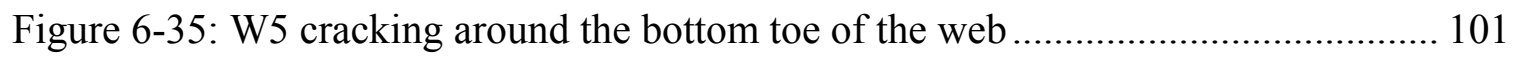

Figure 6-36: Spalling of the ICEBs and grout around the toe of W5 web..................... 102

Figure 6-37: Buckling of unconfined rebar subjected to compressive force................ 103

Figure 6-38: Unconfined rebar in tension during the push..................................... 103

Figure 6-39: External spalling of ICEBs at the web toe of W5 ................................ 104

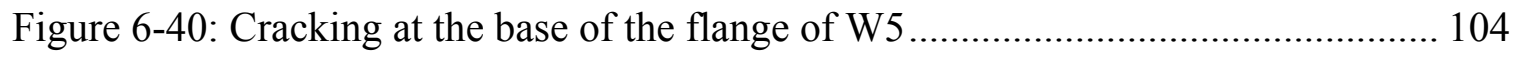

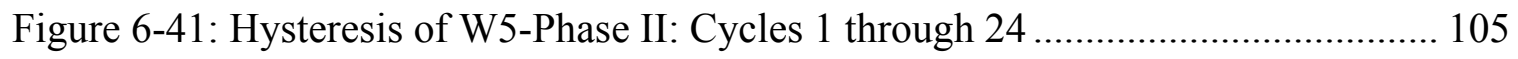

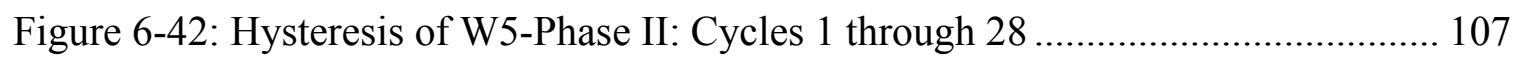

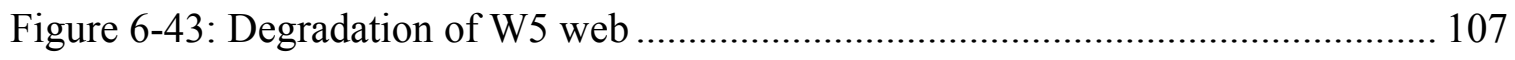

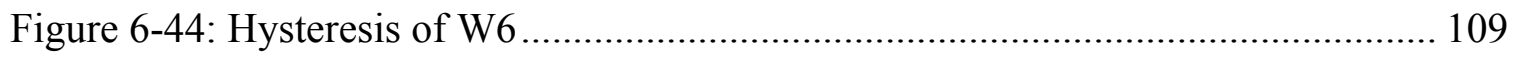

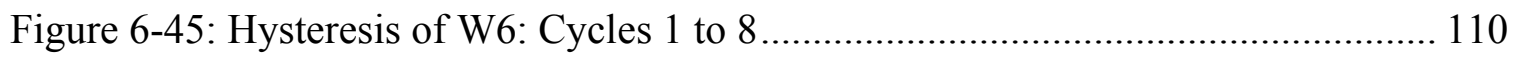

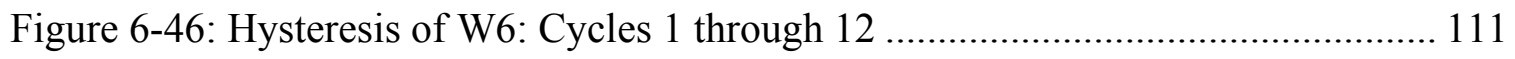

Figure 6-47: W6 cracking around the sill of the windows following Cycle 14............ 112

Figure 6-48: W6 diagonal cracking observed in the left pier after Cycle 16............... 113

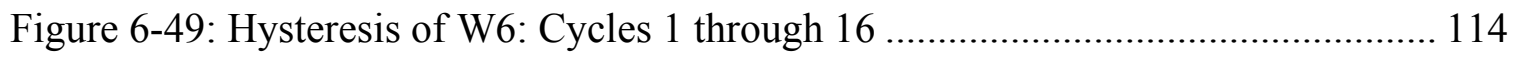

Figure 6-50: New cracks observed in W6 during Cycles 9 and 10 ........................... 115 


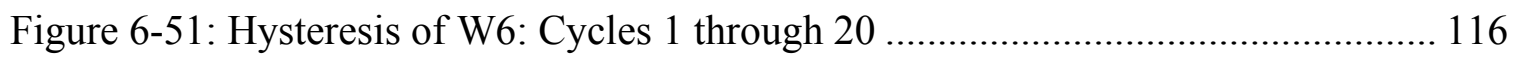

Figure 6-52: Hysteresis of W6: Cycles 1 though 24 ………...................................... 117

Figure 6-53: Cracking pattern of W6 prior to Cycle 21.............................................. 118

Figure 6-54: Cracking pattern of W6 following Cycle 22 .......................................... 118

Figure 6-55: Damage in W6 following Cycle 24...................................................... 119

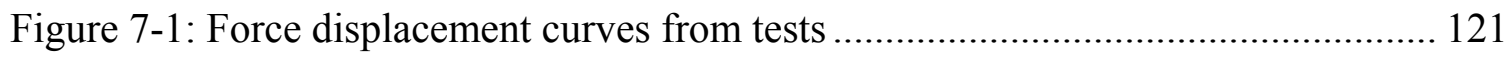

Figure 7-2: Envelopes of the hysteretic curves ....................................................... 122

Figure 7-3: Cumulative energy dissipation comparison ........................................... 123

Figure 7-4: Normalized cumulative energy dissipation comparison .............................. 124

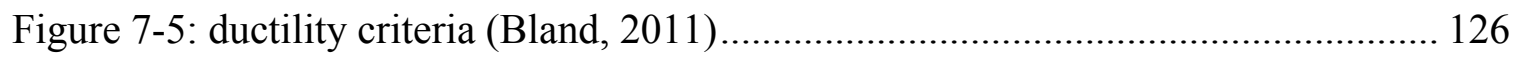

Figure 7-6: Arrangement for rocking deformation instruments .................................. 128

Figure 7-7: Arrangement for shear deformation instruments (from Voon,2007)........... 129

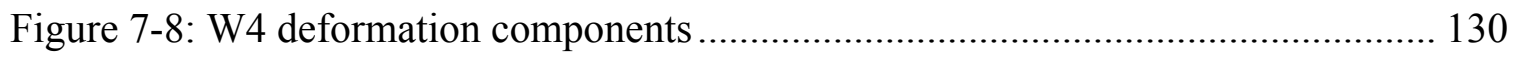

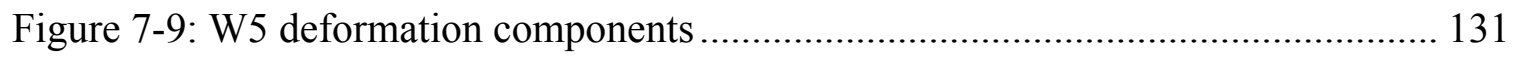

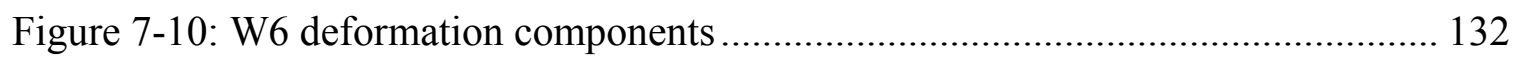

Figure 7-11: W6 shear and bending instrumentation.................................................. 132

Figure 7-12: Idealized normal stress and strain relations (Bland, 2011) ....................... 134

Figure 7-13: Lateral force resistance determination for W6 ........................................ 136

Figure 7-14: Lateral force resistance comparisons: Analytical vs. Testing Data ........... 137

Figure 7-15: Generic Fiber from SAP 2000 model .................................................. 139

Figure 7-16: Lateral force resistance comparisons: SAP 2000 vs Test Data................... 141

Figure 7-17: Lateral force resistance comparisons: Analytical vs SAP …………......... 142

Figure 8-1: Comparison of results from test and IDARC ............................................. 144 
Figure 8-2: Demonstration Building for Nonlinear Dynamic Analysis....................... 145

Figure 8-3: Estimated stiffness and hysteretic curves of W4 ................................... 149

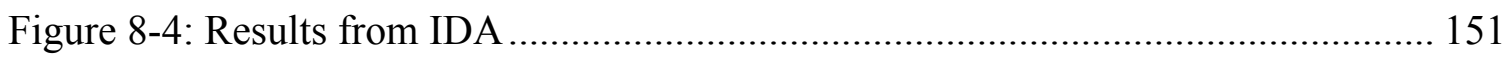

Figure 8-5: Fragility curves of near field ground motions....................................... 153

Figure 8-6: Fragility curves of far field ground motions ...................................... 153

Figure A-1: Stress-Strain data for rebar...................................

Figure C-1: Thailand Seismic Regions (from IISEE)............................

Figure C-2: Seismic Zones for Indonesia.................................

Figure C-3: Indonesia zone based Seismic Design Spectra...........................

Figure C-4: Design Spectra for Cal Poly assuming site class B...................... 10 


\section{INTRODUCTION}

\subsection{Background}

Interlocking compressed earth block (ICEB) construction is a form of dry stack masonry construction used as a low cost building material. The manufacturing and construction process of ICEB buildings requires no special skills and can be performed by inexperienced labors making it an attractive building material for developing countries.

Earth is one of the oldest building materials, and is still widely used around the world. It is estimated that more than 30 percent of the world's building materials are made of various forms of earth construction (Bei and Papayianni, 2003), with the most common forms of earth construction being adobe, rammed earth and compressed earth masonry. Having gained popularity as an aesthetically pleasing, low cost, and sustainable building material, earth masonry construction is becoming more widely used as a form of housing around the world. In 1995 it was estimated that approximately one third of the world's population was housed by unbaked earth wall building (Walker, 1999).

Earth masonry construction can be subdivided into two distinct categories, mortared masonry, and dry stacked masonry. The most common type of dry stacked earth masonry is cement stabilized mechanically compacted earth blocks produced from local soils, sand and cement. Cement contents typically range from 5 to 10 percent, by weight, but can be substituted or supplemented with various types of cementitious materials including but not limited to lime, gypsum, and calcite (Walker 1999). 
The rhino block, shown in Figure 1-1, is a $10 \mathrm{~cm}$ high, $15 \mathrm{~cm}$ wide, and $30 \mathrm{~cm}$ long interlocking compressed earth blocks produced from the Soeng Thai BP6 block press, shown in Figure 1-2. Originally developed in Thailand, the Soeng Thai BP6 is a modern descendant of the smaller CINVA ram block press, used to create the TISTR blocks (Wheeler, 2005). The Soeng Thai BP6 block press uses a combination of removable steel inserts and vertical compression to create blocks of different shapes. As shown in Figure $1-1$, these blocks have a top and bottom interlocking dowels which join together in a form of dry stacked masonry adapted for both vertical and horizontal reinforcement. The wall constructed from "rhino" ICEBs can be used as infill panels for frame structures, but typically as load bearing walls in residential construction, shown in Figure 1-3.

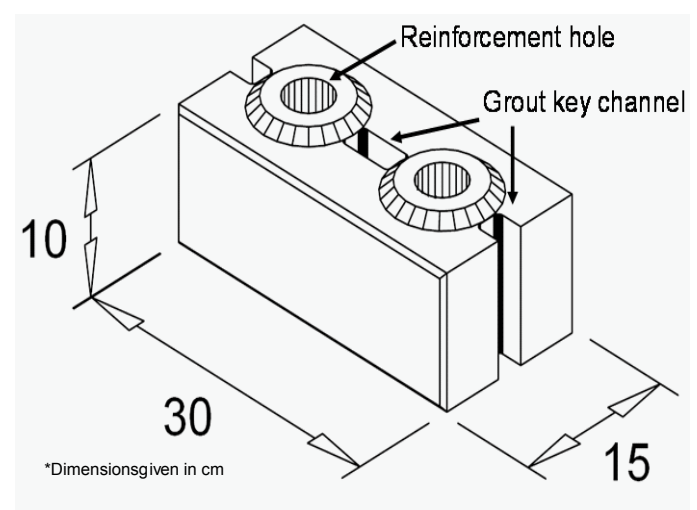

Figure 1-1: ICEB “Rhino” block (Wheeler, 2005)

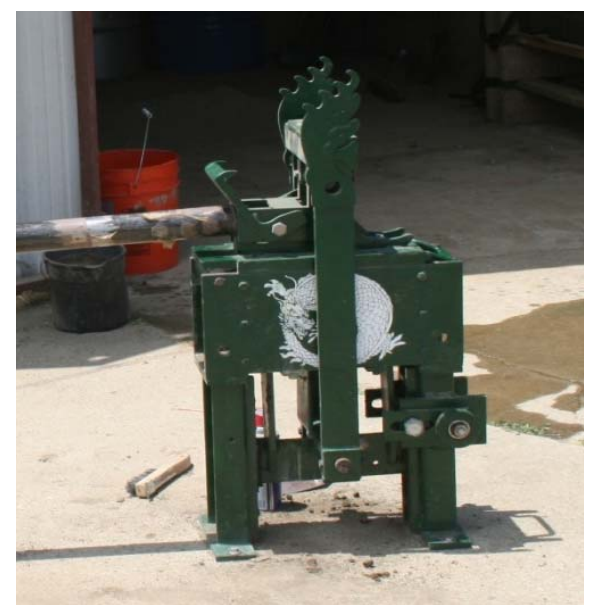

Figure 1-2: Soeng Thai BP6 Block press

This form of dry stack masonry has several advantages in building construction in developing countries. The interlocking dowels easily align adjacent blocks allowing relatively untrained labors to efficiently construct their own dwellings. Not requiring mortar saves construction time, labor and cement used in construction. 


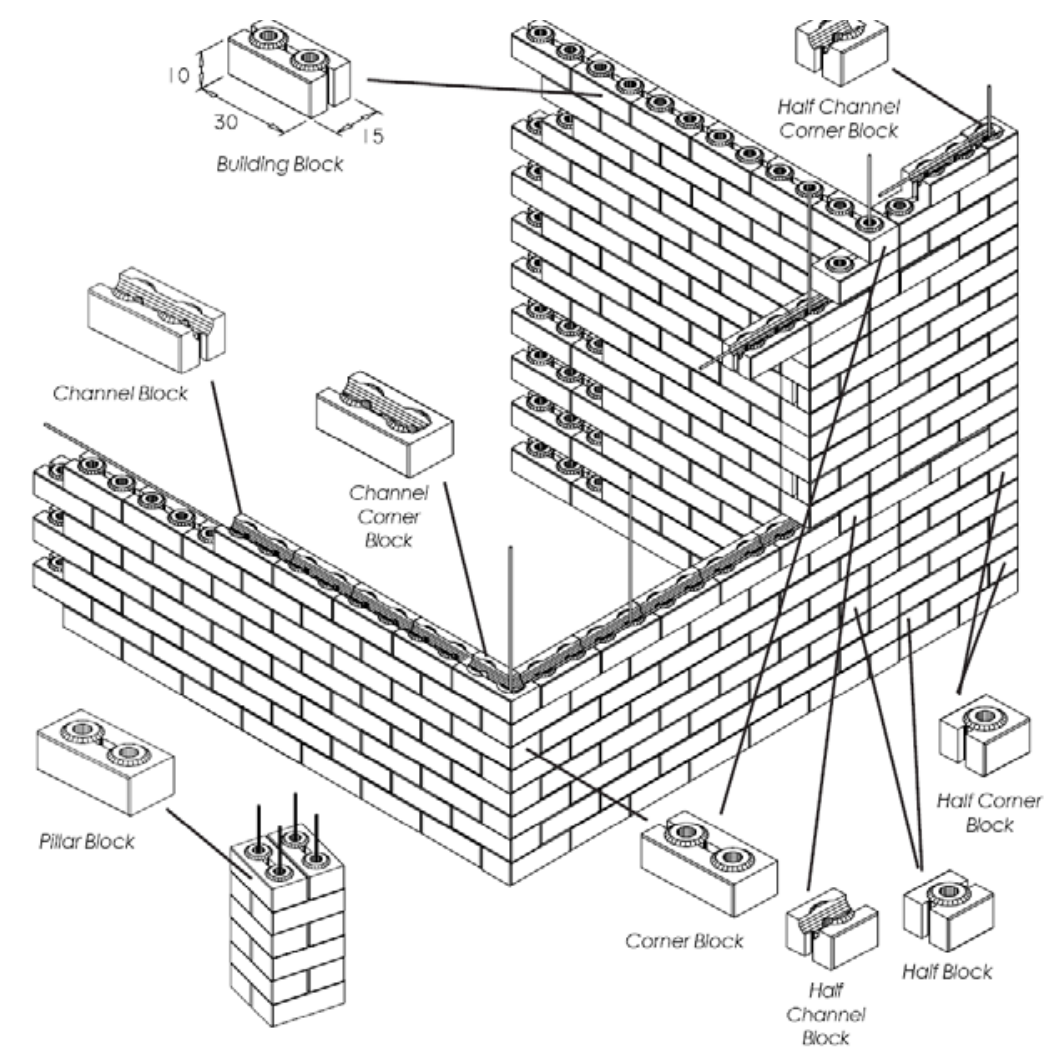

Figure 1-3: Various forms of ICEBs used in building construction (Wheeler, 2005)

The research presented in this thesis builds on a long standing relationship between the Cal Poly San Luis Obispo chapter of Engineers Without Borders chapter and the Center for Vocational Building Technology (CVBT) located in Thailand. Past collaborations with CVBT have resulted in:

- Internships at the CVBT where students preformed design calculations and monitored production efficiency of ICEBs and clay roof tiles.

- A student-led project to design low cost pocket penetrometes used to determine optimal ICEB compaction during the manufacturing process.

- The redesign of the handle latching mechanism of the Soeng Thai BP6 block press used in the production of ICEB. 
- The optimization of Soeng Thai BP6 soil pulverizer, used for soil preparation of ICEBs.

- Experimental research quantifying the structural properties associated with ICEBs as they relate to conventional masonry. These tests included durability testing, compressive testing, and bond strength testing (Bales et al., 2009).

- Development of ICEB manufacturing and construction manual aimed at developing safe and practical methods of construction with ICEB masonry products (Proto et al., 2010).

- Investigation of the performance of large scale ICEB shear walls subjected to cyclic loading (Bland, 2011).

\subsection{Scope}

The ICEB shear wall testing program was initially developed as a two-phase experimental investigation, in which six large-scale specimens were to be tested. Phase 1 was completed in a companion thesis (Bland, 2011), in which three 1:1 aspect ratio shear walls were tested, and the shear behavior was investigated. Phase 2 , reported in this thesis, focuses on the experimental investigation of the flexural behavior of another three large-scale ICEB specimens with different shapes. In addition, analytical models for estimating the ultimate strength of the flexure dominant ICEB walls will be addressed together with a seismic evaluation of ICEB demonstration buildings for the countries of interest. 


\subsection{Organizational of Contents}

This thesis includes nine individual chapters which will provide a brief review of previous research, tested material properties, specimen design and construction, instrumentation and test set-up, experimental observations, testing results and comparison, seismic analysis and conclusions.

Chapter 2 presents a review of previous research relating to the structural properties of compressed earth as well as previous research relating to the testing of masonry shear walls.

Chapter 3 presents the material properties jointly tested in both the companion thesis (Bland, 2011) and this thesis. The results from the materials testing presented in this chapter are later used in the modeling and analysis of the three tested specimens.

Chapter 4 presents the design and construction of the three ICEB specimens tested in this thesis. This chapter covers the reinforcement arraignments, the method of construction, methods for proper grouting, course alignment, design considerations for construction and post construction curing procedures for each specimen.

Chapter 5 presents the laboratory test set-up and procedure for testing each specimen. The relocation of the specimens, instrumentation of the individual specimen and application of the vertical and lateral loads are discussed.

Chapter 6 discusses the failure mode, formation of crack, and accounts of both visual observations and instruments readings throughout the test.

Chapter 7 compares the results from each specimen including hysteric response, energy dissipation capacity, displacement components, ductility, and strength. 
Chapter 8 presents a seismic evaluation of the two demonstration ICEB buildings with flexure dominant behavior. Each building is analyzed using the incremental dynamic analysis procedure. The collapse probabilities of these buildings are discussed for the construction sites of interest.

Chapter 9 presents a summary of the conclusions derived from this thesis together with design recommendations and suggestions of futures research. 


\section{LITERATURE REVIEW}

This thesis focuses on the flexural behavior of ICEB structures. As described in detail in a later chapter, the systems considered here include a slender ICEB wall with relatively large height-to-width aspect ratio; an ICEB wall with a flange at one end; and an ICEB wall with a window opening. This chapter briefly reviews the recent research development and outcomes related to the considered ICEB constructions.

\subsection{Pioneering ICEB Research}

Bales et al. (2009) conducted significant research with the "Rhino" interlocking compressed earth block, produced using the Soeng Thai BP6 press. For determination of an optimum earth block mix, they focused on the impacts of different soil types, cement content, and water content on ICEB durability, compressive strength, and compaction.

ICEBs produced using a design mix formulated by the authors were tested to determine the associated block compressive strength, grouted and ungrouted prism strength, lateral shear strength, and pullout strength with both steel and bamboo reinforcement. Although much of the research remained inconclusive regarding its effect on system performance, significant knowledge was gained about the strength of ICEBs from the ICEB compressive testing and the grouted versus ungrouted prism testing.

All prisms in this investigation were tested with lateral confinement provided to three vertically stacked blocks with an aspect ratio of 2.0. Based on the testing results, it was observed that the compressive strength significantly decreased with an increase in aspect ratio, changing the failure mode from conical hourglass failure of the block to splitting of the prism. From the post testing analysis, two factors were proposed for the 
relationship of grout and ungrouted prisms to that of individual block strength. The factors suggested for modifying the block strength to strength of grouted and ungrouted prisms were 0.43 and 0.37 , respectively.

Bland (2011) experimentally addressed the shear behavior of ICEB walls as a companion effort of this thesis. Two fully grouted and one partially grouted $1.8 \times 1.8$ meter ICEB shear walls were tested using displacement controlled cyclic loading to determine the strengths and failure modes of the ICEB specimens. Material property testing was also conducted on ICEBs and grouted ICEB prisms for use in analytical work.

The testing results showed the ICEB wall which failed in shear exhibited sudden and brittle failures for both fully and partially grouted walls. When horizontal shear reinforcement was added, a more ductile flexural failure was achieved. The failure modes observed in the two specimens without shear reinforcement were typical 45 degree cracking from the top of the wall to the bottom, and shear sliding between blocks. The flexural failure was characterized by the yielding vertical rebar, followed by buckling of the vertical reinforcing steel.

The post testing analysis concluded the ICEB shear walls, which failed in shear, mimic that of wall panel constructed from conventional CMU blocks, while ICEB shear walls exhibiting flexural failure remained ductile until rebar in the compression zone began to buckle. It was found that traditional method of transformed sections significantly overestimates the walls stiffness. In addition, analysis showed that the prediction based on ACI 530-08 drastically overestimates the shear capacity of ICEB walls. Furthermore, it was found that the strength of flexural dominated walls can be 
reasonably predicted from pushover analysis on ICEB wall models with distributed plasticity.

\subsection{Earth Construction}

Perera and Jayasinghe (2003) conducted an experimental investigation to determine optimal cements contents used in cement stabilized earth construction of compressed earth blocks. This experiment investigated both the prism strength of the fully grouted compressed earth block, with varying cement ratio from $2 \%-8 \%$ and soil fines content from $20 \%-45 \%$, and the panel strength of compressed earth blocks with varying cement ratios. The compressed earth blocks used in this investigation were produced using the Aurum 3000 press with dimensions shown in Figure 2-1.

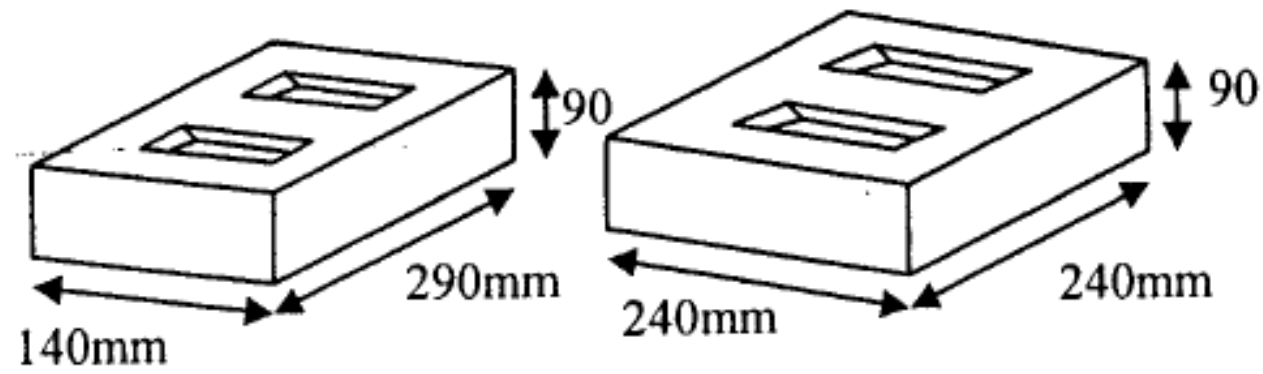

Figure 2-1: Compressed Earth Blocks produced by Aurum press 3000 (from Perera and Jayasinghe, 2003)

From the testing results it was found that the compressive strength was affected by both the cement content and the fines content. The conclusion from the experiment indicated that fines content should not be reduced below $30 \%$ but the cement content could be varied between $2 \%$ and $8 \%$ depending on the desired strength. It was revealed, from compressive testing of the prisms, a significant drop in the compressive strength occurred when the height to width ratio increased beyond 0.6 . 
Jayasinghe and Mallawaarachchi (2009) explored the lateral flexural capacity of cement stabilized earth (CSE) panels (wallets). Four specimens were constructed from common CSE building materials (one rammed-earth panel, two hollow interlocking blocks of differing width blocks, and one-mortared CSE blocks) were loaded in directions both parallel and perpendicular to bed joints.

Testing results showed that the predominant failure mode of all 4 types of walls was the brittle tensile cracking. Based on the testing results, it was determined that solid CSE mortared blocks and rammed earth have considerably higher flexural strength than the two types of interlocking blocks. Due to the various widths of wallets tested, flexural strength was given in terms of force per area of block (MPa). Post testing analysis showed the highest flexural strength could be expected from mortared CSE block with $0.9 \mathrm{MPa}$ and $0.3 \mathrm{MPa}$ of strength perpendicular and parallel to bed joints, respectively. The flexural strength of rammed-earth specimens was calculated to be $0.463 \mathrm{MPa}$ in any direction, and interlock block exhibited the weakest strength having $0.35 \mathrm{MPa}$ both parallel and perpendicular to bed joints. It was the recommendation of the research that CSE blocks would perform comparably to burnt clay masonry with a compressive strength of $5 \mathrm{MPa}$.

Cheah et al. (2008) conducted cyclic load testing on a 5.5 meter long wall with two openings to determine the failure modes, the locations of seismic weakness, interactions of panels, and the overall structural performance of earth construction buildings. The predicted failure mode expected from this experiment was a flexure dominant failure. Previous testing on rammed earth suggested that high shear strength and low compressive strength could be expected from the specimen, combined with the 
high aspect ratio of the piers in the wall. Based on pretesting calculation, the specimen was expected to fail in a combined failure mode, with initial flexural cracks developing and processing into shear cracks.

The test results show that all three wall piers exhibited shear failures as the predominate failure and no yielding was observed in the longitudinal rebars. This caused a more brittle failure and did not provide the ductility expected. Secondary failure modes were also observed as sliding, rocking, and crushing failures. It was also noted that no internal or external shear reinforcement was provided in any of the walls tested.

\subsection{Design Recommendations}

ACI 530-08 (2008) requirements depend on the location of construction and local government regulations. This thesis adopts the document Building Code Requirements and Specification for Masonry Structures (TMS 402-08/ACI 530-08/ASCE5-08), reported by the Masonry Standards Joint Committee (MSJC); for all design requirements and construction theory concerning masonry structures. ACI 530-08, as it will be referred to as in this thesis, uses simple principles of mechanics and analytical correlations to prescribed parameters for design.

Wheeler (2005) developed the Interlocking Compressed Earth Blocks, Volume II. Manual of Construction for the construction of single story residential ICEB structure in developing countries. Explained in this manual are suggested methods for building the various walls types commonly used in construction of a residential structure. However, the document does not provide any expected strength, building requirements, or structure specifications associated with ICEB buildings. The manual of construction is used a teaching aid in conjunction with a 10 day training course provided by Center for 
Vocational Building Technology (CVBT) on the proper building techniques associated with ICEB building. This thesis refers to this manual for common building techniques of various wall types, but does not necessary follow the guidelines set forth in suggested building techniques. Engineering judgment was used in determining proper reinforcing techniques to avoid the premature failures due to inadequate building techniques.

\subsection{Slender Masonry Walls}

Shedid et al. (2008) investigated the effects of vertical reinforcements and axial compression on the inelastic behavior and ductility of six slender masonry shear walls. Each reinforced masonry shear walls was tested under reverse cyclic loading and designed with a 2:1 aspect ratio to ensure flexure dominant behavior with the plastic hinge region occurring near the bottom of the specimen.

It was found that each of the walls failed in flexure in the same characteristic stages. At small displacements, each wall experienced cracking along the bed join connecting the specimen to the reinforced concrete footing, then cracking between joints in lower courses on the wall. As displacements became larger cracking began to step upwards towards the middle third of the shear wall between mortar joints blocks, processing into diagonal cracks. As the displacement continued to increase, vertical splitting cracks began to form along the length of the wall in the compression zone of the wall and the onset of crushing occurred. Following cracking, the section within the compression zone began to spall away from the toe of the wall leaving only the grout column surrounding the rebar. The final stage before failure was the cracking of the grout column, leaving the vertical rebar unconfined to the buckle in plane. 
The posttest analysis indicated that both displacement ductility and yield displacements were highly dependent on the amount of vertical reinforcement. From the lateral deformation profile it was discovered that rotation, caused by the formation of a plastic hinge, occurred at the bottom of the wall while the top of the wall remained a rigid body.

Shedid et al. (2009) tested six slender masonry shear walls under displaced controlled cyclic loading to investigate the energy dissipation, ductility, shear and flexural displacement, and stiffness of flexural dominated shear walls. Each specimen was designed as a 2:1 aspect ratio, over reinforced in shear, with vertical reinforcing on the outer most cells of the wall.

The post testing analysis indicated that Equation (1-1), suggested for shearing displacements, is unconservative.

$$
\Delta_{s}=\left(1.2 \cdot \frac{Q \cdot h_{w}}{0.4 E_{m} \cdot A_{e}}\right)
$$

where $h_{\mathrm{w}}$ is the wall height, $E_{\mathrm{m}}$ is the modulus of elasticity of masonry, and $A_{\mathrm{e}}$ is the effective shear area. From testing and instruments readings, the effective shear area was back calculated to be an average of $14.8 \%$ and $13.2 \%$ of the gross masonry area at yielding and maximum load, respectively.

Energy dissipation was calculated as the area enclosed by hysteretic loops at each displacement level, intended to track the rate of energy dissipation before and after yielding. It was found that energy dissipation increased drastically after the yielding occurred due to the widening of the hysteric loops. A direct comparison of the energy dissipation on a per wall basis was not possible due to the variation of displacements each 
wall was pushed; however the trend of normalized energy dissipation indicated that percent energy dissipation increased linearly with the ratio post -yield to yield displacements.

\subsection{Flanged Masonry Walls}

Priestley and Limin (1990) tested four T-section masonry shear walls to investigate the effect of flange width and mortar bed confinement on masonry shear walls. To test the effect of flange length, all walls were built with the same height and web length, but the flange length was doubled in one specimen. Mortar bed confinement was tested by using confining plates in the bottom courses of a specimen throughout the web. Each specimen was tested under slow pseudo-static loading until failure.

From the testing of the four T-sections, it was discovered that there was a significant difference in the strength when the flange was in tension or compression for all four specimens. Due to the asymmetry of the cross section it was found that the section was 2.5 times as stiff with the flange in tension compared to when the flange was in compression. It was also observed that there was a significant difference in the energy dissipation depending on whether the flange was in tension or compression.

The effect of the mortar bed confinement provided a significant increased in the ultimate strength and displacement capacity of the specimen. It was also observed that the confining plates provided a significant decrease in the load degradation of the specimen following the compression zone failure. The extra confinement from the confining plates changed the failure mechanism from concrete crushing to lateral buckling of the web.

Shedid et al. (2010) tested seven reinforced masonry walls with different boundary frame elements under displacement controlled cyclic loading. Of the seven walls tested 
two were traditional rectangular walls, two were flanged, two had square boundary element, and one had a spiral boundary element. All seven walls were designed to have the same lateral resistance when subjected to the same axial loading.

From experimental results it was discovered that very little observed difference between the strengths of each respective wall due to the change in aspect ratio. This indicated that cross sectional properties have a greater impact on the strength than height, and the plastic hinge length has a better correlation to the length than the height of the wall. The comparison of the flanged and end-confined walls to the regular rectangular walls indicated that a $39 \%$ to $106 \%$ increase in ductility could be expected, suggesting that flanged and end-confined walls could be beneficial in seismic zones.

\subsection{Masonry Shear Walls with Opening}

Voon and Ingham (2008) tested eight partially grouted single story masonry shear walls with opening. The shear walls tested varied in overall length and width, as well as the length and width of the openings, and the number of openings per walls tested. Of the eight walls tested, five had single openings and three with double opening. Both the opening size was varied to reflect square and rectangular openings a well as doors.

From the experimental testing it was found that all of the force displacement plots exhibited pinched shape which was correlated to the presents of significant shear deformations. It was observed that diagonal cracks, which passed from the lintel into the pier essentially, created a pinned connection at that joint reducing all the moment capacity associated with the connection.

The experimental results concluded that the size of the opening directly affects the lateral strength of the wall. The strength degradation of each specimen was gradual with 
no specimen exhibiting sudden or brittle failure, directly attributed to the fully grouted bond beam which caused a frame type action and developed double curvature in central piers. Based on the cracking patterns it was concluded that altering the trim reinforcement below the opening changed the locations of the cracks.

Elshafie et al. (2002) tested thirteen single story reinforced masonry shear walls with opening to study the response of lateral loading. Each specimen was $1 / 3$ scale with opening of various sizes in different locations. Each wall was designed to fail in a ductile mode with plastic hinges forming at the ends of members.

The testing results confirmed the used of plastic analysis for determination of the lateral load resisting capacity. Plastic analysis was used in this study because it did not require an accurate understanding of the section stiffness which is difficult to accurately determine for shear walls with openings. From plastic analysis four possible failure mechanisms were analyzed and expected to occur. The failure mechanism, shown is Figure 2-2, are: strong pier/ weak beam mechanism; strong beam/weak pier mechanism; mixed mechanism; and tension mechanism. 


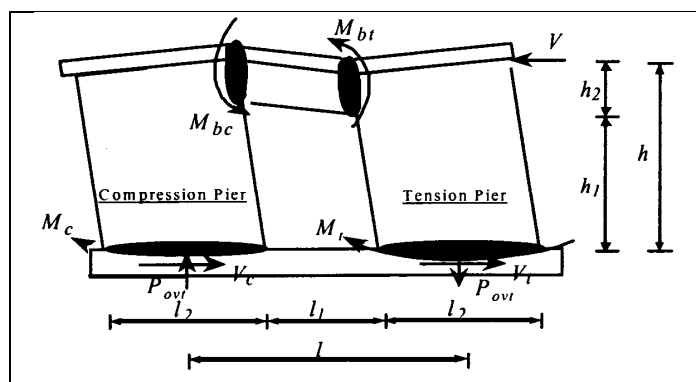

$$
\begin{aligned}
P_{o w}= & \frac{M_{b c}+M_{b t}}{l_{1}} \\
V_{c} & =\frac{M_{c}+M_{b c}+P_{o v}\left(l_{2} / 2\right)}{h} \\
V_{1} & =\frac{M_{1}+M_{b t}+P_{o v}\left(l_{2} / 2\right)}{h} \\
V_{u} & =V_{c}+V_{t}=\frac{M_{c}+M_{1}+P_{o v} l}{h} \\
& \text { Plastic hinge }
\end{aligned}
$$

\section{Strong piers /Week Beam Mechanism}

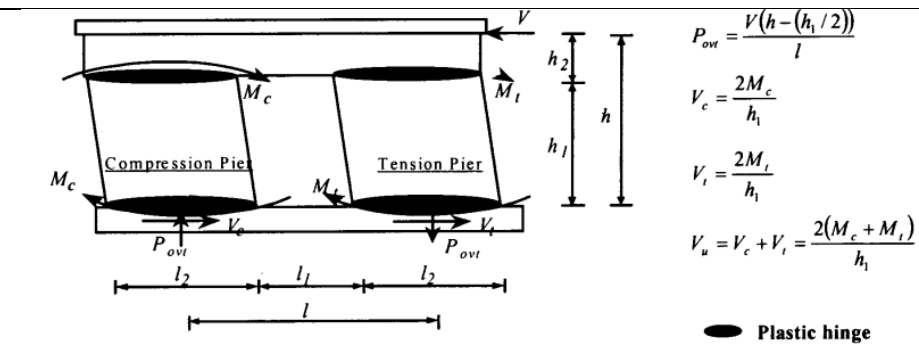

2. Strong Beam /Weak Piers Mechanism

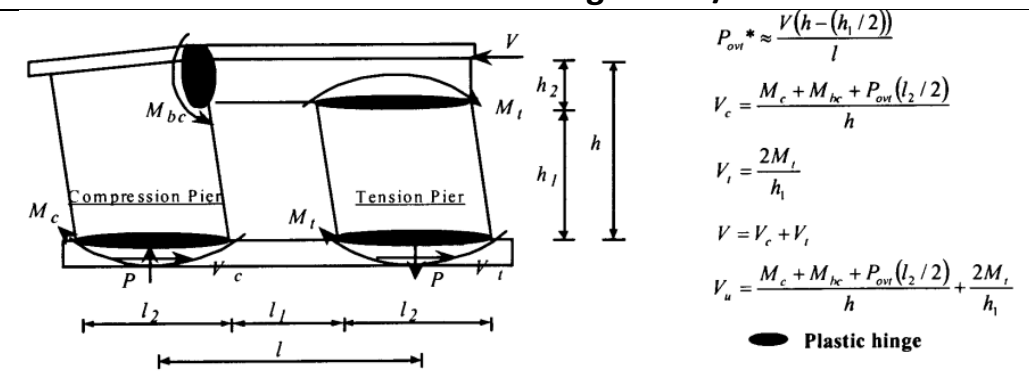

3. Combined Mechanism

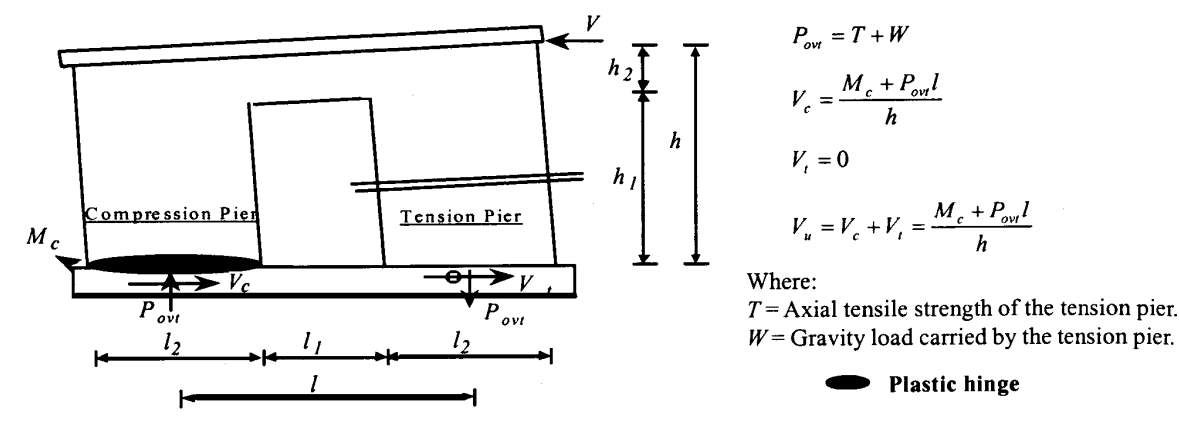

4. Tension Mechanism

Figure 2-2: Failure Mechanism for Shear walls with openings (Elshafie et al., 2002) 


\section{MATERIAL PROPERTIES}

\subsection{Introduction}

This chapter briefly presents the material properties pertinent to the experimental and analytical work of this thesis, containing a brief discussion of compressed earth blocks and reinforcing steel rebar, strength of the masonry prism, and the idealized models of the masonry which are required in the numerical work presented in Chapters 7 and 8. More detailed information about compressed earth blocks and reinforcing steel are provided in Appendix A. Incidentally, other important aspects of the materials properties can be found in the companion thesis (Bland, 2011), which includes the soil profile of the ICEBs, the ICEB manufacturing processes, quality control methods, ICEB testing procedure, and properties of the grout material.

\subsection{Interlocking Compressed Earth Blocks}

The interlocking Compressed Earth Blocks used in this thesis were constructed onsite at Cal Poly using a Soeng Thai Model BP6 press. The Soeng Thai Model BP6 press is capable of producing different types of block by adding or removing various

inserts. The base block, shown in Figure 1-1, is a full block commonly called the "Rhino Block" used to interconnect any form of dry stack masonry construction. The "Rhino Block" is composed of two reinforcement holes used for vertical grouted reinforcement-and three "grout key channels" commonly filled with a fluid grout to provide wall stability and load transfer. For the construction of the three wall specimens tested in this thesis, six different variations of the standard full block were used, shown in Figure 3-1. 


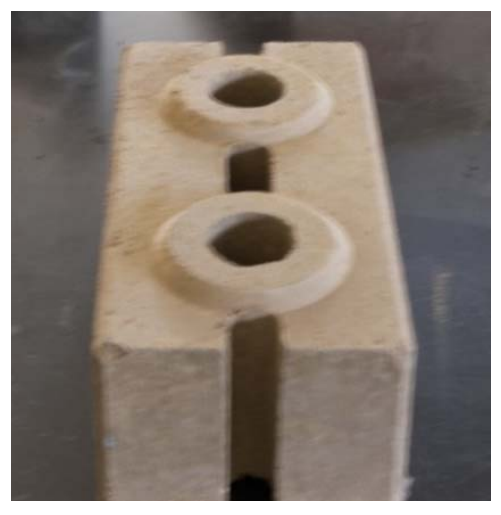

a) Full Block

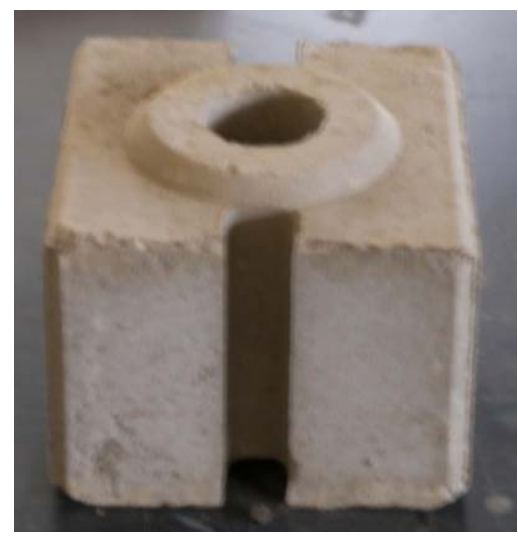

c) Half Block

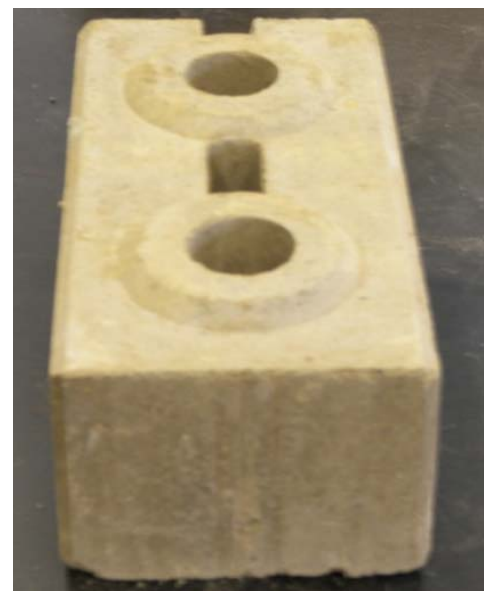

e) End Block

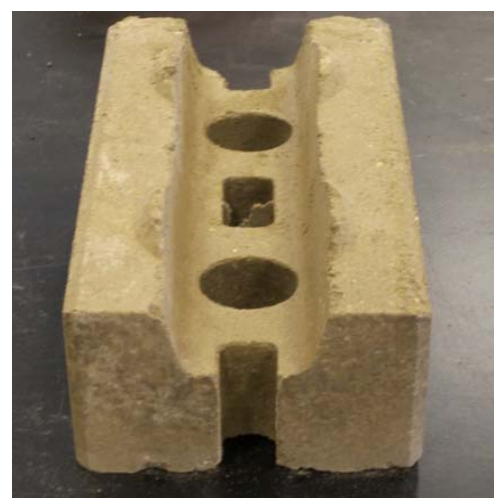

b) Full Channel Block

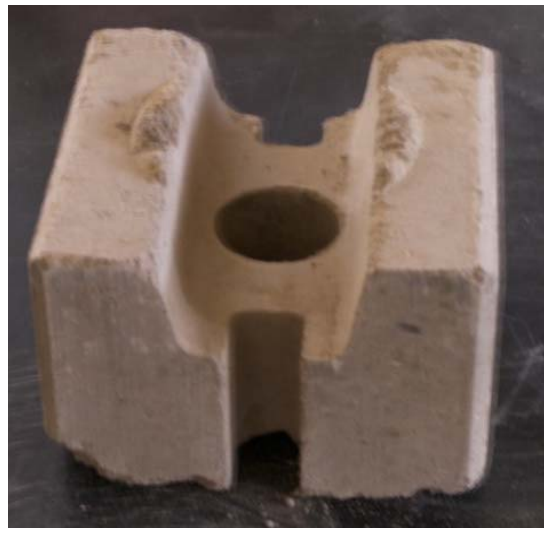

d) Half Channel Block

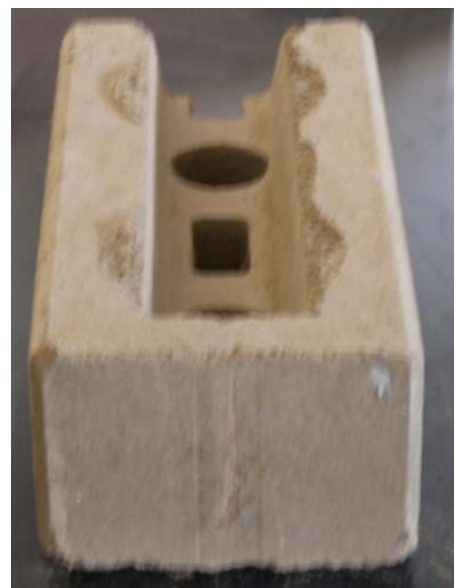

f) End Channel Block

Figure 3-1: The six types of blocks used in wall construction 
The full fabrication process for constructing ICEBs using the Soeng Thai Model BP6 press is described in detail in the companion thesis (Bland, 2011). Each eight-block batch used a mixture comprised of soil, sand, cement, and water in the construction of each ICEB. The mixture that provided the most durable, compressive strengths and best aesthetics is summarized in Table 3-1. The wet weight of the mixture, which was packed into the press to make each type of block, along with the number of block produced for each wall is summarized in Table 3-2.

Table 3-1: ICEB mixture proportion for an 8 block mix (Proto et al., 2010)

\begin{tabular}{lcc}
\hline & Weight $(\mathrm{kg})$ & \% of Total \\
\hline Soil & 50.0 & 74.3 \\
Sand & 6.7 & 10.0 \\
Cement & 4.2 & 6.2 \\
Water & $\sim 6.4$ & 9.5 \\
\hline Total & 67.3 & 100.0
\end{tabular}

Table 3-2: ICEB produced for specimen construction

\begin{tabular}{ccccc|c} 
Block Type & Mass per Block & \multicolumn{3}{c|}{ Number of Blocks per Wall } & Total Number \\
& $(\mathrm{Kg})$ & W4 & W5 & W6 & of Blocks \\
\hline Full Block & 7.9 & 30 & 78 & 32 & 140 \\
Half Block & 4 & 16 & 15 & 27 & 58 \\
Full Channel & 7 & 14 & 39 & 36 & 89 \\
Half Channel & 3.5 & 2 & 1 & 10 & 13 \\
End Block & 8 & 0 & 14 & 0 & 14 \\
End Channel & 7.2 & 0 & 4 & 0 & 4 \\
\hline Total & -- & 62 & 151 & 105 & 318 \\
& & & & &
\end{tabular}




\subsection{Rebar Testing}

To determine the actual strength of the vertical reinforcement used in the specimens, samples of the vertical rebar were subjected to tensile testing. The rebar was tested according to ASTM A370-10 (2011), on the Satec universal test machine shown in Figure 3-2. Each piece of vertical rebar was clamped at the top and bottom of the bar, 100 $\mathrm{mm}$ from the center. The reinforcement was then subjected to a tensile force that was induced by a vertically ascending crosshead at an average displacement rate of 0.18 $\mathrm{mm} / \mathrm{sec}$. The rebar was restrained by a stationary crosshead and was tested until the rebar ruptured. Values for the average yield strength and average ultimate strength for each piece of rebar are reported in Table 3-3. Complete results are shown in Appendix A.

Table 3-3: Rebar strength

\begin{tabular}{ccc} 
Wall \# & $\begin{array}{c}\text { Average Yield } \\
\text { Strength } \\
\text { (MPa) }\end{array}$ & $\begin{array}{c}\text { Average Ultimate } \\
\text { Strength } \\
\text { (MPa) }\end{array}$ \\
\hline W4 & 378 & 541 \\
W5 & 370 & 542 \\
W6 & 356 & 497
\end{tabular}




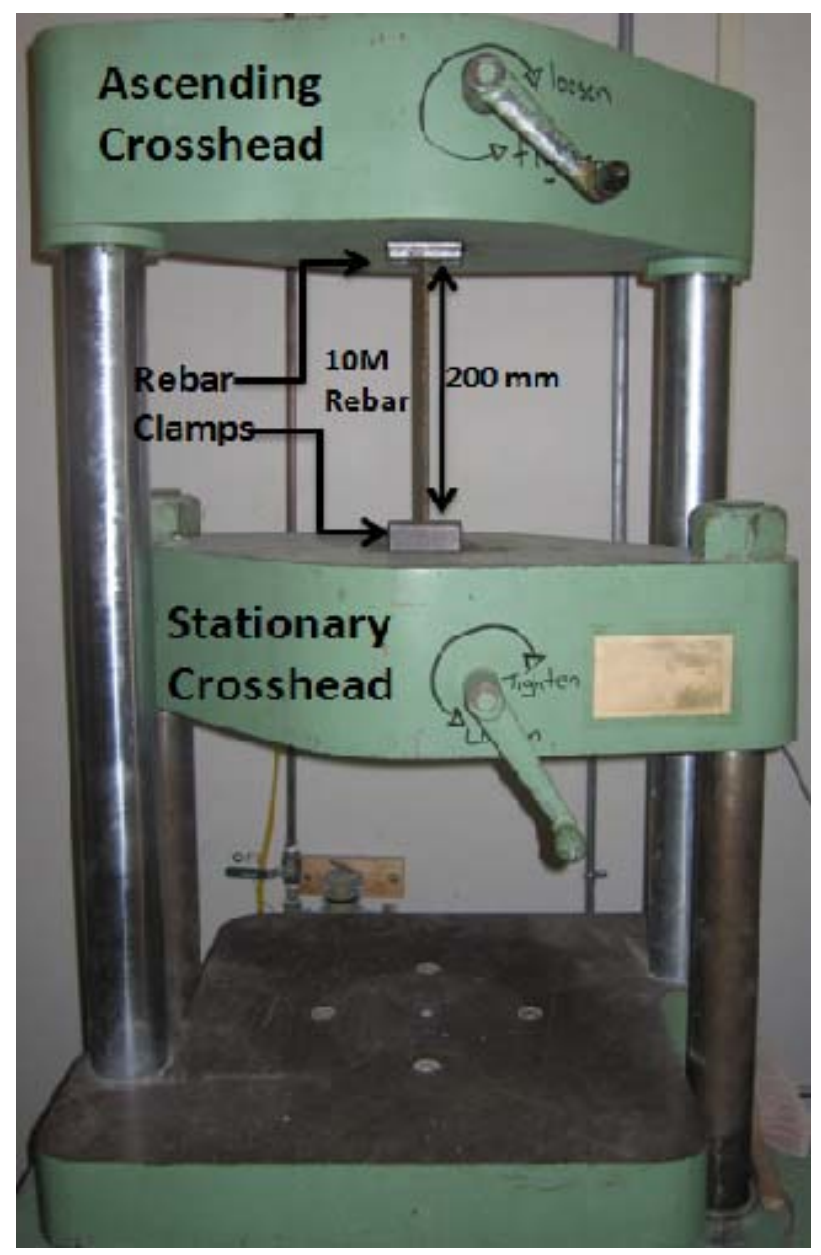

Figure 3-2: Rebar testing facility

\subsection{Masonry Prism Testing}

The average compressive strength of the masonry $\left(\mathrm{f}_{\mathrm{m}}{ }_{\mathrm{m}}\right)$ of each specimen was tested with masonry prisms. Each prism was constructed from three fully grouted, vertically stacked ICEBs which were built at the same time and cured under the similar conditions as the wall specimens. The prisms were capped top and bottom with a hydrostone capping compound to form a flat surface and to ensure a uniform load distribution on the prism. Confinement was applied to each prism with plywood boards tightened against the end of the prism with three sets of two thread rods, hand tightened, to provide passive 
confinement. Each prism was loaded at a strain rate of 20 microstrains per seconds $(\mu \varepsilon / \mathrm{s})$, which corresponded to a displacement rate of approximately 0.4 millimeters per minute $(\mathrm{mm} / \mathrm{min})$ in order to achieve an accurate stress versus strain profile of the tested prisms. Each test was run for approximately 40 minutes allowing for a total $15.8 \mathrm{~mm}$ of compression on the prism.

The strain was measured in two different ways, with extensometers fastened to the outside of the prism to directly measure the strain in the masonry and with LVDTs placed on either end in of the prism. Extensometers were used to measure the strain in the masonry until the prism began to crack and spall outwardly; the extensometers were then removed to prevent the instruments from damage. Following the removal of the extensometers the strain for the remainder of the test was measured by the two LVDTs. The resisting force of each prism was measured by a load cell as part of the universal testing machine. It is understood a reduction in strength would be associated with 2:1 aspect ratio of each prism (Bales et al., 2009); however, the reported stress and strain values correspond to the tested values of each prism with no reduction based on aspect ratio. The test set-up of the masonry prisms can be seen in Figure 3-3.

The compressive strengths of the tested prisms are summarized in Table 3-4 and the corresponding strain-stress curves are included in Figure 3-4. The cross-sectional area associated each fully grouted prism is $45,000 \mathrm{~mm}^{2}$. All of the tested prisms experienced a similar failure mode of to that of an ungrouted ICEB blocks. At the beginning of each test diagonal compression cracking was observed in the prism, followed by conical spalling on the unconfined sides of the prism, followed by the vertical crushing of the prism. 


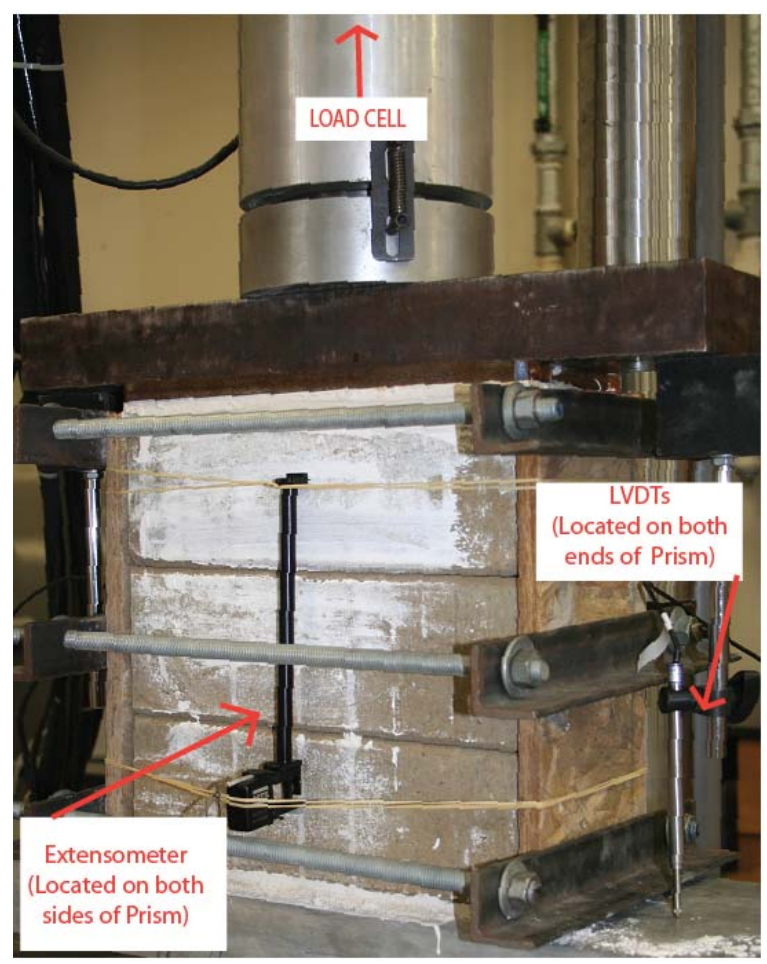

Figure 3-3: Masonry prism test setup

\section{Table 3-4: Average Prism Compressive Strength}

\begin{tabular}{cc}
$\begin{array}{c}\text { Wall } \\
\text { Specimen }\end{array}$ & $\begin{array}{c}\text { Average Compressive } \\
\text { Strength } \\
\text { (MPa) }\end{array}$ \\
\hline W4 & 2.77 \\
W5 & 3.16 \\
W6 & 2.25
\end{tabular}

\subsection{Models for Masonry}

The strength of masonry prisms were obtained from specimens W4B and W5A in this thesis, W2A, and W2B from the companion thesis (Bland, 2011). More detailed information about these specimens is provided in Appendix A. It is recognized that 
additional prisms associated with W6 were also tested; however the strain data was found to be unreliable. Therefore,W6 prism data was excluded.

Presented in Figure 3-4 are two idealized models, namely, a modified Hognestad model and a bilinear model, which will be used to approximate the system behavior in the numerical studies presented in Chapters 7 and 8. The modified Hognestad model expressed below was adopted in the nonlinear static analysis presented in the companion thesis (Bland, 2011) :

$$
\begin{gathered}
f_{m}=f^{\prime}{ }_{m o}\left(\frac{2 \varepsilon_{c}}{\varepsilon_{o}}-\left(\frac{\varepsilon_{c}}{\varepsilon_{o}}\right)^{2}\right) \quad\left(\text { for } \varepsilon_{\mathrm{c}} \leq \varepsilon_{\mathrm{o}}\right) \\
f_{m}={f^{\prime}}_{0}-0.25 f^{\prime}{ }_{m 0}\left(\frac{\varepsilon_{c}-\varepsilon_{0}}{\varepsilon_{c u}-\varepsilon_{0}}\right) \quad\left(\text { for } \varepsilon_{0} \leq \varepsilon_{\mathrm{c}} \leq \varepsilon_{\mathrm{cu}}\right)
\end{gathered}
$$

where $f_{m}$ represents the strength of the masonry; $f^{\prime}$ mo represents the maximum compressive strength of the masonry; and $\varepsilon_{\mathrm{c},}, \varepsilon_{\mathrm{o}}$ and $\varepsilon_{\mathrm{cu}}$ represent the strain of interest, the stain associated with the maximum masonry strength, and the maximum considered strain, respectively. The bilinear, elastic-perfectly-plastic model with a maximum compressive strength of $3 \mathrm{MPa}$ will be used in the simulation presented in Chapter 7. Both models used modulus of elasticity of $575 \mathrm{MPa}$, which was obtained, per Section 1.8.2.2.1 of ACI 530-08. 


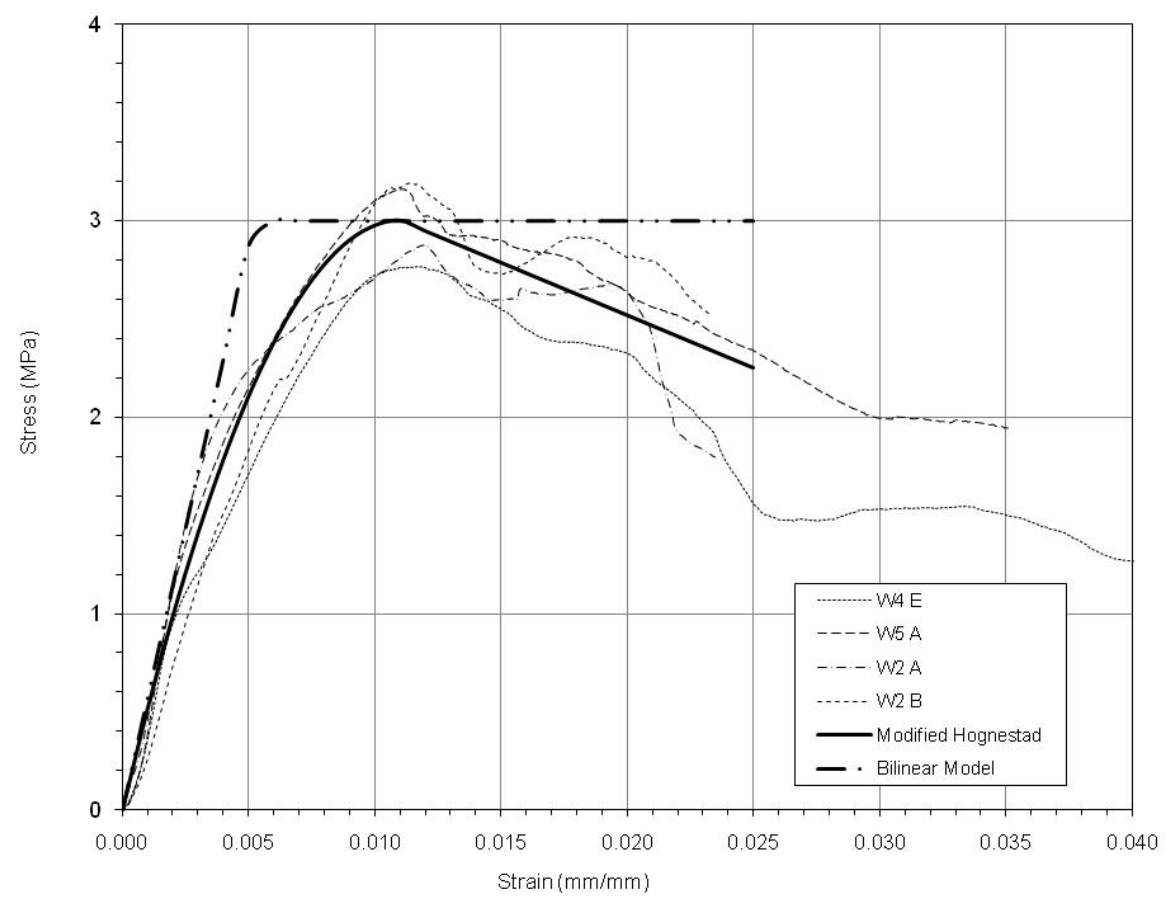

Figure 3-4: Stress vs. Strain Data from Masonry Prism Tests 


\section{SPECIMEN DESIGN AND CONSTRUCTION}

\subsection{Introduction}

This chapter provides a detailed description of the design and construction process of the ICEB specimens. All specimens were reinforced with 10M steel rebar, longitudinally and transversely. Detailed information about the rebar arrangements can be found in the following sections; while grout and mortar proportions, used in specimen construction can be found in Appendix A.

W4 is a 1.8 meter tall and 0.9 meter long wall with a 2:1 height-to-width aspect ratio designed to investigate the effect of aspect ratio on ICEB walls. To focus on the impact of wall aspect ratio on its seismic behavior, the only variable changed from W3 (tested in the companion thesis) to W4 was the aspect ratio, done by essentially building half of W3. The procedure presented in Section 4.2 outlines and explains the steps taken to build W4 and the rationale behind the manner in which the wall was constructed, while the overall reinforcing pattern is shown in Figure 4-1. 


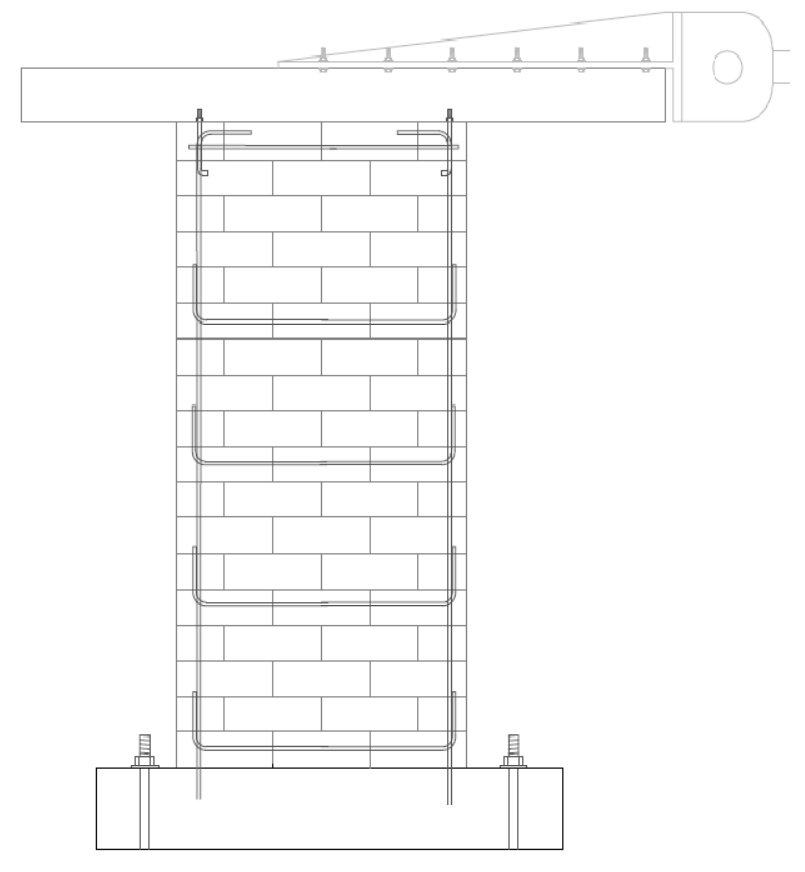

Figure 4-1: W4 reinforcing pattern

The T-wall (W5) was designed as an intersecting flanged wall with the web having a 1:1 aspect ratio and a 0.75 meter wide flange on one end of the wall. Testing W5 allows for a direct comparison between $\mathrm{W} 3$ and a flanged wall with the exact same reinforcing to determined on the contribution of the flange to the walls strength, ductility, and overall performance. To focus on the impact of an intersecting wall, the only change to the design of W3 was the addition of a flange. The reinforcement in the flange can be found in Figure 4-2. The transverse reinforcement in the flange was added for continuity between the intersecting walls, not for strength, as it was anticipated that the web would take the vast majority of the shear force in the in-plane direction. The design and building procedure presented in Section 4.3 outlines the steps taken to build W5 and 
design decision in which the wall was constructed, while the overall reinforcing pattern is shown in Figure 4-2.
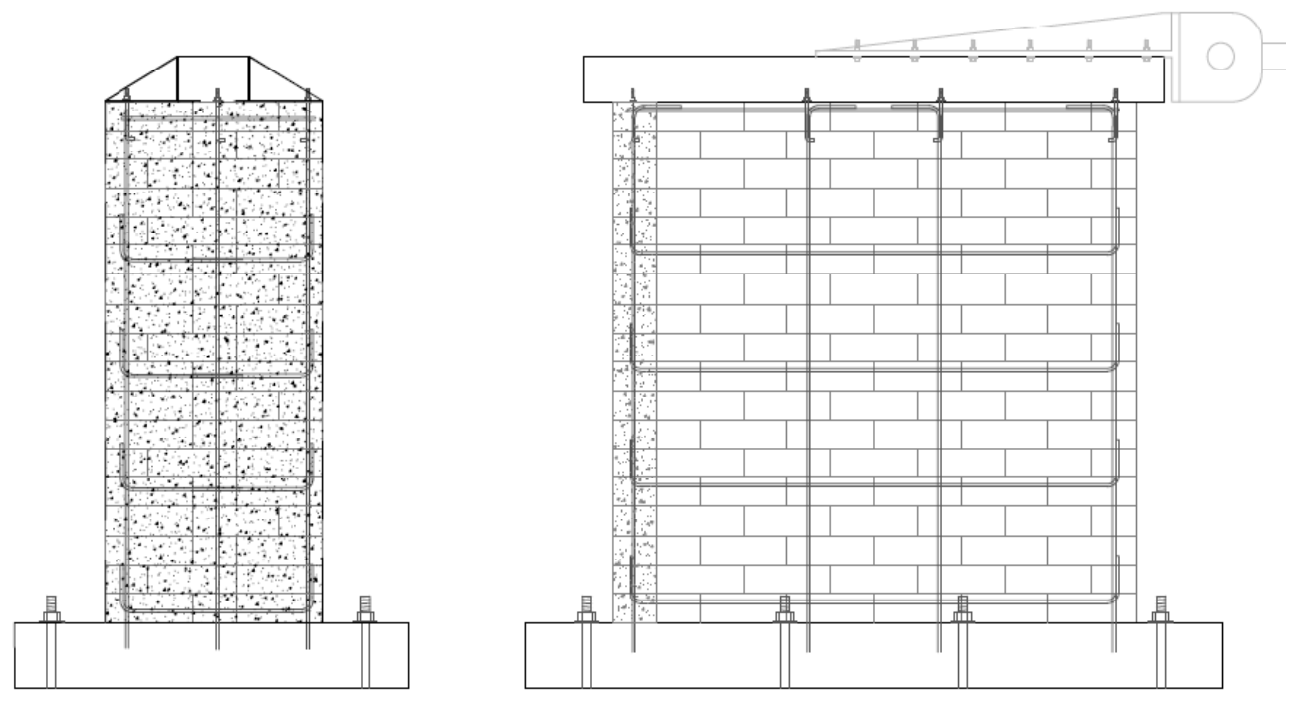

Figure 4-2: W5 reinforcing pattern

W6, a $1.8 \mathrm{~m}$ tall and $1.8 \mathrm{~m}$ wide wall with a $0.9 \mathrm{~m}$ x $0.9 \mathrm{~m}$ square window opening at its center, was designed to create a direct comparison between a solid wall and one with a opening. To focus on the performance of the piers of $\mathrm{W} 6$, the wall was designed according to the strong beam/weak pier methodology as described in the literature (Elshafie et al., 2002). The procedure presented in Section 4.4 outlines and explains the steps taken to build W6 and the rationale behind the manner in which the wall was constructed, while the overall reinforcing pattern is shown in Figure 4-3. 


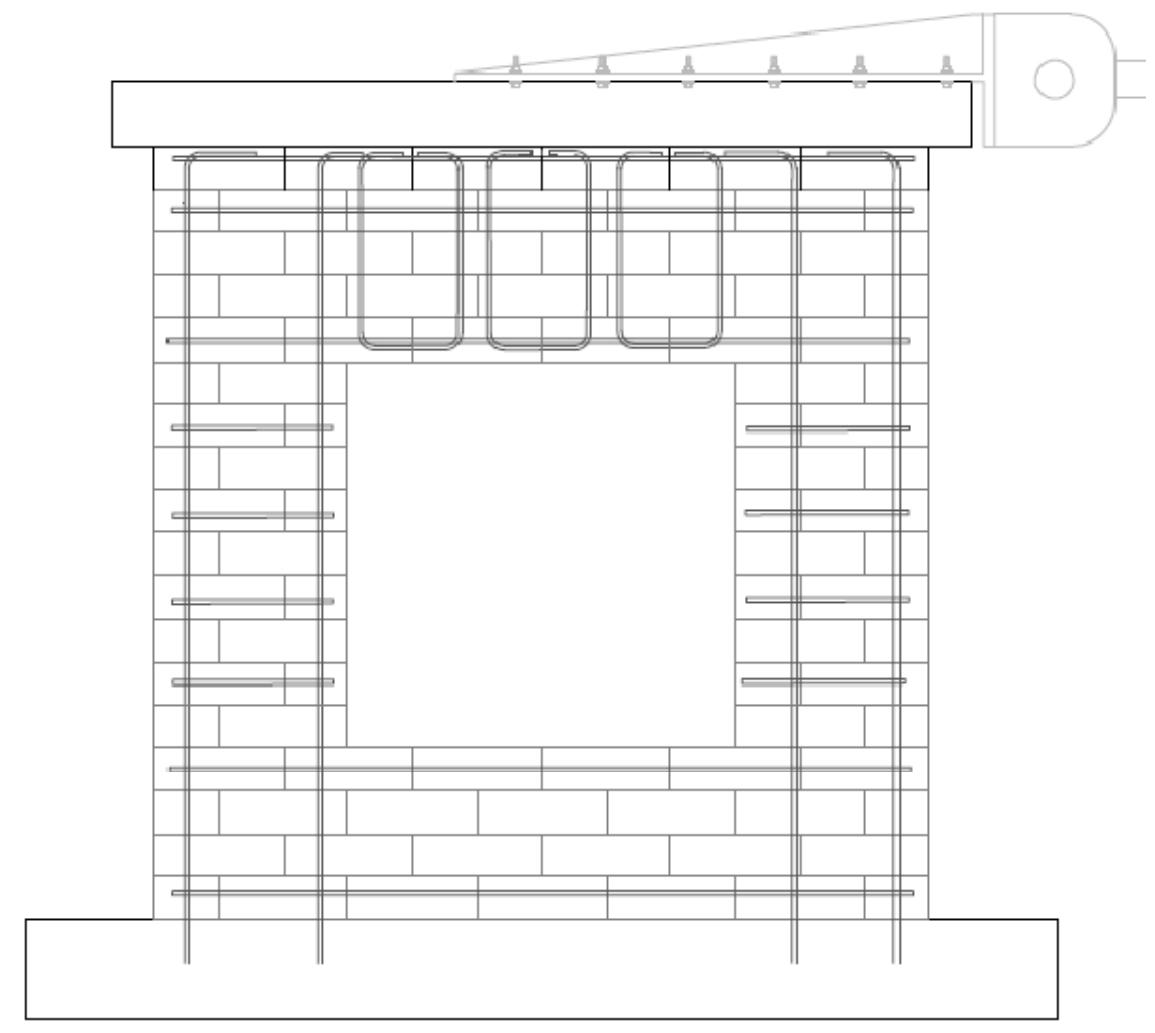

Figure 4-3: W6 Reinforcing Pattern

\subsection{Construction of the Slim Wall (W4)}

Construction of W4 began with the preparation of two pieces of $10 \mathrm{M}$ rebar, purchased from a local supplier with specifications found in Chapter 3 for the application of strain gauges. Both rebar were trimmed to 2.1 meters and marked in four different designating locations between which the strain gauges would be applied. Grinding the rebar with a flap disk between marks placed at $177 \mathrm{~mm}$ and $228 \mathrm{~mm}$, and $177 \mathrm{~mm}$ and $328 \mathrm{~mm}$ began the preparation process by removing their mill scale and ribs. During this process, over grinding occurred on both rebars causing reduction in cross-sectional area by roughly $6.45 \mathrm{~mm}^{2}$. Sanding then followed using three progressively finer grades of 
sand paper, followed by degreasing. The strain gauges were then applied following the steps set forth by the strain gauge manufacturer. Following completion of the stain gauge applications, the strain gauges were coated in polyethylene for insulation and then covered with electrical tape to create a barrier against the mortar and grout applied during the wall construction.

The slim wall construction continued with anchoring the prepared rebar to the 160 $\mathrm{mm}$ thick footing. The rebar were anchored by two $12.7 \mathrm{~mm}$ diameters holes drilled to a depth of $127 \mathrm{~mm}$ into the footing. The ends of the rebar were secured to the footing by filling the two holes with anchoring adhesive followed by each rebar. The rebar was vertically leveled and anchoring adhesive allowed 24 hours to set prior to any further construction. Special care was taken during the rebar setting process to ensure that the strain gauges were aligned with the neutral axis to prevent strain from being measured due to local bending .

Constructing the first layer (course) of ICEB's began after a 24 hours of curing the anchoring epoxy around the rebar in the footing. The first layer was laid prior to construction of the wall due to the unevenness of the footing and to allow the mortar, under the first layer, to cure. Mortar was built up under the first course of ICEBs to ensure the wall would be both plumb and level. Adjusting for the uneven leveling in the footing was done by varying the thickness of mortar. Channel blocks were laid on the bottom layer of blocks to provide horizontal shear reinforcement. This provided better load transferring from the wall to the footing. Mortar was pushed up into the reinforcement holes in the ICEB in order to create a better bond between the block and the footing but prevent from flowing into the channel to avoid a cold joint at the top of 
the block. A 10M rebar was then placed along the length of the channel as the vertical reinforcement. 90 degree bends with $200 \mathrm{~mm}$ tails were inserted at the location of the vertical reinforcement to ensure proper bonding developed both horizontally and vertically along the rebar as shown in Figure 4-4.

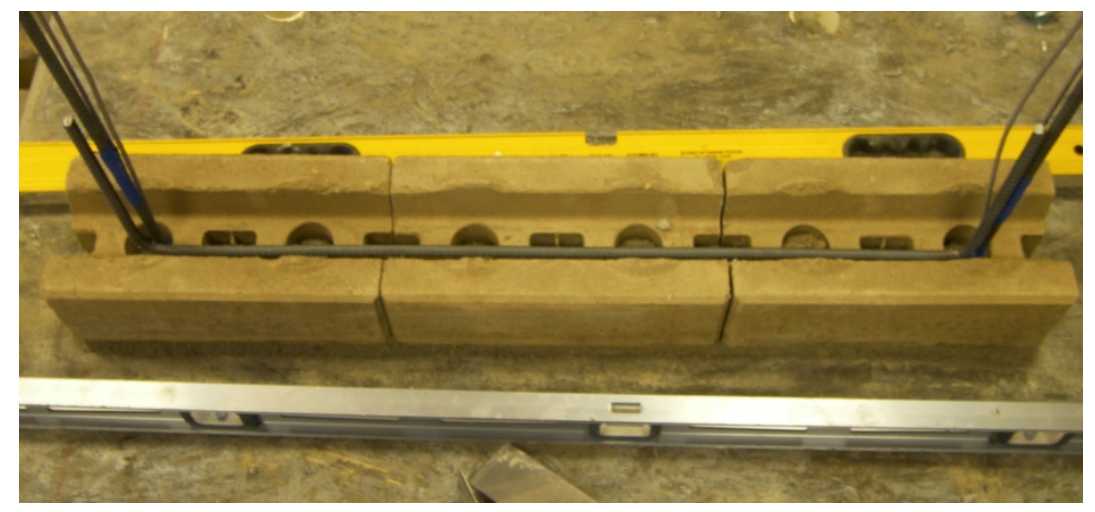

\section{Figure 4-4: Rebar Anchored Footing of W4}

Twenty-four hours after the first course of ICEBs were set; construction began on the rest of the wall which began by weighing pre-calculated amounts of sand, cement, and lime into separate batches to be used as mortar ingredients. Courses 2 through 4 were entirely constructed of full and half blocks and dry stacked using the running bond pattern. The courses were leveled and made plumb before the next layer of channel blocks were set, as standard blocks were more uniform than the channel blocks. Course 2 through 4 were leveled in all three directions using a standard level, a string line, roofing nails, and a rubber mallet. The vertically uneven bricks were found using a level and were corrected by tapping with the rubber mallet in the course where the leaning was observed. The level was then placed on the top course of wall to determine where bows or sags were present. Due to the ICEB's lack of uniformity two different approaches were taken. The first approach was to simply rotate or switch out one or more blocks with a 
height difference located at either end of the block. The second approach, used when the first was unable to remedy, was to wedge one or two roofing nails under uneven blocks which raised the end of key blocks a few millimeters. By raising one or two of the blocks a few millimeters, the wall could be leveled relatively easily without the use of mortar, a method commonly used in non dry stack masonry. The string line was used to straighten each course in the plane of the wall by running a string line from one end of the wall to the other. The string was moved closer or further away from the wall while "eyeballing" the string in relation to the wall to determine how much the wall need be adjusted horizontally. A rubber mallet was also used to tap ICEBs that were out of plane with the string back into alignment with the plane of wall.

The fifth course of ICEB's laid were channel blocks, which were set and leveled in a similar manner to the full blocks on the previous courses. A $1.3 \mathrm{~m}$ length of $10 \mathrm{M}$ rebar was cut and bent 90 degrees, $200 \mathrm{~mm}$ on each end for shear reinforced vertical hooks. The rebar was set approximately $5 \mathrm{~mm}$ above the channel and tied with steel wire to the vertical rebar. This prevented the rebar from resting on the bottom of the channel, and provided a stronger bond between the grout and rebar. Duct tape was used to cover the grout key on the outside of the wall and to restrain the fluid grout on the either end of the wall. Due to the weight of the grout being poured down the grout keys on the ends of the wall, plywood boards had to be cut to the width of the wall and butted against the ends of the wall with $2 \times 4$ 's spanning between the plywood boards. Ratchet straps were looped around the length of the wall and tighten to provide confinement for the grout.

Grouting the first five courses began by mixing the previously weighed portions of cement, sand and lime in a small five gallon mixer. Water was added to obtain the 
proper consistency, but was not directly measured as the consistency of grout had been determined from previous experience. This building experience came from building W1 through W3 in the companion thesis (Bland 2011). It was found that the grout needed to be extremely fluid because a significant quantity of the water was absorbed in the ICEB shortly after application. Once the grout mixture was deemed pourable enough, the grout was removed from the mixer, scooped into a funnel, and poured into the wall. The grout was poured from one side of the wall to the other, while rebar rods were inserted into the holes simultaneously after filling. Grouting was completed as a two person job, with one person pouring the grout, with the second person rodded continuously. This was done for every hole (both grout keys and reinforcement holes) from one end of the wall to the other to preventing air voids from forming in the grout. Once all the holes in the wall were filled, the channel of course 5 was filled just enough grout to cover the rebar as shown in Figure 4-5, to prevent a cold joint at the top of the ICEB course.
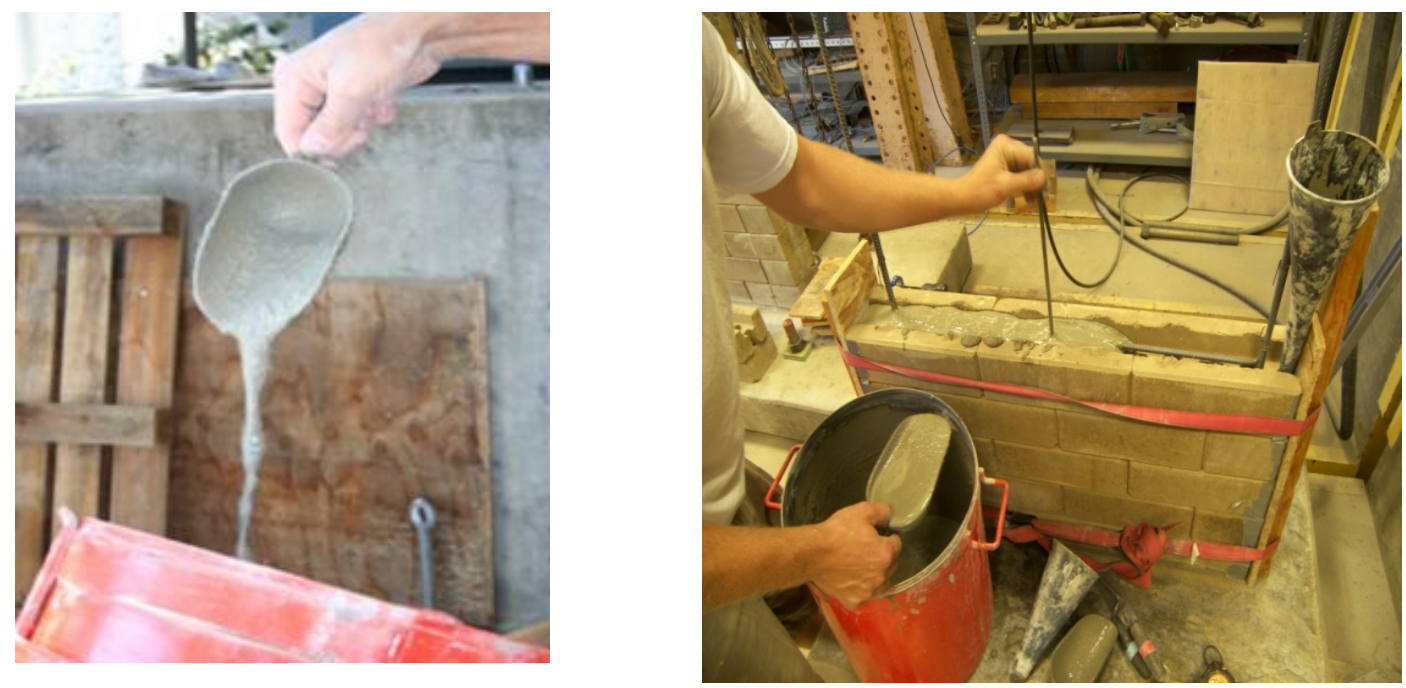

Figure 4-5: Grout used in specimen construction 
The process used to set, level, and grout courses two through five was repeated twice more in setting courses six through nine and courses ten through thirteen. During the building of the wall, increased height showed how important it was to keep each course level. Due to the aspect ratio of the wall, and its relative slenderness compared to the other walls, it was increasingly prone to tilting out-of-plane. As a result, leveling of the courses began to occur at every level instead of at every three levels which stabilized the wall exceedingly well in comparison.

It became apparent while the grout was setting that the more fluid grout hardened fairly quickly. Therefore, the plywood boards and ratchet straps, used to keep the grout in the grout keys on the outer side of the walls, became unnecessary at the bottom and were placed further up the wall. Removing the confinement around the open grout keys on either side of the wall allowed small touch-ups in areas where the grout may not have completely filled all voids to be performed as the grout was still workable. In areas where the confinement had not completely worked, a trowel could be used to remove the excess grout. When the plywood boards were removed, it was apparent that the duct tape was very effective in providing an impervious barrier but poor for providing confinement. In the areas where a gap was present between plywood boards, the duct tape would rupture allowing grout to pour out of the confinement and leave either a budge or a void in the grout (Figure 4-6). 


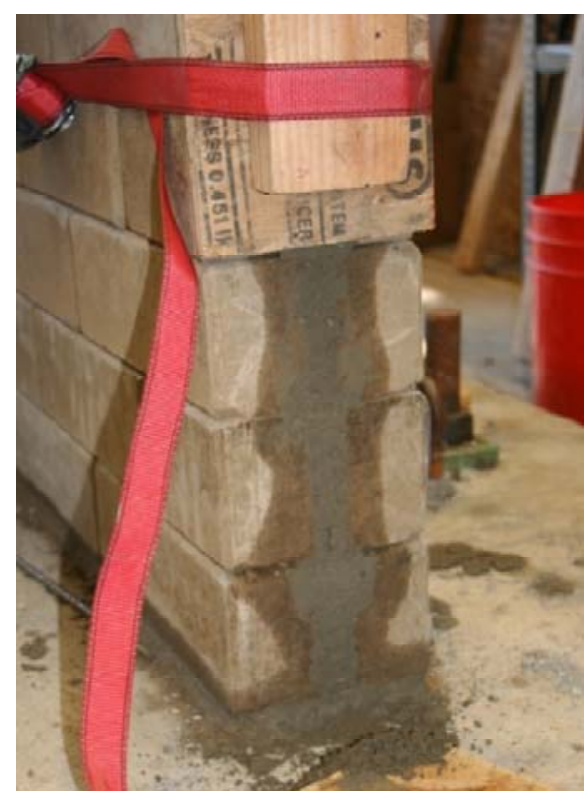

\section{Figure 4-6: Plywood confinements for grout keys}

Due to the dimensions selected for the wall, it was not possible to keep the horizontal reinforcing pattern consistent with the entire height of the wall. As a result, four courses of full blocks were laid in-between courses of reinforcement. It was determined that even with the fluid grout it would be easier to lay three courses of full blocks, grout, setting the next two courses, and then grout them separately. This procedure, although effective, provided a major drawback which was spillage of excess grout. Typically grout would be applied only with channel blocks on the top of the wall. This would provide a catchment for the grout in the channel blocks which might spill over from the reinforcement holes or grout keys. Without a channel block to catch the excess grout from the funnel, the excess grout would flow into the top layer of the blocks and create an uneven surface on which the next course would be laid. To prevent this uneven surface, a wet sponge was used to remove the spilled grout before it set. 
Courses 17 and 18 were laid and leveled on top of the already grouted courses in the same manner as Courses 3 and 4; however, before grouting began, two 6 inch anchor L bolts were set directly next to the vertical rebar in the reinforcement hole without the anchor L bolt touching the side of the reinforcement hole. This also allowed the grout to create a better bond to all of the anchor bolts. The anchor bolts were set at the designed depth, and in the correct location, by constructing an adjustable jig. The jig was designed to rest on the top of channel block and side of the wall to allow only the threads of the anchor bolts to remain above the wall and the rest of the anchor to be set into the $17^{\text {th }}$ course. Preceding the setting of the anchor bolts, the $17^{\text {th }}$ and half of the $18^{\text {th }}$ course was set and grouted, leaving the channel of the $18^{\text {th }}$ course empty. This course was left empty because the rebar in the top course would not be set until the steel loading beam had set. 


\subsection{Construction of the $T$ Wall (W5)}

Construction of W5 began with preparing six pieces of $10 \mathrm{M}$ rebar for the application of strain gauges. Each piece of rebar was marked at $177 \mathrm{~mm}$ and $228 \mathrm{~mm}$, and the foil strain gages were applied between these marks.

Following the application of the strain gauges six $11.25 \mathrm{~mm}$ diameter holes were drilled to a depth of $127 \mathrm{~mm}$ into the $150 \mathrm{~mm}$ thick reinforced concrete footing. The holes were spaced according to the locations where the rebar was to be set shown in Figure 4-7. The web of the wall had the same vertical rebar spacing as W1 though W3 (Bland 2011), while the flange of the wall had one rebar on either side of the wall. The flange width was determined by calculating the minimum flange width which accurately depicts an intersecting wall. A conservative estimation of the flange width was used in order to mobilize all the rebar in the flange. The minimum effective width was determined according to the following equation recommended by (Paulay and Priestley, 1992):

$$
b_{e f f}=0.3 h_{w}+b_{w}<b
$$

where $h_{\mathrm{w}}$ is the height of the wall, $b_{\mathrm{w}}$ is the width of the wall, and $b_{\text {eff }}$ is the effective length of the flange. The results of this equation provided an effective flange width of $690 \mathrm{~mm}$. Using a full block on either side of the web of provided an effective flange width of $750 \mathrm{~mm}$ which was the closest possible width under the constraints of the ICEB lengths. 

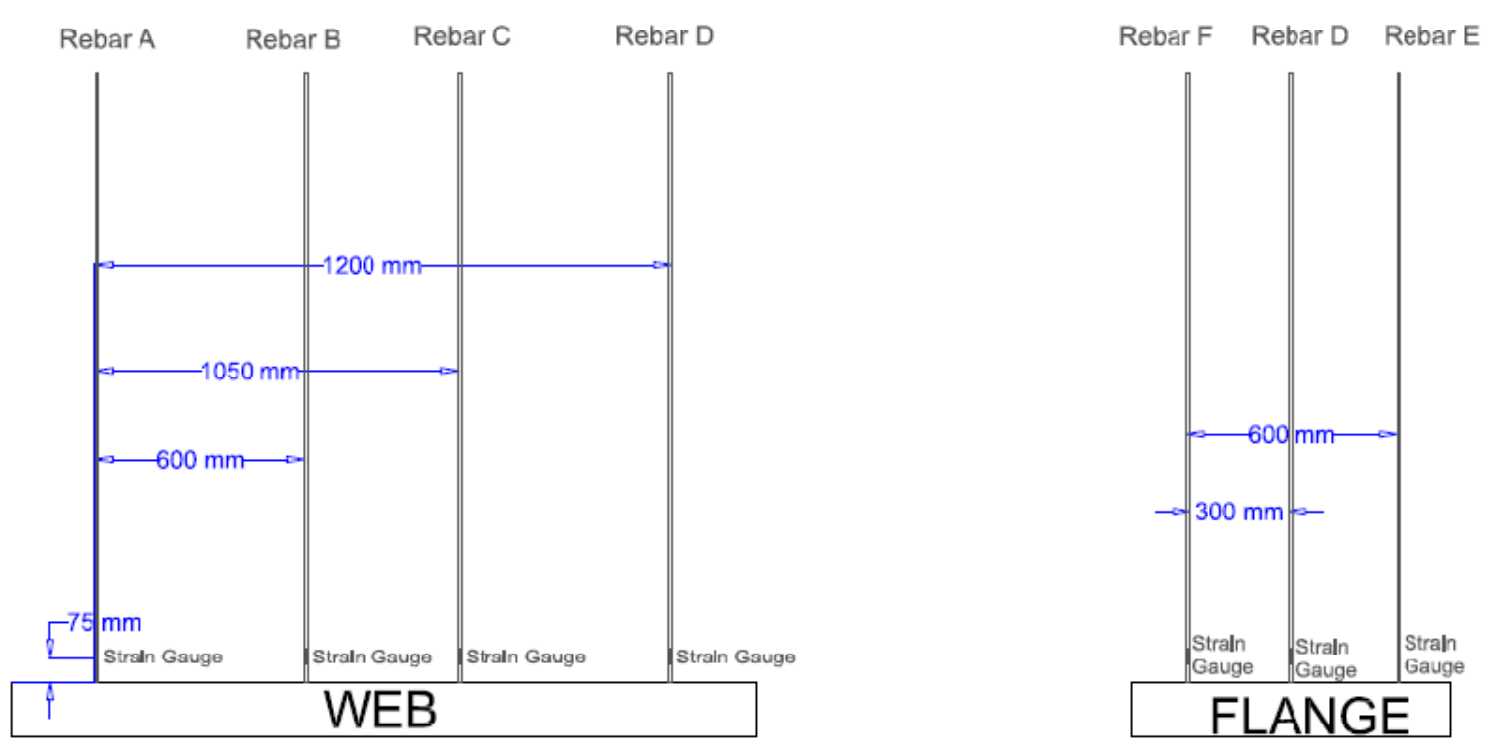

Figure 4-7: Vertical rebar layout of W5

Following the 24 hour curing period for the epoxy, the first course of blocks was laid. Several modifications had to be made, before construction, to accommodate the intersection of the web and flange. The first course of ICEBs consisted of seven regular full blocks and one full end channel block. The end blocks were used at this intersection to allow for a continuous end grout key, as the cobra pattern (overlapping pattern) does not allow for this at the intersections face. To allow the continuous reinforcement from the web into and throughout the flange, a portion of the side of the end channel block had to be removed to allow for the rebar to be inserted. A $50 \mathrm{~mm}$ section of the channel end block wall was selected to be removed, starting from the wall end of the block and toward the middle. Removal of this wall section was started by marking the cutting area on either end of the section and using a skill saw with a masonry blade set to the same depth as the channel. Once the cuts had been across the entire width of the block, the block was set on its side and a wood file was lined up along the bottom of the cut to 
gently tap out the notch from the cut section (Figure 4-8). In cases where the section did not break away cleanly from the brick, the file was used to tap extra pieces of the brick away leaving the notched section level with the bottom of the channel.
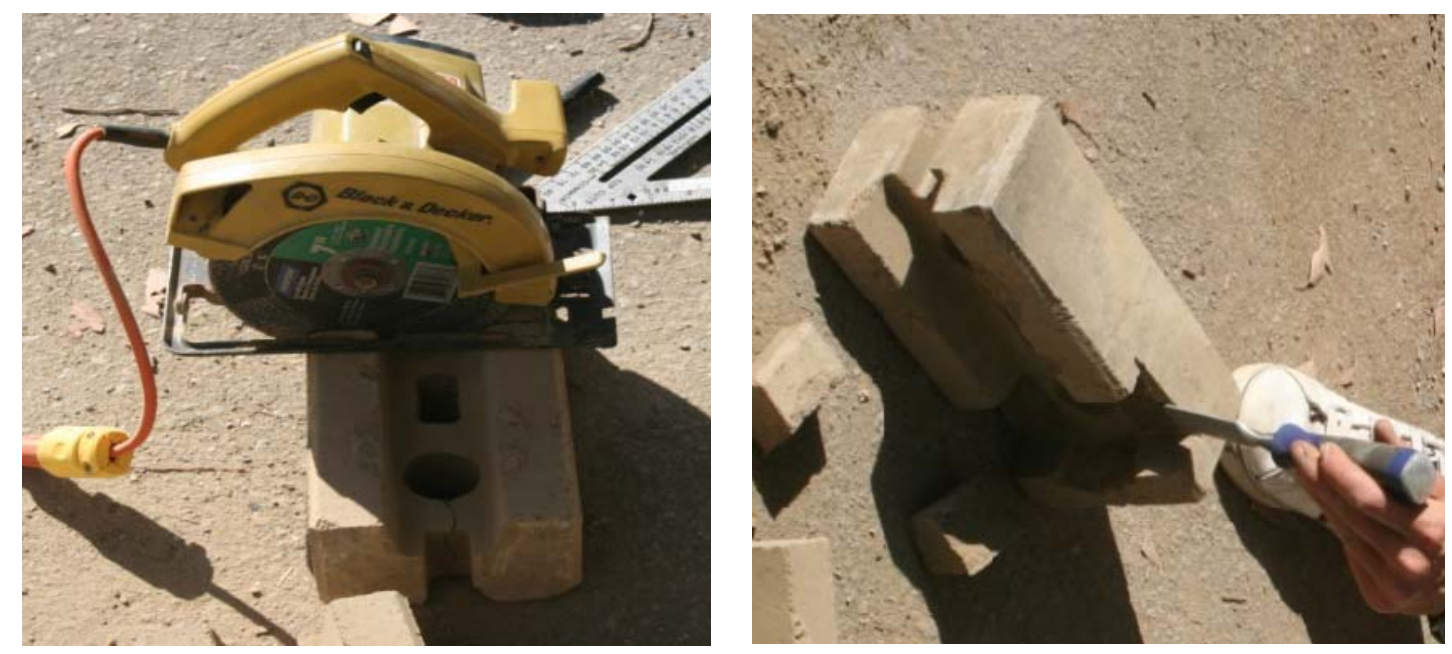

Figure 4-8: Modification of end blocks for reinforcement

Following the notching of the end blocks, all eight channel block were arranged on the footing with five channel blocks lined up from rebar A towards rebar D (see Figure 4-7) The end block was used as a channel block at the end around rebar D, and the other two channel blocks were lined up perpendicularly to the notches cutout of the end block. A level was used to determine the low spots on the footings, under the bricks, where more mortar would be used to level the first course of the wall. The two open ends of the flange and the web were duct taped to contain the mortar and the mortar was laid under the each block, by lifting one block at a time, packing the mortar under the block and then letting the block sink into the fresh mortar. The blocks were leveled by either tapping individual block further into the mortar with a rubber mallet or by adding more mortar under each block. The mortar was allowed to set for a day before anymore 
construction was completed on the wall (Figure 4-9). This allowed the bottom course to remain level while the wall could be constructed on top of it.

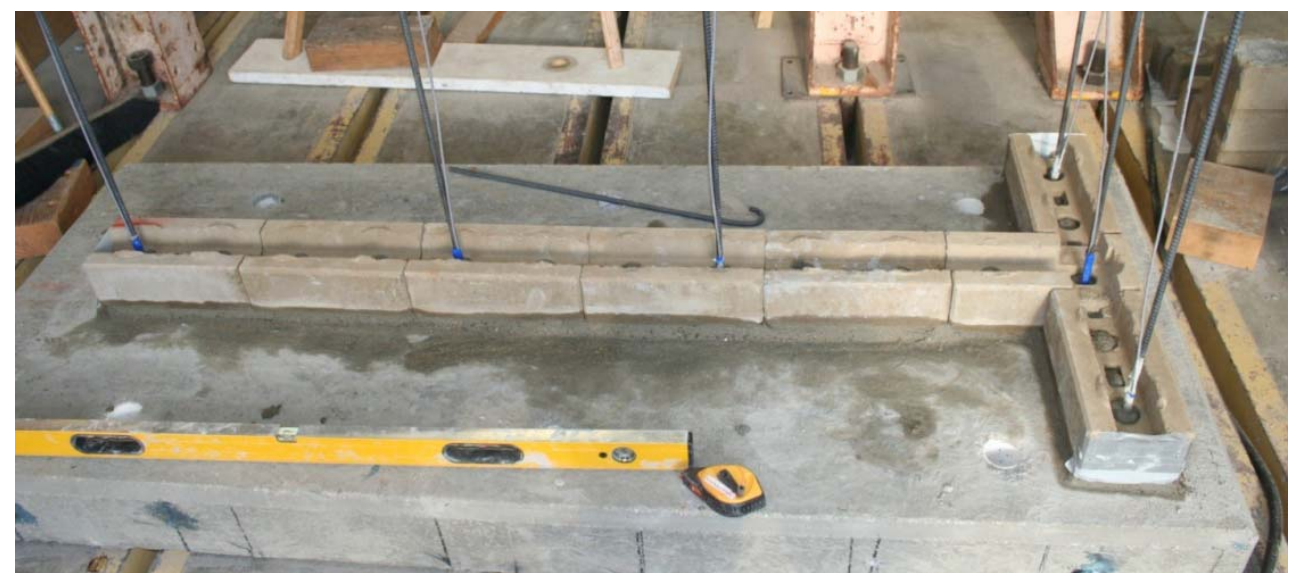

Figure 4-9: W5 after the first course was laid.

Twenty four hours after the first course of ICEBs had cured; major construction began with the setting of the transverse rebar in the first course of the channel block. A length of rebar was cut to $2.25 \mathrm{~m}$ and marked at $300 \mathrm{~mm}$ and $2097 \mathrm{~mm}$ where 90 degree bends would be made in the rebar. The bends would be constructed perpendicular to each other as to allow one bend to hook around the outside rebar $\mathrm{D}$, in the flange, and travel towards rebar E. The 90 degree hook at the other end of the transverse rebar would be bent upwards and then run parallel to, and in line with, rebar A. Once the rebar was set into place, steel ties were used to secure the transverse rebar in the center of channel by tying it to the vertical rebar. Another $750 \mathrm{~mm}$ section of rebar was cut for use as a transverse reinforcement in the flange. Two 90 degree vertical bends were made at 150 $\mathrm{mm}$ and $600 \mathrm{~mm}$ from one end and then tied to rebar $\mathrm{E}$ and $\mathrm{F}$ using steel ties with the two bends facing up. The combination of two lengths of transverse rebar in the flange and in the web provided continuous shear reinforcement throughout the entire course. 


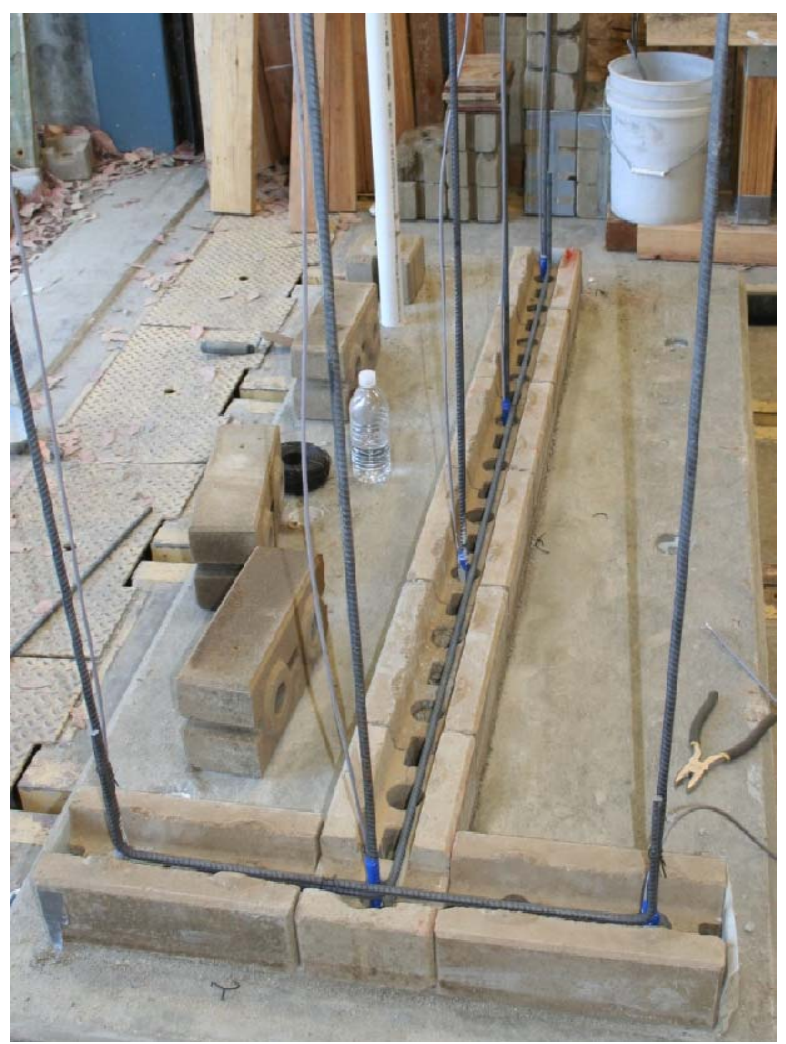

Figure 4-10: Course 1 of W5 with shear reinforcement placed.

Following the placement of the shear reinforcement in the first course, and before the second course was laid, five full blocks and one half blocks had $6.35 \mathrm{~mm}$ holes drilled into the side of each block through the center of the reinforcement hole to supply the wire to the strain gauge. The location for these holes was determined to be the areas with little stress throughout the duration of the test and that could be easily connected to the data acquisition system. The blocks were lifted over the vertical rebar, the wires fed through the drilled holes, and the blocks set into place on the second course.

To create the intersection between the flange and the web it was necessary to determine an appropriate way join them. According to the Interlocking Compressed Earth Block Manual, (Wheeler, 2005) two patterns are used to construct intersecting walls which are called the cobra pattern and the peacock pattern as shown in Figure 4-11. 
Cobra pattern was chosen over the peacock pattern due to the number of half blocks used. The cobra pattern used half as many half-blocks as the peacock pattern which would provide better stability and overall continuity for the flange wall. A third pattern, which was not in the construction manual, was briefly considered using $3 / 4$ block and eliminating the need for half blocks but was deemed impractical as our press was not designed to create $3 / 4$ blocks.

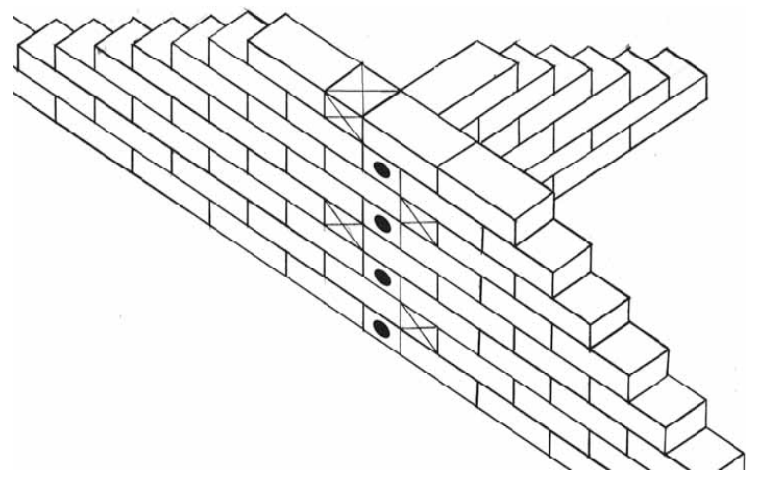

- =full bloc $k$ into the wall $x=$ half block

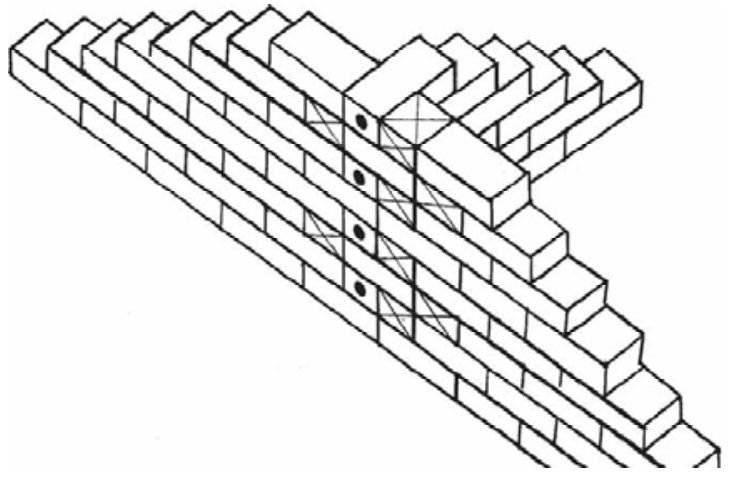

- = full block into the wall $x=$ half block

Figure 4-11: Cobra (left) and Peacock (right) Pattern for intersecting Walls (from Wheeler, 2005)

Although the decision to build the intersection using the cobra pattern was made the width of the one block flange provided a problem with the location of the half blocks. The flange was designed as shown in Figure 4-12. 


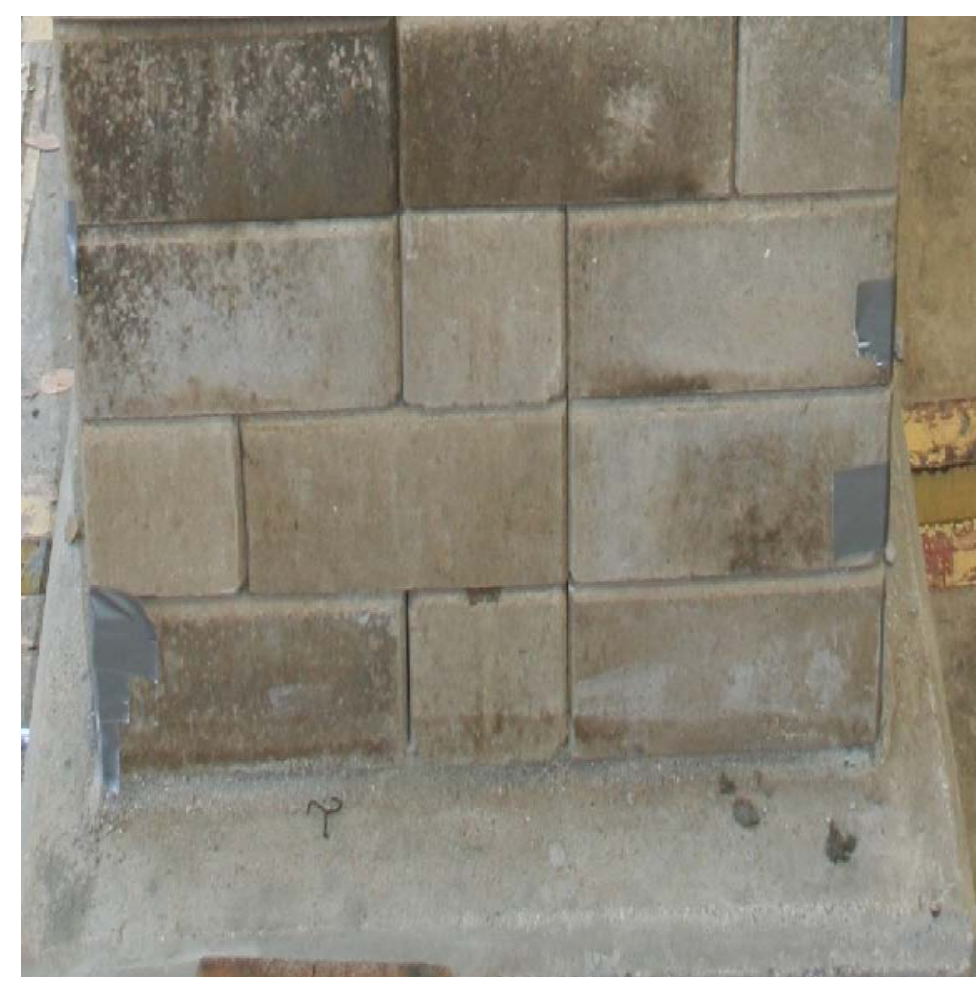

Figure 4-12: Adapted cobra pattern for W5

The pattern in the fifth course of the flange was the same the first course, as the pattern repeats itself every five courses. The same is true with the horizontal reinforcing pattern of transverse rebar; however, in order to more evenly distribute the shear forces from the web into the flange, the transverse rebar coming into the web was hooked opposite to the reinforcement below it. Hooking the rebar on both sides of the flange helped balance the shear transferred into both sides of the flange in the push and pull cycles.

After rebar had been inserted in both the web and the flange of the fifth course of the wall, it was necessary to make the wall both level and plumb. The addition of the flange to this wall made leveling the wall much easier as the overlapping pattern of the 
flange helped line up the blocks in the web, and vice versa. A few minor leveling adjustments had to be made by either changing out uneven blocks or by inserting spacer nails between the blocks in low spots to raise the height in key locations. Grouting was completed by mixing two batches of grout to fill the entire four and half courses. The grout was poured into the channel in the fifth course and filled from the top down moving from the web to the flange. Each hole was filled in sequence and rodded after filling; grout was refilled after the level dropped. Special care was taken to ensure that each hole was rodded the entire height. The channel of the fifth course was filled last, just enough to cover the horizontal reinforcement, then rodded the entire length of the web and flange to remove any air voids as shown in Figure 4-13.

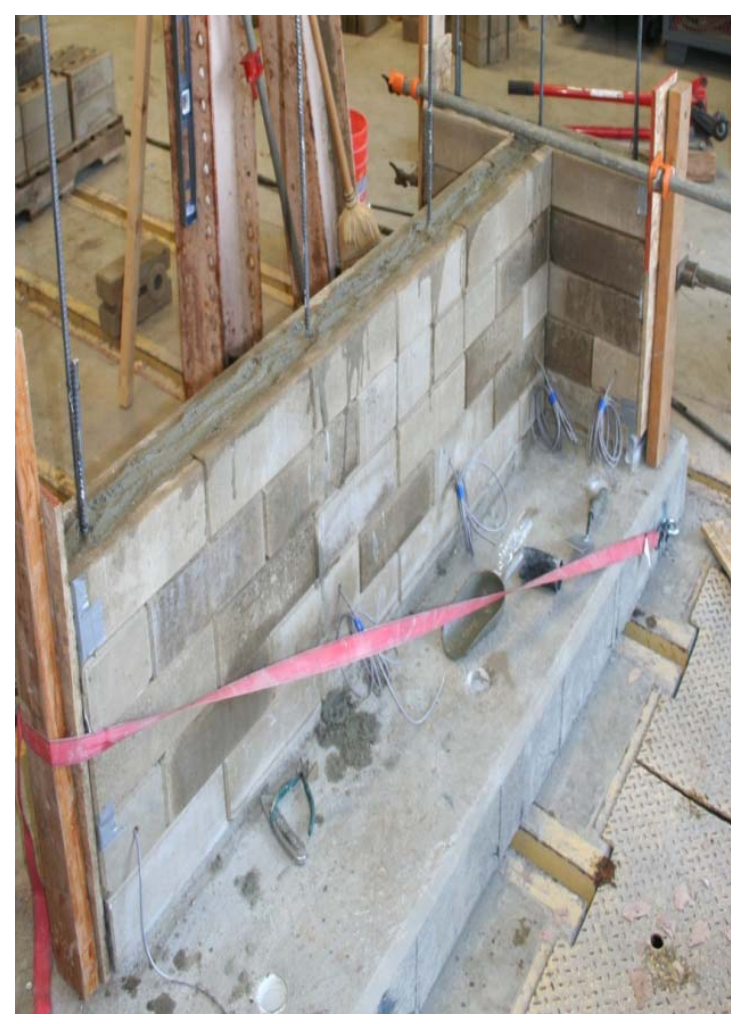

Figure 4-13: Courses 1 through 5 of W5 after grouting, 
Courses 6 through 13 were laid, leveled, stacked, and grouted the same as courses 1 through 5 in two different lifts. Due to the asymmetry of the transverse reinforcement, courses 14 through 18 were set in two different lifts instead of one. Similar to W4, W5 had three courses of full blocks between layers of reinforcement until Course 13. Courses 13 through 18 had four layers of full blocks between two layers of reinforcement; therefore, grout would need to be applied over five and a half courses, instead of four and a half. It was determined five and a half courses would be too big of a risk to pour even the most fluid grout through; therefore, the five courses were leveled and grouted at Course 16 (a course of full blocks) and again at Course 18. Following laying and leveling Courses 14 through 16, forms around the courses were erected to confine the grout. The grout was carefully poured into the grout keys and the reinforcement holes using a scoop, a funnel, and then rodded to aid the removal of voids.

The seventeenth and eighteenth courses were laid and leveled at the same time, but were not set in the same pattern as the other courses (see Figure 4-14). The seventeenth course was constructed with a full block coming thought the web into the flange. The reinforcement was set in course 18 with a block arrangement similar to Courses 1, 6, 10 and 14. The eighteenth course was constructed from seven full channel blocks and two half channel blocks to hold the transverse reinforcement. Once Course 17 and 18 were laid and leveled anchor L bolts were set in the center of the reinforcement holes, close to the vertical reinforcement and deep enough to penetrate through the eighteenth course and into the seventeenth course. The L bolts protruded above the eighteenth course to allow the steel loading beam to be bolted to the wall at a later time. The seventeenth course and all but the channel of Course 18 were grouted once the 
outsides had the form built up around the outside grout channel. The top channel was left open to provide a layer of reinforcement and the mortar which would be used to fill the channel of the eighteenth course and bond the steel loading beam to the wall.
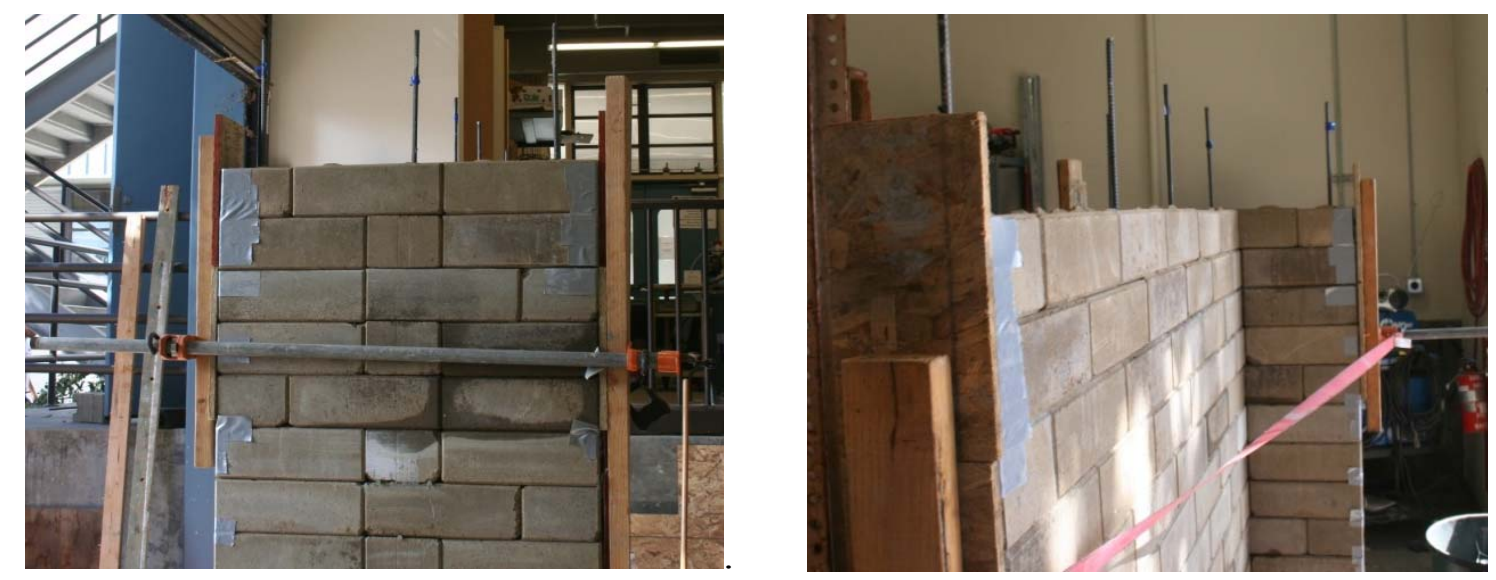

Figure 4-14: Courses 17 and 18 in the flange (left) and web (right) of W5

The eighteenth course was allowed to set after the grout was poured and the wall was washed down with a hose to remove any excess grout on the side of the wall. This made the wall more aesthetically pleasing and also allowed the grout and mortar to cure slower so cracking and separating from the blocks wouldn't become a problem. The wall was watered every 12 hours for 48 hours to assist in proper curing. Following the first 24 hours of curing, all the form work and duct tape was removed before the grout was completely cured which allowed the tape to be removed easier. The wall was left to solidify for 21 days before the steel loading beam was mounted to the top of the wall. 


\subsection{Construction of the Window Wall (W6)}

The internal reinforcing design of the wall is based on a combination of observations from the performance of previously tested walls and the ICEB manual (wheeler, 2005). The ICEB manual suggests that no less than one reinforcing bar should surround all four sides of the window for an opening less than $1.2 \mathrm{~m}$ (see Figure 4-15). Previous testing suggests that reinforcement with tight bends, such as around the frame of the window, would produce tearing around the corners of the window when the rebar goes into tension. To prevent this failure, four separate reinforcing bars were used along the outside of the opening allowing each bar to be stressed without effecting the bars in the other direction, preventing stress concentrations around the corner of the opening as shown in Figure 4-16.
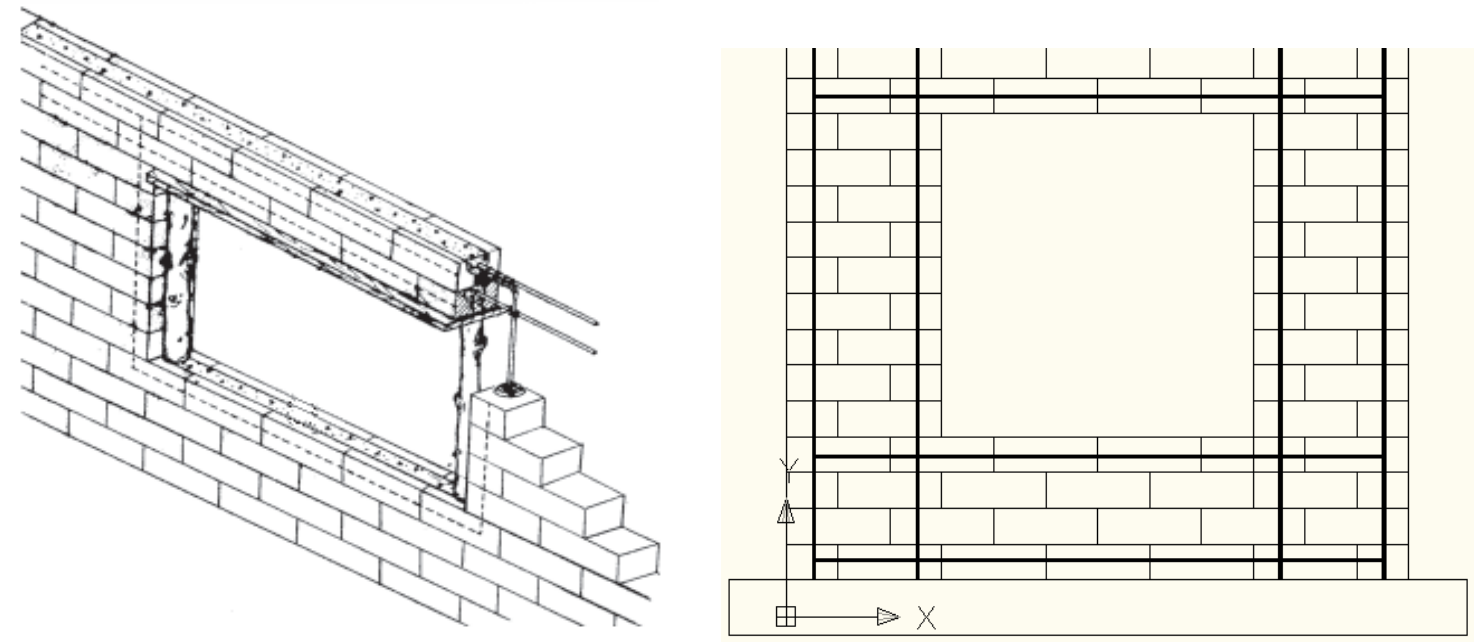

Figure 4-15: proposed method for Window reinforcement (Wheeler, 2005) 
Construction of W6 started with the preparation of the vertical reinforcement, with four pieces of $10 \mathrm{M}$ rebar cut to be 2.1 meter long. Strain gauges were applied at various locations on all four pieces of rebar. Two of the pieces (rebar A and rebar B) were fitted with 2 foil strain gauges each, while the remaining pieces (rebar $\mathrm{C}$ and rebar D) were fitted with one strain gauge each. The two strain gauges on rebar A and B, starting from the bottom, were to be set at 540 and $1430 \mathrm{~mm}$ respectively, while the gauges on rebar C and D were set at $540 \mathrm{~mm}$ from the bottom.

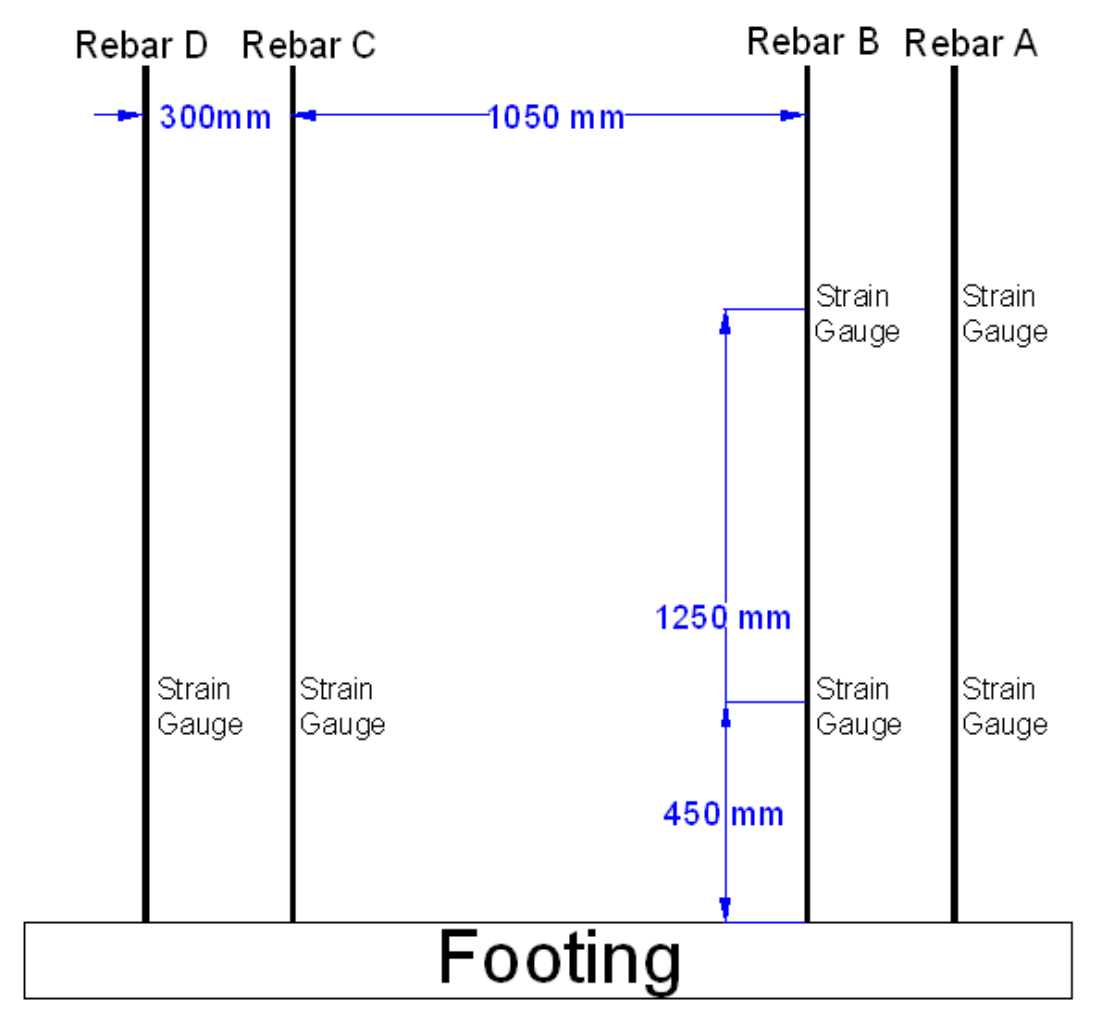

Figure 4-17: Vertical rebar layout for W6

After the anchoring epoxy had cured for 24 hours, the first course of ICEBs was set. A batch of thick mortar was prepared according to the proportions specified in Appendix A and laid along the footing where the first course was to be set. It was necessary to set the first course of bricks well in advance because the reinforced concrete 
footing was not level. To compensate, extra mortar filled in the low spots making the first course of ICEBs level. Five full channels and two half-channel ICEB's were set in the wet mortar with the two half blocks on the outside corners and the full blocks in the middle. This configuration was selected in order to allow the header above the window and the ring beam below to have full blocks at the corners of the window. To level the blocks vertically, mortar was added or removed under the blocks and a rubber mallet was used to tap the bricks straight in the plane of the wall. A 24 hour curing period followed to ensure that the mortar had sufficient strength to withstand the self weight of the wall.

A 2 meter long 10M rebar was bent with two $150 \mathrm{~mm}, 180$ degree hooks and was placed around the outside of the vertical rebar A and D (see Figure 4-18), as horizontal shear reinforcement. After the top failures of W3 and W5, the decision was made to use 180 degree hooks, which would be better to transfer forces from vertical to horizontal, rebar. In the past, 180 degree hooks were felt to be too hard to manufacture in developing countries and scantly meet the ACI requirement for bend diameters (ACI 530-08). By tilting the rebar with the 180 degree hooks, it was possible to fit the rebar in the channels and around the vertical reinforcement. 


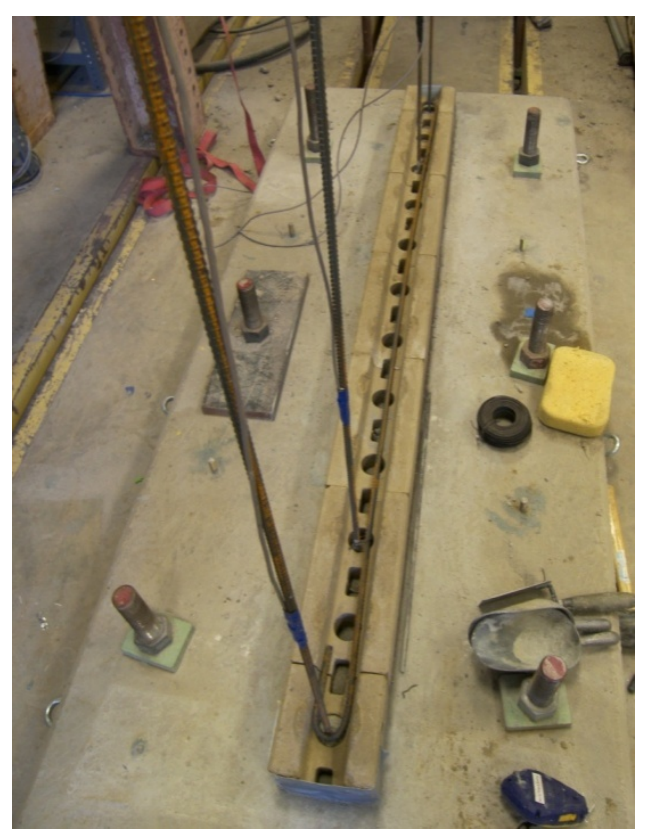

Figure 4-18: Transverse reinforcement hooked around vertical rebar of W6

Courses 2 and 3 of the wall were dry stacked using the running bond pattern, making the second course all full block and the third course having half blocks on either end of the wall, similar to the first course. The fourth course consisted of all channel blocks and would become the bottom layer of the window. These blocks were laid in a pattern similar to that of course 2 and the transverse reinforcement was again hooked around the two outside bars (rebar A and D) using 180 degree hooks with $150 \mathrm{~mm}$ tails. Duct tape was taped to the end of the blocks of the wall, and plywood boards cut to the width of the ICEB were butted against either end of the wall. Ratchet-straps were then strapped around the length of the specimen to prevent the grout from pouring out on either end. Fluid grout was then poured into each hole and rodded 3 to 5 times to prevent any air voids which can be seen in Figure 4-19. The wet mortar which filled the channel was then smoothed using a trowel for esthetic purposes. 


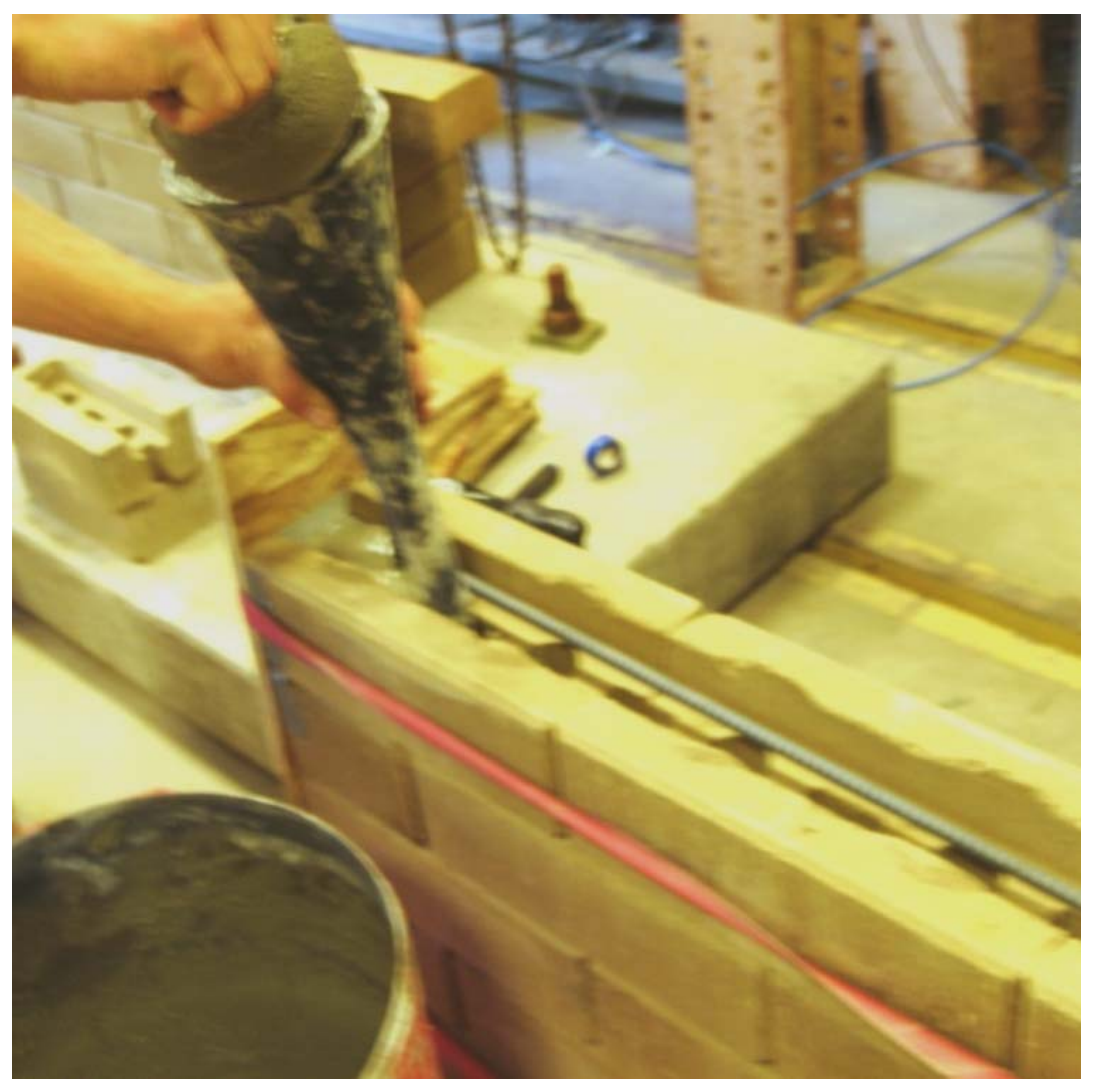

Figure 4-19: Courses 1-4 of W6 being grouted

The pier design revolved around creating a flexural failure in the wall, and preventing a shear failure in the piers. Due to the relatively small amount of shear area provided by each pier, it was determine that steel reinforcement would be needed throughout the piers. A conservative estimation of the shear capacity from each pier suggested that two horizontal reinforcing bars would produce sufficient shear capacity to create a flexural failure. The combination of the narrow width of each pier and the lack of shear strength of the material do not meet the ACI requirement for reinforcing to be half the depth of the member where reinforcement is required (ACI 530-08). The resulting design required reinforcement to be placed in every other course of the pier keeping reinforcing pattern constant and meeting all $\mathrm{ACI}$ requirements for the piers. 
The construction of the piers on either side of the 3 block wide and 9 block high opening began at the fifth course. Each of the piers consisted of a half block and a full block which continued to alternate in the running bond pattern. Shear reinforcement was placed in Course $6,8,10$, and 12, translating to every other course of the pier starting at the second course of the pier. The transverse reinforcement was hooked around the longitudinal reinforcement using 180 degree hooks. Grouting took place at all the courses where shear reinforcement was placed, and filled only enough to cover the reinforcement to ensure that the cold joint was midway up the block, and not at the joint between the bricks. Duct tape was used on the outside of the blocks on either side of the piers in order to keep the grout in place in the outside grout key of the brick. Ratchet straps, plywood and boards were used as form work on both piers to contain the grout.

Before setting the lintel above, the window formwork was constructed to frame the window and hold the bricks in place over the unsupported distance above the window. The design of the formwork was constructed to allow the removal of the timber frame without putting any stress on the specimen after the grout cured. The formwork was created using six pieces of scrap lumber; a top and bottom piece, two side pieces, and two inside pieces which can be seen in Figure 4-20. The two side pieces were designed and cut in length to run the full length of the piers. These two timbers also acted as a formwork to the piers on the inside of the window along with part of the frame. Both the header and the bottom piece were cut to approximately $824 \mathrm{~mm}$, and fitted between the two $0.9 \mathrm{~m}$ side pieces. The two inner pieces were cut to approximately the same length as the bottom piece to fit between the bottom and header pieces. The two inner pieces 
were nailed to the outer pieces supporting the top and bottom pieces of the frame, allowing a flat bridge across the top of the window to keep the header level.

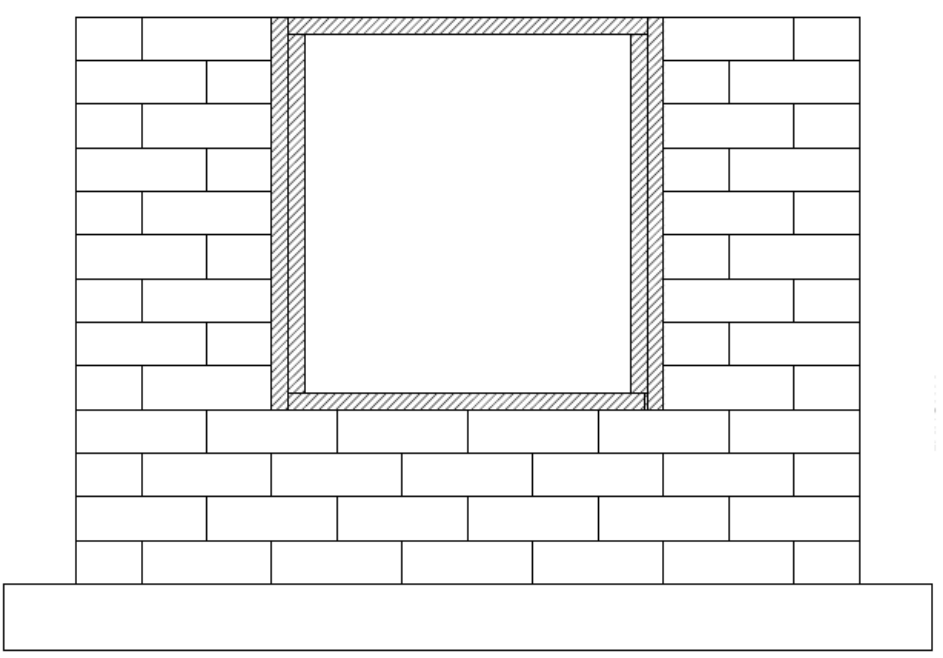

Figure 4-20: Schematic of the timber frame for the window

The header was designed to accommodate both the self weight and the moment produced over the opening. The single ring beam set in the first course of the header was designed based on the ICEB manual (Wheeler, 2005) for openings less than 1.2 meters. The ring beam helped distribute the force from the roof load and the self weight of the header into the piers. The ICEB manual made no recommendation for the manner in which to set shear reinforcement, however calculations suggested that shear forces would be present in the header and require extra shear reinforcement. Even thought extensive testing had been done on the shear capacity of ICEB walls, no testing had been completed using ICEB in a beam setting. It was decided to over reinforce the header. It was assumed that the header would not have enough shear capacity without reinforcement, which required stirrups to be placed no further than half the depth of the beam apart. The geometry of the ICEBs made it possible to set stirrups at $150 \mathrm{~mm}$ increments. Three stirrup U-shaped stirrups ran the full high of the header and up the reinforcement holes of 
the header in every block of the header which can be seen in Figure 4-21. All the vertical reinforcement extended past the top of the wall and bent into the top channel, but shown terminating where the bend would begin in Figure 4-21 for clarity of the figure.

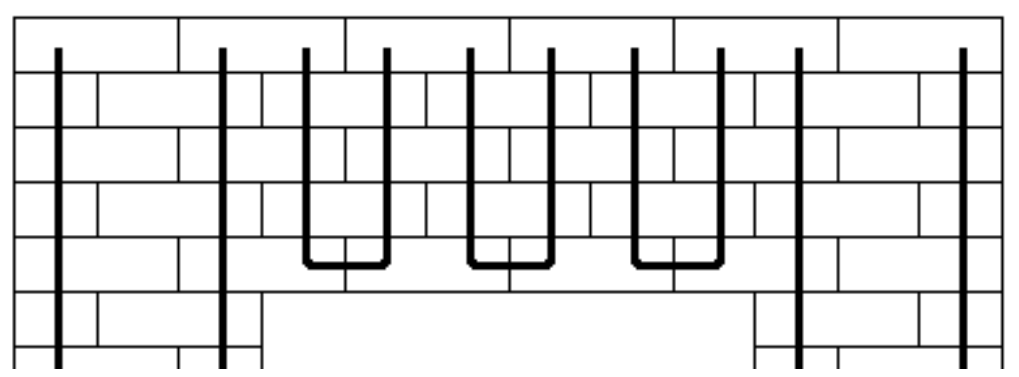

Figure 4-21: shear reinforcement design of W6 header

The header was set as a ring beam with reinforcement continuously across the wall. The reinforcement was set the same as the ring beam below the window, with the 180 degree hooks being hooked around the outer most vertical rebars on either side of the wall. The transverse reinforcement in the header was tied to the inner vertical bars of the piers, which were used to keep them in the center of the holes allowing the grout to bond better to both the reinforcement and the block. Before the grout was poured into the header, three vertical stirrups were fashioned for the header to prevent the lintel from failing in shear. The stirrups were made of scrap pieces of vertical rebar and were bent into a U-shape with both ends being roughly $40 \mathrm{~cm}$ long and the middle section being 15 $\mathrm{cm}$ long. These three vertical stirrups were set in the middle of the header, spanning the length of the window opening and running up the circular reinforcement holes of each of the blocks of the lintel over the opening which can be seen in Figure 4-22. By setting the fifteenth course of ICEBs before filling the channel of the fourteenth course, the vertical 
stirrups were held in place, and the grout was poured by lifting the blocks of the fifteenth course, one at a time, pouring the grout into the channel, then resetting each block.
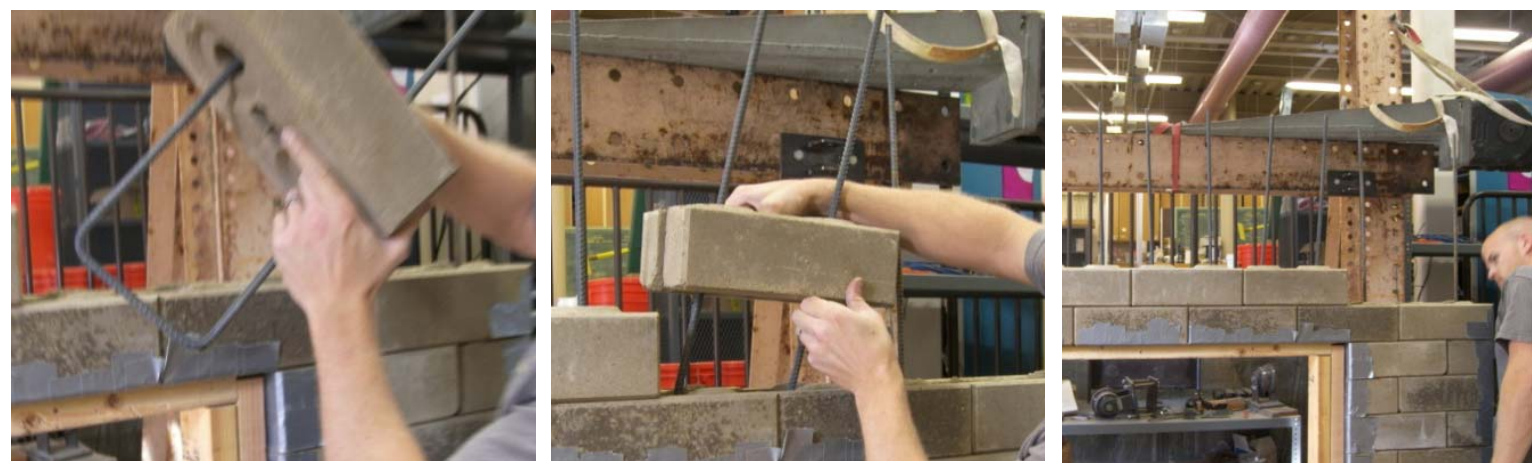

Figure 4-22: Setting the shear reinforcement for the lintel of W6

The top three layers of the wall to be set were Courses 16 though 18 with Course 16 being the last layer of full blocks and Courses 17 and 18 being channel blocks. All three layers were set at the same time pouring the grout in-between stacking layers. This was done due to the large amount of vertical steel running throughout the top three layers and the importance of keeping the vertical stirrups, partially set in grout, from moving. Courses 17 and 18 were channel blocks with 10M rebar placed in them as they were laid with 180 degree angle hooks bent around the two outermost vertical rebar. From the top failures of W3 and W5 it was understood that extra reinforcing was needed to transfer the load from the actuator to the wall resulting in course 17 becoming a ring beam in W6. To transfer this load, four modified L anchor bolts were set into the top two courses, allowing the anchor bolts to be spaced correctly and set down past the reinforcement of the seventeenth course.

Grout was poured from the top of the eighteenth course using an extra fluid grout and a funnel. This grout was made more fluid by adding more water allowing the grout to flow better to ensure that it filled all the voids in the reinforcement holes and the grout 
keys in all four layers. As each reinforcement hole or grout key was filled with grout, it was rodded between two and four times to help consolidate the grout by removing the air voids. Special care was made to ensure that proper bonding took place around the vertical rebar and $\mathrm{L}$ hooks by rodding around them, then quickly refilling any voids caused by the rodding. Courses 15,16 , and 17 were grouted this way, but Course 18 was only grouted enough to cover the rebar in the channel as to prevent a cold joint at the top. The grout would be given two days to harden before the vertical rebar would be bent over into the channel of the eighteenth course of bricks in order to ensure a tighter bends of the rebar and prevent cracking of the grout and blocks.

Forty-eight hours after the final grouting was completed on the eighteenth course of the wall, the vertical rebar was bent over using a pipe with an inner diameter slightly larger than that of the rebar, allowing it to slide over the rebar and provide more leverage for bending. Once the rebar was bent as far as the geometry of the pipe would allow, a $3 / 8$ " wrench was used to further bend the rebar allowing it to lie flat in the channel of the top course of blocks. Mortar was then used to fill the rest of the channel of the eighteenth course of the wall. Extra mortar was added on top of the wall to provide additional bond for the steel loading beam to the wall. The vast majority of the load transfer would be supplied by the four anchor bolts embedded in the top two courses of the wall. While the mortar was still wet, the steel load beam wall was lifted into place with a crane and slowly lowered onto the wall and bolted with L bolts. Excess mortar between the load beam and the wall was then sponged off for esthetic reasons and the entire wall was watered down every 12 hours for 2 days to allow the cement in the grout and mortar to cure. 


\section{INSTRUMENTATION AND TEST SET-UP}

\subsection{Wall Relocation}

Specimens W4 and W5 were built outside the testing set-up and moved into place before testing instrumentation. W6 was built inside the testing setup, and required no movement of the wall. W4 and W5 were moved in a similar manner with a pallet jack or forklift wheeling the wall into place, inside the testing setup, then a crane was used to lift the wall and footing over the bolts in the strong floor. Between moving of the walls into the testing area and lifting the walls onto the bolts in the strong floor, the steel loading beam was mounted to the top of the wall. After a period no less than 24 hours following the mounting of the load beam, providing time for the load beam to set, the process of lifting the walls into place commenced. As shown in Figure 5-1 ratchet straps were strapped over wall and fastened to the footing to minimize tensile stresses from developing in the wall during moving. The walls were lifted by strapping a wide flange beam to the top of the loading steel beam and using a second set of ratchet straps connected to the footing. The wide flange beam was used to add rigidity to the wall during the lifting process, minimize the stresses from being transferred into the wall from the crane. The crane was connected to the wide flange beam at a single lift point above the center of gravity allowing the wall to be lifted vertically without tilting. 


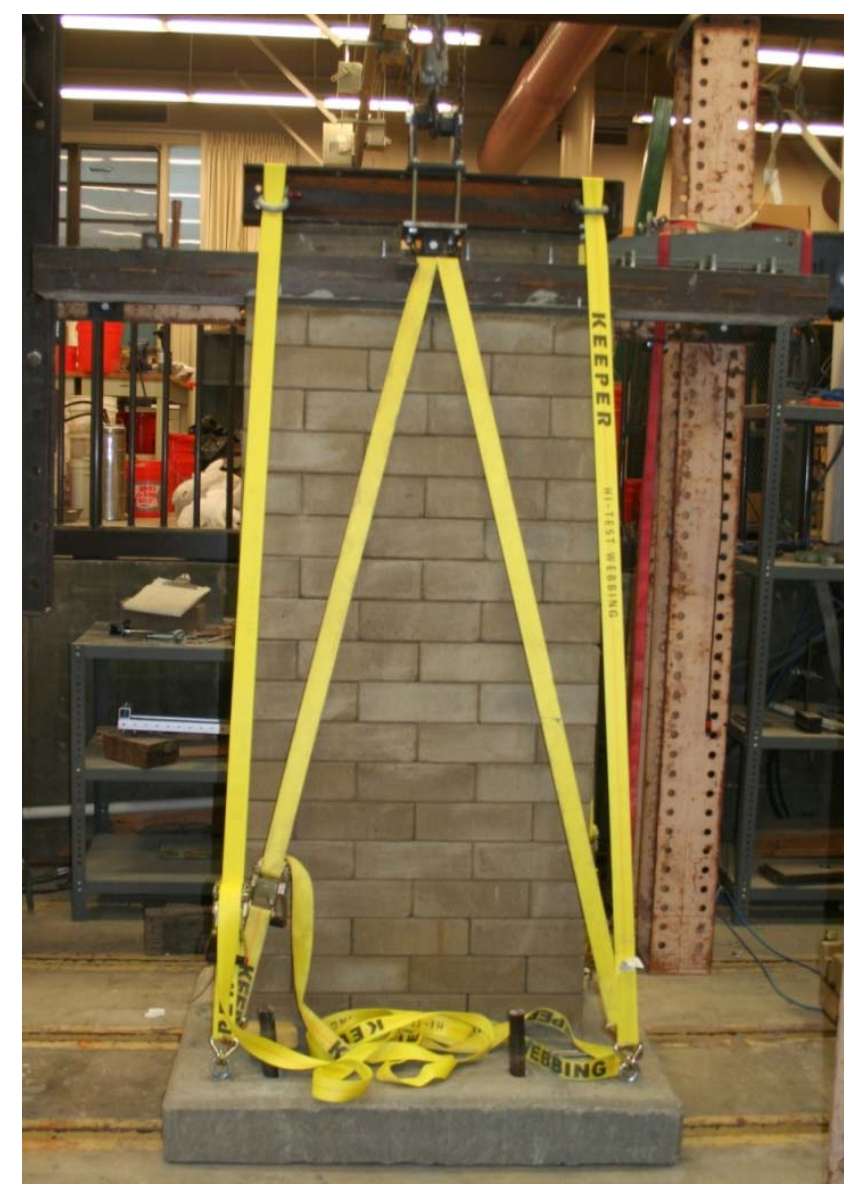

Figure 5-1: W4 being lifted into place with a crane

\subsection{Laboratory Set-up}

The same laboratory testing configuration used in the companion thesis (Bland, 2011) was used in testing all three specimens in this thesis. The lateral load was provided by a $350 \mathrm{kN}$ MTS hydraulic actuator with stroke of $+/-250 \mathrm{~mm}$. The actuator was pinned to a meter thick reinforced concrete "Strong Wall" assumed to ideally rigid and hence provides no deflection caused by the force application from the actuator. The reinforced concrete footing, which the wall was built on, was bolted to a stiff reinforced concrete "Strong Floor" to prevent movement during the application of the load. The top of the walls were restrained from out-of-plane deflections by a steel frame as shown in Figure 
5-2. Rollers attached to the wide flange vertical members restrained the wall in the outof-plane direction at either end, but allowed the wall to translate in plane. W4 and W6 used two sets of vertical bracing beams, one at each end of the wall, as shown by Figure 5-2. The addition of the flange to W5 negated the need for the second set of braces at the flange end of the wall; as the flange was assumed to prevent the wall web from rotating out of plane. During the testing of W5 only one set of vertical braces were used as shown in Figure 5-3.

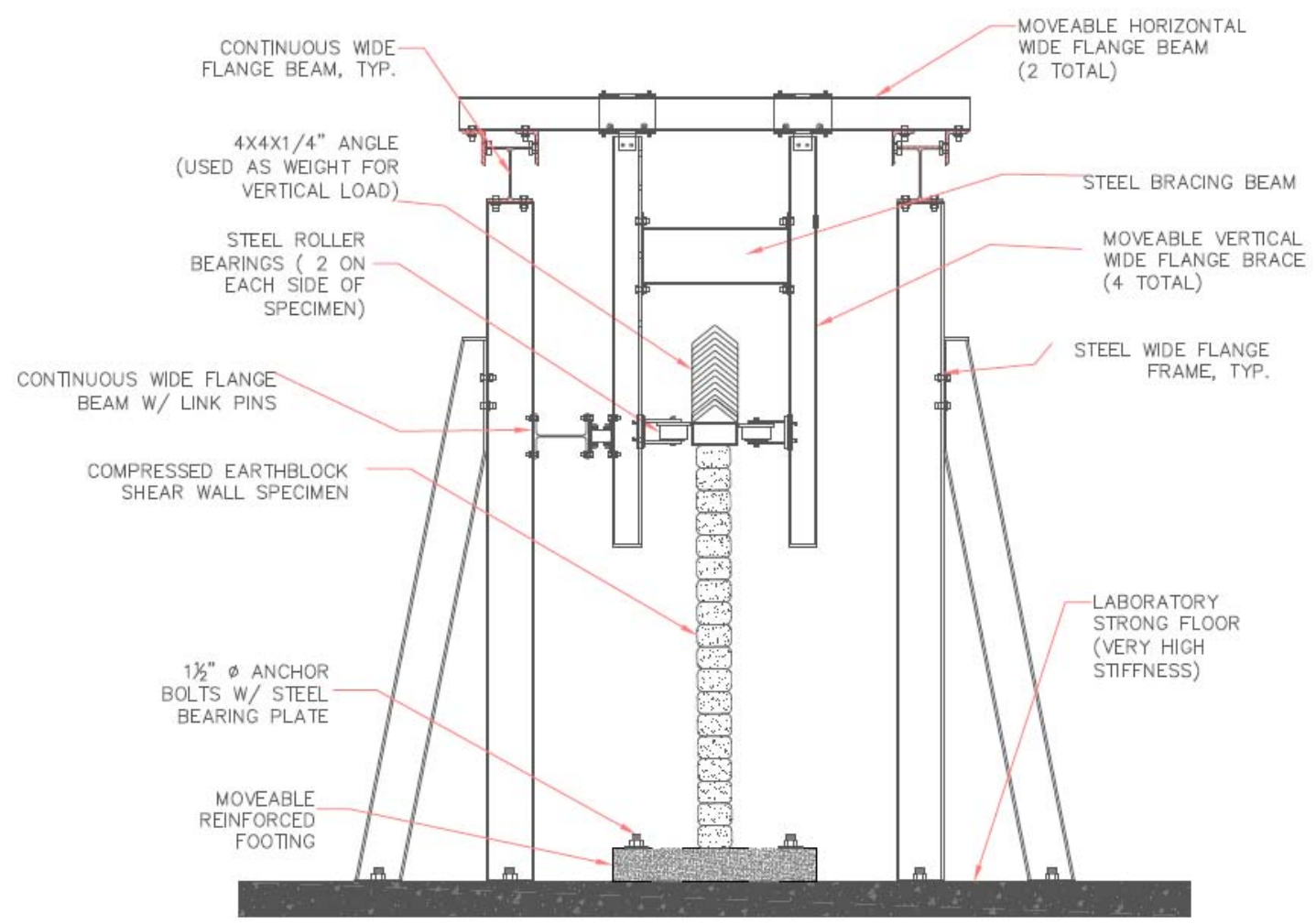

Figure 5-2: Test set-up for testing of W4 and W6 (Out-of-plane) 


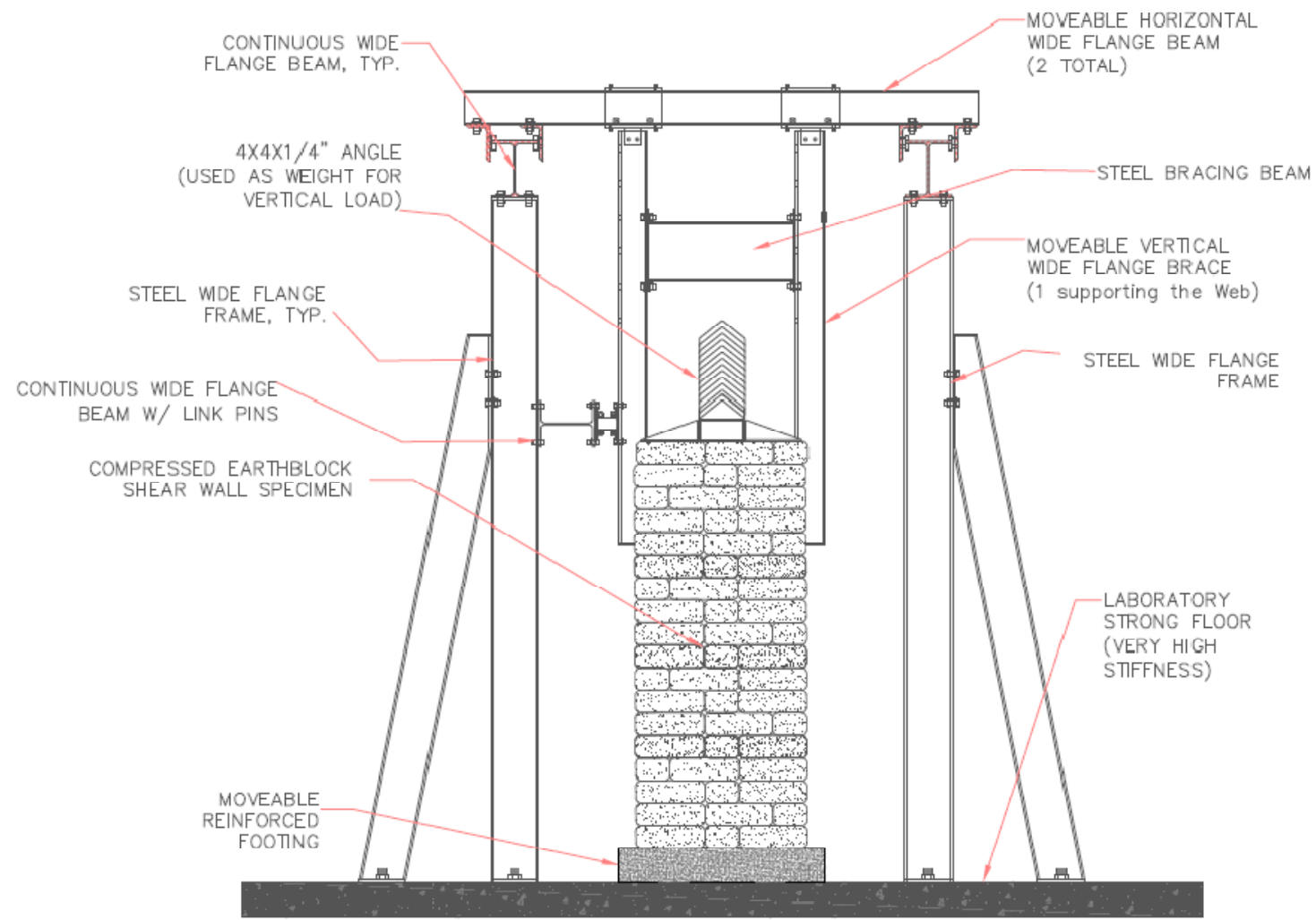

Figure 5-3: Test Set-up for W5 (Out-of-plane)

Each specimen was loaded by the actuator thought a steel loading beam at the top of the specimen which transferred the load into the wall. The loading beam, which ran the full length of the wall, was connected to the wall with $152 \mathrm{~mm}$ Simpson Strong-Tie L anchor bolts, bolting to the steel plate, anchored into the reinforcement hole. The actuator was attached to the top of the steel loading beam by 12 bolts configuration welded to the loading beam corresponding to the bolt pattern of the actuator as shown in Figure 5-4. 

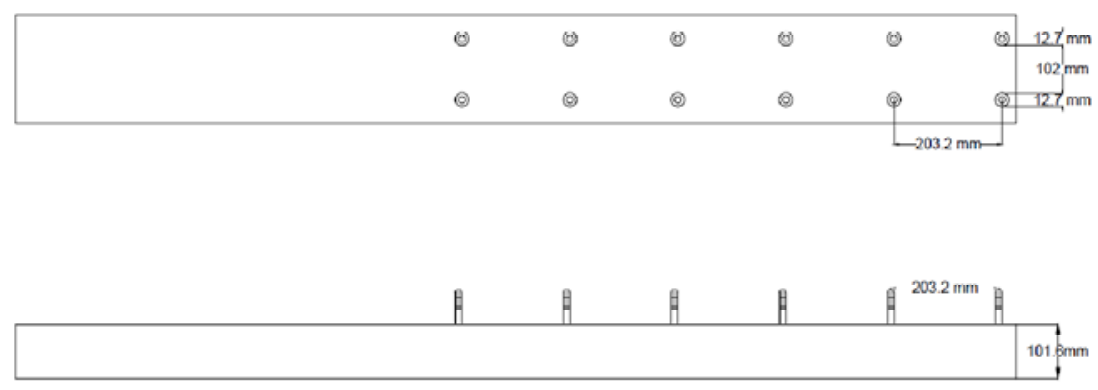

Figure 5-4: Steel loading beam used for load transfer from the actuator to wall

\subsection{Instrumentation}

The instruments used in the testing of all three shear wall specimens remain the same. Each wall utilized six linear displacement resistance transducers (DTR 0 through 5), seven linear variable differential transformer (LVDTs, designated by the length of the stroke and letters), eight linear potentiometer (LPOT 0 though7), and varying number of foil strain gauges, applied to the rebars described in Chapter 4. Although the configuration of many of the instruments changed from specimen to specimen, four remain the same: 2" LVDT A, 0.3" LVDT A, 0.3" LVDT B, and 0.1" LVDT. The 2" LVDT A was in line with the actuator and was used to track the displacement of the actuator throughout the testing. The 0.3" LVDT A and B, and the 0.1" LVDT were used to monitor slip at different locations of the test set-up. The 0.3 " LVDT A monitored the horizontal slip between the steel loading beam the wall, while 0.3 " LVDT B monitored the horizontal slip between the bottom of the wall and the reinforced concrete footing. The 0.1 " LVDT monitored the slip between the strong floor and the reinforced concrete footing on which the wall was built. 


\subsubsection{W4 Instrumentation}

Specimen W4 was expected to exhibit flexure dominant behavior for which the majority of the damage would occur in the bottom half of the wall. As such, the instrumentation was focused on the bottom half of the wall. DTRs 2 through 5 were configured to measure the shear deformation on the bottom half of the wall by mounting the instruments to studs epoxyed into the wall. Two 0.5" LVDTs (0.5" LVDTs A and B shown in Figure 5-5), set at either toe of the wall, measured the uplift at each corner of the wall. Lateral deflections were captured by DTRs 0 and 1 which measured displacements at the top (below the loading beam) and midpoint of the wall respectively. To capture flexural displacements at the bottom half of the wall the six LPOTs were attached to angle irons, which extended on either side of the wall to increase the resolution of the instruments. All six LPOTs were attached to the $1550 \mathrm{~mm}$ long angle irons which were bolted to the studs epoxyed in the wall. Figure 5-5 shows the configuration of the instruments arranged on W4.

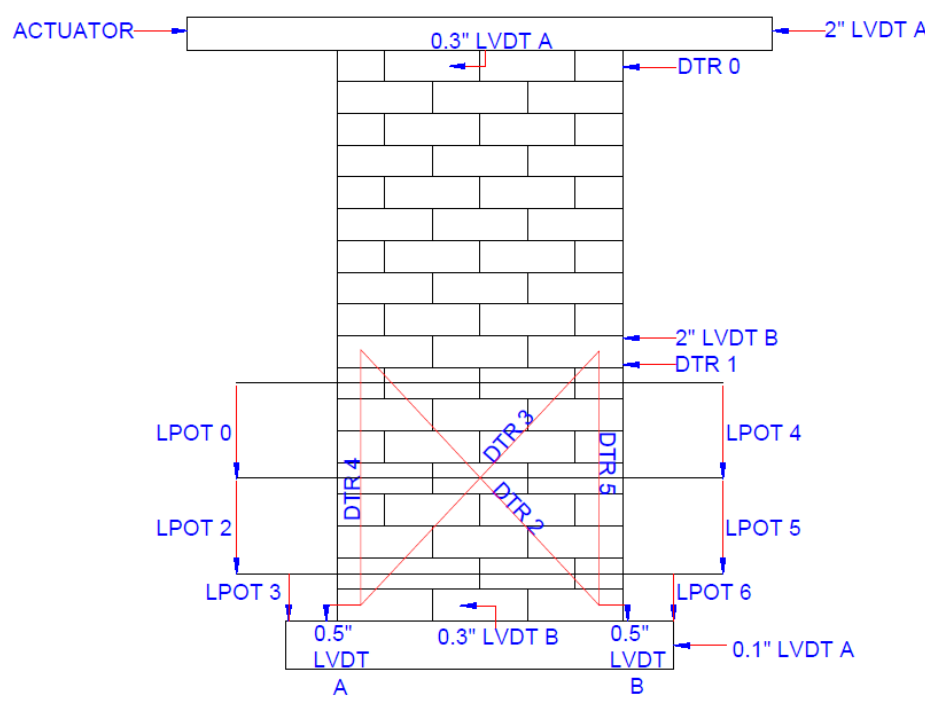

Figure 5-5: Instrumentation configuration of W4 


\subsubsection{W5 Instrumentation}

The instrumentation of W5 was similar to the instrumentation of Specimen W3 of the companion thesis (Bland, 2011) to allow for a direct comparison between flanged and regular walls. DTRs 2 through 5 were configured to measure the shear deformation over the web with instruments mounted to the wall through the studs epoxyed into the wall. The two 0.5 " LVDTs were used to measure the uplift at each corner of the wall. The 0.5 " LVDTs were attached to the wall similar to the DTRs on the shear panel, with studs epoxed into the masonry. In plane lateral deflections were measured in the same manner as in W4 with the same DTRs and LVDTs mounted to a free standing frame adjacent to the wall.

LPOTs 3 and 4 were used to measure the lateral displacement of the flange to the web, while LPOTs 2 and 5 measure the vertical displacement of the flange relative to the web. The vertical and horizontal measurements were taken at the top and bottom of the web-flange intersection to determine relative displacement from the top of the flange to the bottom. Figure 5-6 shows the configuration of which the instruments were arranged on W5. 


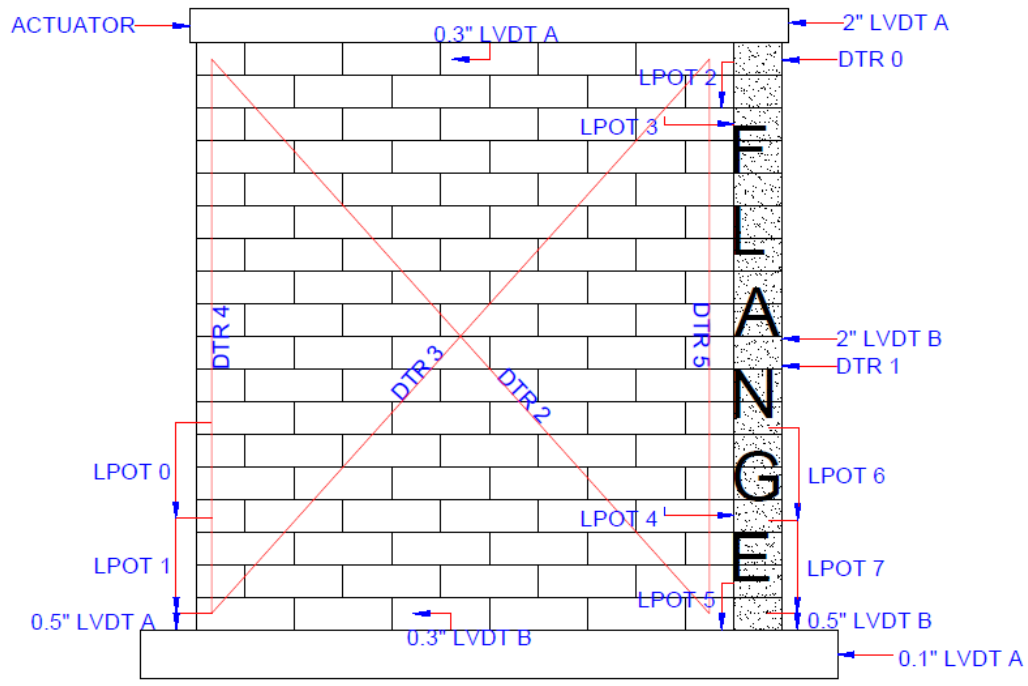

Figure 5-6: Instrumentation configuration of W5

\subsubsection{W5 Retest Instrumentation}

As described in detail in Chapter 6, an unexpected mechanical failure occurred at the initial stage of the testing of W5. The specimen was then repaired and subjected to retests. The configurations of some of the instruments were modified slightly in the repaired specimen due to the change in geometry of the wall. DTRs 2 though 5 were moved four courses down, below the reinforced concrete segment shown in Figure 5-7 to capture the behavior of the masonry. In order to determine whether movement occurred between concrete retrofit and the masonry wall, LPOT 3 was moved from measuring vertical movement of the flange to measuring slip between the reinforced concrete segment and the rest of the wall. Figure 5-7 shows the configuration of which the instruments were arranged on W5 after the retrofit. 


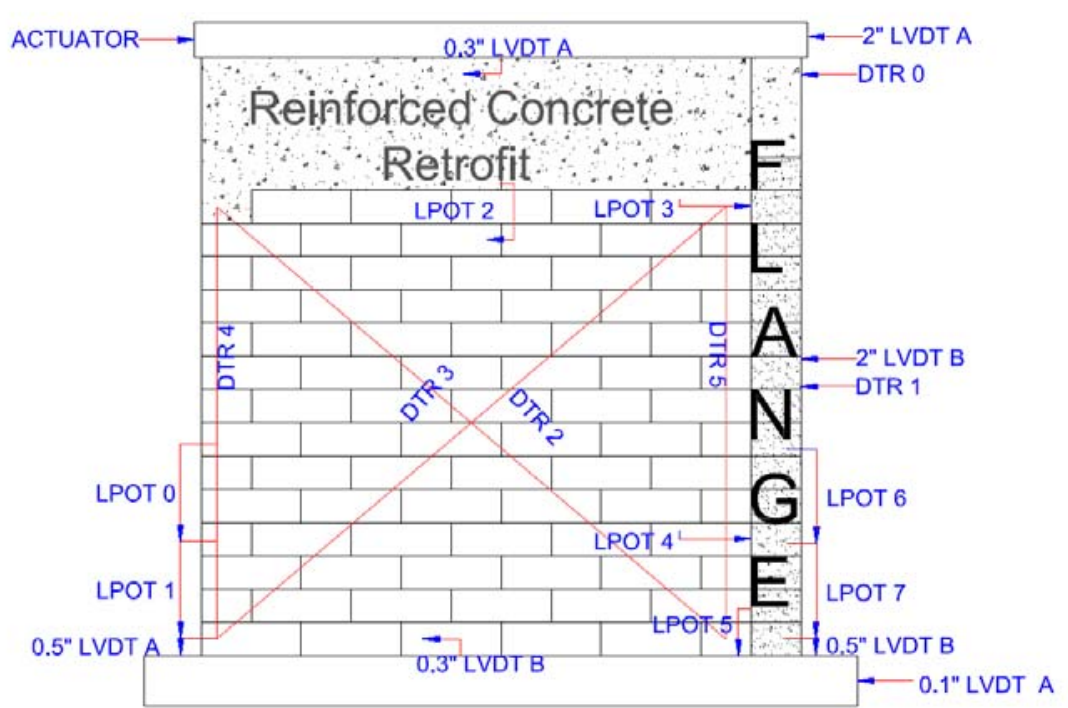

Figure 5-7: Instrumentation configuration of W5 after reinforced concrete retrofit

\subsubsection{W6 Instrumentation}

The instrumentation of W6 was different from any of the previous walls as only one pier of the wall was instrumented. All six DTRs were used to measure diagonal shearing strains while the LPOTs were used to measure the strains in the vertical rebar on the left side of the wall. It was decided to only instrument one pier of the wall based on the assumption that each side should exhibit similar behavior. The instrumentation of the DRTs and LPOTs were divided into three portions; two in the pier and one in the lintel as shown in Figure 5-8.

Lateral displacements were measured at four different locations on W6; at actuator level, at the top of the left pier, the midpoint of the left pier, and at the bottom of the left pier. The 2" LVDT A was positioned on in line with actuator, at the opposite end of the wall. The remaining three LVDTs were positioned directly below the actuator, on a separate free stranding structure away from the wall. Figure 5-8 shows the configuration of the instruments on W6. 


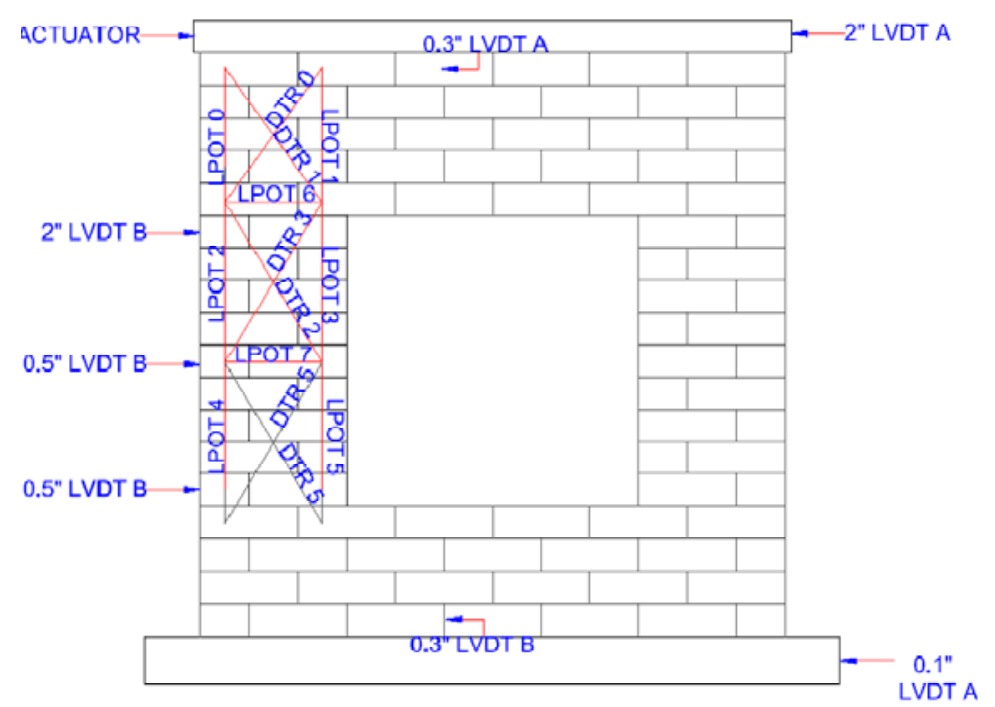

Figure 5-8: Instrumentation configuration of W6

\subsection{In Plane Loading Protocol}

The displacement controlled loading protocol presented in Table 5-1 and Figure 5-9 was used for testing all specimens considered in this thesis. Incidentally, the same loading protocol was used in the companion thesis (Bland, 2011), allowing a direct comparison of the wall behaviors obtained from different tests. It is noted that the cyclic loads applied on the top of the specimens can be differentiated into two cases, i.e. the push and pull cycles which cause tension and compressions forces on the actuator side, respectively. As presented in Table 5-1, the displacements corresponding to the pull and push cycles were respectively assigned to be positive and negative. Also note from Figure 5-9 that such a loading protocol consists of two push and pull cycles at each deflection level. The deformation capacity of the specimens were determined when 20 percent reduction in strength was observed during the tests; however the protocol was continued until more than 50 percent of the strength has degraded, or the wall became unstable. 
Table 5-1: loading protocol used on specimens

\begin{tabular}{|c|c|c|c|c|}
\hline $\begin{array}{c}\text { Displacement } \\
\text { Step }\end{array}$ & $\begin{array}{c}\text { Number of } \\
\text { Cycles }\end{array}$ & Cycles & $\begin{array}{c}\text { Deflection } \\
(\mathbf{m m})\end{array}$ & \% Drift \\
\hline 1 & 2 & $1-2$ & 0.5 & $0.03 \%$ \\
\hline 2 & 2 & $3-4$ & 1 & $0.06 \%$ \\
\hline 3 & 2 & $5-6$ & 2 & $0.11 \%$ \\
\hline 4 & 2 & $7-8$ & 4 & $0.22 \%$ \\
\hline 5 & 2 & $9-10$ & 6 & $0.33 \%$ \\
\hline 6 & 2 & $11-12$ & 8 & $0.44 \%$ \\
\hline 7 & 2 & $13-14$ & 10 & $0.56 \%$ \\
\hline 8 & 2 & $15-16$ & 12 & $0.67 \%$ \\
\hline 9 & 2 & $17-18$ & 14 & $0.78 \%$ \\
\hline 10 & 2 & $19-20$ & 16 & $0.89 \%$ \\
\hline 11 & 2 & $21-22$ & 20 & $1.11 \%$ \\
\hline 12 & 2 & $23-24$ & 24 & $1.33 \%$ \\
\hline 13 & 2 & $25-26$ & 28 & $1.56 \%$ \\
\hline 14 & 2 & $27-28$ & 32 & $1.78 \%$ \\
\hline 15 & 2 & $29-30$ & 36 & $2.00 \%$ \\
\hline 16 & 2 & $31-32$ & 40 & $2.22 \%$ \\
\hline
\end{tabular}

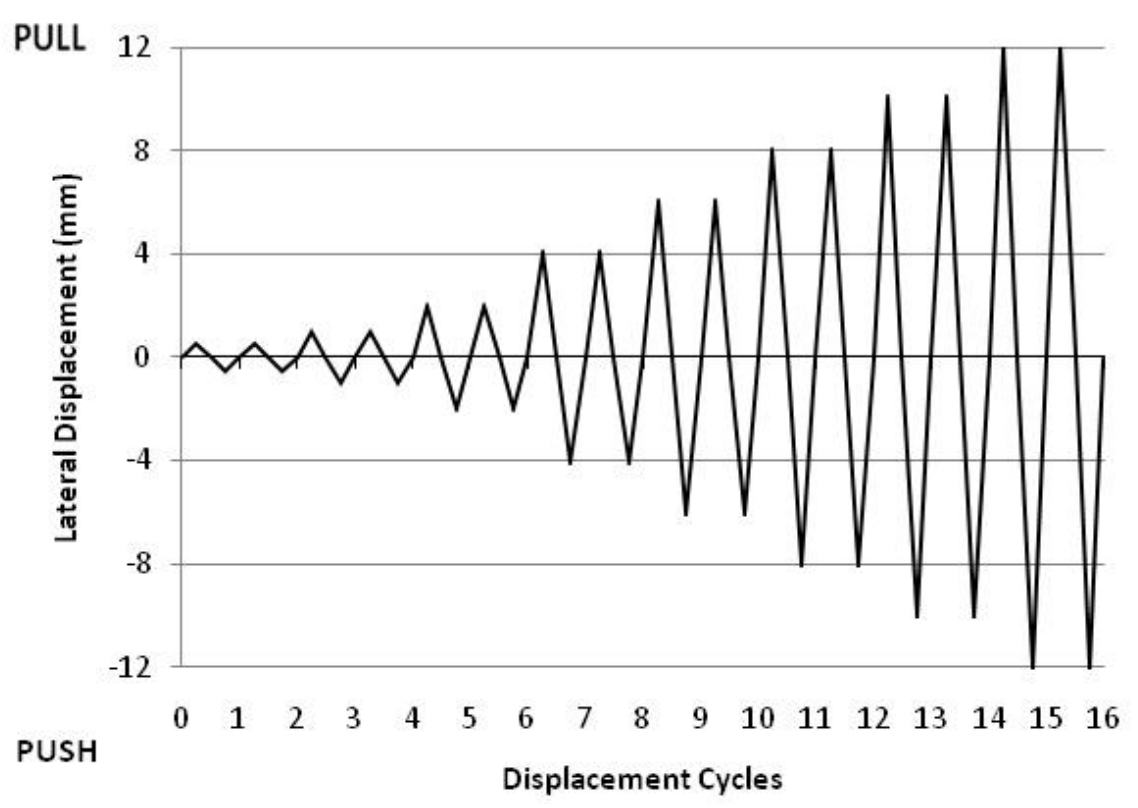

Figure 5-9: Graphical representation of the loading protocol 


\section{$5.5 \quad$ Vertical Loading}

Vertical loading was applied to each specimen by adding a series of meter long steel angles stacked on top of the steel loading beam to simulate the weight of the lightweight roofing system. In addition, a portion of the vertical loading was provided by the self-weight of the actuator head, which was weighted before being mounted to the top of the wall. The vertical load imposed on the specimens remained at a constant of 2.5 $\mathrm{kN} / \mathrm{m}$; however due to the varying lengths of the wall different amount of the total load were applied on each wall. Table 5-2 summarizes the vertical load applied to each specimen. Incidentally, steel angles that used as the vertical loads on W5 were welded to the steel loading beam in order to distribute the load over both the flange and web.

Table 5-2: Applied vertical loads to specimens

\begin{tabular}{|c|c|c|c|}
\hline Specimen & $\begin{array}{c}\text { Wall length } \\
(\mathbf{m})\end{array}$ & $\begin{array}{c}\text { Vertical load applied } \\
(\mathbf{k N})\end{array}$ & $\begin{array}{c}\text { Number of } \\
\text { angles }\end{array}$ \\
\hline W4 & 0.9 & 2.25 & 9 \\
\hline W5 ${ }^{*}$ & 2.4 & 6.0 & 24 \\
\hline W6 & 1.8 & 4.5 & 18 \\
\hline *W5 includes flange length
\end{tabular}




\section{OBSERVATIONS FROM THE TESTS}

This chapter presents in detail the observation from the testing of all the specimens described in Chapter 4.

\subsection{Testing of W4}

\subsubsection{Overview}

The slim wall (W4) was tested 25 days after construction. The testing consisted of thirty-one cycles of the prescribed loading protocol. The maximum force produced from W4 in the pull and push directions were $13.2 \mathrm{kN}$ and $14.4 \mathrm{kN}$, respectively. The corresponding displacements were 16 and $20 \mathrm{~mm}$ in the pull and push directions, respectively. During testing, the force resisted by the wall was recorded at the corresponding displacements; however, a significant amount of slip was detected between the footing and the strong floor, as shown in Figure 6-1. These slip values were subtracted from the displacements recorded at the top of the wall to give a more accurate force displacement relationship shown in Figure 6-2.

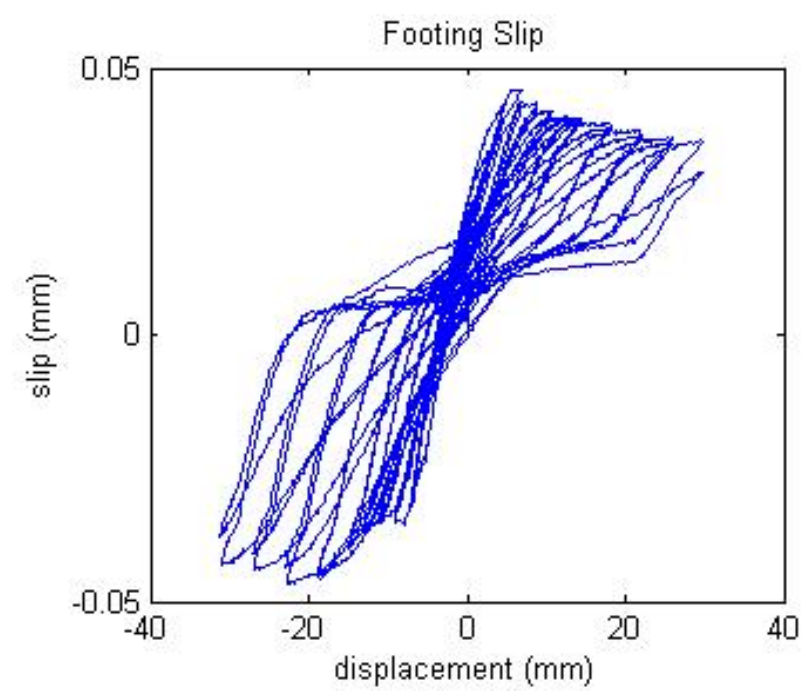

Figure 6-1: W4 footing slip vs. lateral displacement of actuator 
The wall resisted $9 \%$ more force in the push direction than in the pull direction as described by the force and displacement relationship depicted in Figure 6-2. It is noted that there are many reasons which may have contribution to this observation (e.g. horizontal slip deformation at footing, initial imperfection of construction, non-uniform property of the construction materials; and possible premature failure at wall base resulting in slight uplift deformation of the wall at the tension side). However, to further quantify their impacts is beyond the scope of this thesis given that the resistance difference is within the acceptable range from the perspective of engineering design. The following sections describe in detail the observed behavior of W4 at different deformation levels. 


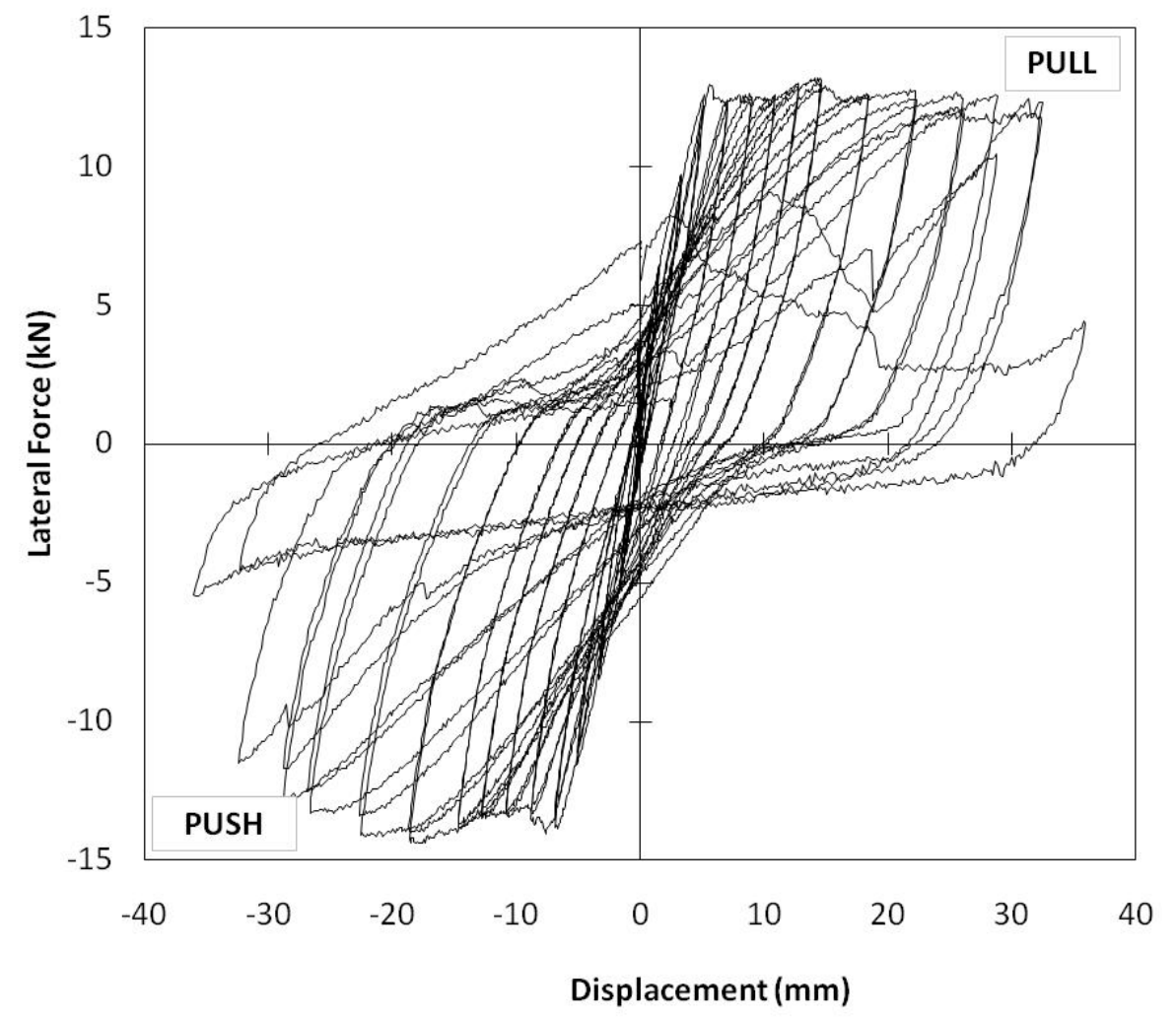

Figure 6-2: Hysteresis of W4

\subsubsection{W4: Cycles 1 through 8}

Throughout the first eight cycles, there was very little noteworthy visual damage in the wall. From $0.5 \mathrm{~mm}$ to $4 \mathrm{~mm}$ displacements, no cracking or sliding of any kind was observed anywhere in the wall. There were no lateral movements observed at the base of the wall where the maximum moment occurred. Photographs show small extensions and compression along the outer most fibers at the base of the wall near the end of Cycle 8, which indicated a small degree of energy dissipation occurring in Cycle 8. The hysteresis, shown in Figure 6-3, confirms that energy dissipation begins in Cycle 8 where it can be observed that the hysteric loops are beginning to widen. Prior to Cycle 8 the wall remained in the elastic range as the push-to-maximum displacement and the return-tozero displacement occurred along the same line. Inelasticity occurred in the eight cycle 
where two distinct paths can be seen. These two distinct paths, making the loops appear thicker, indicted that energy dissipation was beginning to occur. Although, the start of energy dissipation was observed in Cycle 8, the wall is primarily in the elastic region based on the almost linear relationship of the force displacement curve.

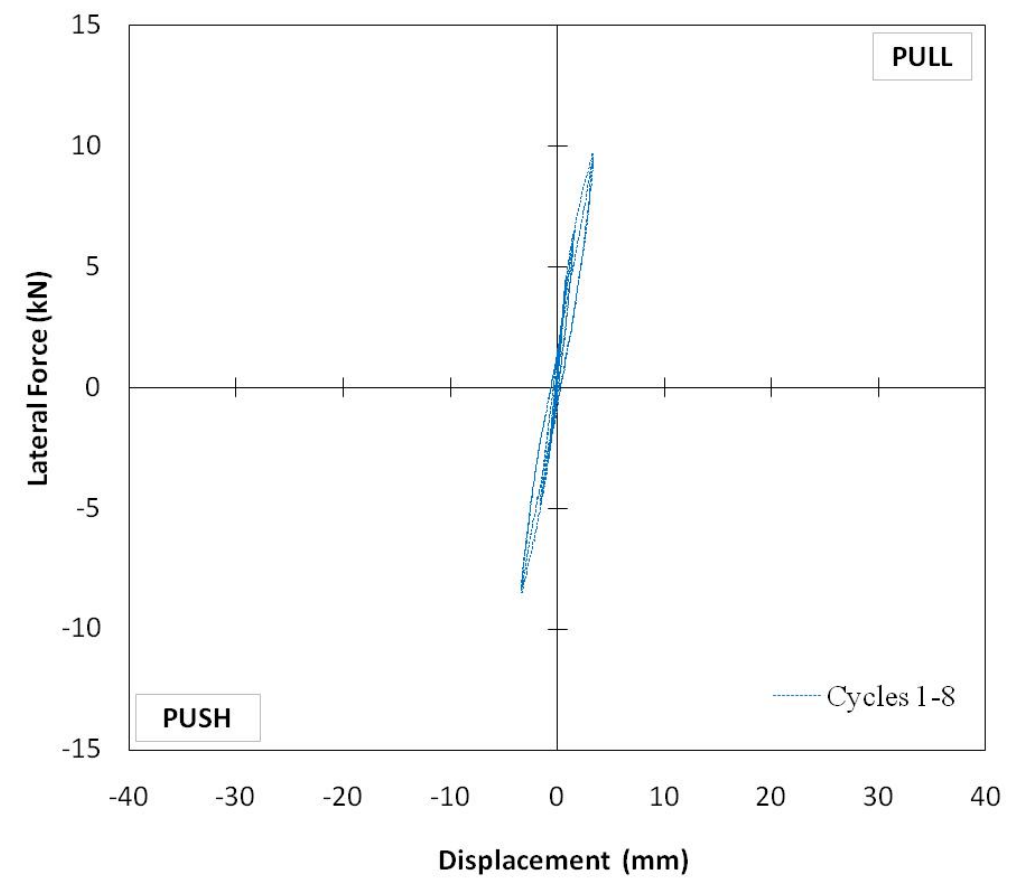

Figure 6-3: Hysteresis of W4 Cycles 1 through 8 


\subsubsection{W4: Cycles 9 and 12}

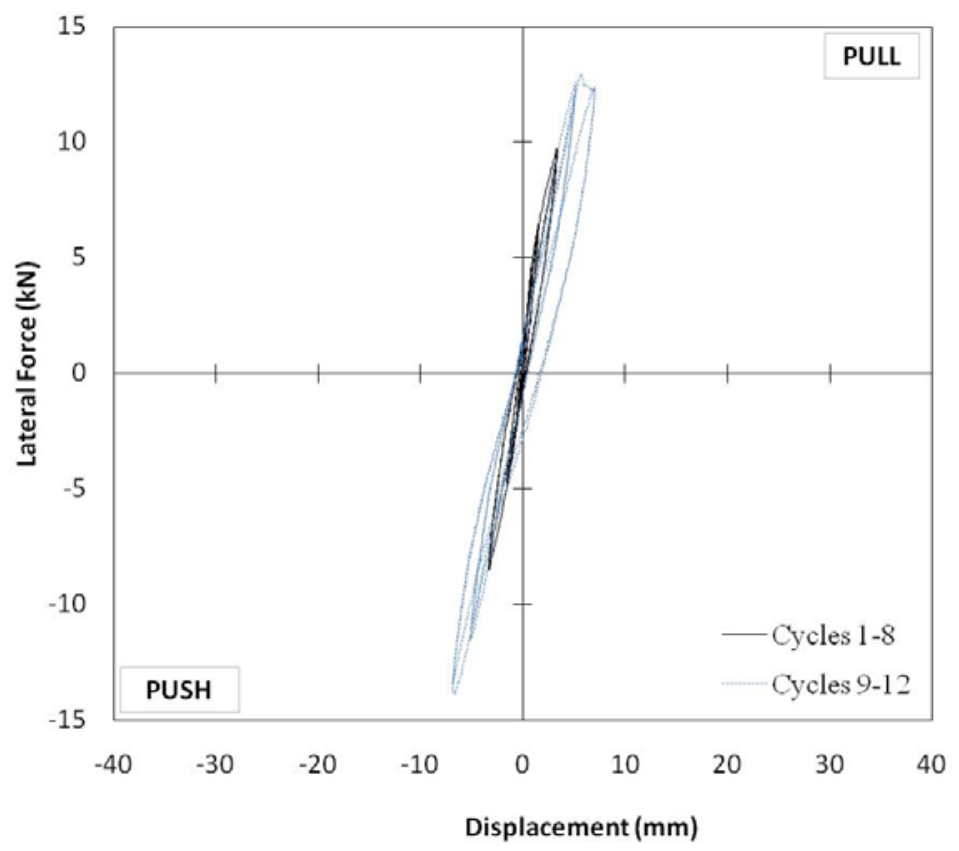

Figure 6-4: Hysteresis of W4: Cycles 1 through 12

Cycles 9 to 12 corresponded to displacements of 6 and $8 \mathrm{~mm}$ in which the wall transitioned from the elastic to inelastic zone as shown in Figure 6-4. This transition can be seen in both rebars yielding after it reached a maximum strength in Cycle 10. In Cycle 12, the wall reached the same maximum strength as Cycles 10 and 11 . Once the force reached $9.7 \mathrm{kN}$, it remained generally constant as the displacement continued to increase. Another indication that the rebar had yielded was that non-zero forces were observed when the actuator returned to zero displacement.

Cycle 11 showed that the first cracking observed in the wall, which is shown in Figure 6-5 occurred between the mortar on the reinforced concrete footing and the first course of ICEBs where the maximum moment is expected. The cracking, although barely visible, is the result of combined uplift and shear effects and can be seen faintly 
around the base of the wall. The cracking of the toe, in addition to the yielding of the rebar, resulted in the first considerable energy dissipation observed in the test.

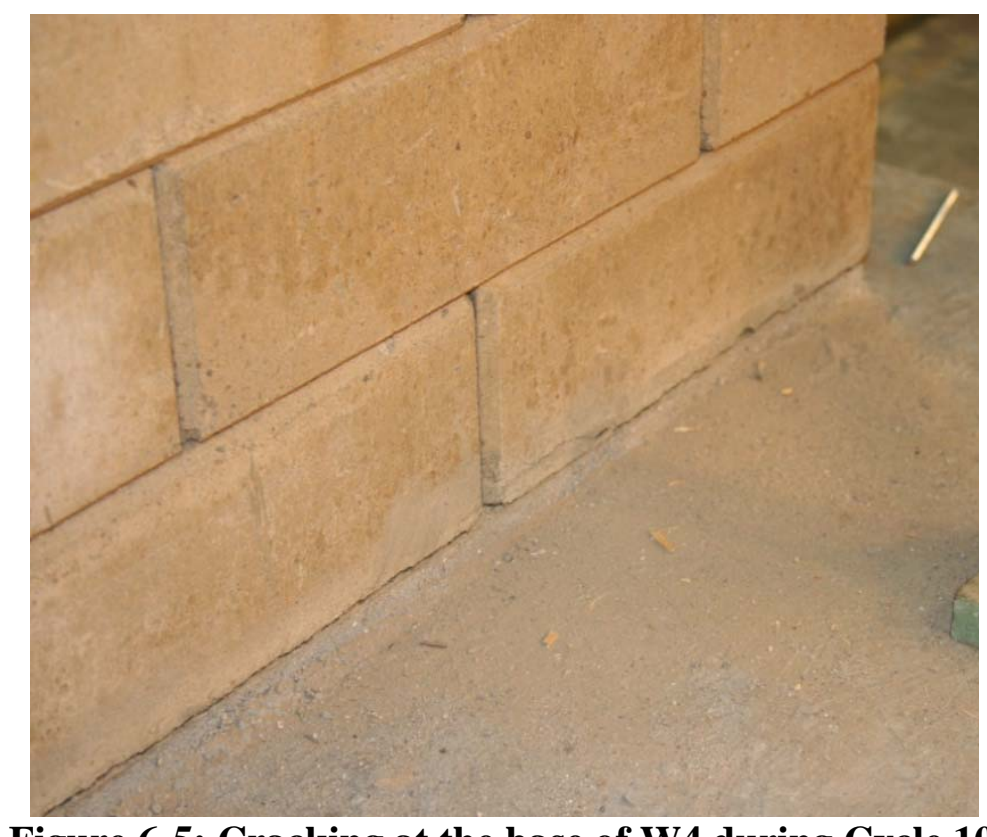

Figure 6-5: Cracking at the base of W4 during Cycle 10

\subsubsection{W4: Cycles 13 through 20}

In Cycles 13 through 20, corresponding to displacements of $10 \mathrm{~mm}$ through $16 \mathrm{~mm}$, the maximum horizontal resisting force observed in each cycle was about $13.2 \mathrm{kN}$ $( \pm 0.5 \mathrm{kN})$ in the pull direction and $14.2 \mathrm{kN}( \pm 0.5 \mathrm{kN})$ in the push direction, demonstrating the stable resistance of the wall. Each successive cycle dissipated more energy than the preceding cycle, increasing at a proportional amount to the displacement. This trend can be observed in Figure 6-6 showing the hysteric loops of each of the cycles. It was also observed that with each progressive cycle, the zero force moves further from zero displacement. 


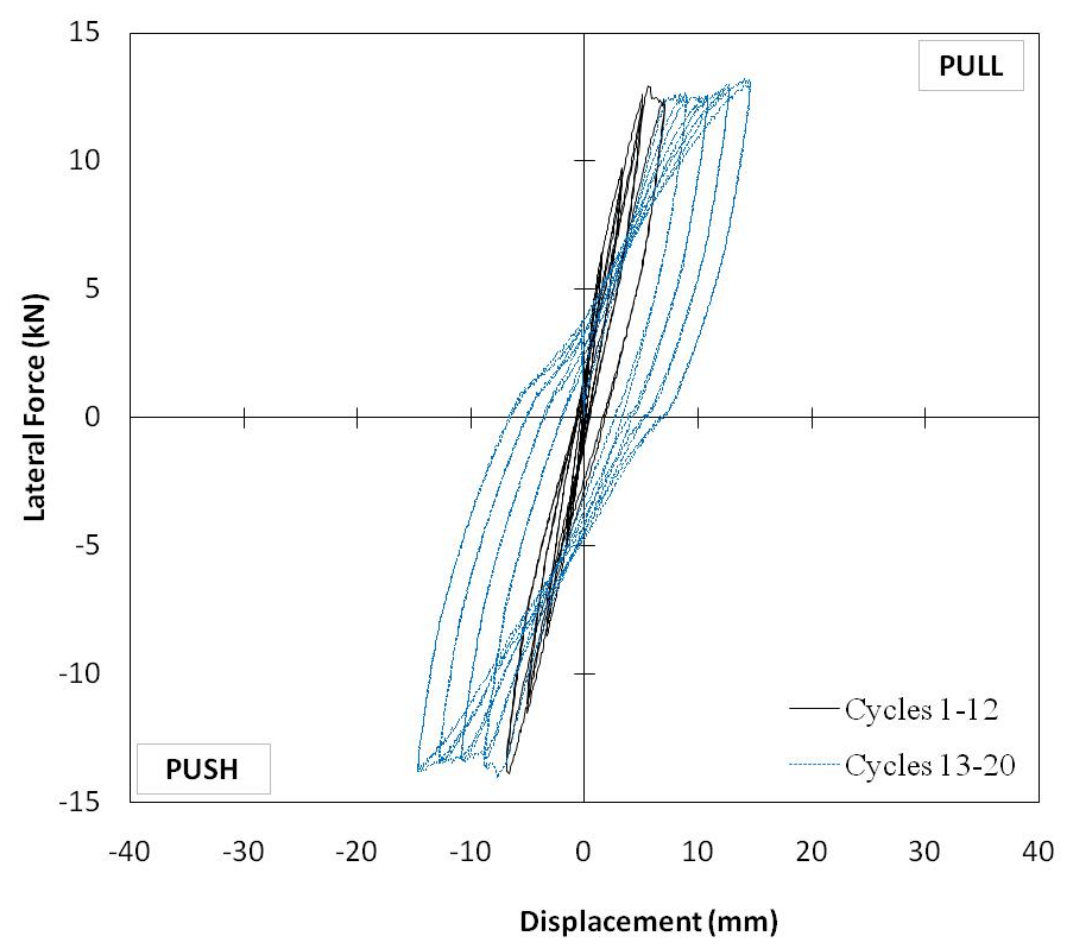

Figure 6-6: Hysteresis of W4: Cycles 1 thought 20

The uplift observed on either side of the wall in Cycle 15 continued to increase in size reaching a maximum uplift of $3.72 \mathrm{~mm}$ and $3.97 \mathrm{~mm}$ on the right and left sides, respectively. With each successive cycle, the corner cracks expanded to approximately $0.75 \mathrm{~mm}$ more than the previous cycle, causing the wall to begin to rock. As the rocking grew in magnitude, the cracking along the base also became more pronounced; essentially causing the bond to break between mortar and the first course of ICEBs as shown in Figure 6-7.

Damage occurred in the top half of the wall during Cycles 13 and 20. Cracking between the load beam and the top of the wall was observed around the outside of the grout channel. The crack began to propagate from the top of the grout channel, which provides the main connection between the anchor bolts and load beam as shown in Figure 
6-8. The cracking was first observed after the completion of Cycle 14 and became more pronounced after the completion of Cycle 16; however, there were no more changes throughout the rest of the wall testing. This crack, though prevalent to visual observation, appeared to have very little impact on the strength of the wall.

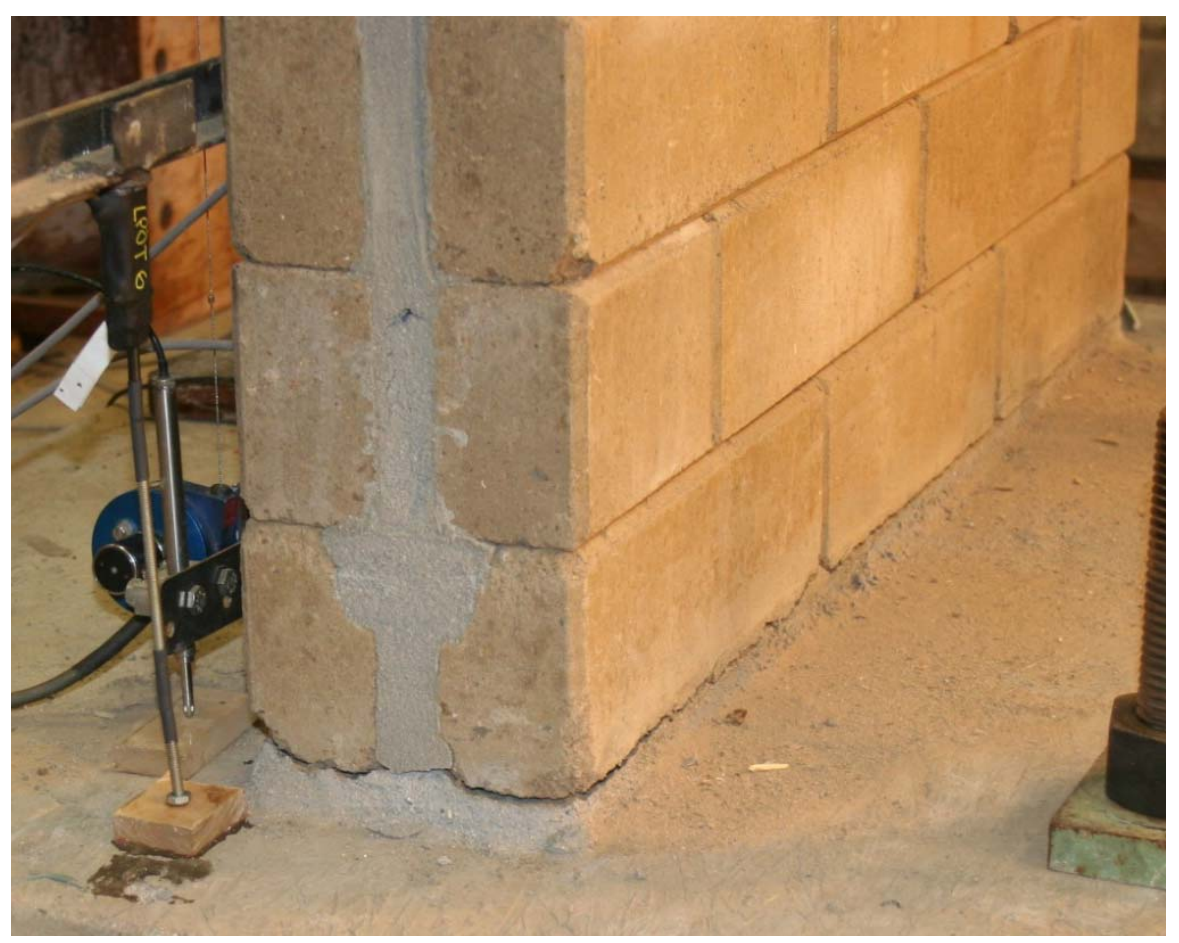

Figure 6-7: Cracking around the base of W4 


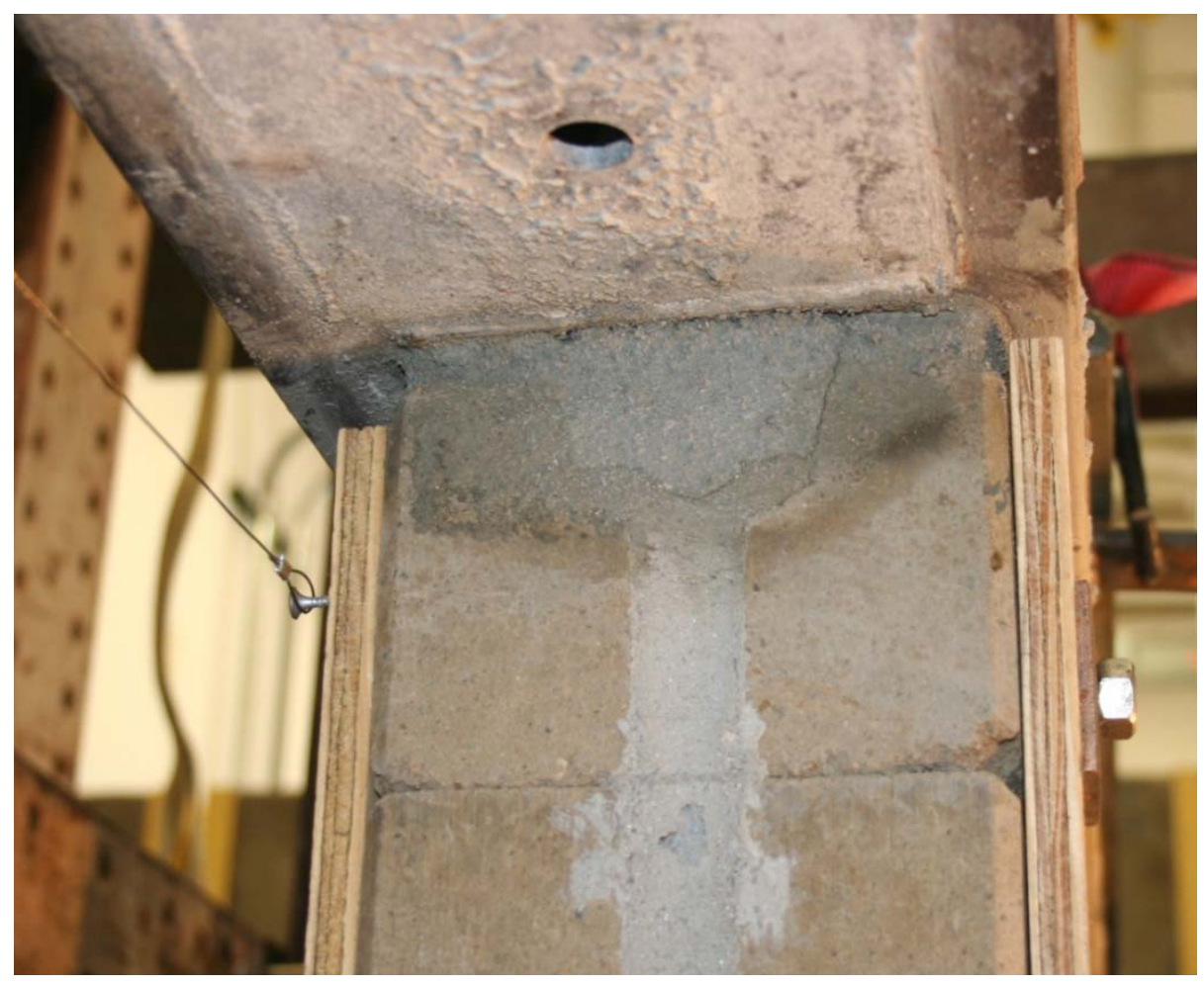

Figure 6-8: W4 cracking around the grout channel and the loading beam

\subsubsection{W4: Cycles 21 through 24}

Throughout Cycles 21 and 24, slip became increasingly more prominent, contributing significantly to the overall specimen deformation. The observed slip at the base of the wall was more than doubled from Cycles 12 to 24. This increase in slip resulted from the complete fracture between the bottom course of ICEBs and the mortar. The uplift noted in the previous cycles continued to grow, causing the propagation of cracking along the base. Although this sliding was visually observed throughout Cycles 21 through 24, it became more apparent that the bottom course had completely sheared away from the base as shown in Figure 6-9. Shear cracking became visible in the pull excursion of Cycle 23 with the start of the typical 45 degree cracking. The cracking 
propagated from the vertical rebar on the left side of the wall to the shear rebar in the bottom course of the wall as shown in Figure 6-10. The shear cracks opened as the displacement increased and closed when the displacement returned to zero. It was observed that all the shear cracking took place in the bottom half of the wall. There was no sign of damage taking place above the midpoint of the wall.

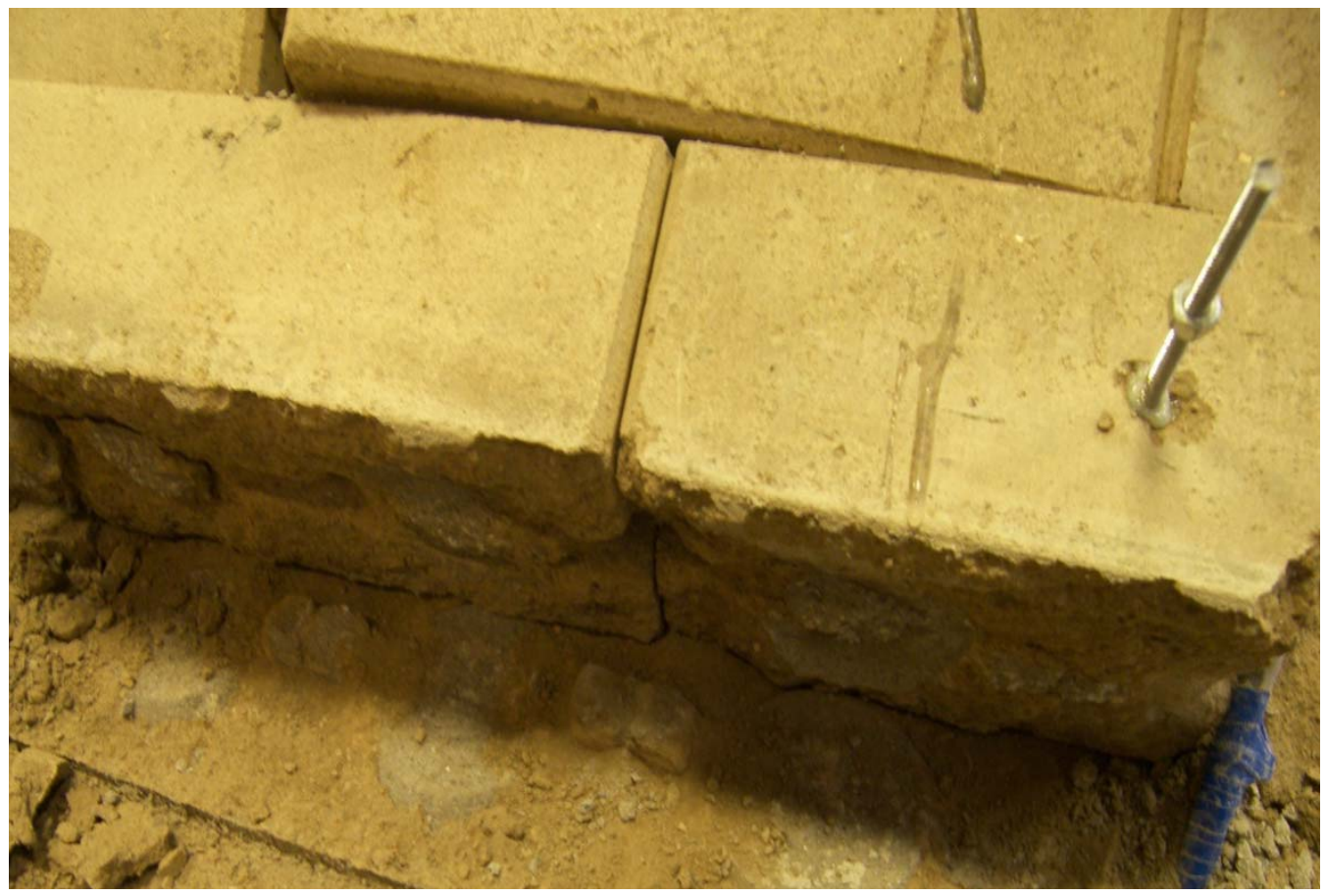

Figure 6-9: Shearing between the bottom courses of $\mathrm{W} 4$ and the mortar in the footing 


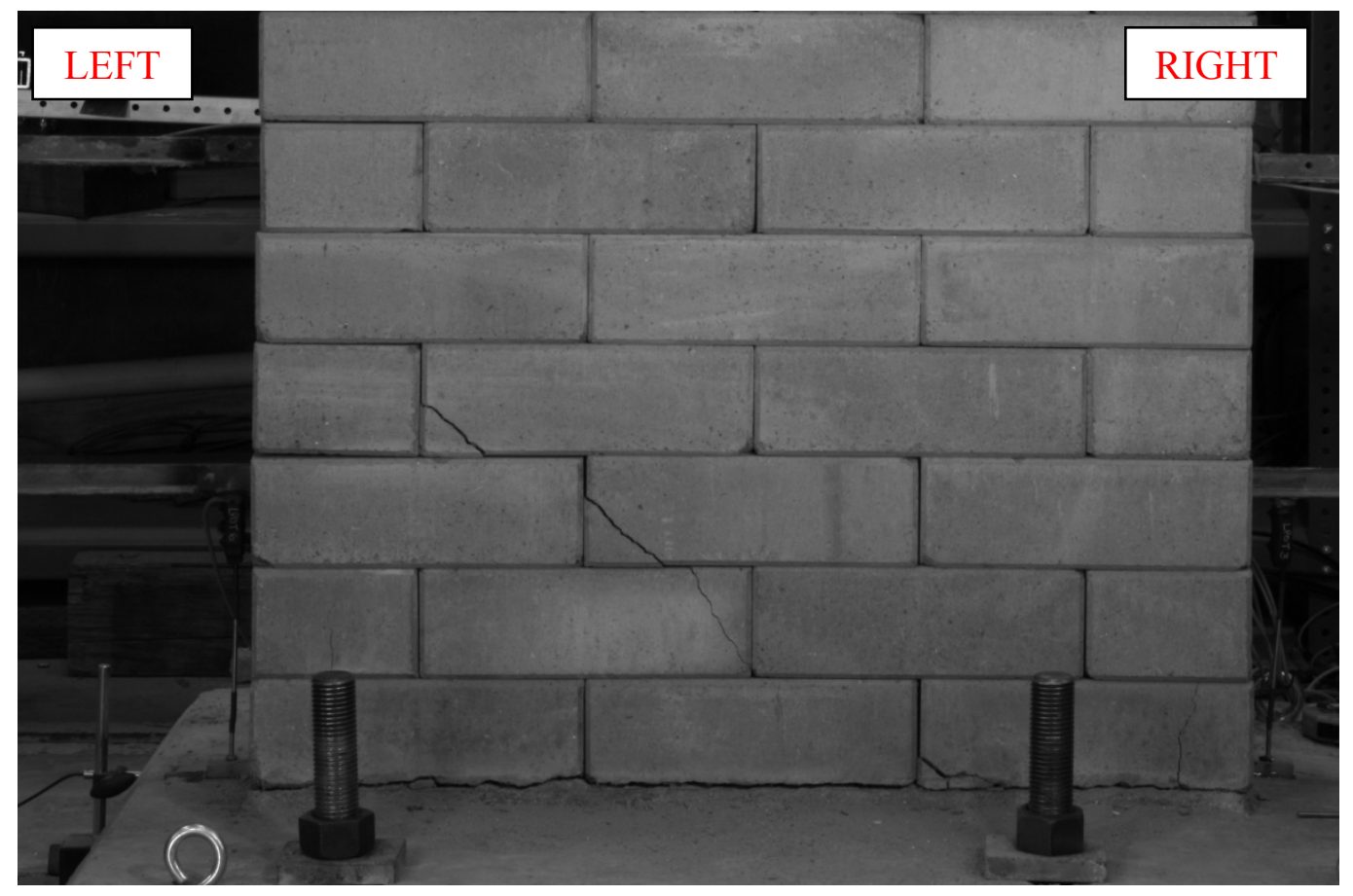

Figure 6-10: Shear cracking along the bottom of W4

From the hysteresis shown in Figure 6-11, it can be observed that the shear cracking does not appear to have a significant impact on the strength of the wall. A small amount of strength degradation was observed in the pull excursion of Cycle 21, but the strength increased slightly in the push direction. When the wall was subjected to the push cycle, no shear cracking in the other direction was observed. 


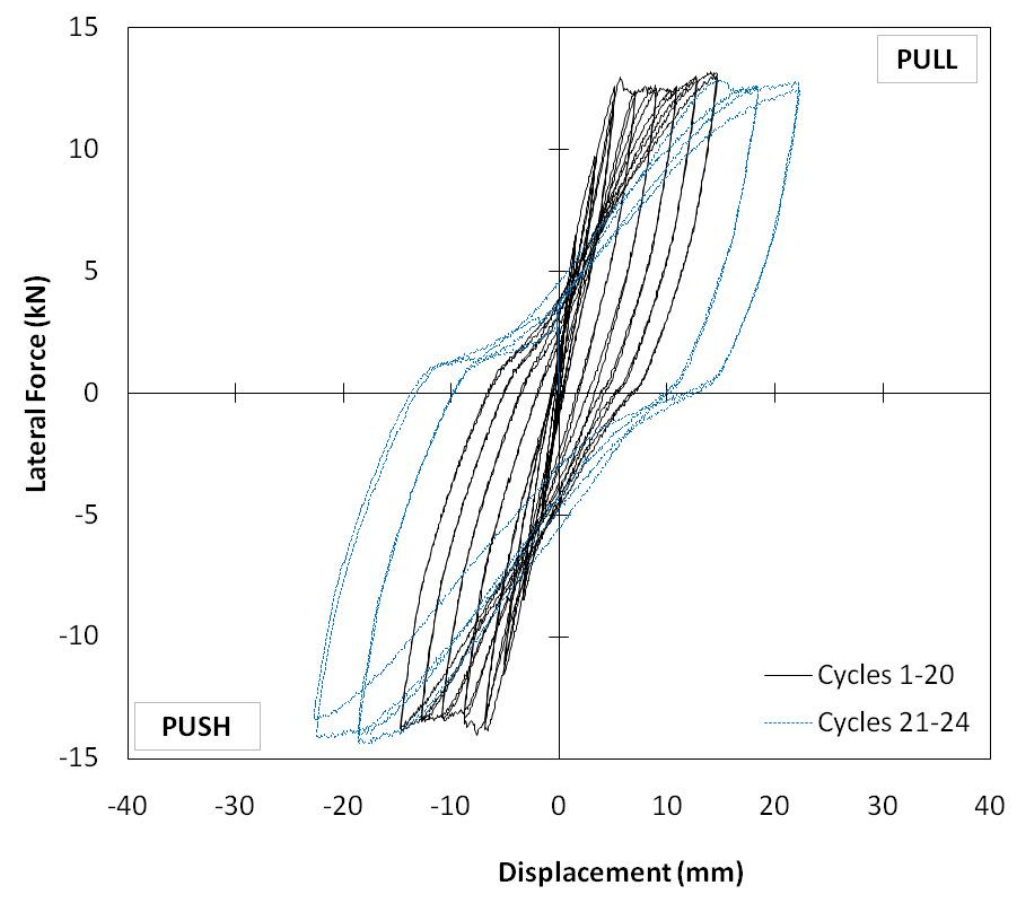

Figure 6-11: Hysteresis of W4: Cycles 1 through 24

As shown in Figure 6-12, two other types of failure were also observed: sliding shear failure and progressive vertical cracking at the toe of the wall. The more notable of the two was the horizontal cracking. The horizontal cracking began to propagate from the base of the wall upwards almost immediately following the beginning of Cycle 21, and grew wider throughout the following cycles. The toe cracking, at either end of the wall, formed on both sides of the wall (back and front) and began to separate the toe from the rest of the wall as shown in Figure 6-13. 


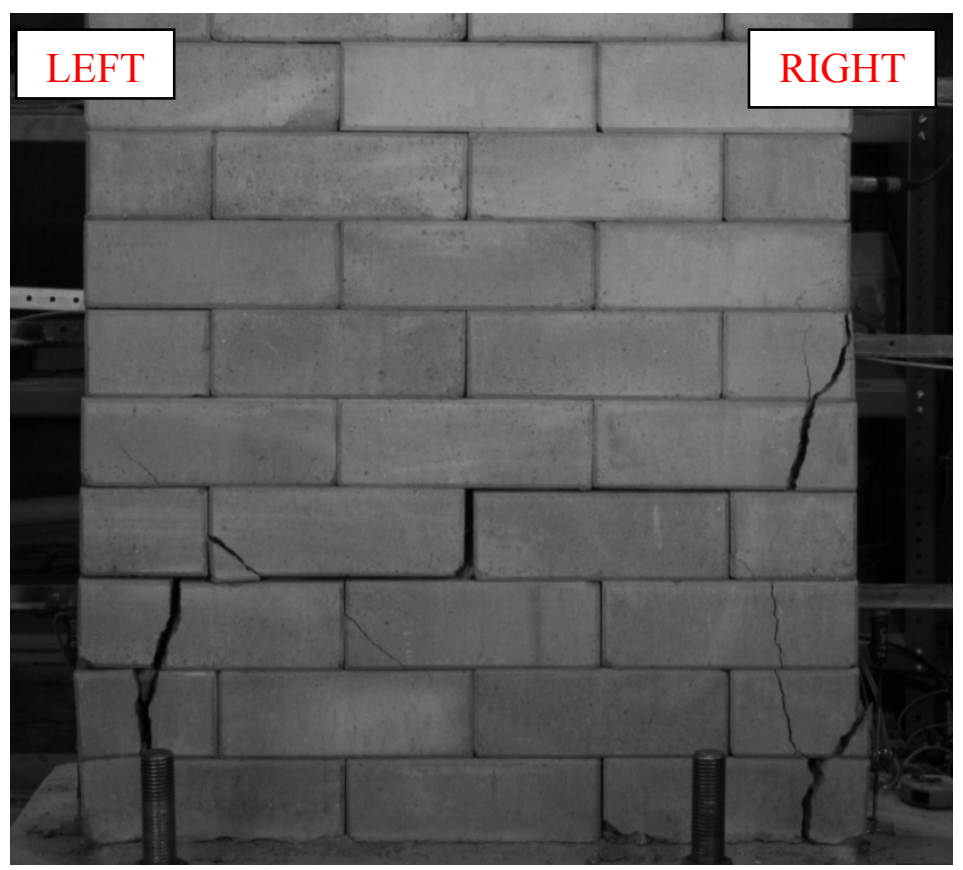

Figure 6-12: Cracks in W4 in Cycles 21 thought 24

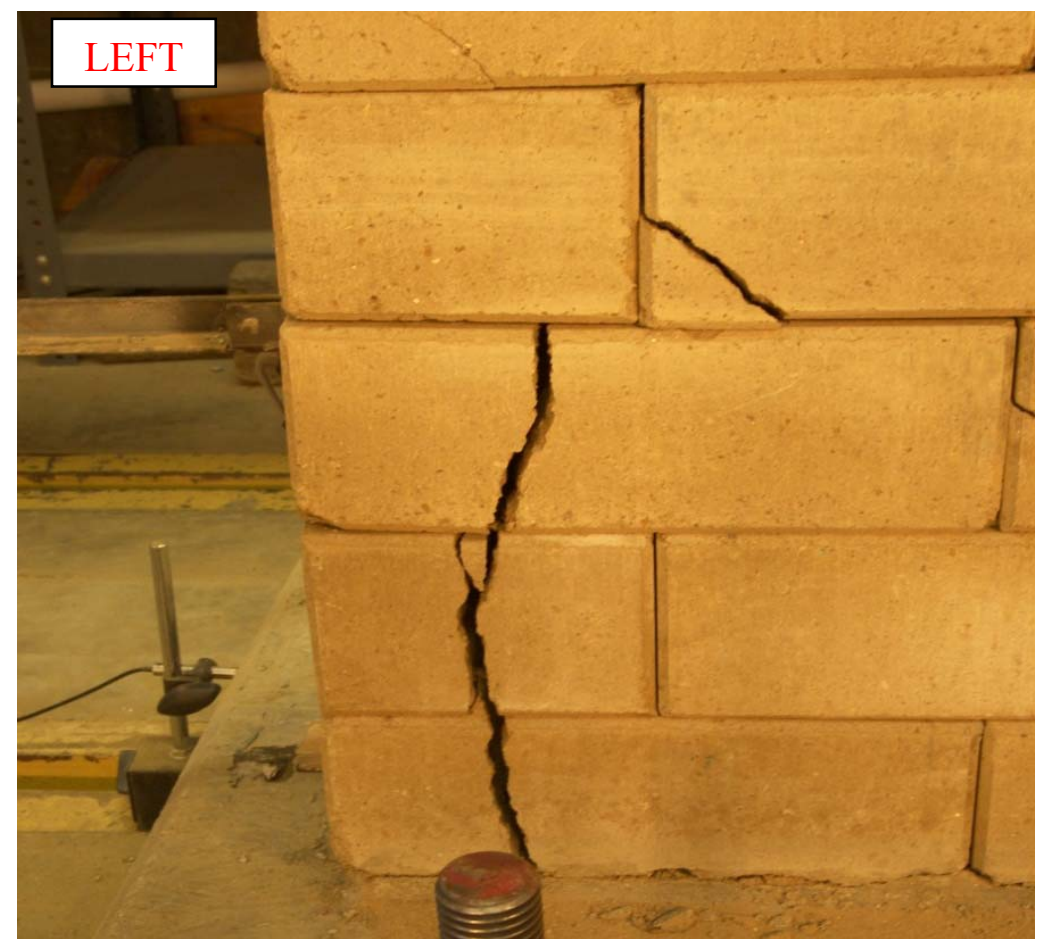

Figure 6-13: Toe cracking of W4 in Cycle 24 


\subsubsection{W4: Cycles 25 through 28}

While it appeared that the damage to the wall consistently increased throughout Cycles 25 to 28; however, the hysteresis reflects that most of the strength derogation is prevalent in Cycle 28 as shown in Figure 6-14. From the hysteresis it can be observed that in Cycles 25, 26 and 27 the strength of the wall remained stable. In Cycle 28; however, it became apparent that significant strength degradation had begun.

A significant dip in the hysteresis can be observed in the last push excursion of Cycle 28. The wall suddenly lost $1.85 \mathrm{kN}$ of strength. This sudden loss in the strength was the result of the lower part of the toe suddenly opening up around the rebar. It is clear that prior to the fracture, little strength was provided by the toe, only stability. From the hysteresis shown in Figure 6-14, it can be observed that the stiffness had the similar slope before and after the strength reduction, indicating no significant change in stiffness. 


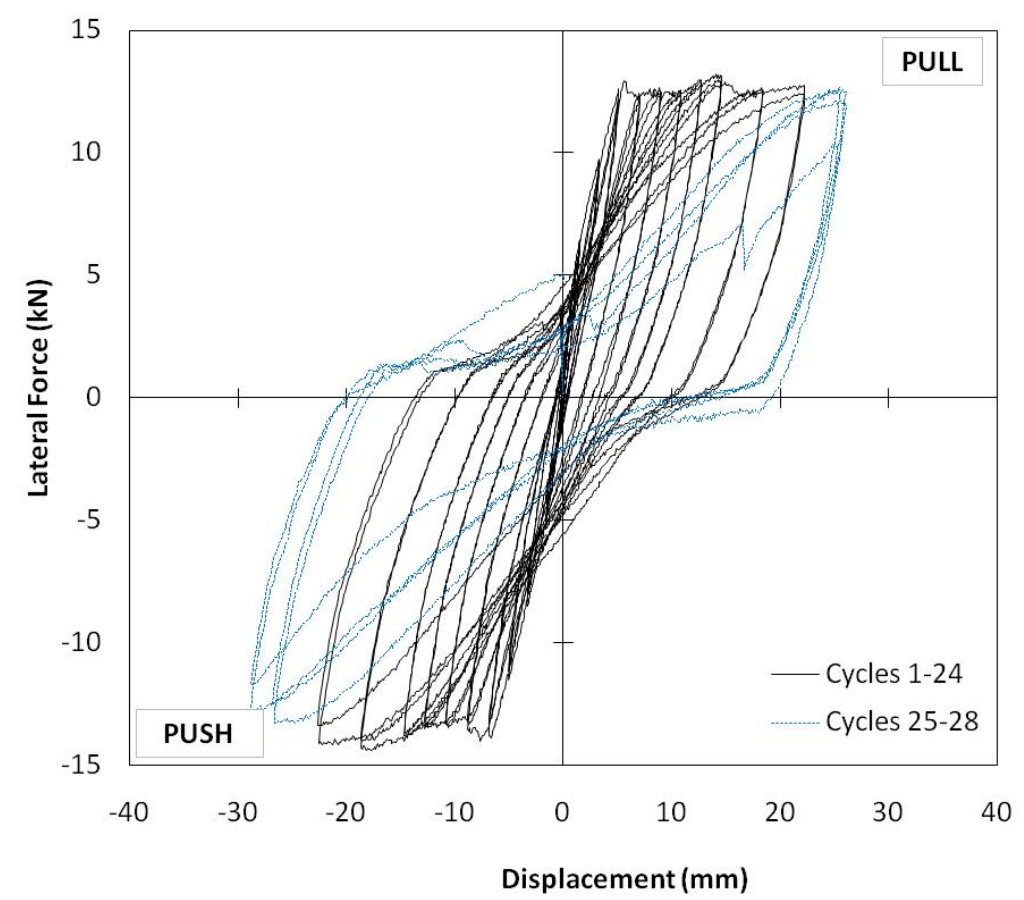

Figure 6-14: Hysteresis of W4: Cycles 1 through 28

\subsubsection{W4: Cycles 29 and 32}

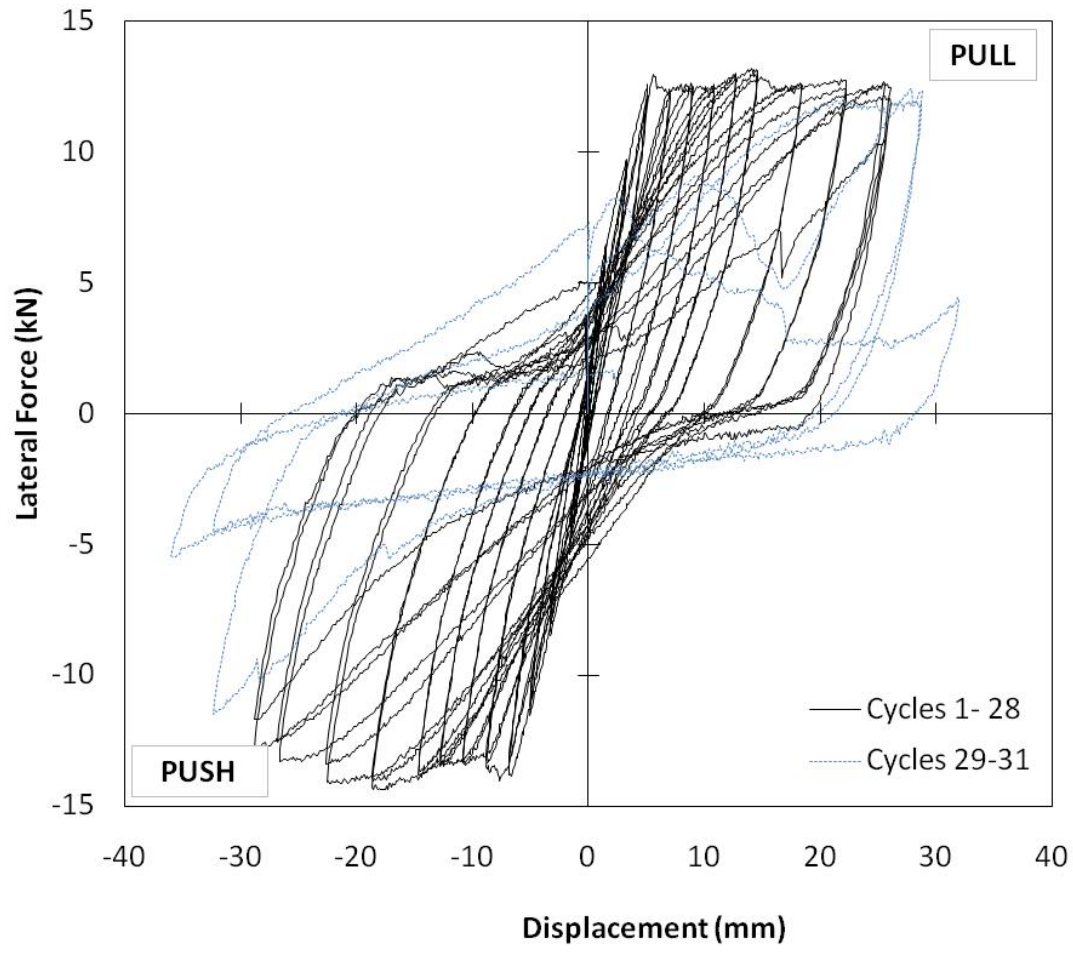

Figure 6-15: Hysteresis of W4: Cycles 1 through 31 
Due to the toe failure at the end of the Cycle 28, it was necessary to remove all external instruments before proceeding with Cycles 29 and 30. Although in excess of $20 \%$ strength loss was observed during Cycle 28, Cycles 29 through 32 were deemed necessary to investigate the ultimate behavior of the specimen. Cycle 29 caused the complete deterioration of the toe on both sides of the wall. Although the hysteresis shows similar strength degradation on either direction, the right side of the wall provides a more visible example of the failure mode as shown in Figure 6-16. Upon completion of Cycle 31, the trend of decreasing strength was clearly shown in Figure 6-15 and the test was concluded due to the instability of the wall.

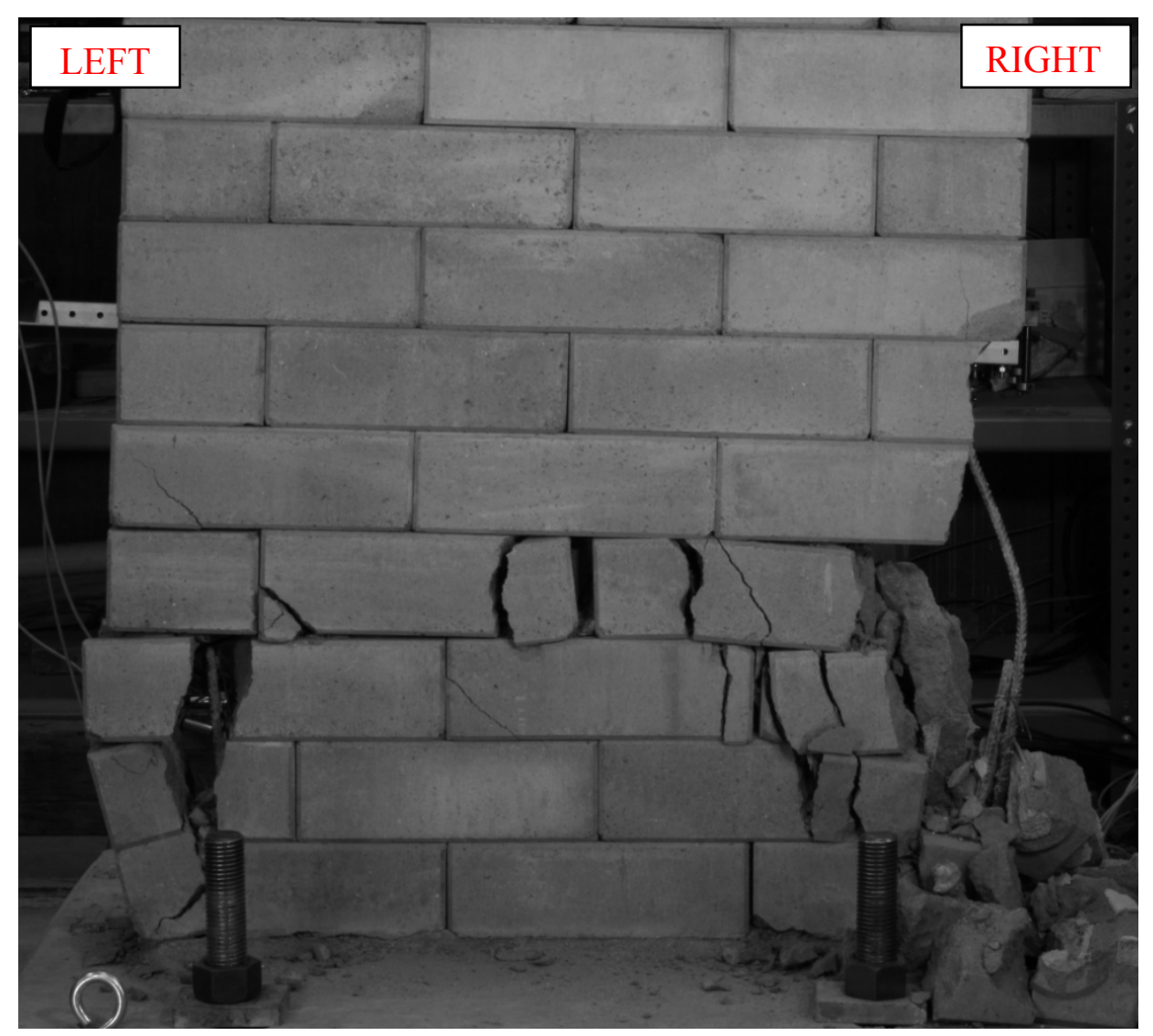

Figure 6-16: Complete degradation of toe due to Cycle 31 


\subsection{Testing of W5}

\subsubsection{W5 -Phase I}

W5 was scheduled to be tested 24 days after construction. Following the test setup, a mechanical failure occurred while zeroing the instruments for testing. The actuator moved at rate of approximately $24 \mathrm{~mm}$ per second and was stopped at a displacement of $60.25 \mathrm{~mm}$, corresponding to a 3.34 percent drift. The loading rate that the actuator moved at did not correspond to any prescribed loading protocol. Although data acquisition was running at a speed of four hertz at the time of loading, only ten data points were recorded before the actuator was stopped. The force-displacement graph, shown in Figure 6-17, shows the data recording over the course of the movement of the actuator. Due to the high speed of loading, very little useful data could be salvaged for analysis, but it provided useful information regarding the new state of the specimen after retrofitting took place for retesting. 


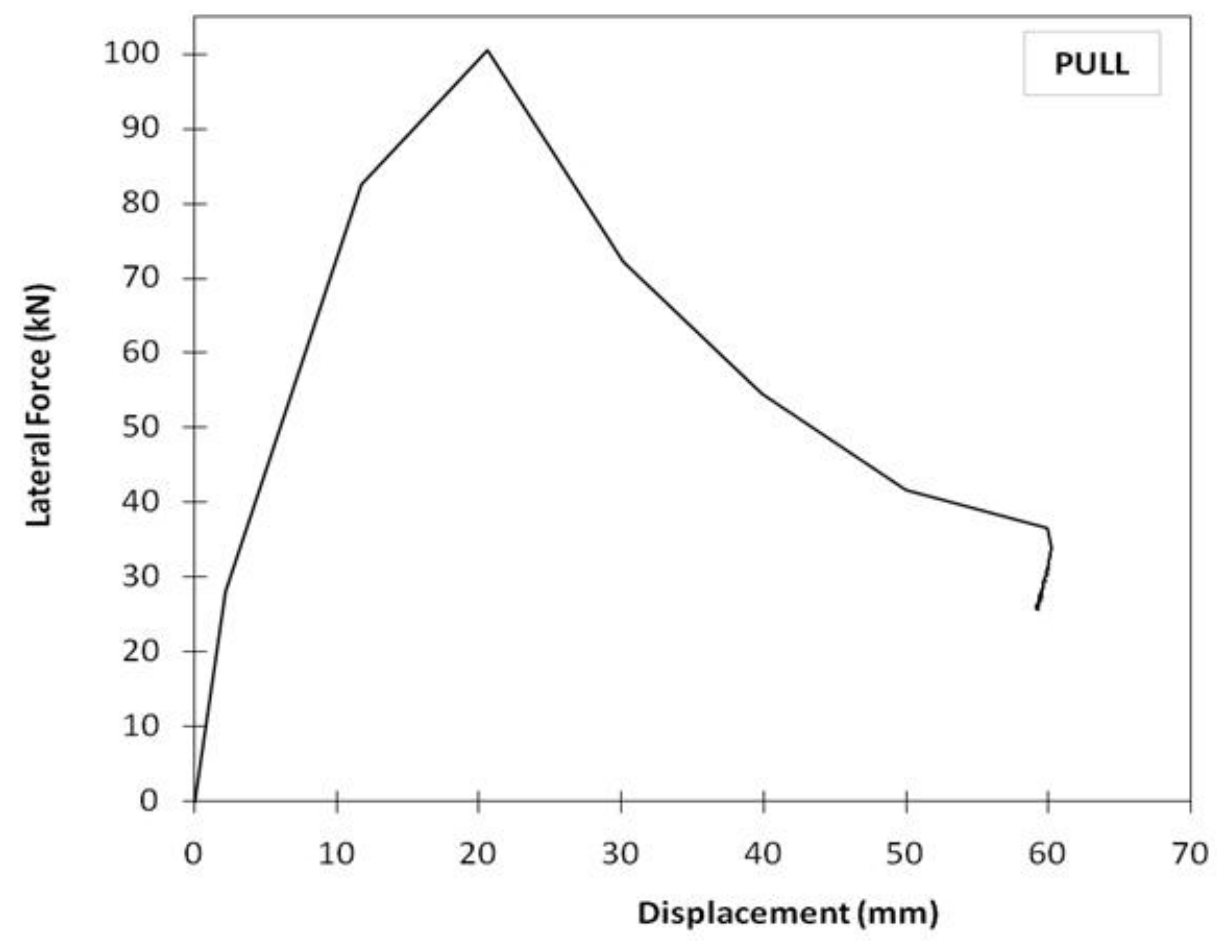

Figure 6-17: Force vs. Displacement of W5-Phase I

The maximum force from the load cell was recorded as $100.5 \mathrm{kN}$ at a displacement of $20.6 \mathrm{~mm}$. Steel in the web was recorded to begin yielding at a displacement of $11.70 \mathrm{~mm}$, corresponding to a force of $82.6 \mathrm{kN}$, and flexural cracking was observed on the backside of the flange around the exterior grout channels. The toe of the web showed similar cracking around the bottom in the compression zone but no cracking around the reinforcement was detected.

The damage to the wall from the $60.25 \mathrm{~mm}$ shift was extensive but was primarily confined to the top four courses of the wall. Shear cracking in the top four courses completely diminished the flange and the webs capacity to resist shear and left a residual shift at the top of the wall as shown in Figure 6-19 and Figure 6-20. The top of the flange 
was shifted $9.67 \mathrm{~mm}$ relative to the web. Although the damage to the web was mostly concentrated in the top four courses, two places where considerable damage took place were at the web toe and the intersection between the web and the flange, as shown in Figure 6-18 and Figure 6-19. The compressive failure at the toe of the web caused spalling around the top of the toe due to the increased force from the overturning moment. The web is designed to take most of the in-plane shear, while the flange simulates an intersecting wall, making the web relatively stiff compared to the flange. The majority of the damage found in the web was the result of shear failure and was predominant in the top four courses of the web. The crack shown in Figure 6-19 shows the characteristic shear crack. Other characteristics of a shear failure were seen in the vertical and horizontal extensions between blocks as well as spalling in high tension regions of the wall.

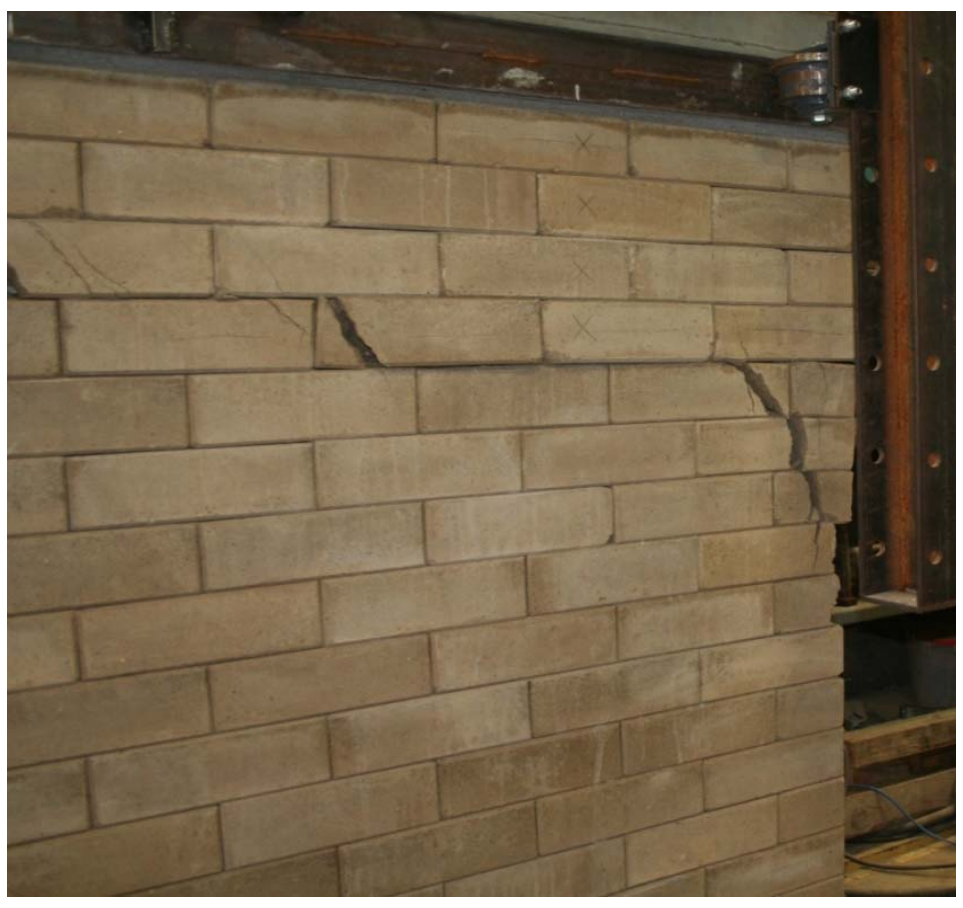

Figure 6-18: Damages in W5 Web resulting from mechanical failure of actuator 


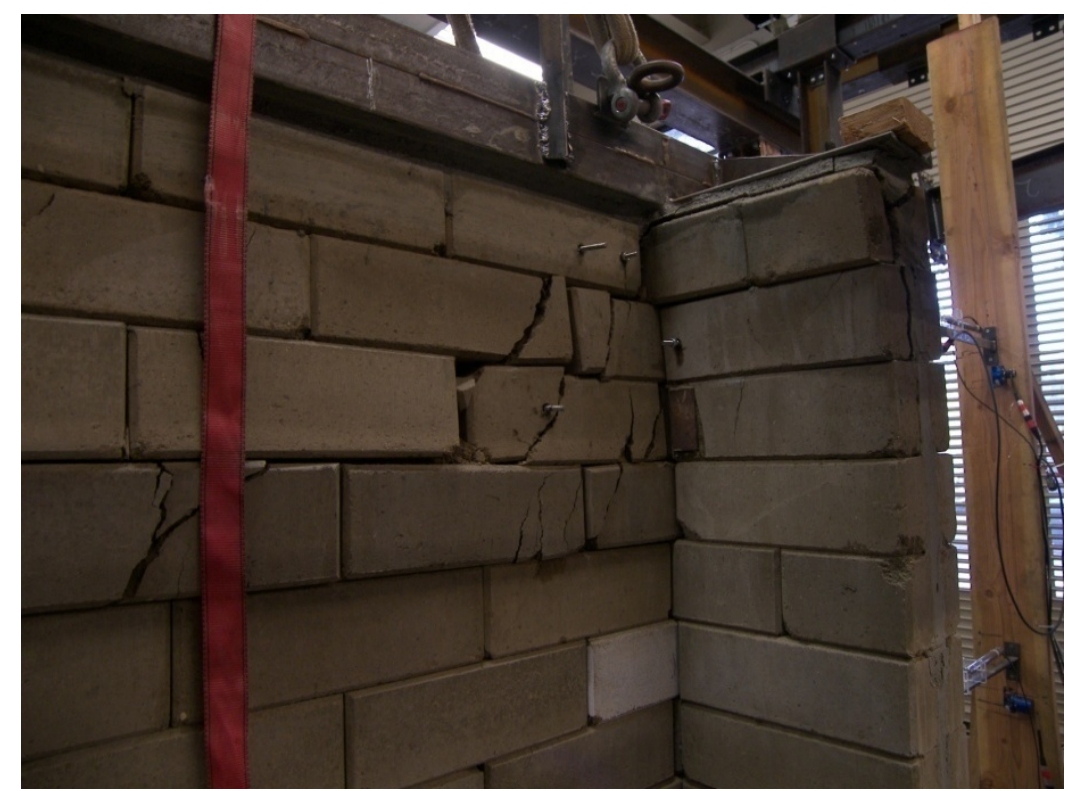

Figure 6-19: Compression failure at the intersection of the web and flange

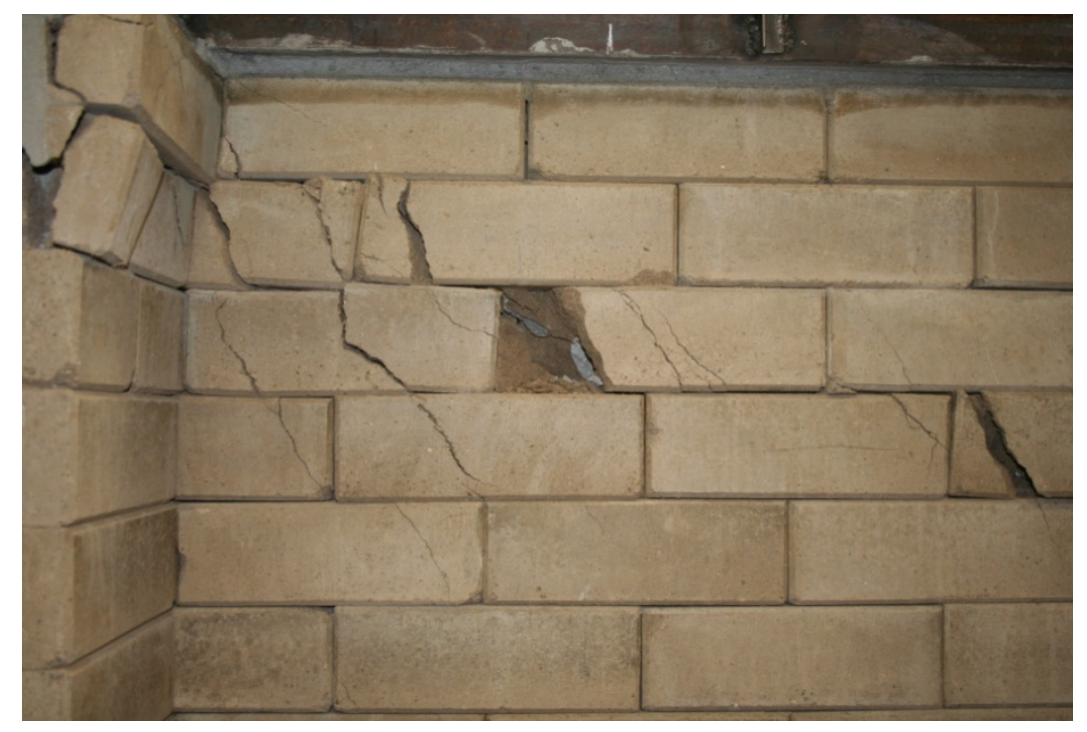

Figure 6-20: Shear Failure of the web and flange.

It was determined that the majority of the damage inflicted by the sudden

movement of the actuator was located in the top four courses of the wall and the rest of the specimen was salvageable. Due to the extensive damage to the top of the wall, the 
method for repair was the complete replacement of the top four courses with a reinforced concrete top. This was done by carefully removing all the blocks on the top four courses of the web, and the top three of the flange. The vertical rebar, which was bent during the shift, was returned to vertical. The horizontal rebar located in the top course was removed completely and replaced with horizontal reinforcing at each course level in the reinforced concrete top.

The reinforced concrete for the repair purpose was designed to be a high strength, fast curing, fluid mix, which would provide load transfer from the actuator to the remaining fourteen courses in the wall. In order to accomplish this, extra horizontal reinforcing was added as shown in Figure 6-21 and Figure 6-22. Formwork was then built around the areas where the blocks had been removed in both the web and flange. Areas surrounding the toe where significant spalling occurred were formed up to maintain the original shape of the wall. Reinforced concrete was then mixed and poured into the wall. After each batch of the concrete was poured, it was then vibrated to prevent any air voids. 


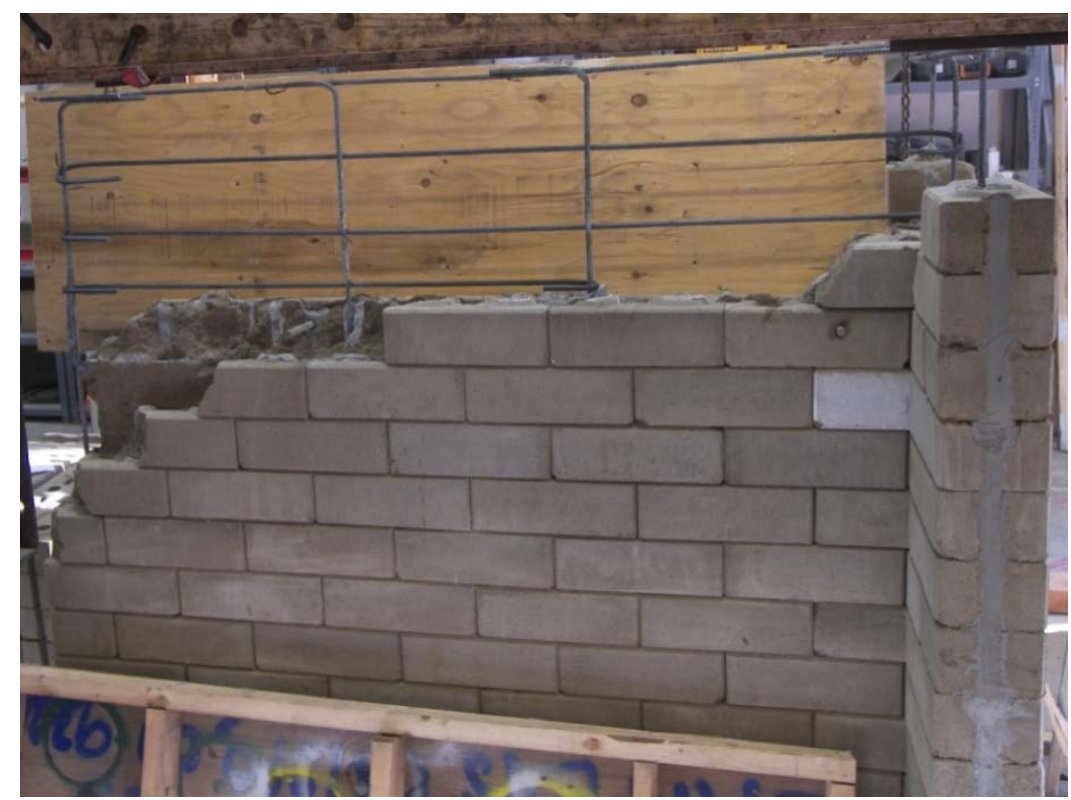

Figure 6-21: Repair of the web of W5 before reinforced concrete was cast

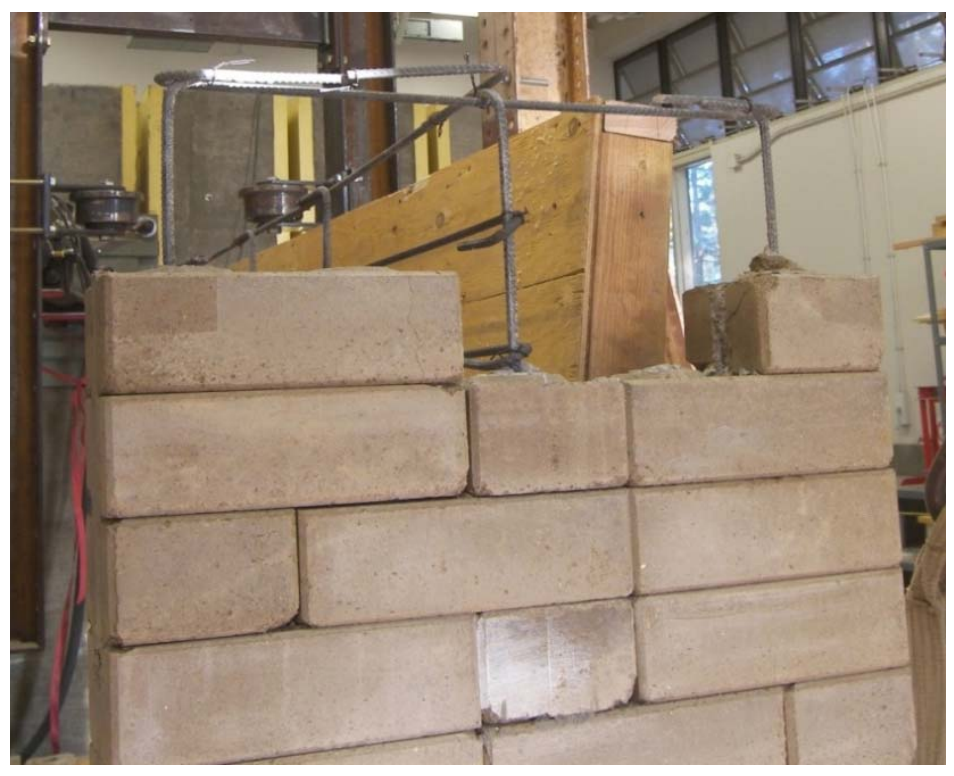

Figure 6-22: Repair of the flange of W5 before reinforced concrete was cast 
The final stage in the repair was to attach the steel load beam to the rigid concrete portion. To create a good load transfer from the actuator to the wall, the steel load beam was connected to the concrete section.

Twelve hours after the reinforced concrete section was poured, the formwork was removed for re-instrumentation and visual inspection. The repaired specimen is shown in Figure 6-23 and Figure 6-24. The visual inspection detected two bonding defects in the reinforced concrete section. The first was between the steel loading beam and the concrete top, and the other near the bottom of the concrete where the formwork bulged. Hydrostone was dry packed in these areas to close any visible gaps but provided little structural benefit.

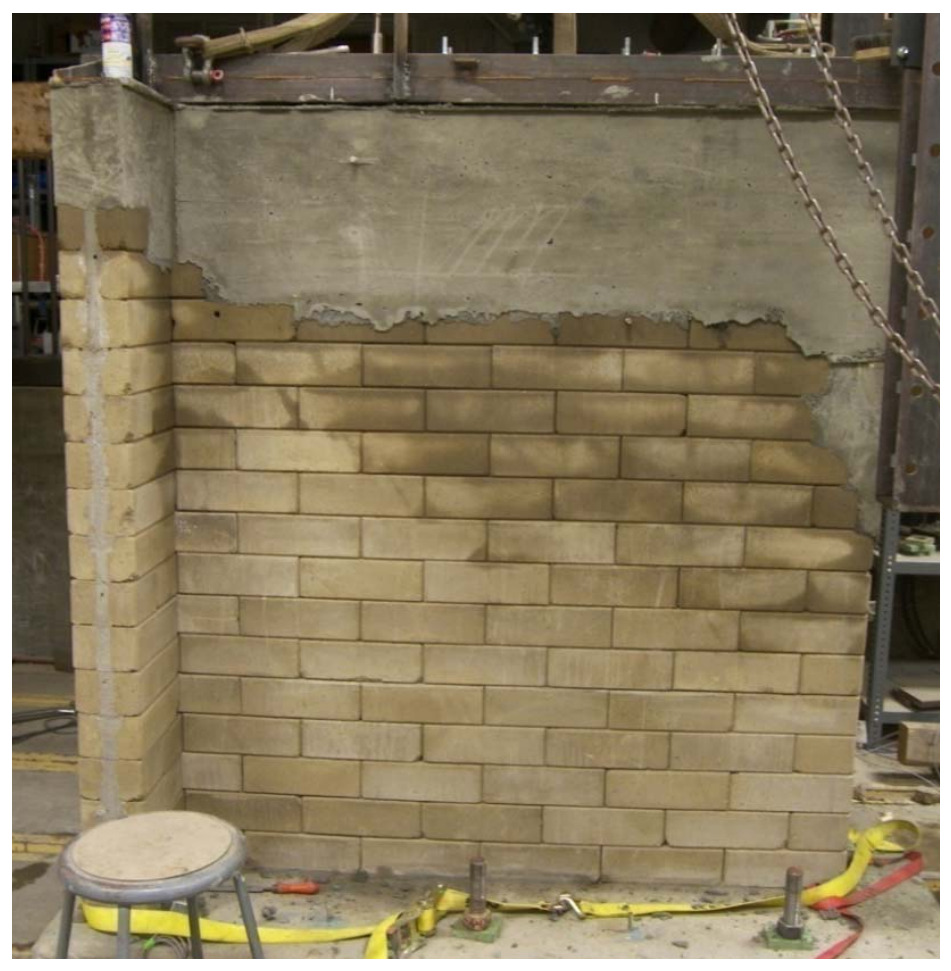

Figure 6-23: Web of W5 after removal of the reinforced concrete formwork 


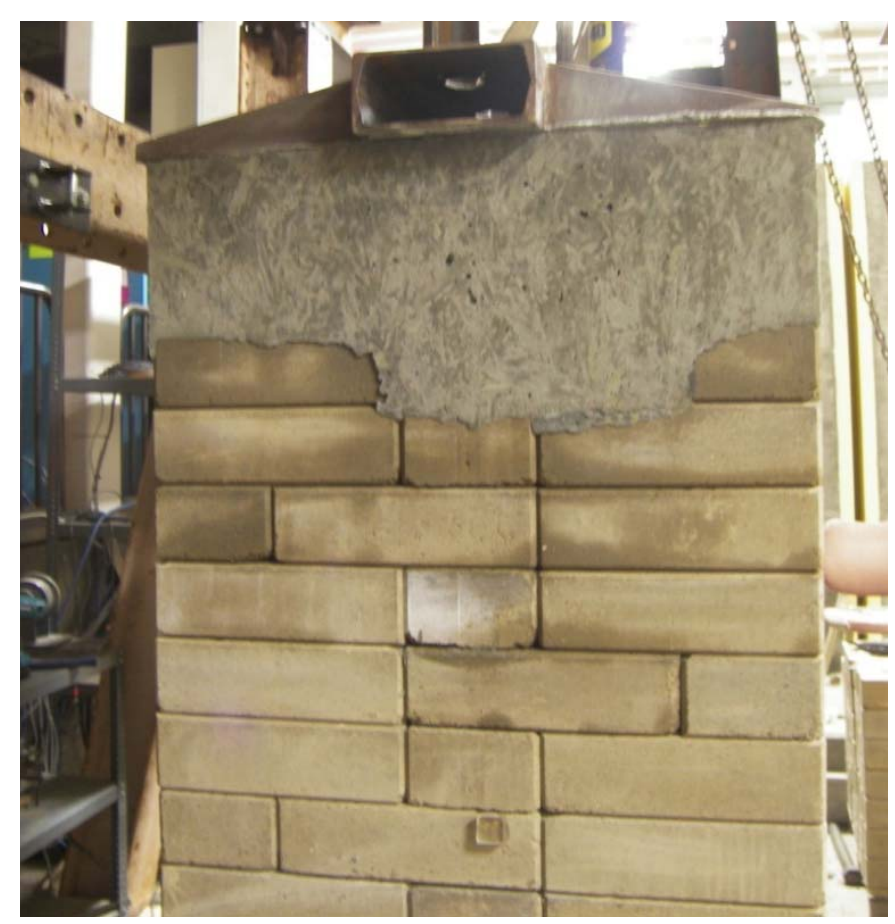

Figure 6-24: Flange of W5 after removal of the reinforced concrete formwork

\subsubsection{W5 -Phase II}

W5 was retested 31 days after the original construction was completed and 7 days following the repair using reinforced concrete. Through the duration of the experiment, 28 cycles of the loading protocol, found in Chapter 5, were used. W5 was tested to a maximum displacement of $32 \mathrm{~mm}$, corresponding to 1.77 percent drift, which was roughly half of the maximum displacement from W5-Phase I test. A maximum resisting force from the wall was recorded as $76.71 \mathrm{kN}$ at a displacement of $14 \mathrm{~mm}$ in the pull direction, and $55.1 \mathrm{kN}$ at the same displacement in the push direction as shown in Figure $6-25$. 


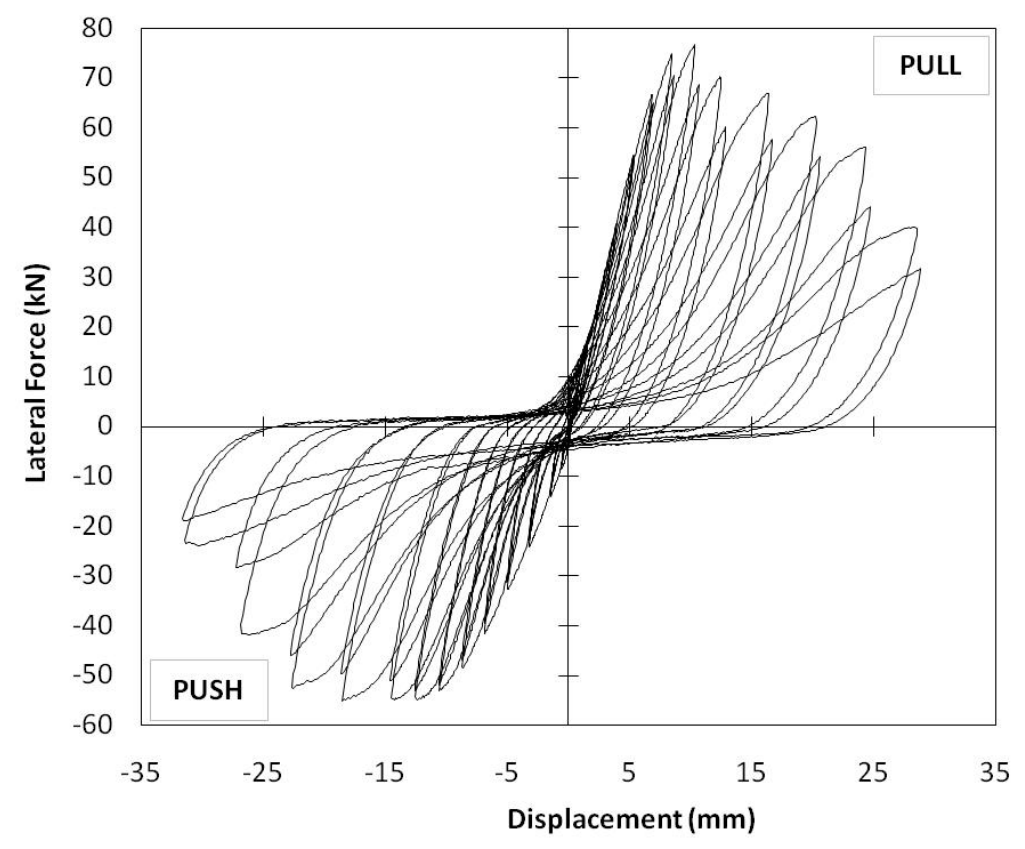

Figure 6-25: Hysteresis of W5-Phase II

\subsubsection{W5-Phase II: Cycles 1 through 8}

Throughout the duration of the first eight cycles very little noticeable damage took place with respect the deformation of the wall. Close inspection of the web of the wall showed cracks, created from the initial $60.25 \mathrm{~mm}$ shift of Phase I test, opening and closing with the displacement of the wall. This opening and closing action can be seen by comparing the closed crack at zero displacement, and the open crack at maximum displacement shown in Figure 6-26 and Figure 6-27, respectively. It was clear from the observations that the wall remained elastic throughout the first eight cycles based on the small amount of cracking observed. The hysteric loops produced during testing further confirmed these observations. A closer observation of the hysteric loops, seen in Figure 6-28, shows the loops enclose negligible area indicating that very little energy has been dissipated by the wall. 


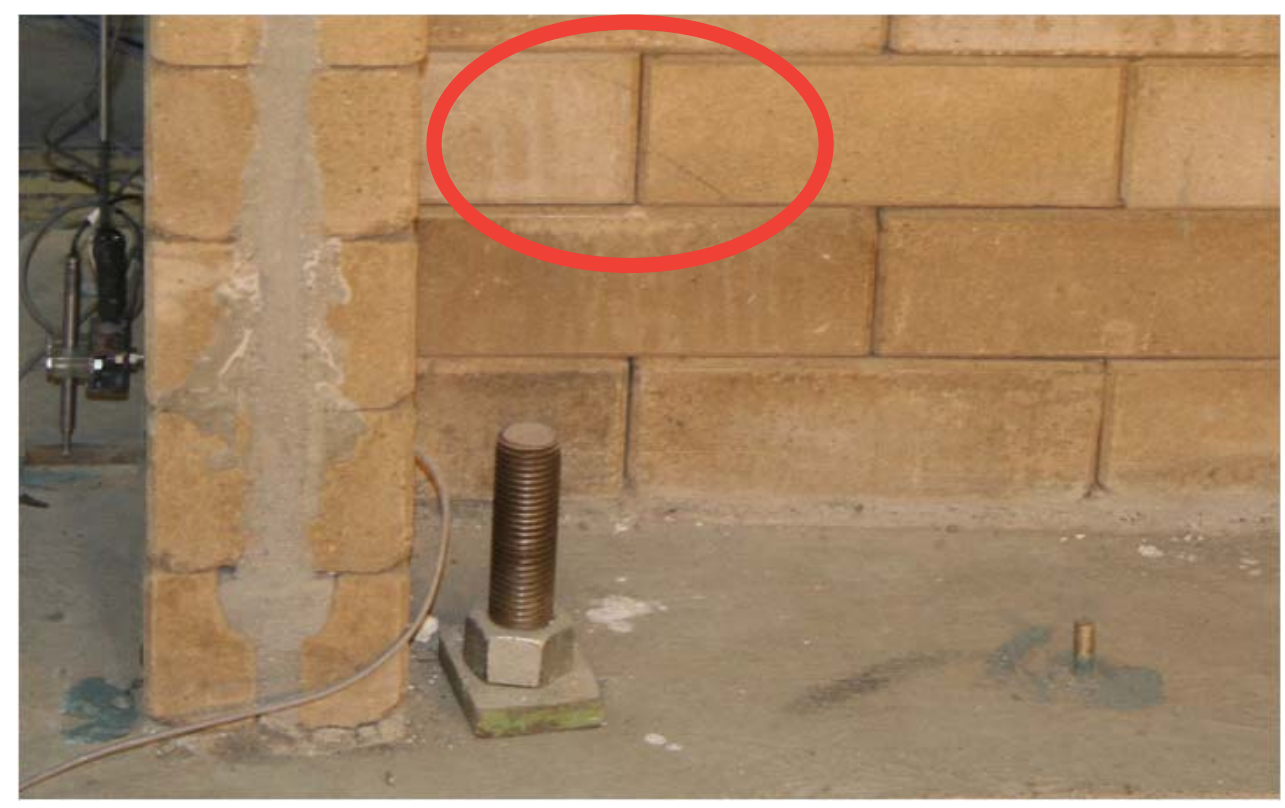

Figure 6-26: Crack in W5 at zero displacement

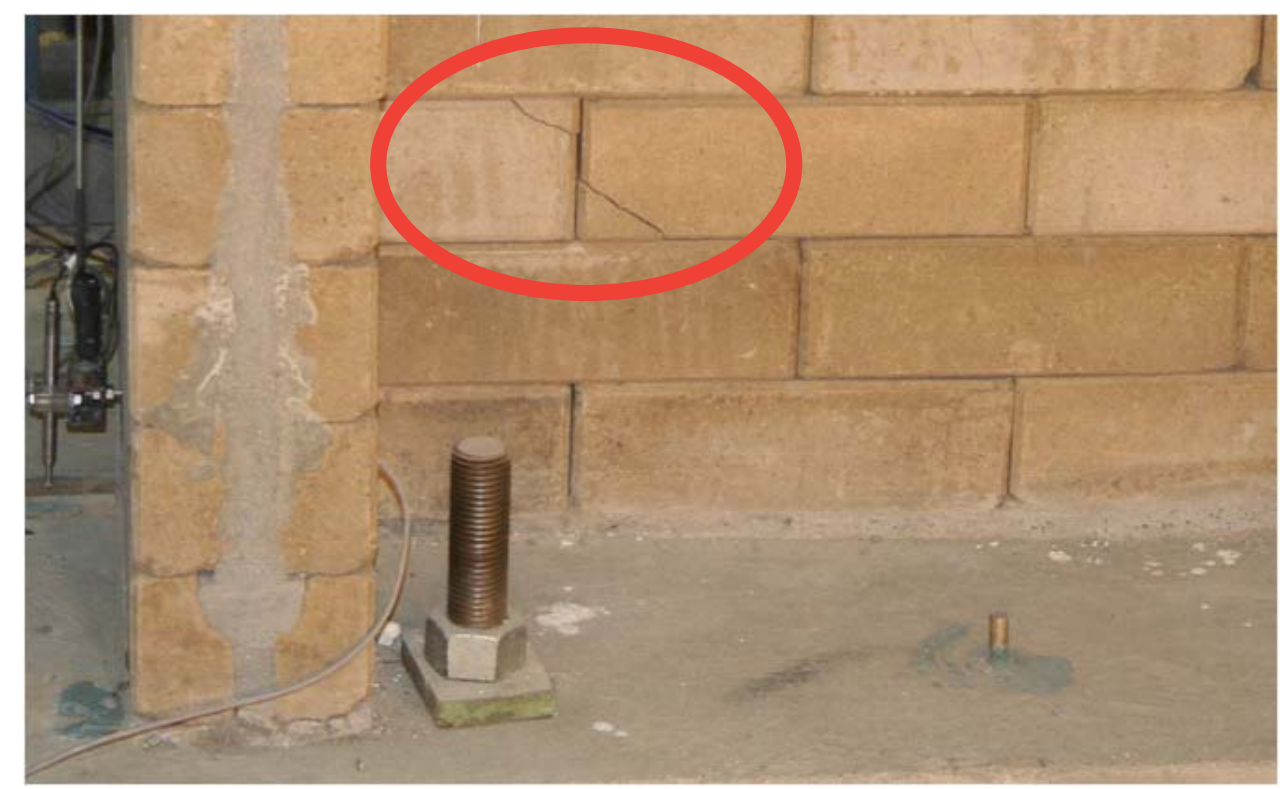

Figure 6-27: Crack in the W5 at maximum displacement of cycle 8 


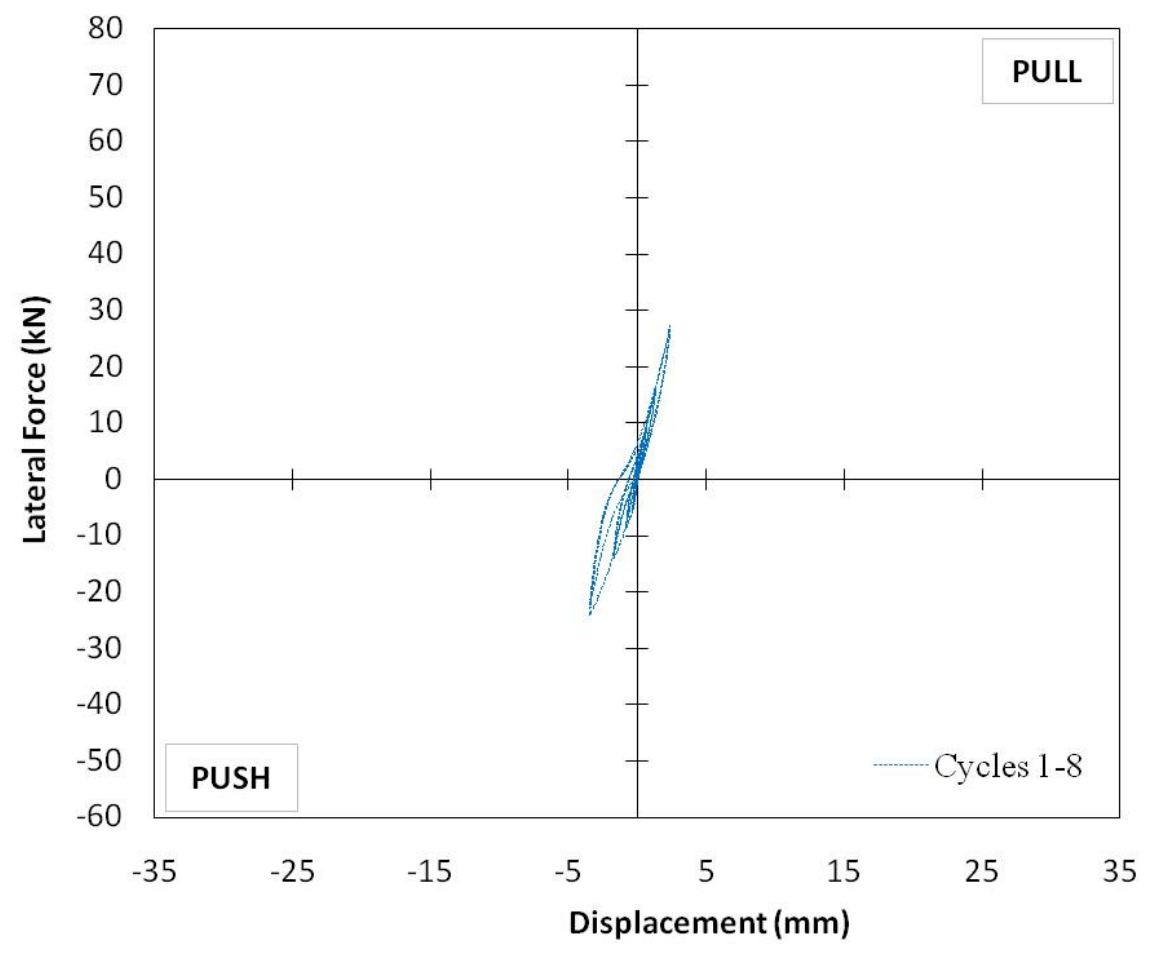

Figure 6-28: Hysteresis of W5- Phase II: Cycles 1 thought 8

\subsubsection{W5-Phase II: Cycles 9 through 12}

As shown in Figure 6-29, at the peak displacements of Cycles 10 and 12 (i.e., at 6 $\mathrm{mm}$ and $8 \mathrm{~mm}$ respectively), that the strength of the wall continues to grow with very little energy dissipated. The beginning of significant energy dissipation could be seen in the push excursion of Cycle 11, primarily due to the horizontal cracking between blocks at the toe of the web which is shown in Figure 6-30. The hysteresis, shown in Figure 6-29, clearly shows that the zero force line being crossed at two separate displacements, neither of which are zero, indicating a residual shift in the wall from a previous displacement. 


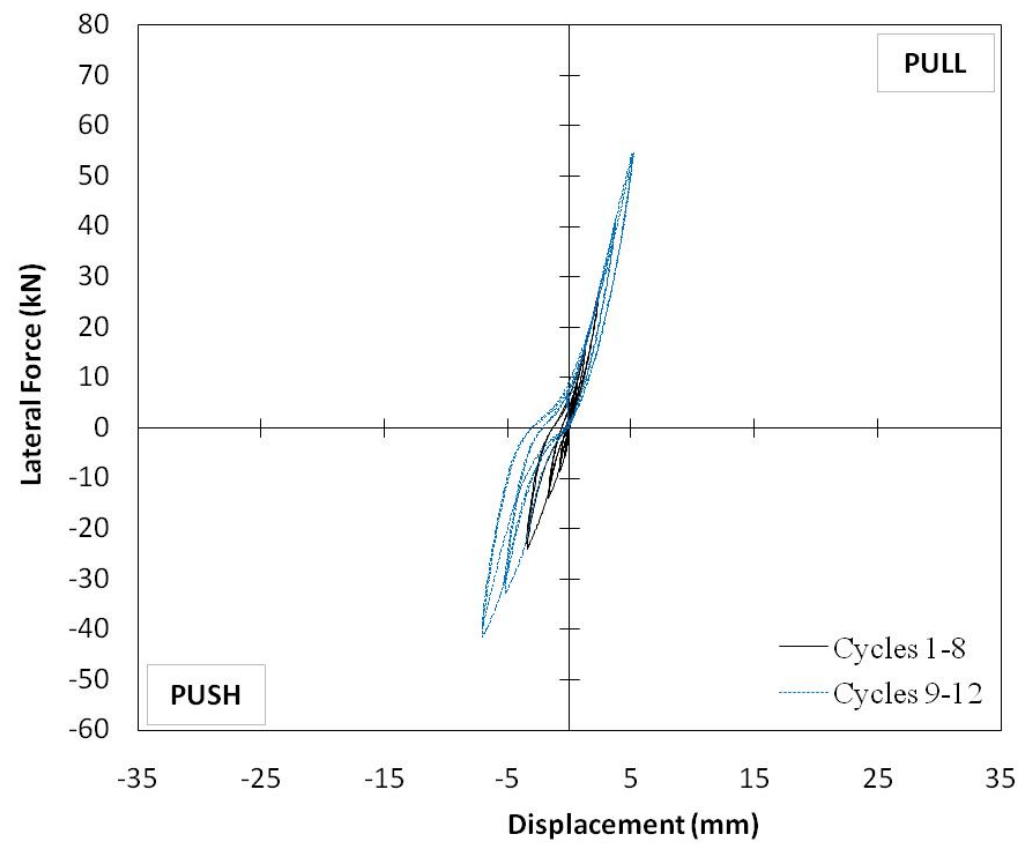

Figure 6-29: Hysteresis of W5: Phase II Cycles 1 through 12

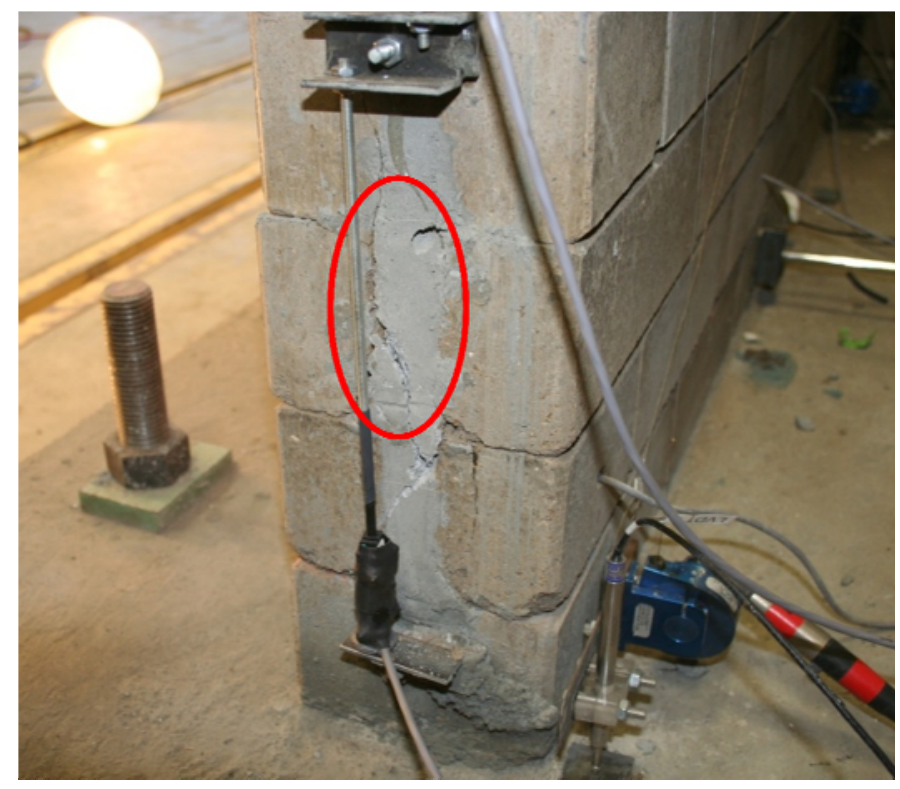

Figure 6-30: Tension cracks at the base of the toe of W5 web 


\subsubsection{W5-Phase II: Cycles 13 Through 16}

Cycles 13 through 16 corresponded to peak displacements of 10 and $12 \mathrm{~mm}$ in which different strengths were observed when the flange is under compression and tension. This trend is most predominant when looking at the maximum forces the wall produced in the Cycles 15 and 16. As shown in Figure 6-31, when the flange was in tension, the maximum force resisted by the wall was $76.7 \mathrm{kN}$ which is larger than 55.1 $\mathrm{kN}$ when the web was in tension.

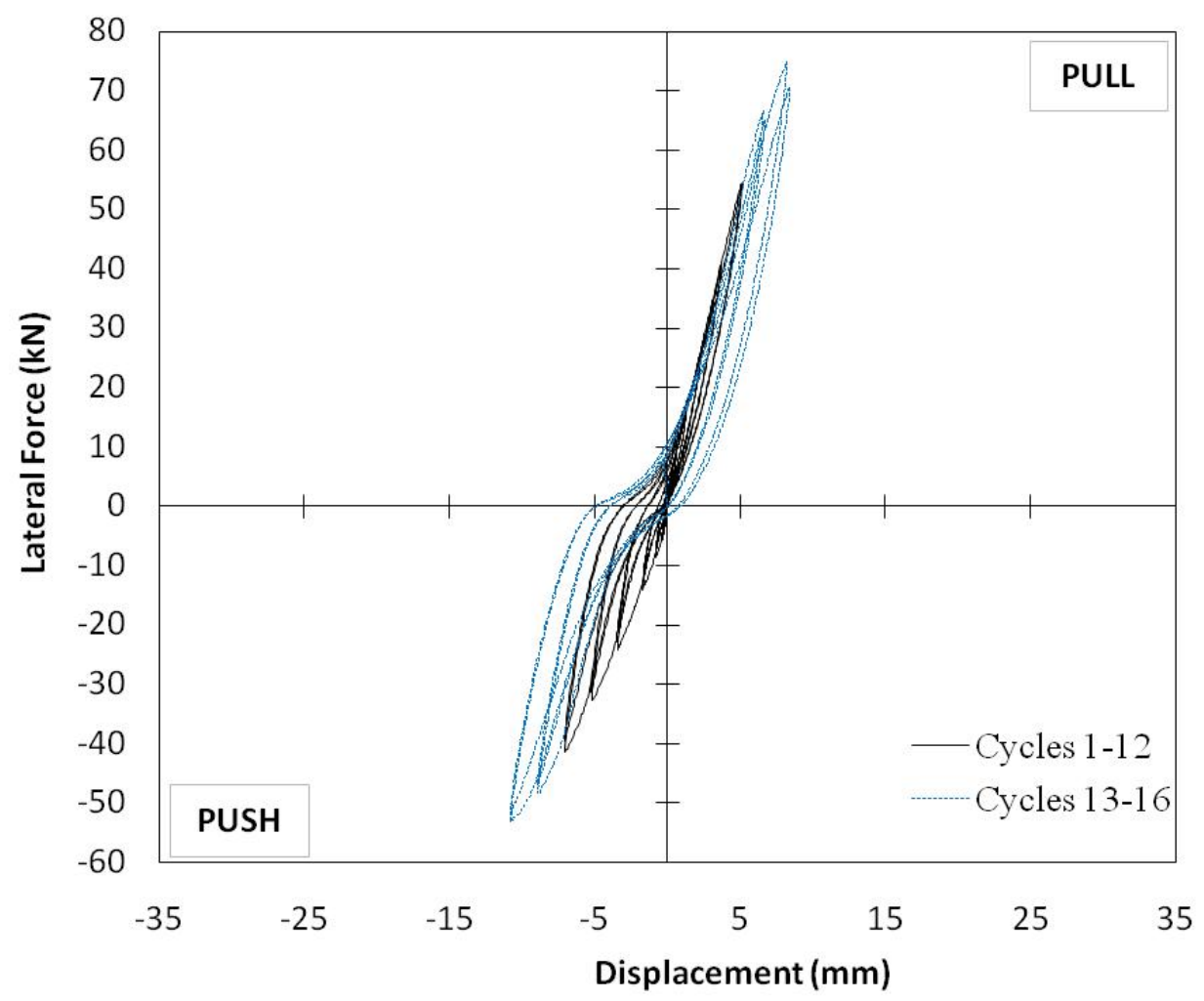

Figure 6-31: Hysteresis of W5-Phase II: Cycles 1 through 16

A visual inspection of the wall throughout Cycles 13 to 16 revealed three definite damages in the walls. The most predominant damage was the beginning of spalling at the base of the web as shown in Figure 6-32. It was also noticed that cracks which had been 
opening and closing in the previous cycles had become significantly wider and was remaining open in both the push and pull cycles of the test. It was also noted that the majority of these cracks were found to be focused around the joint between the web and the flange, indicating that the flange was beginning to separate from the web. The third observation of damage in the wall was the beginning of shear cracking, which is shown in Figure 6-33.

A closer observation of the strain gauge data revealed that rebar $\mathrm{D}$, in the middle of the flange, reached a strain of 0.0023 indicating that the steel rebar yielded. Due to the failure of several strain gauges, it was impossible to determine the strains of all rebars. Using the assumptions that plane sections remain plane it was estimated that the rebar in the web should have yielded as well.

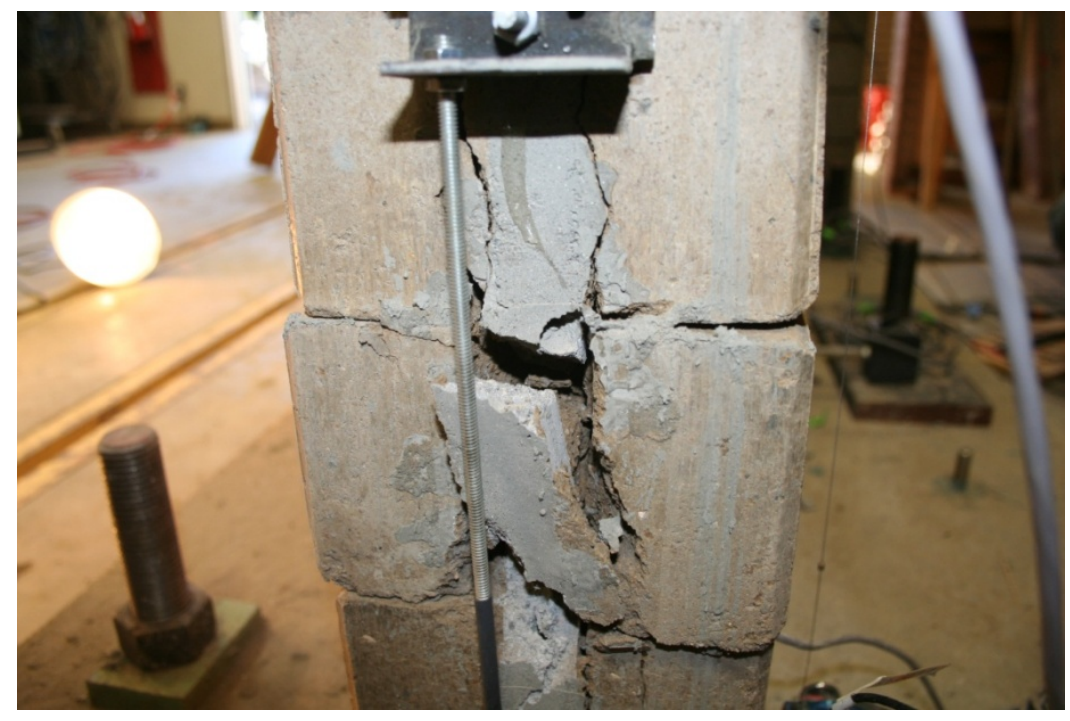

Figure 6-32: Spalling of the outer grout channel of the W5 web during Cycle 16 


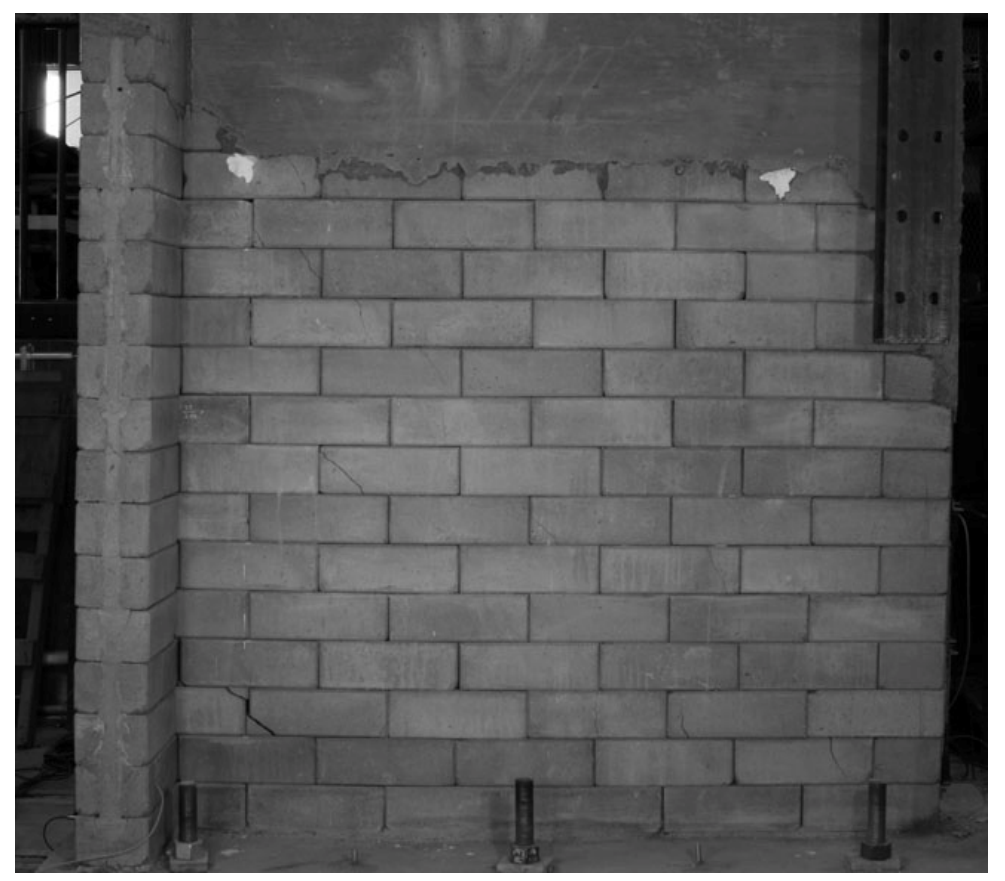

Figure 6-33: Cracking of W5 web at zero displacement after Cycle 16

\subsubsection{W5-Phase II: Cycles 17 through 20}

The $14 \mathrm{~mm}$ peak displacement in Cycle 17 produced the maximum force on the wall before strength degradation occurred. The highest obtained force with the flange in tension was $76.7 \mathrm{kN}$ and with the web in tension was $55.1 \mathrm{kN}$. Throughout the duration of Cycles 17 through 20, the strength of the web in tension remained approximately constant as shown in Figure 6-34. Cracking in the lower five courses of the toe is shown in Figure 6-35. It was observed that throughout Cycles 17 through 20, the cracks parallel to the reinforcement propagated upward on either side of the block. As the cracked section around the outside of the rebar grew with each cycle, the strength continually degraded. Shear sliding also became prevalent in Cycles 17 through 20, particularly in courses 3 thought 5 from the bottom. 


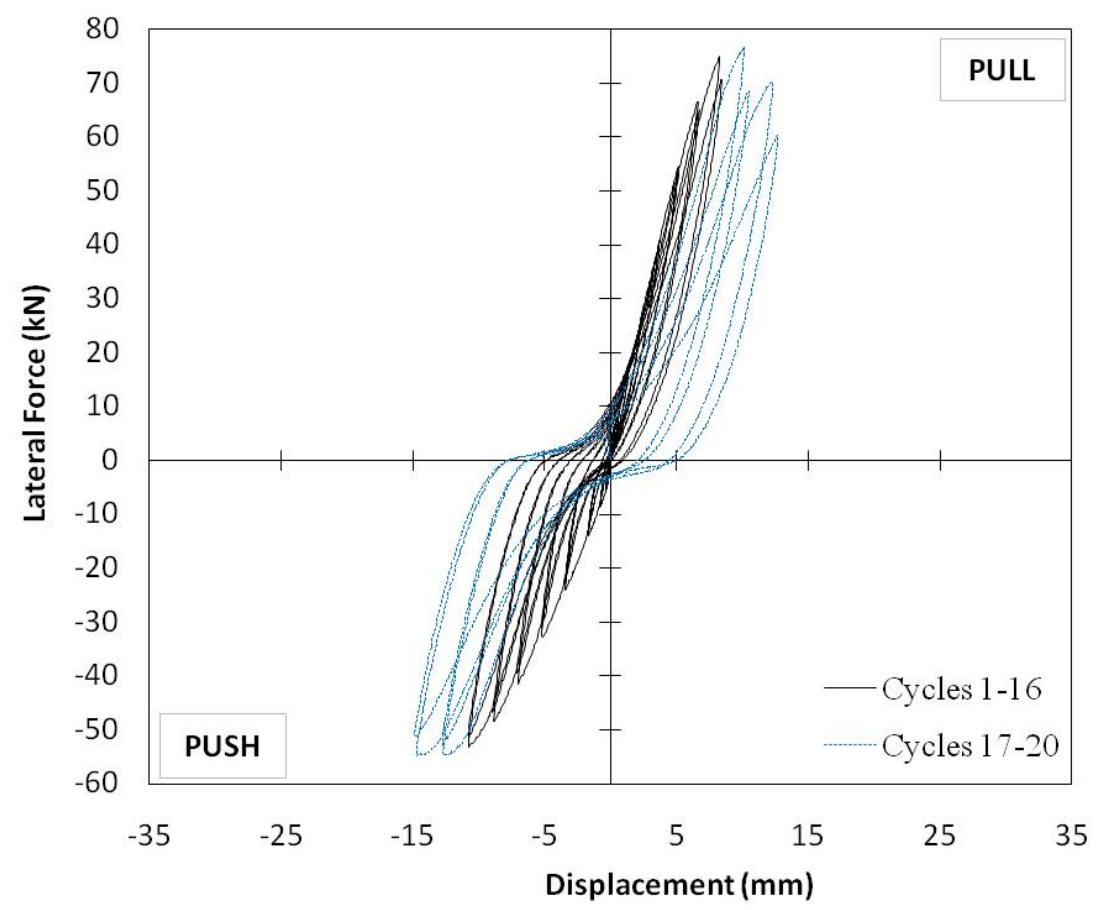

Figure 6-34: Hysteresis of W5-Phase II: Cycles 1 through 20

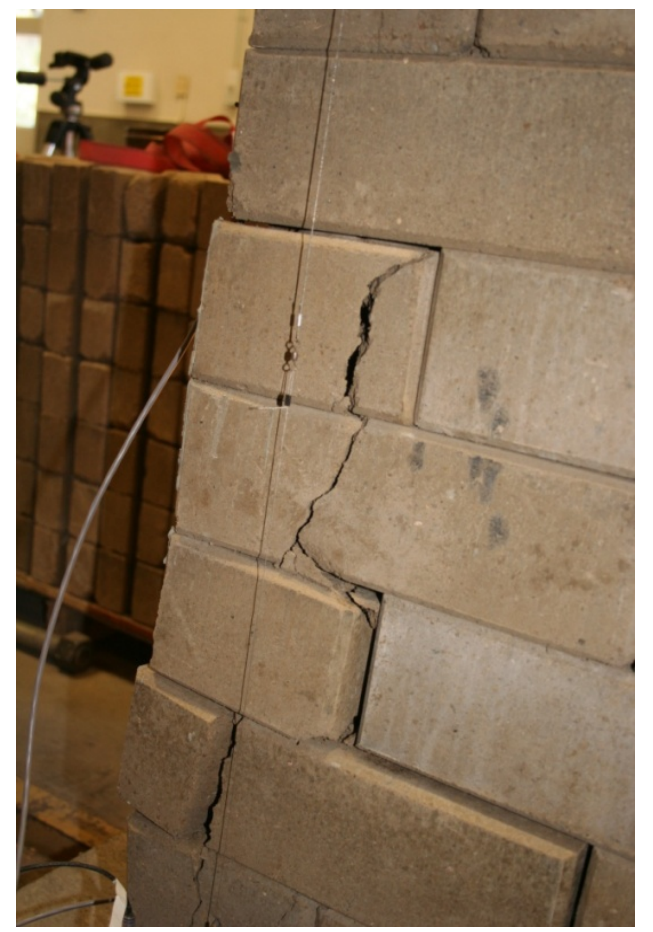

Figure 6-35: W5 cracking around the bottom toe of the web 101 


\subsubsection{W5-Phase II: Cycles 21 through 24}

Beginning with Cycle 21, displacement increment increased from 2 to $4 \mathrm{~mm}$ per cycle, which caused drastic deformation to the wall and continued to degrade the wall strengths. To prevent damage to the instruments at the toe of the wall, DTR 4, 0.5 " LVDT B, LPOT 0 and LPOT1 were removed from the wall during the test. During the Cycle 22, the toe spalled off on the right side of the toe and pushed away from the left side as shown in Figure 6-36. The unconfined rebar was then subjected to all the compressive force typically taken by the spalled masonry at the toe of the wall, causing the rebar to buckle as shown in Figure 6-37. When the load was reversed during the push excursion of the cycle, tension force developed in the rebar and the rebar was straightened as shown in Figure 6-38.

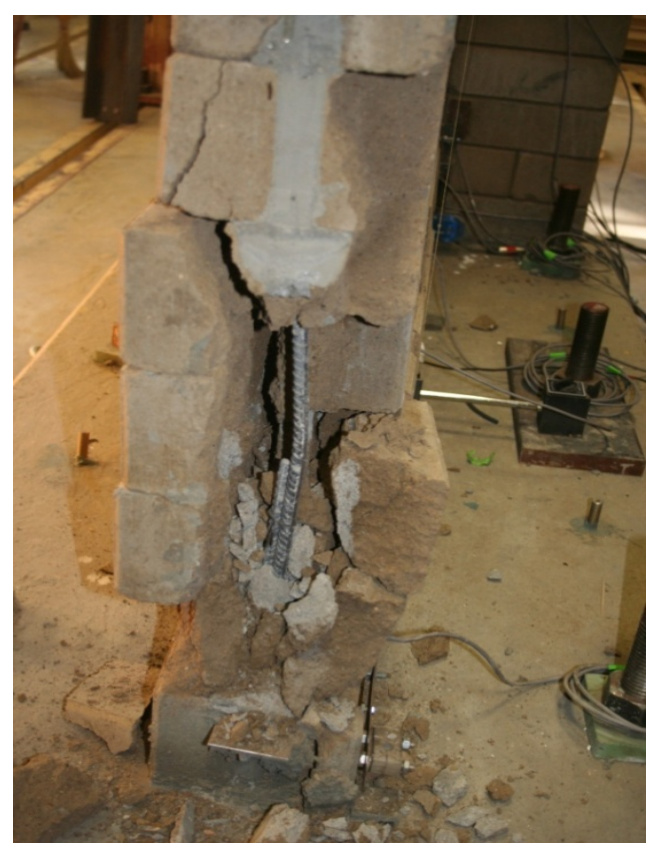

Figure 6-36: Spalling of the ICEBs and grout around the toe of W5 web 


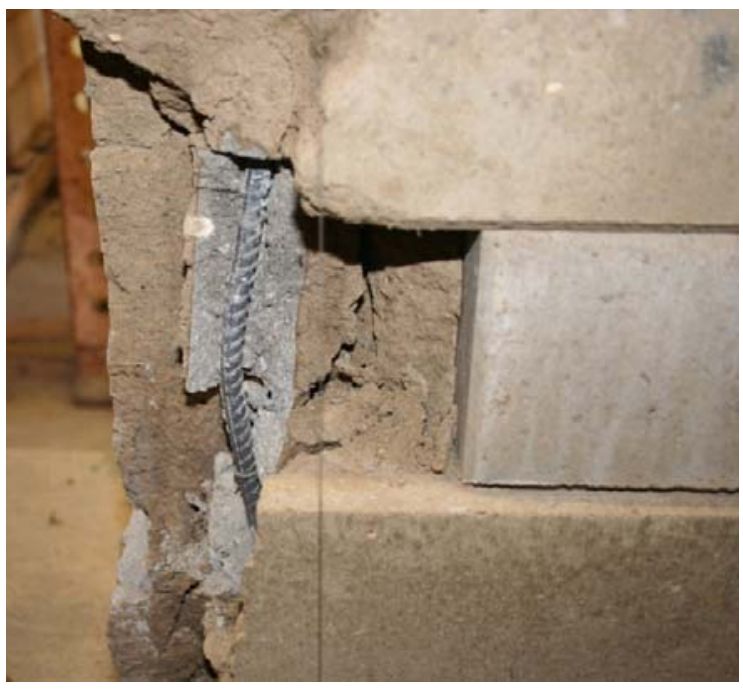

Figure 6-37: Buckling of unconfined rebar subjected to compressive force during pull excursion of Cycle 24.

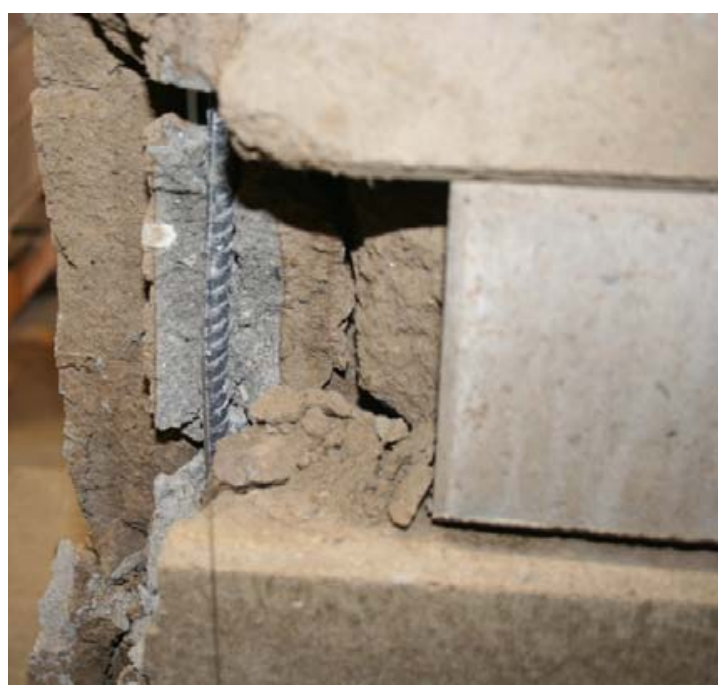

Figure 6-38: Unconfined rebar in tension during the push excursion of Cycle 24.

Cycles 23 and 24 continued the same failure seen in the previous cycles, i.e., damaging the toe of the web. The pull excursion of Cycle 23 caused the remaining intact portion of the ICEB to spall off leaving only the bare rebar at the toe of the web. Figure 6-39 shows the ICEBs split down the middle of the brick on either side of the grout channel as result of the compression taken at the toe. The only part of the brick remaining intact from the compressive force are the grout keys, reinforcement holes (without reinforcement), and the steel rebar which appear to be taking the majority of the compressive force. Examples of the other failures were shear sliding in the web and cracking in the flange. Increased sliding could be observed in the third and forth courses of the web. Cracks on the outer face and at the base of the flange is shown in Figure 6-40. This was the first time which any significant cracking was observed in the flange. 


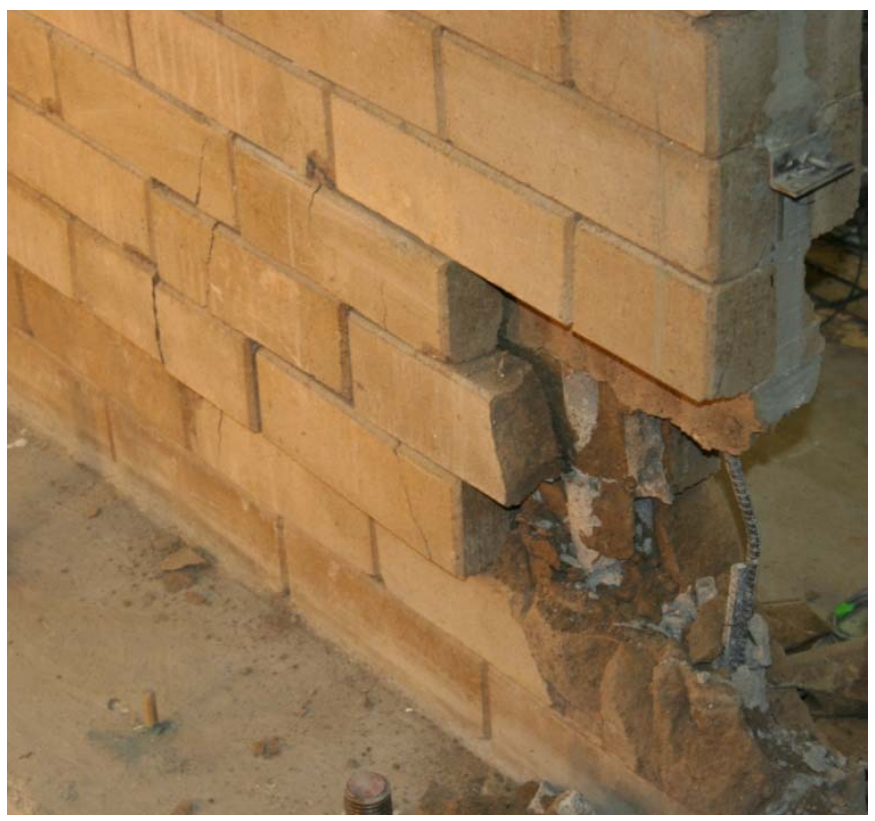

Figure 6-39: External spalling of ICEBs at the web toe of W5.

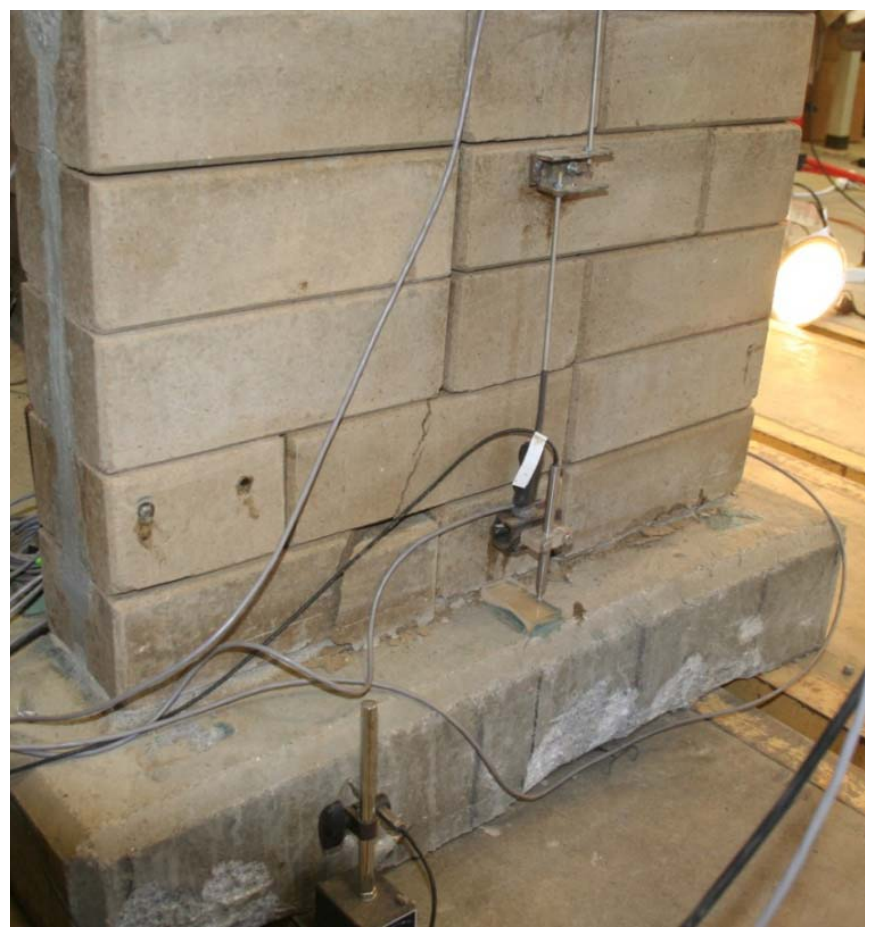

Figure 6-40: Cracking at the base of the flange of W5 
Cycles 21 though 24 showed a drastic reduction in the strength of the wall. Approximately $15 \%$ of the wall's maximum strength had been lost at the peak displacement of $20 \mathrm{~mm}$, in Cycle 21, and 20\% had been lost at the peak displacement of $24 \mathrm{~mm}$, in Cycle 24. The majority of the walls strength loss can be attributed to the cracking and spalling at the toe of the web; and very little was attributed to the degradation in the flange. The hysteresis loops, shown in Figure 6-41, show the strength degradation.

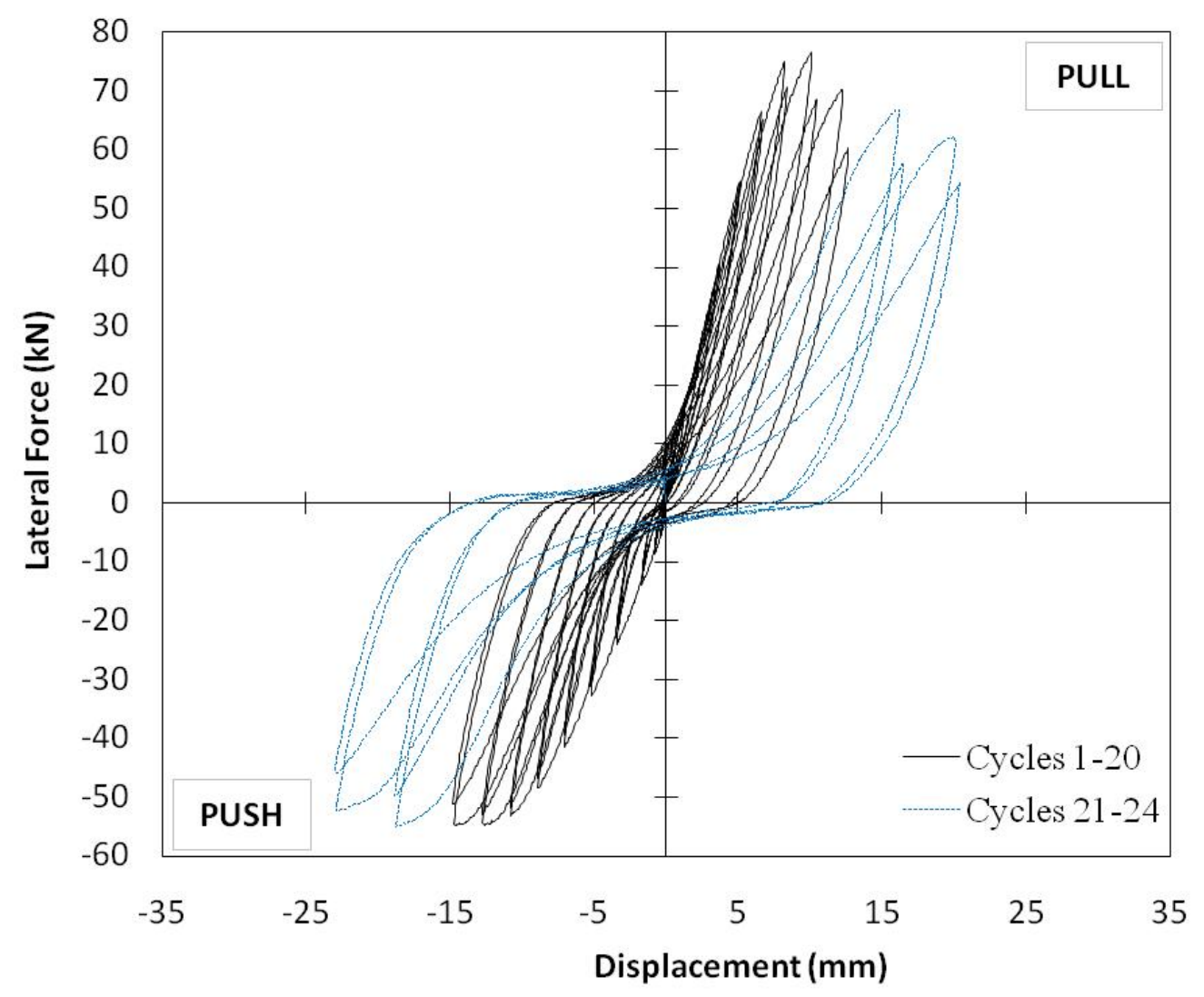

Figure 6-41: Hysteresis of W5-Phase II: Cycles 1 through 24 


\subsubsection{W5-Phase II: Cycles 25 and 28}

Before Cycle 25 began, the instruments at the base of the flange were removed to prevent possible damage of the instruments. The only instruments remaining on the wall were DTRs 0 through 3 and both 2 inch LVDTs which were safe from falling debris.

The hystereses of the Cycles 25 through 28 shown in Figure 6-42 indicates that wall has failed based on the strength degradation in both directions. The most notable reduction in strength was observed. For the push direction, an overall strength reduction of 23 percent was observed at the maximum displacement of Cycle 25, while 54 percent reduction was obtained at the maximum displacement of Cycle 27. As shown in Figure 6-42, a similar trend was observed in the pull direction: strength reductions of 22 percent and 51 percent were observed between Cycle 25 and 28, respectively. Figure 6-43 shows that the web degraded exactly as predicted by classic flexural theory.

Having seen more than 50 percent reduction in strength during Cycle 28, the decision to stop the wall test at the end of the Cycle 28 was made. The test concluded having completed 28 cycles ranging in displacement from $0.5 \mathrm{~mm}$ to $32 \mathrm{~mm}$. The predominant failure mode was identified as tensile yielding of rebar, with masonry crushing and shear sliding following. Shear sliding was observed between the third and fifth courses, and masonry crushing was seen at both the toe of the web and at the base of the flange. It was the degradation of the toe and the movement of the neutral axis towards the flange that caused the eventual reduction in strength. 


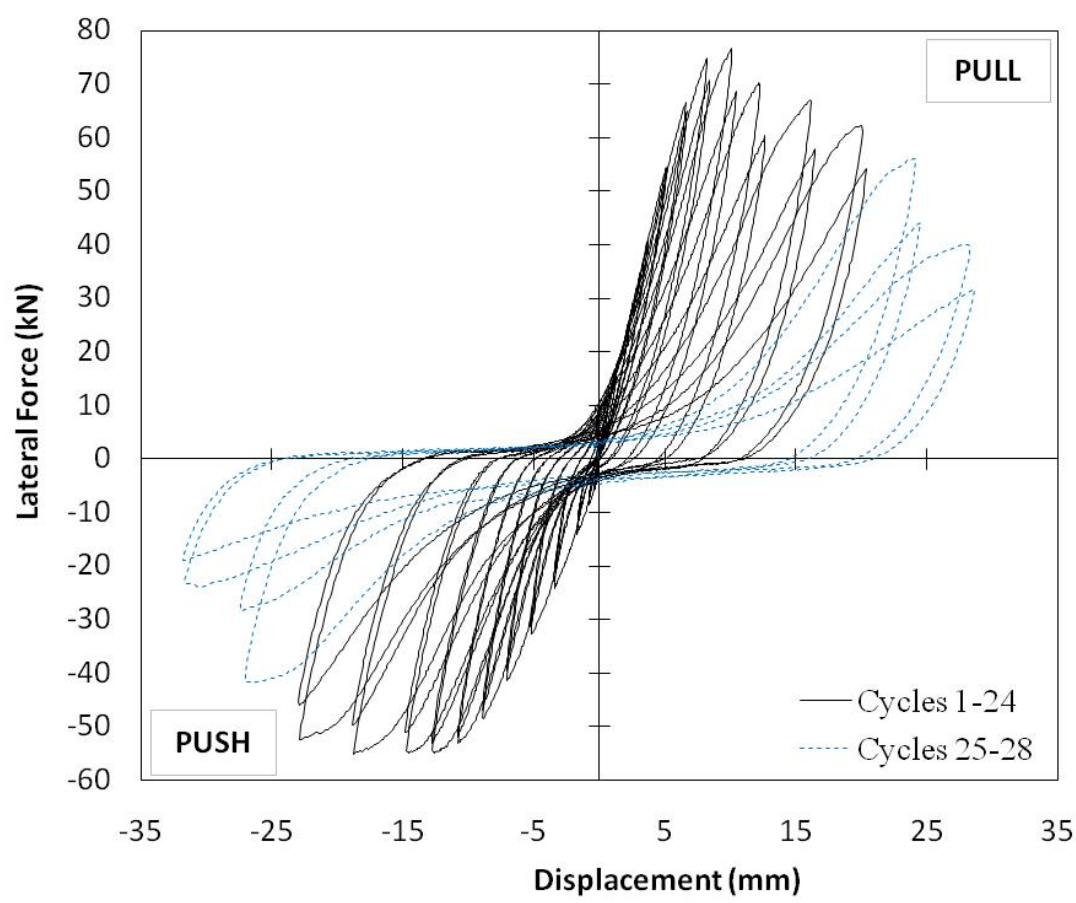

Figure 6-42: Hysteresis of W5-Phase II: Cycles 1 through 28

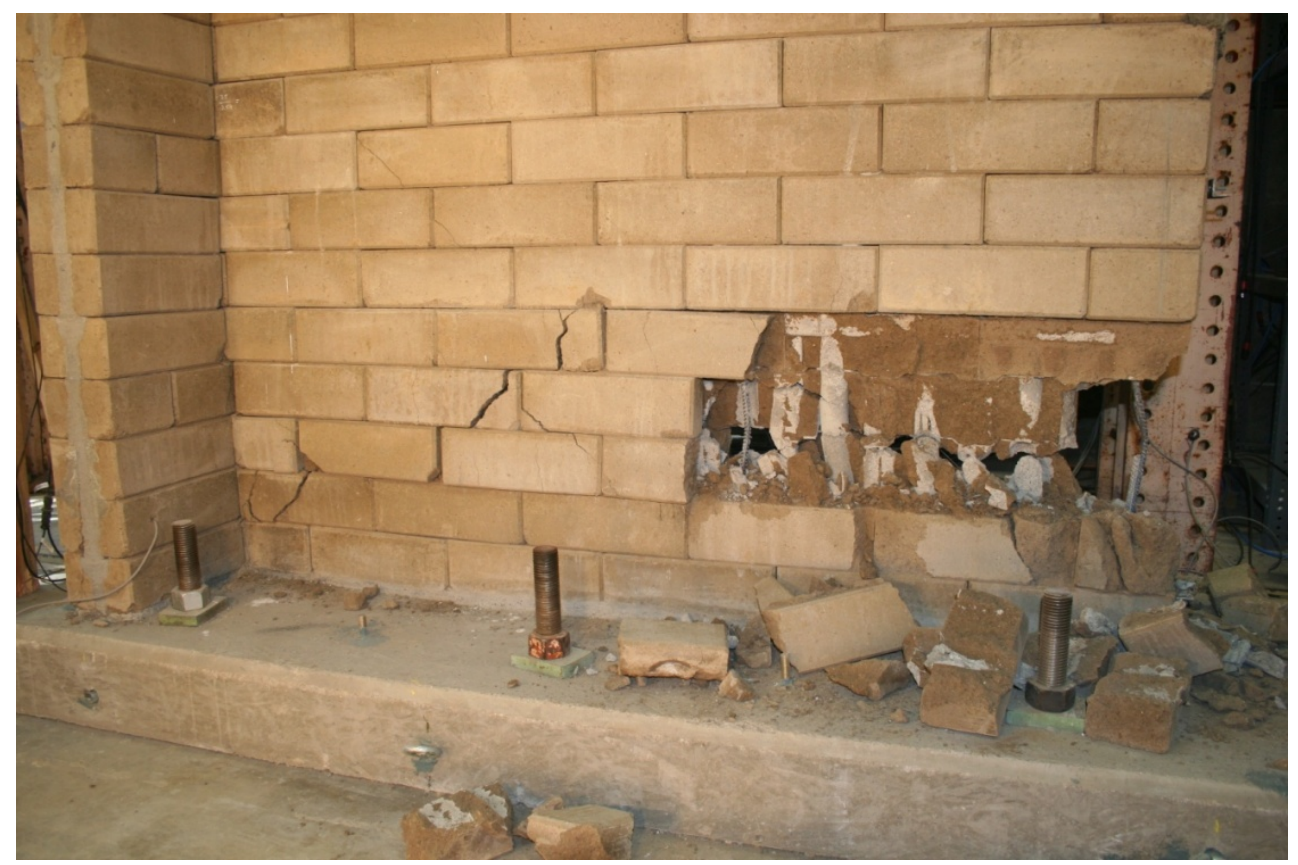

Figure 6-43: Degradation of W5 web 


\section{Testing of W6}

\subsubsection{Overview}

Specimen W6 was tested 21 days after the original construction was completed, and 18 days following the application of the steel loading beam onto the top of the wall. With the wall being built inside the testing area, no delays in testing were needed to accommodate relocation of the wall. A total of 24 cycles of the loading protocol presented in Chapter 5 were used before it was decided that no more useful data could be achieved. W6 was tested to a maximum displacement of $24 \mathrm{~mm}$, corresponding to 1.33 percent drift. The maximum resisting force from the wall was recorded at the displacement of $14 \mathrm{~mm}$ of $30.18 \mathrm{kN}$ in the pull direction, and $28.23 \mathrm{kN}$ force was recorded in the push direction.

The failure mode of the wall was determined to be a combination of flexural yielding of the steel and diagonal compression failure in the blocks. Based on visual observations, it was determined that cracking began at $4 \mathrm{~mm}$ displacements in Cycle 7 and continued to grow throughout the testing. The left pier of the wall experienced considerably more damage than the right pier. Strain gauge data indicated that yielding occurred only on the outside rebar on the bottom of the piers during Cycles 9 through 24 . Instrument readings indicated no slip developed between the top of the wall and the footing, the load beam and the top of the wall, or between the footing and the strong floor; therefore no modifications were made to the hysteresis curve shown in Figure 6-44. The following sections describe in detail the wall performance observed during the test. 


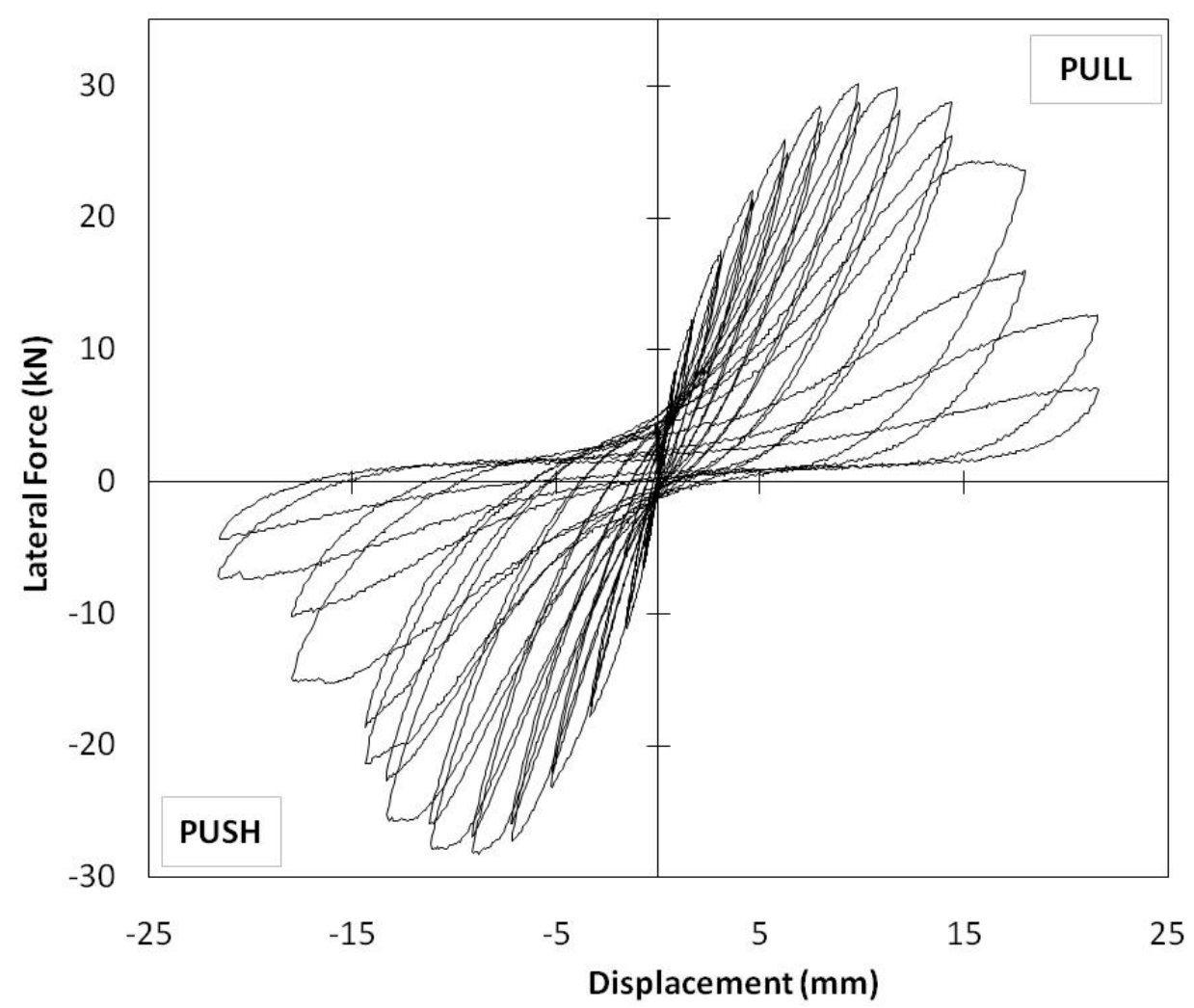

Figure 6-44: Hysteresis of W6

\subsubsection{W6: Cycles 1 through 8}

The specimen behaved essentially elastic during the first three cycles of test and visual observations were recorded since the fourth cycle. Throughout Cycles 1 to 6, no cracking or sliding of any kind could be observed anywhere in the wall. Cracking in the specimen was first visually observed at the beginning of Cycle 7 in the right pier. A crack was observed on the face directly above the right pier in the $14^{\text {th }}$ course of ICEBs. It was observed that the crack opened in the pull cycles and closed in the push cycles but did not appear to grow in the subsequent cycles. Following Cycle 8 the entire specimen was reviewed for cracking but no other cracks were found. 
The hysteresis shown in Figure 6-45 further confirms these observations. As shown, the specimen exhibited linear loading and unloading behavior through Cycles 1 to 6 , indicating the system primarily remained in the linear elastic range and thus negligible energy was dissipated in the system. However, in Cycles 7 and 8, the loops are beginning to widen, indicating the initiation of energy dissipation.

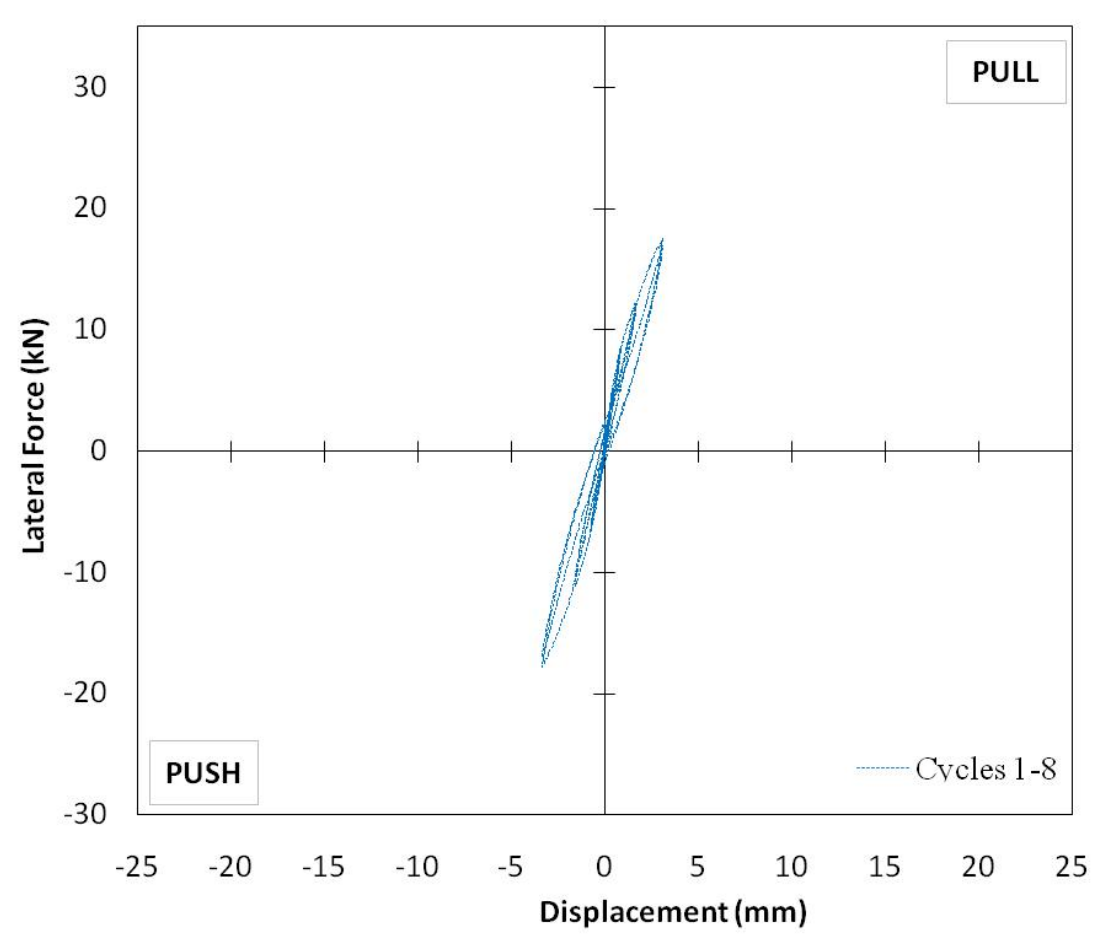

Figure 6-45: Hysteresis of W6: Cycles 1 to 8

\subsubsection{W6: Cycles 9 through 12}

In the hysteresis shown in Figure 6-46 it can be observed that energy dissipation continues to increase throughout Cycles 9 through 12. A closer inspection of the hysteresis shows that Cycles 10 and 12, no longer follows the path of Cycles 9 and 11, indicating the development of cumulative damages in the specimen. 


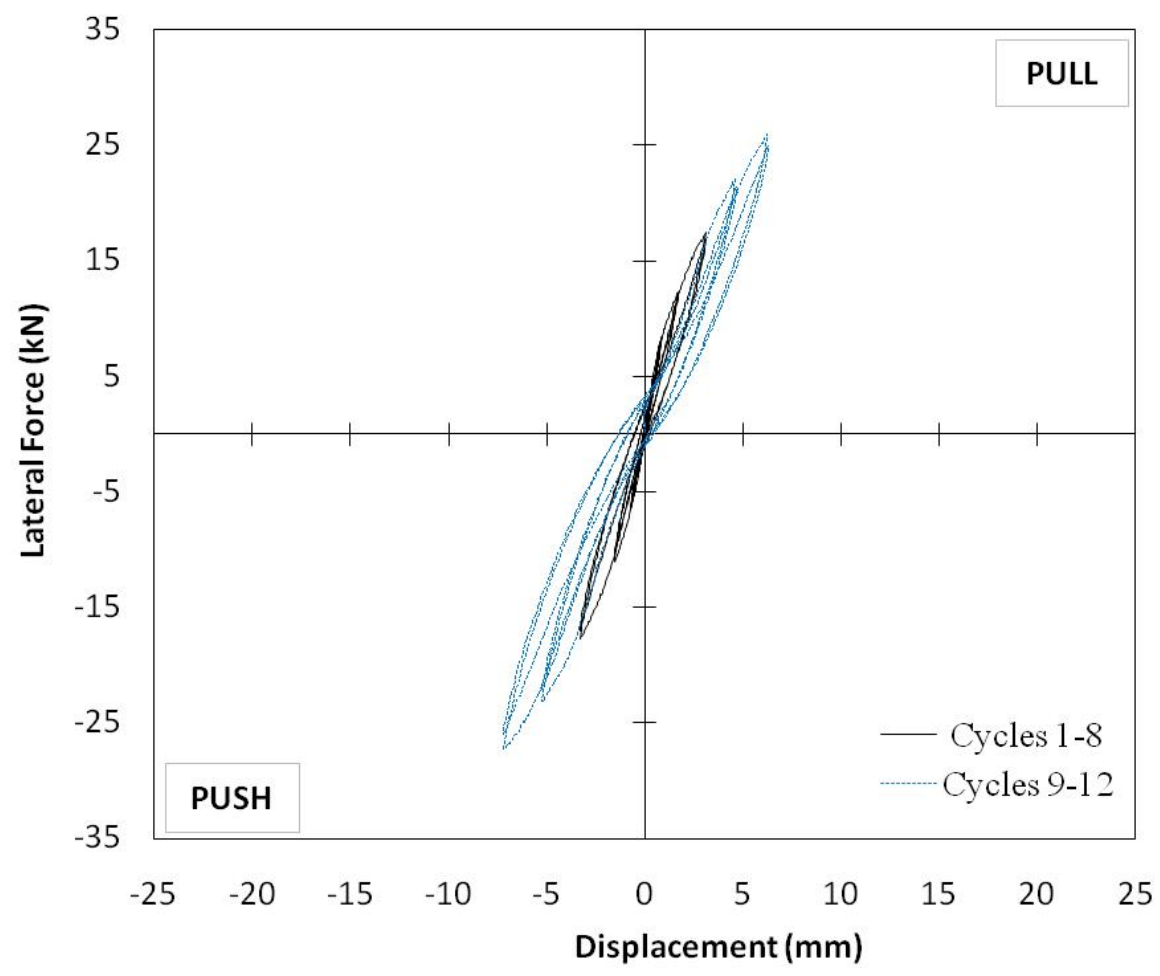

Figure 6-46: Hysteresis of W6: Cycles 1 through 12

Throughout Cycles 9 through 12 very few physical changes could be observed in the specimen. The crack initially developed in Cycle 7 over the left pier continued to open and close, but no significant growth in crack size was recognized. Rocking was noted at the bottom of both piers (around the $4^{\text {th }}$ and $5^{\text {th }}$ courses) when they were in tension; however no further cracking or crushing was detected.

\subsubsection{W6: Cycles 13 through 16}

In Cycles 13 to 16, visually noteworthy damages occurred in the specimen. Following the completion of Cycles 14, the bottom sill plate of the windows began to crack. The parallel cracks could be seen running along the outer side of the grout channel along the bottom of the window sill as shown in Figure 6-47. From visual observation, it appeared that the grout and rebar in channel were separating from the ICEBs of the sill. 
The crack shown in Figure 6-47 was observed to occur only at the end of Cycle 14 and was not observed to grow in any following cycles. In addition, small inclined cracks were seen developing in the two courses at the top right corner of the pier and three courses lower on the left corner of the pier, as shown in Figure 6-48. The locations where the cracks are beginning to form are in areas where shear reinforcement was not present suggesting that the shear rebar would enhance the shear force transfer capacity and hence prevent the diagonal cracking caused by shear force.

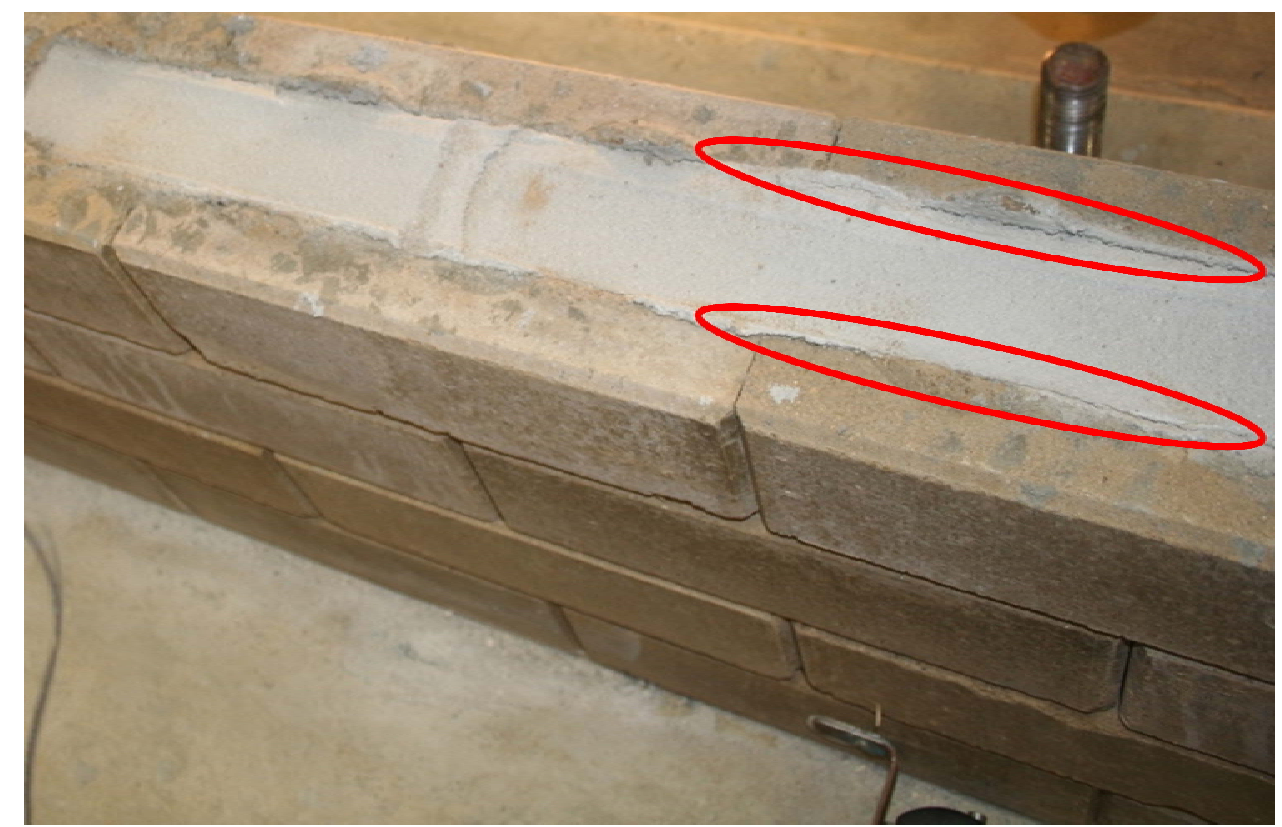

Figure 6-47: W6 cracking around the sill of the windows following Cycle 14 


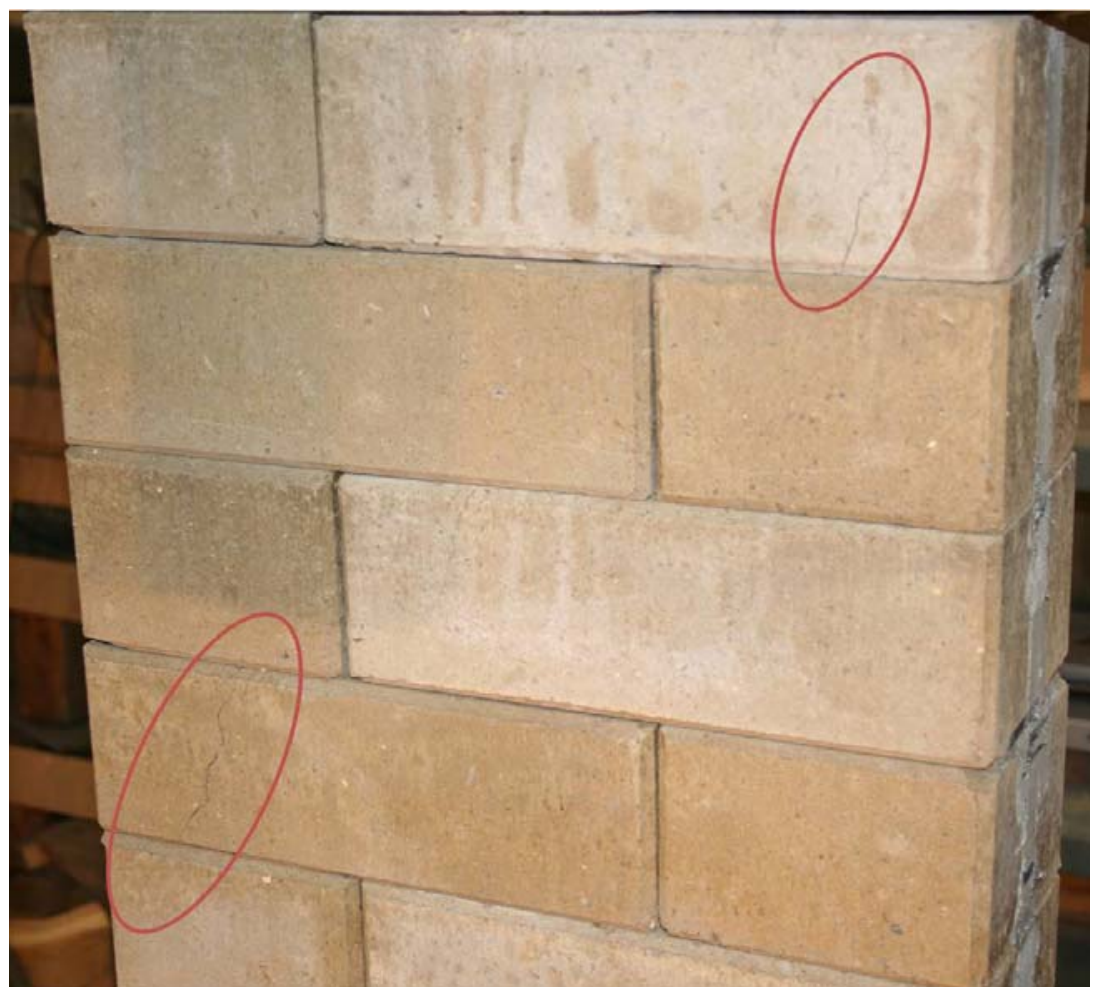

Figure 6-48: W6 diagonal cracking observed in the left pier after Cycle 16

From the hysteresis of Cycles 13 through 16, shown in Figure 6-49, and the strain gauge data it can be concluded that rebar yielding has occurred at the bottom ends of both piers; however, strain at the top ends of the instrumented pier did not indicate yielding. The peak shear forces resisted by the specimen during Cycle 15 are $30.12 \mathrm{kN}$ in the pull direction and $28.28 \mathrm{kN}$ in the push direction. 


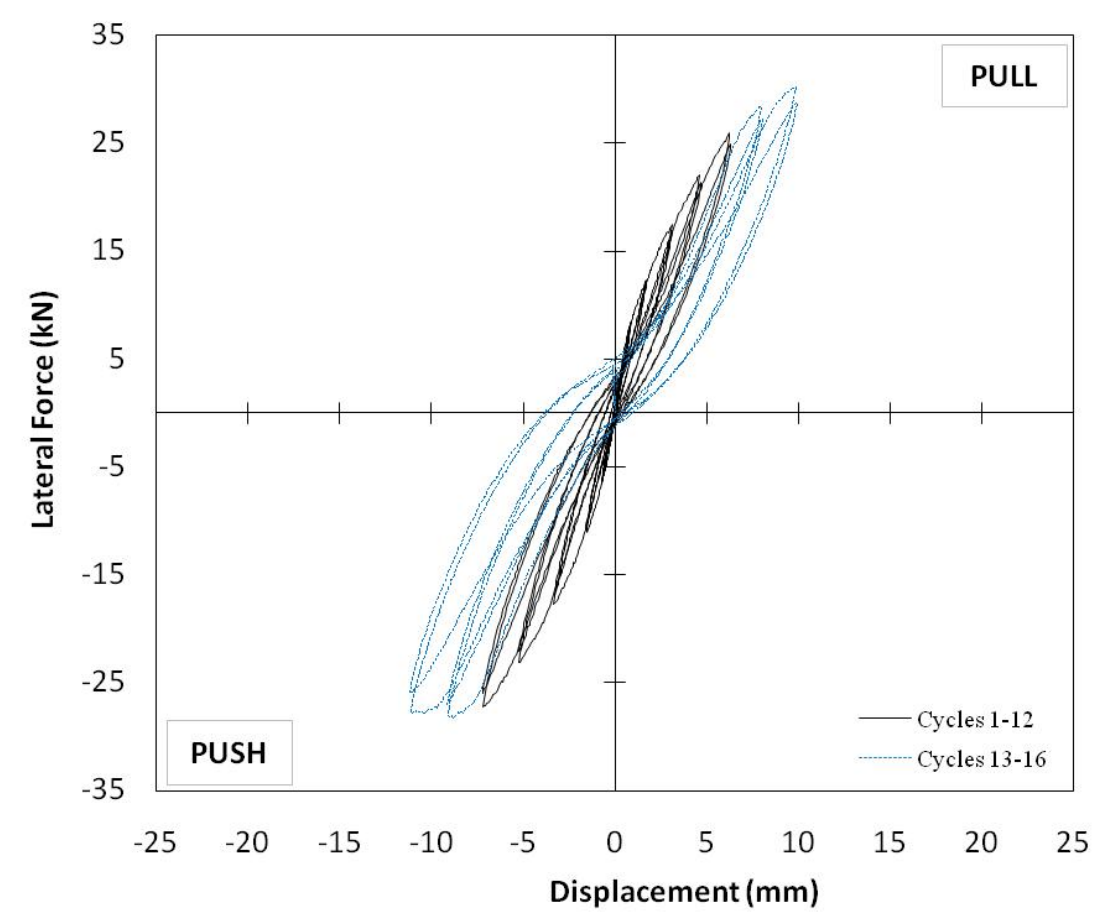

Figure 6-49: Hysteresis of W6: Cycles 1 through 16

\subsubsection{W6: Cycles 17 through 20}

Visual observations from Cycles 17 through 20 show the continual crack propagation and the formation of new cracks in both piers. The diagonal cracks observed from previous cycles continued to propagate from the flexural rebar in a diagonally manner indicating development of a shear cracking. New cracks were observed in three locations: above the left pier, along the longitudinal reinforcement in the left pier, and the right pier. The cracking above the left pier shown in Figure 6-50, propagated downwards from approximately two courses above the left pier. The second new crack shown in Figure 6-50 was observed to begin in the Cycle 17 and grew larger through Cycle 20. This crack branched off the original diagonal crack at a shallower angle and followed the flexural reinforcement towards the bottom of the pier. The third set of new cracks observed to 
develop on the right pier in a manner similar to what was seen in the left pier during Cycle 17. These diagonal cracks began on the outer face of the pier and propagated towards the vertical reinforcement.

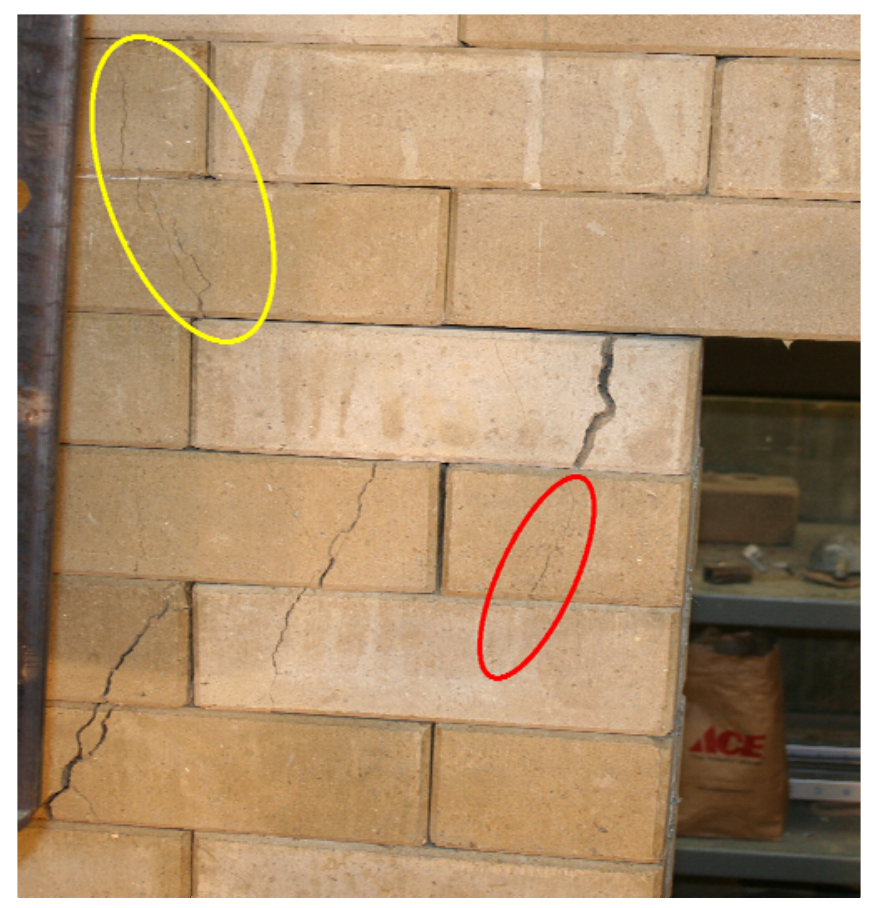

Figure 6-50: New cracks observed in W6 during Cycles 9 and 10 


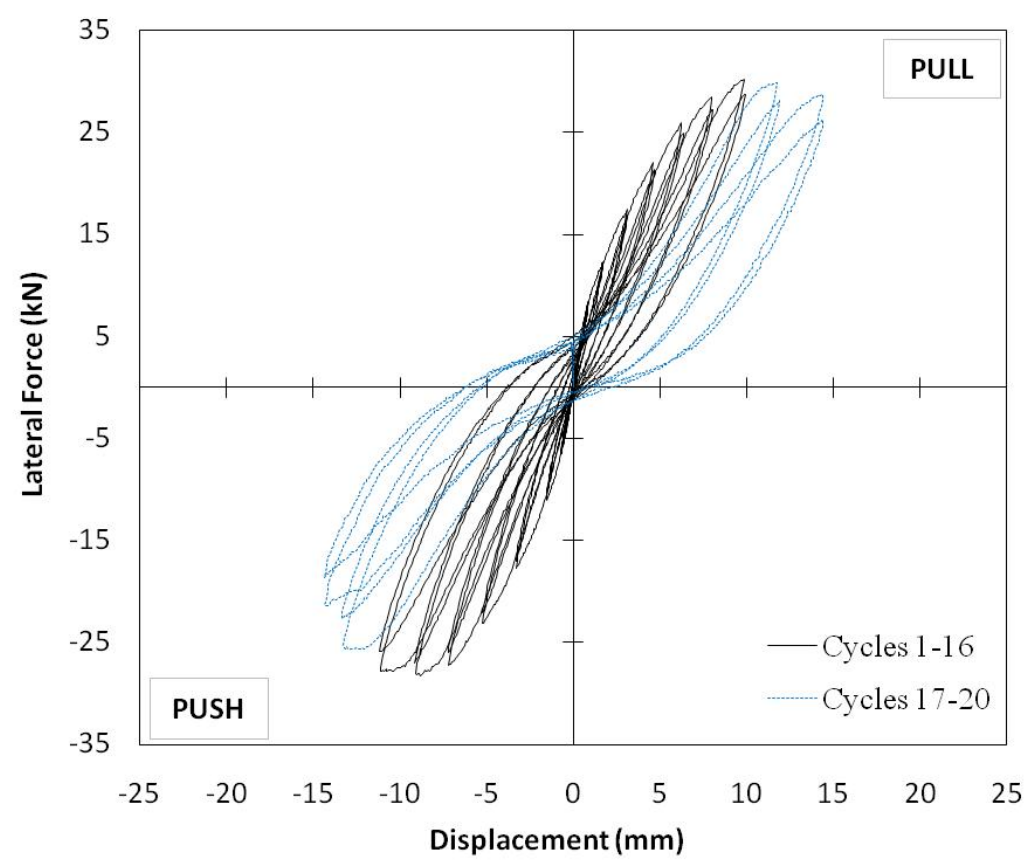

Figure 6-51: Hysteresis of W6: Cycles 1 through 20

From the hysteresis shown in Figure 6-51, energy was stably dissipated during Cycles 17 through 20. In addition, the shear forces resisted by the wall at the peak displacements of the pull cycles remain relatively constant, however, considerable strength degradations are observed in the push cycles. The observed difference in strength degradation between the pull and push cycles is due to the fact that more cracks took place in the left pier; resulting in reduced strength.

The cracking pattern in the piers seem to illustrate that they failed in shear, based on the angle of the cracks, however due to the extensive amount of horizontal reinforcement in each pier it is likely the diagonal cracks seen are the result of diagonal compression cracks are from the masonry crushing (Pauley et al., 1982). The major indicators that these cracks are from diagonal compression is the ductile natures of the specimen observed, compared to that of a shear failure. Although this could indicate a combined 
failure, it is more likely that these cracks were caused from the reversed cyclic loading compression as explained in by Paulay et al.,1982.

\subsubsection{W6: Cycles 21 through 24}

In Cycle 21 the displacement increment increased from $2 \mathrm{~mm}$ to $4 \mathrm{~mm}$ per cycle. From the hysteresis shown in Figure 6-52, the maximum shear force resisted by W6 during cycle 21 is $23.8 \mathrm{kN}$ which is 22 percent lower than the maximum strength of the wall. A discrepancy between maximum force of Cycle 21 and 22 was 32 percent. A similar trend was observed between the push cycles of Cycles 21 and 21 with a 20 percent reduction in strength observed. Although the specimen has lost more than 20 percent strength, Cycles 23 and 24 were run to capture the ultimate behavior of the specimen. Cycle 23 saw a 58 percent reduction in maximum strength from the specimen and a 44 percent reduction between Cycles 23 and 24. It was clear after Cycle 24 no residual strength would be gained from the specimen.

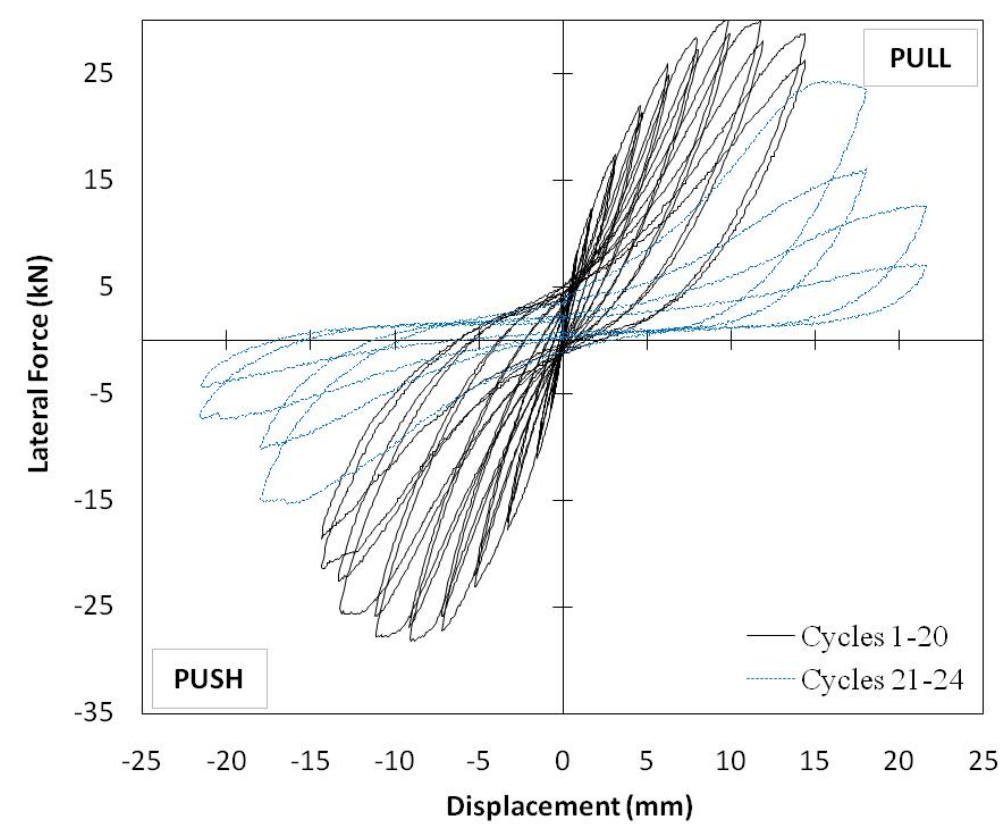

Figure 6-52: Hysteresis of W6: Cycles 1 though 24 
Cycles 21 thought 24 caused serious damage to the piers of the specimen. Prior Cycle 21, the left pier showed visible cracking but remained intacted, while the right pier show very little structurally significant cracking (see Figure 6-53). Following Cycles 21 and 22, both the right and left piers showed more damage, in particular, the left pier suffered from block spalling around the vertical rebar and the width of the cracking increased (see Figure 6-54).

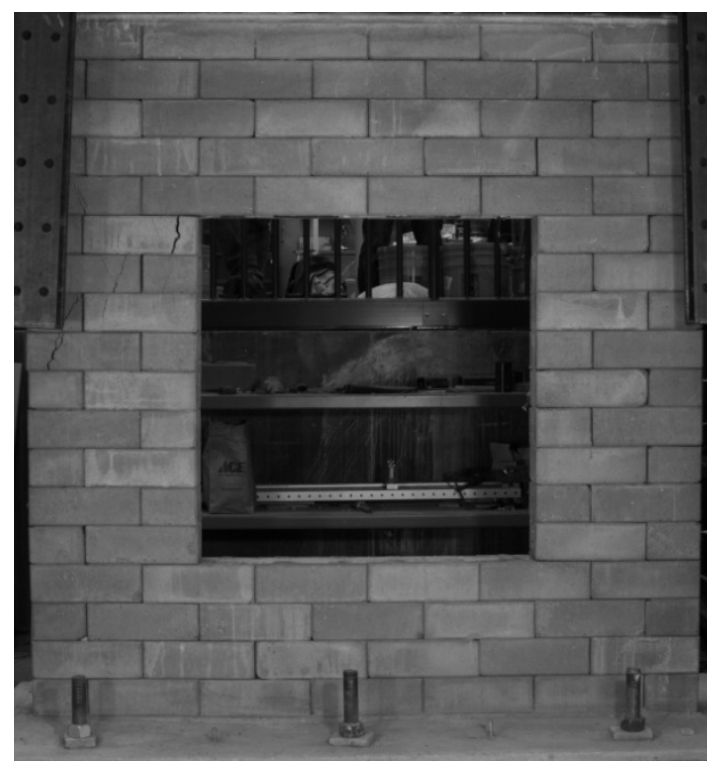

Figure 6-53: Cracking pattern of W6 prior to Cycle 21

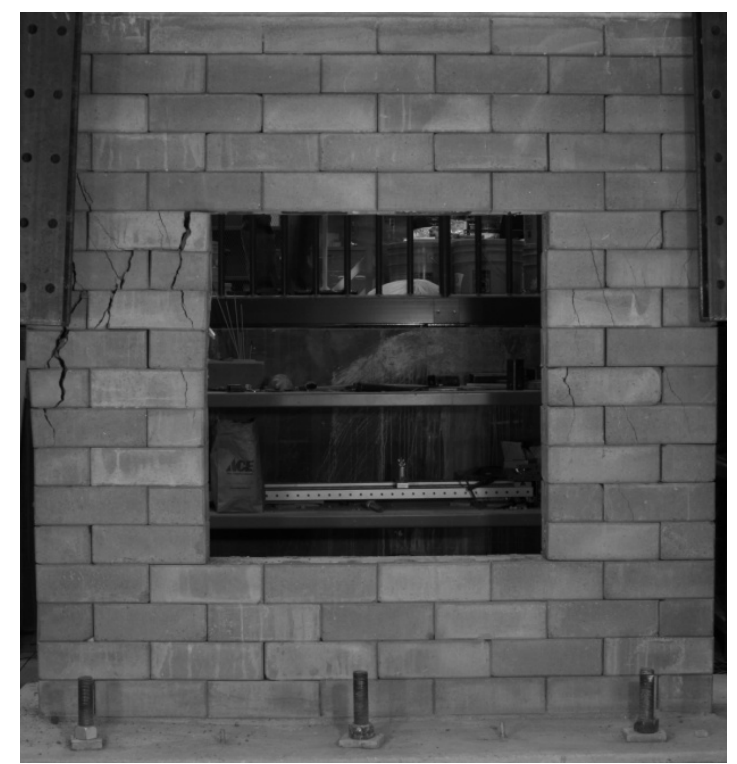

Figure 6-54: Cracking pattern of W6 following Cycle 22

Before Cycle 21 was run, all external instruments were removed to prevent damage from the falling debris. Following Cycle 24, the test was concluded due to the significant strength loss and possible instability of the specimen. The final damage to the specimen can be seen in Figure 6-55. At the end of Cycle 24, all of the masonry blocks surrounding the vertical rebars spalled off in the left pier, and the outside vertical rebar in 
the pier became visible. The right pier did not suffer from any block spalling but the level of cracking increased significantly.

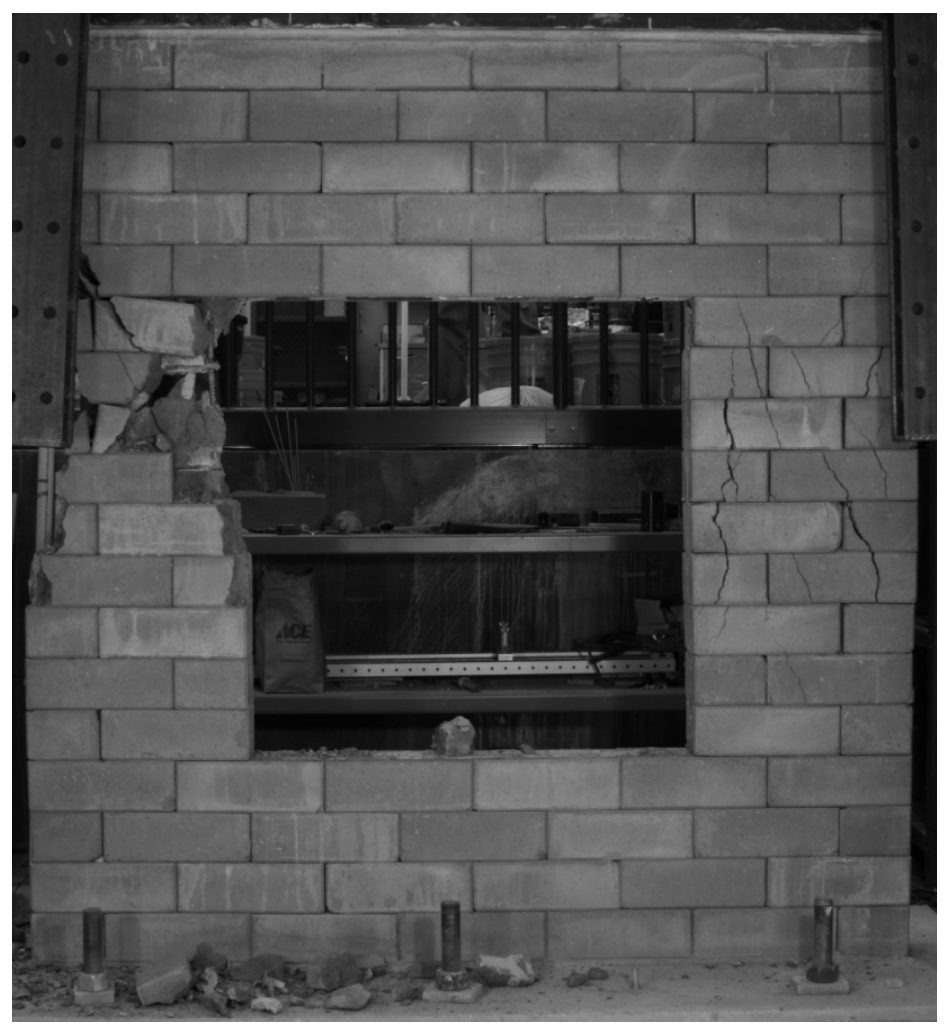

Figure 6-55: Damage in W6 following Cycle 24 


\section{DISCUSSION OF TESTING RESULTS}

\subsection{Hysteretic Curves}

The hysteretic curves from all tests are summarized in the Figure 7-1. It is recognized that specimen W5 experienced a testing accident as described in Section 6.2.1 and it was re-tested after the repair work. As such, the testing data associated with W5 were classified as Phase I and Phase II for the original specimen and repaired specimen, respectively. The maximum resisting force and the corresponding displacement, and the maximum obtained displacement and the corresponding resisting force of each specimen are summarized in Table 7-1. The envelopes for the force displacement curves of the W4, W5-Phase I, W5-Phase II, and W6 tests are shown in Figure 7-2. 


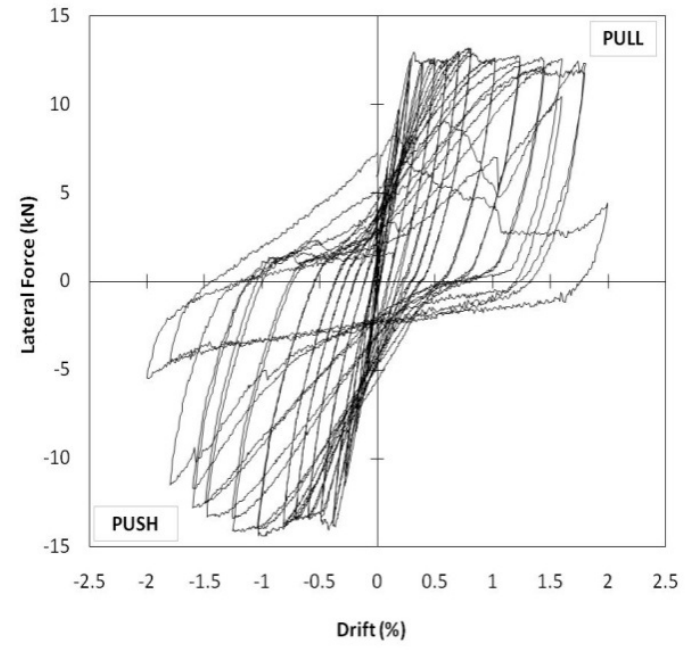

W4

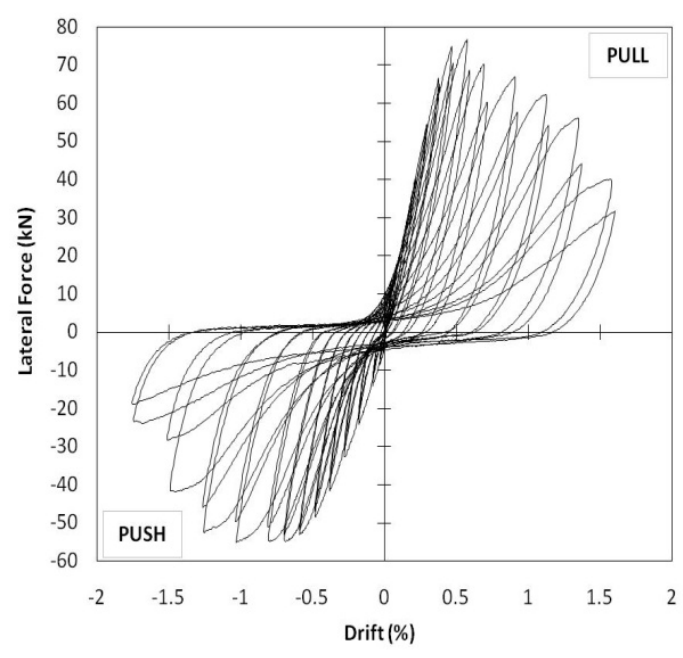

W5-Phase II

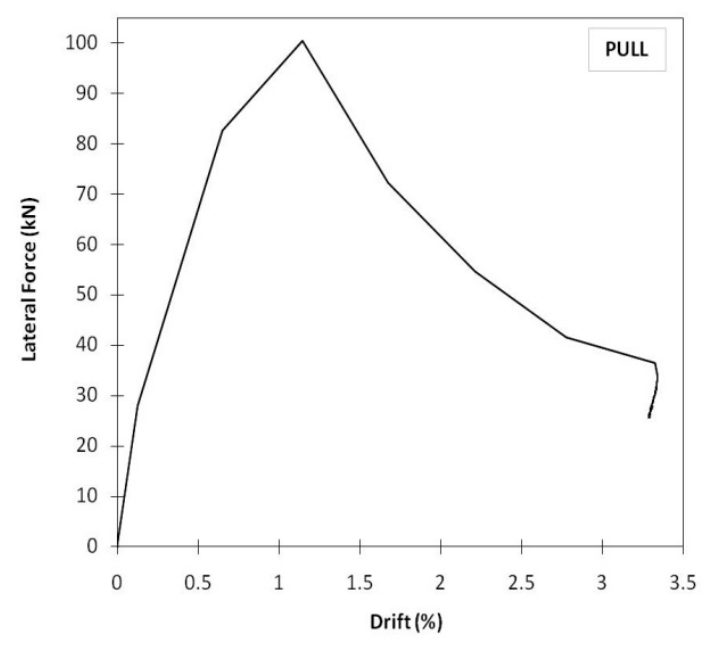

W5-Phase I

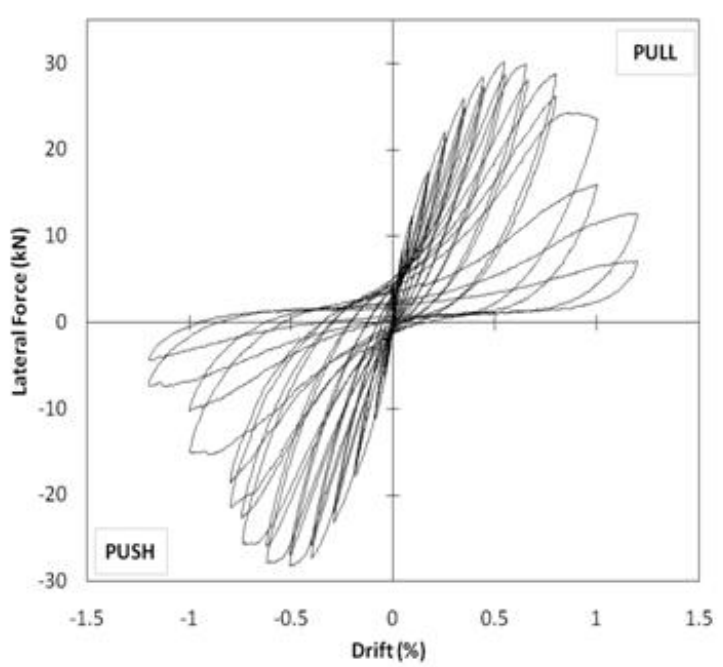

W6

Figure 7-1: Force displacement curves from tests

Table 7-1 Maximum displacement and forces of specimens

\begin{tabular}{ccccccccc} 
Specimen ID & $\begin{array}{c}\text { Maximum } \\
\text { Lateral } \\
\text { Resistance } \\
(\mathrm{kN})\end{array}$ & $\begin{array}{c}\text { Displacement } \\
\text { corresponding } \\
\text { to Maximum } \\
\text { Resistance } \\
(\mathrm{mm})\end{array}$ & $\begin{array}{c}\text { Maximum } \\
\text { Recorded Lateral } \\
\text { Displacement } \\
(\mathrm{mm})\end{array}$ & $\begin{array}{c}\text { Force } \\
\text { corresponding } \\
\text { to Maximum } \\
\text { Displacement } \\
\text { (kN) }\end{array}$ \\
\hline W4 & 13.2 & 14.5 & 14.1 & 22.2 & 35.9 & 35.8 & 4.4 & 5.6 \\
W5- Phase I & 100.5 & -- & 20.7 & -- & 60.2 & -- & 33.6 & - \\
W5-Phase II & 72.7 & 55.1 & 10.2 & 18.2 & 28.6 & 31.8 & 31.9 & 18.9 \\
W6 & 30.2 & 28.2 & 8.8 & 9.83 & 21.6 & 21.4 & 12.6 & 7.2 \\
\hline
\end{tabular}




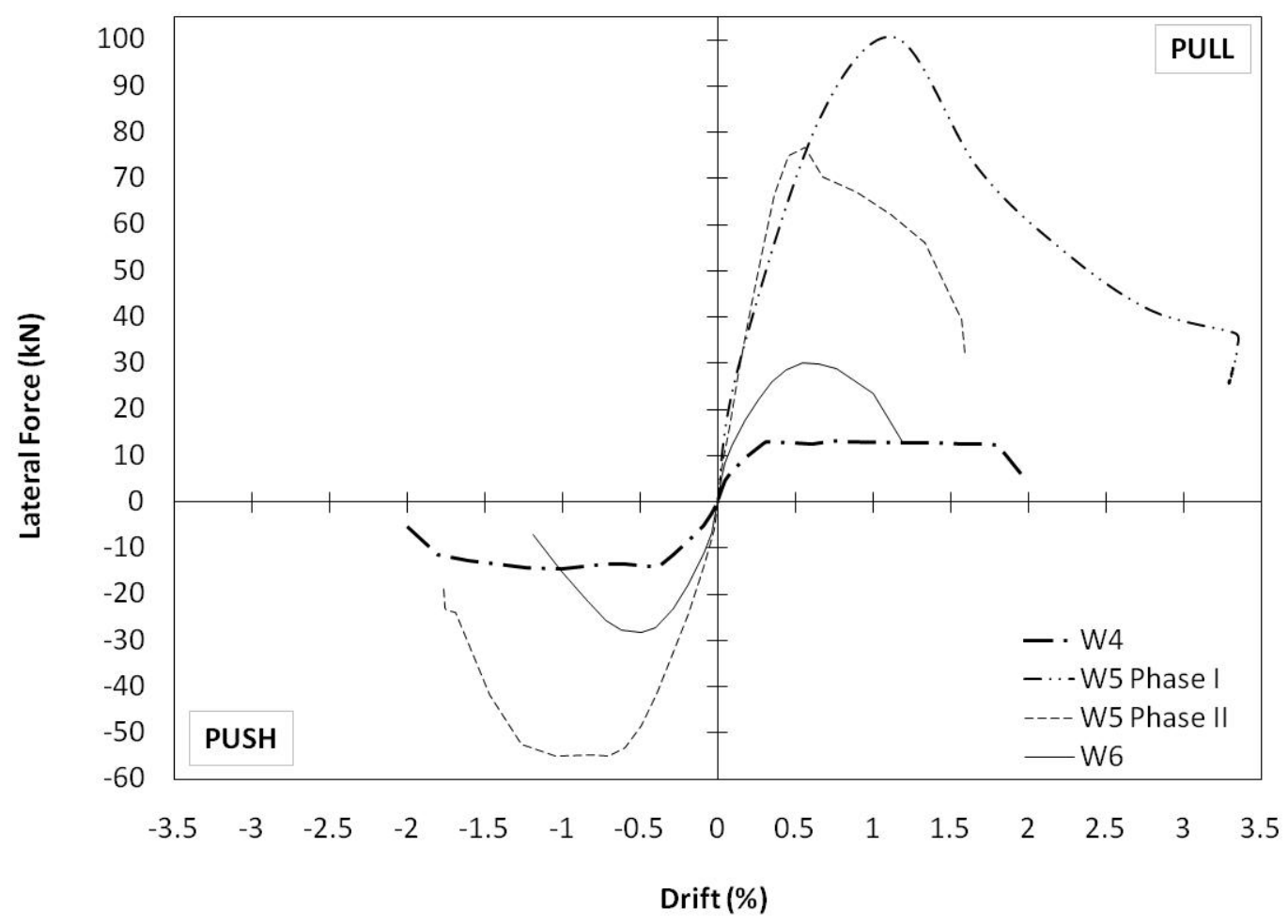

Figure 7-2: Envelopes of the hysteretic curves

\subsection{Hysteretic Enegry Disipation}

Hysteretic energy dissipation of the three walls from this thesis (i.e., W4, W5, and W6) and the flexure-dominant wall from the companion thesis (i.e., W3) were compared in this section. The energy dissipated by each specimen was quantified by the area enclosed by the corresponding hysteretic loops. At each displacement level, the hysteretic loops from the two loading cycles (the primary and secondary cycles) were considered using the trapezoidal integration equation. The cumulative energy dissipated by each specimen is summarized in Figure 7-3 and the total energy dissipation at end of the tests of the considered specimen is presented in Table 7-2. For comparison purpose, 
Figure 7-3 compares the cumulatively dissipated energy normalized by the total energy dissipation of each specimen at the displacement level of interest.

Table 7-2: Wall Energy Dissipation

\begin{tabular}{cc} 
Specimen ID & $\begin{array}{c}\text { Maximum Energy } \\
\text { Dissipation } \\
(\mathrm{kN}-\mathrm{mm})\end{array}$ \\
\hline $\mathrm{W} 3$ & 10,400 \\
$\mathrm{~W} 4$ & 5,640 \\
W5 & 8,630 \\
W6 & 2,120 \\
\hline " considered from phase II test
\end{tabular}

Total Energy Dissipation

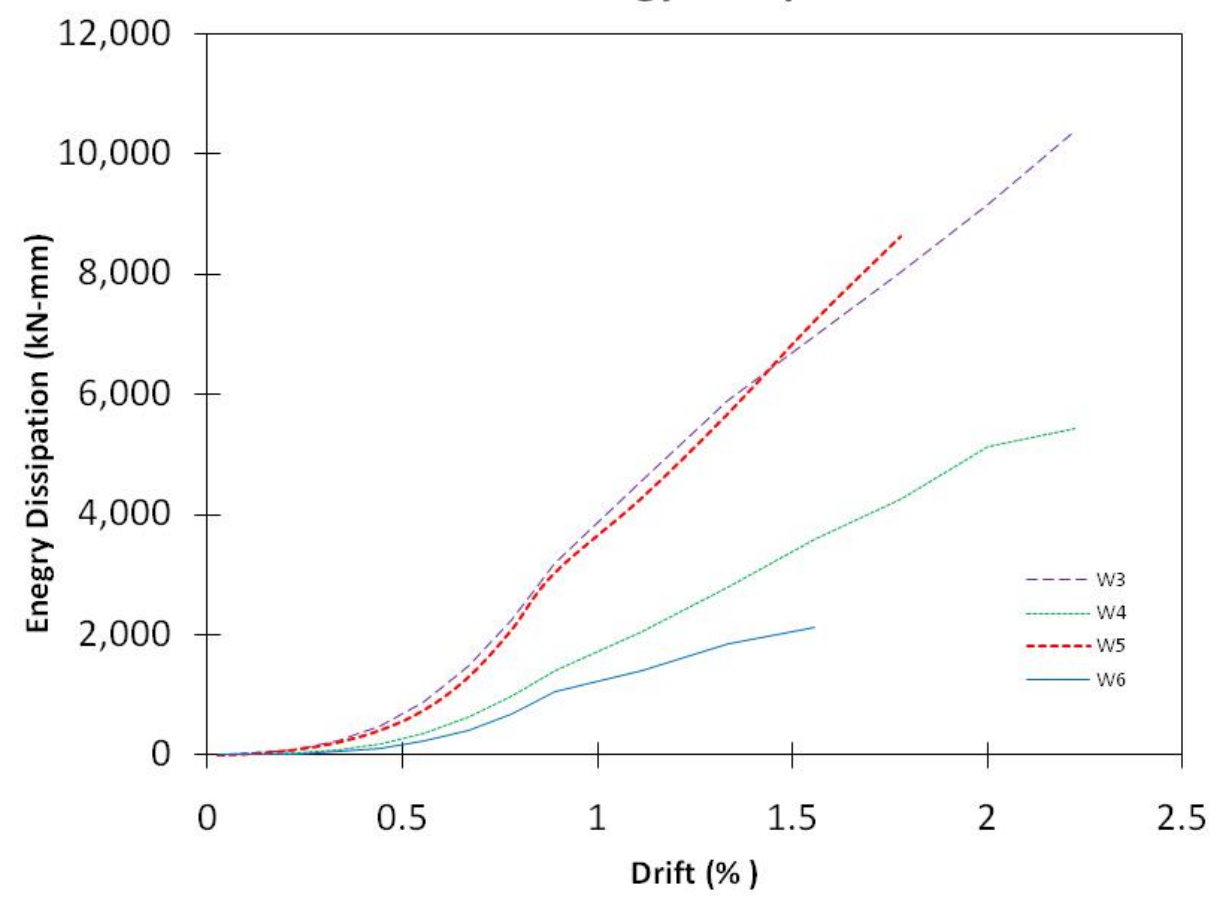

Figure 7-3: Cumulative energy dissipation comparison 

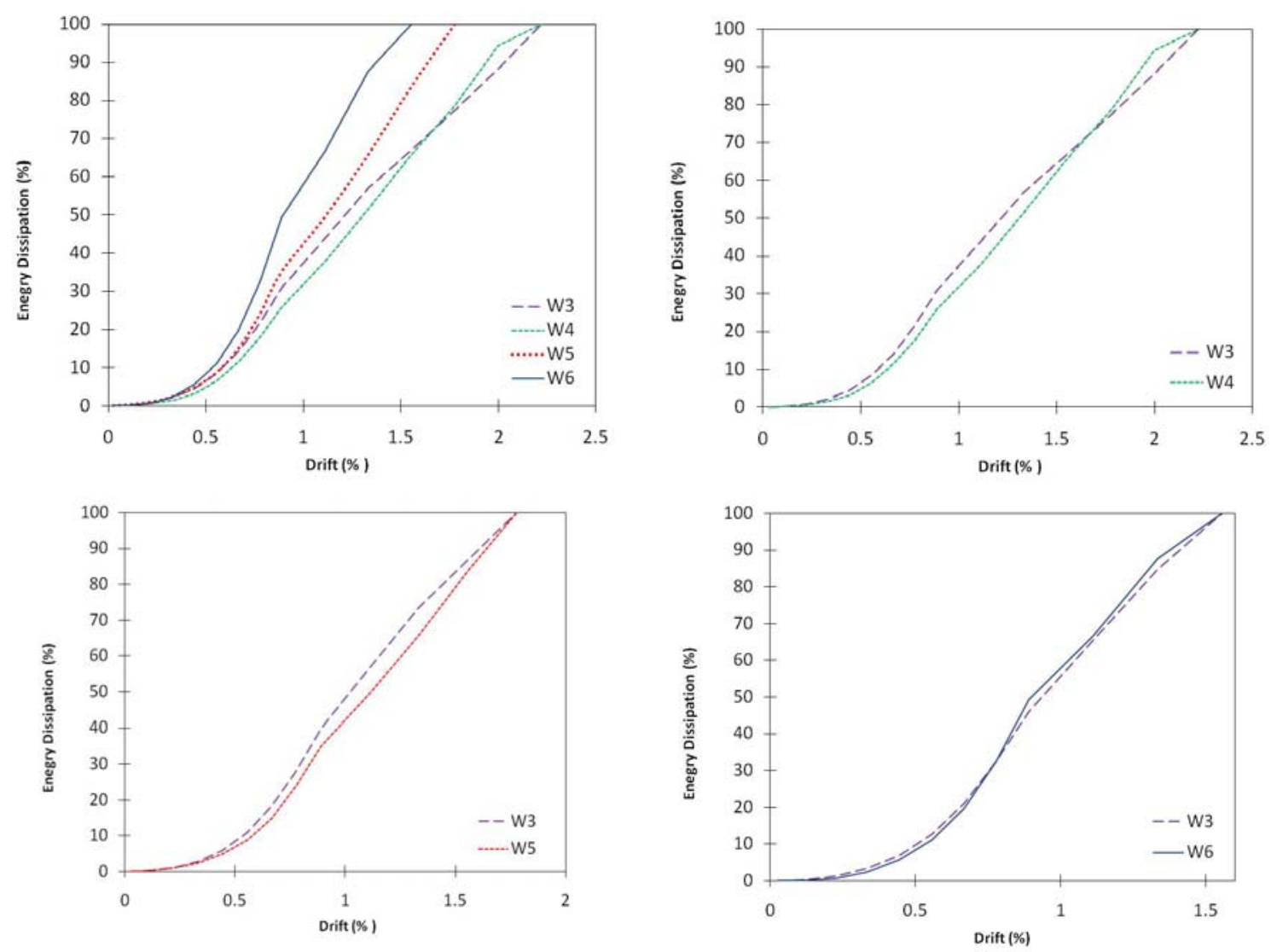

Figure 7-4: Normalized cumulative energy dissipation comparison

\subsubsection{W4 Energy Dissipation}

W3 and W4 were both pushed to a maximum displacement of $40 \mathrm{~mm}$ which

allows for a direct comparison. W4 and W3 have the same height and rebar size; but the depth of W4 is only half of that of W3, indicating that more energy would be dissipated by W3 due to its relatively larger cross-section. The comparison presented in Figure 7-4 further confirms this point. As shown, the energy dissipation of W3 is approximately two times greater than W4. However, when comparing the normalized cumulatively dissipated energy, one can observe that W3 and W4 exhibited similar performance as 
shown in Figure 7-4 indicating that, while W3 and W4 have different aspect ratios, they both exhibited the same energy dissipation performance.

\subsubsection{W5 Energy Dissipation}

W5 shares the same in-plane dimension as W3, with a two block wide flange on one end of the wall. W5 was tested to two cycles less than W3 which only allows percycle energy dissipation comparison up to the drift of $1.78 \%$. From the Figure 7-4, it can be observed that W5 dissipation of is not quite as stable as that of W3. In each cycle W5 dissipates a lower percentage of its total energy earlier, until the last cycle.

\subsubsection{W6 Energy Dissipation}

W6 was designed with the same outer dimension as W3, with a 0.9 by 0.9 meter opening in the center, but was only tested to a lower drift level, which only allows a per cycle comparison available up to the drift of $1.55 \%$. Due to the reduced cross-section of W6, it only exhibited 30 percent of the total energy dissipated by W3 at the maximum

displacement. A per cycle comparison shows that walls with openings are slightly less stable in dissipating energy at the larger displacement levels, but show a similar overall performance up to the drift of $1.55 \%$.

\subsection{Ductility}

Ductility, in seismic design, is a structure's ability to undergo larger amplitude deformations in the inelastic range without a substantial reduction in strength. For the purposes of this thesis, ductility will be defined as the ratio of the maximum deformation of the structure to the deformation at the structure's yield point. Here the maximum deformation is defined as the point at which the structure experiences a 20 percent 
reduction in strength on the envelop curves shown in Figure 7-2. The yield displacement of the structure is defined as the location of equal energy absorption of the equivalent elasto-plastic system and the real system (Park, 1989), as shown in Figure 7-5. The ductility results for all of the walls are summarized in Table 7-3.

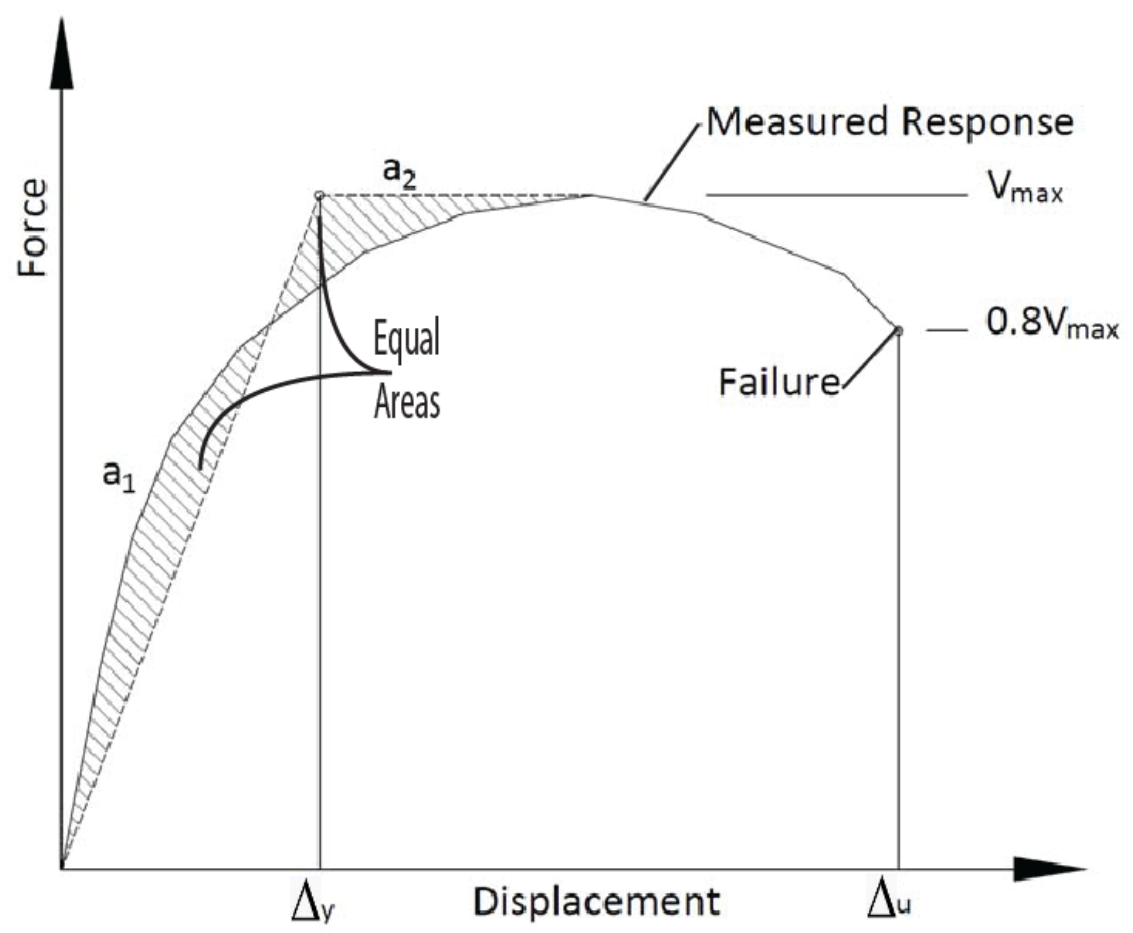

Figure 7-5: ductility criteria (Bland, 2011)

Table 7-3: Ductility Comparison

\begin{tabular}{cccccc} 
Specimen & Direction & $\Delta_{\mathrm{u}}$ & $\Delta_{\mathrm{y}}$ & $\mu$ & $\mu_{\mathrm{avg}}$ \\
\hline \multirow{2}{*}{ W3 } & Pull & 22.47 & 8.24 & 2.72 & \multirow{2}{*}{2.63} \\
& Push & -28.33 & -11.00 & 2.54 & \\
W4 & Pull & 33.21 & 4.63 & 7.17 & \multirow{2}{*}{6.06} \\
& Push & -32.34 & -6.05 & 4.96 & \\
W5 & Pull & 20.08 & 7.75 & 2.60 & \multirow{2}{*}{ N/A } \\
& Push & -26.36 & -8.48 & 3.10 & \\
W6 & Pull & 17.52 & 6.10 & 2.87 & \multirow{2}{*}{2.73} \\
& Push & -14.53 & -5.63 & 2.58 & \\
\hline
\end{tabular}


Comparing the ductility of W3 and W4, it is observed that the ductility of a 2:1 aspect ratio shear wall is approximately two and one third times that of a $1: 1$ aspect ratio shear wall with the same reinforcing pattern. In addition, based on the ductility results of $\mathrm{W} 3$ and $\mathrm{W} 5$, it is found that a flanged wall has roughly the same ductility with the flange in tension and $20 \%$ more with the flange in compression compared to the same wall without a flange. It is noted that Shedid et al. (2010) reported that $43 \%$ to $106 \%$ increases in ductility can be expected by the addition of a flange. A portion of the underestimate in ductility observed in W5 can be attributed to the initial shift in Phase I test of W5. Last, results from W3 and W6 indicate that a wall which has an opening in the center and is ensured to exhibit flexure-dominant behavior, has approximately the same ductility as same wall without opening.

\subsection{Wall Displacements}

Wall displacement components were calculated based on the recorded measurements taken during the shear walls tests. Sections 7.4.1 through 7.4.3 compare the decoupled deformation components that include sliding, shearing, rocking, bending, and overall end deformations of the wall at the peak drift of each cycle. The end deformations were directly recorded from the DTRs at the top and midpoint of each specimen. Sliding deformations were calculated as the sum of the three LVDT's measuring slip between the top of the wall and the loading beam, between the bottom of the wall and the footing, and between the footing and the strong floor. Rocking deformations were derived from the two uplift LVDTs on either side of the wall using the following equation (Bland, 2011): 


$$
u_{r}=\frac{\delta_{r 1}-\delta_{r 2}}{L_{w}+2 l_{s}} \cdot h_{e}
$$

where $\delta_{\mathrm{r} 1}$ and $\delta_{\mathrm{r} 2}$ came from the 0.5 " LVDT A and 0.5 " LVDT B respectively; $L_{\mathrm{w}}$ and and $h_{\mathrm{e}}$ are the length and height of the wall, respectively; and $l_{\mathrm{s}}$ is the distance from the LVDT to the near side of the wall.

For a given displacement component of the wall, the rocking deformation was calculated based on the rotation between the two transducers multiplied by the height, as shown in Figure 7-6.
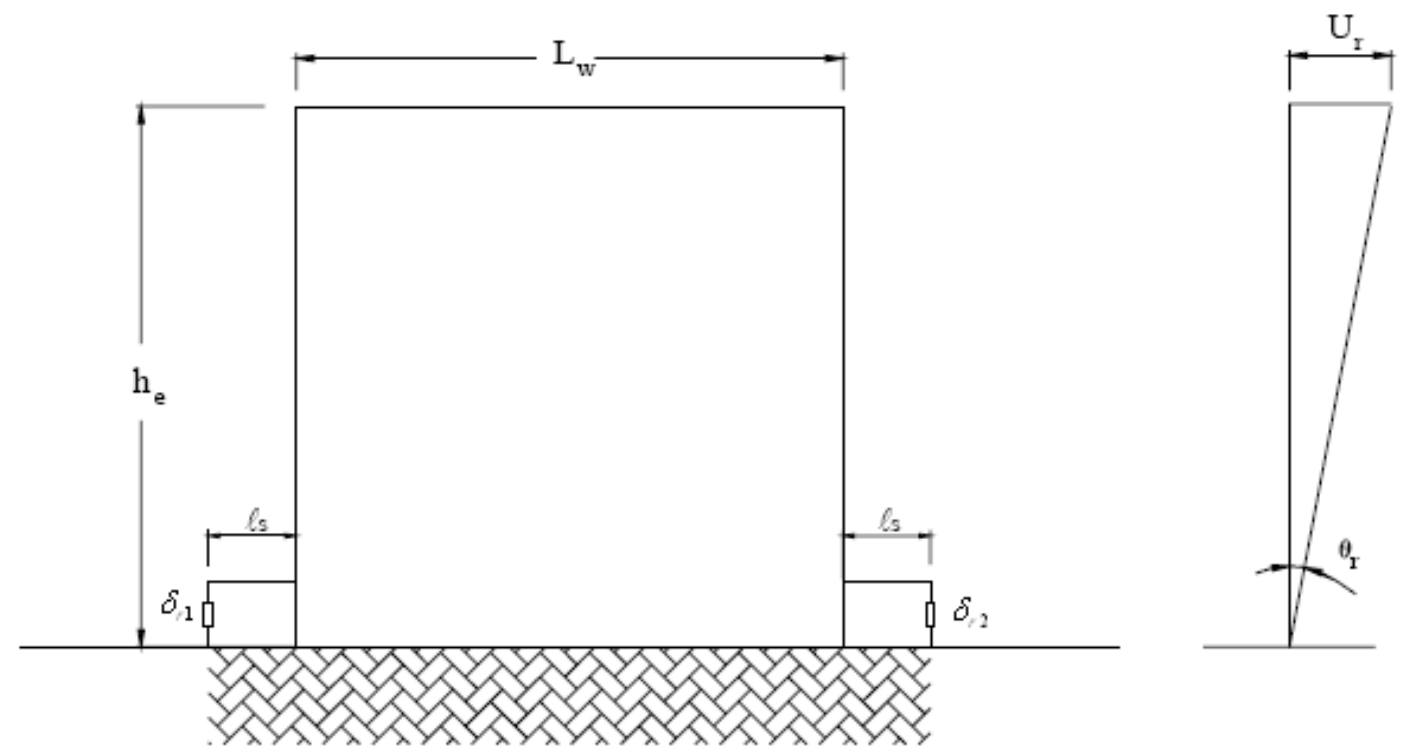

Figure 7-6: Arrangement for rocking deformation instruments (from Voon, 2007)

The shear and bending displacements were calculated based on the extension and contraction of the DTRs and LPOTs. According to Bland (2011) the shear and bending deformation components, $u_{\mathrm{s}}$ and $u_{\mathrm{b}}$, respectively are: 


$$
\begin{aligned}
& u_{s}=\frac{d\left(\delta_{d 1}-\delta_{d 2}\right)}{2 L}-\frac{h^{2}}{6\left(2 d_{u}+h\right)} \frac{\left(\delta_{v 1}-\delta_{v 2}\right)}{L} \\
& u_{b}=\frac{\left(\delta_{v 1}-\delta_{v 2}\right)}{L}-\left(h \frac{d_{u}+\frac{2 h}{3}}{2 d_{u}+h}+d_{u}\right)
\end{aligned}
$$

where $\delta_{\mathrm{v} 1}$ and $\delta_{\mathrm{v} 2}$ represent vertical transducer measurements, $\delta_{\mathrm{d} 1}$ and $\delta_{\mathrm{d} 2}$ represent diagonal transducer measurements, $d_{\mathrm{u}}$ represents the distance from the top of the wall to the top of the instruments measuring shear and bending deformations, $h$ represents the specimen height, $L$ is the specimen length, and $d$ is the diagonal distance. Figure 7-6 illustrates the arrangement the measurements. More detailed derivations for these equations can be found in the companion thesis (Bland, 2011).

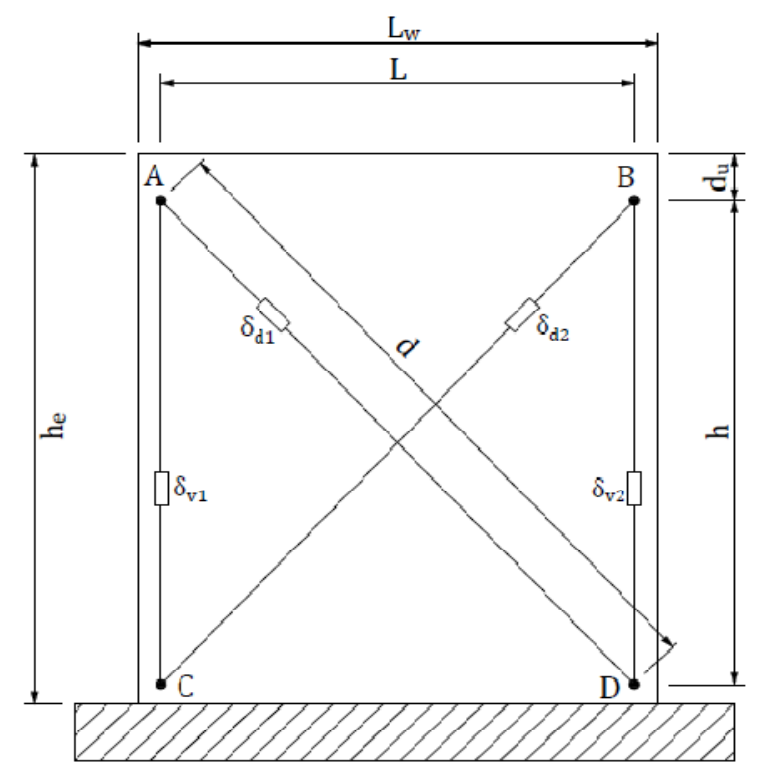

Figure 7-7: Arrangement for shear deformation instruments (from Voon, 2007) 


\subsubsection{W4}

As shown in Figure 7-8, the flexural deformation is larger than the shear deformation at lower displacement levels, indicating the behavior of the wall is flexuredominant. With the increase of lateral displacement, the shear deformations become more predominate, corresponding to the sliding shear observed in the experiment. It is also evident that rocking and sliding of the wall contributed substantially to the overall deformation of the wall at the higher displacement levels. Displacement at the midpoint end of the wall remains approximately half of that at the top end of the wall. This suggests that no severe damage has occurred from the midpoint of the wall to the top which is consistent with the visual observations taken during the test.
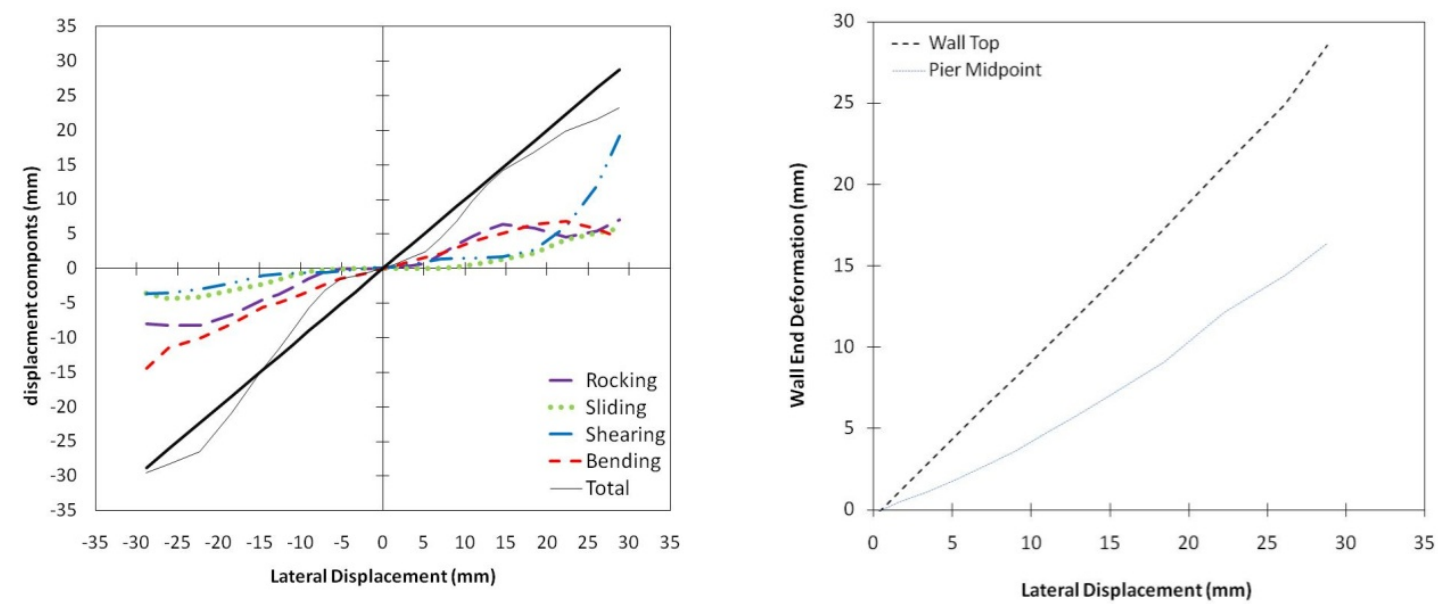

Figure 7-8: W4 deformation components

\subsubsection{W5}

The displacement components of W5 are shown in Figure 7-9, and the lengths over which they are measured are summed shown in Table 7-4. Results indicate that the specimen experienced significant shear deformation which may be due to the 
imperfection of the wall caused by the W5-Phase I test, the contribution of the flange, or a combination of the two. As described in Chapter 6, the premature failure of the wall in the Phase I test loosened many of the blocks which increased the potential for sliding shear, making the wall more likely to slide than bend. In addition, results for the flexural deformation show that the wall is more prone to bending in the push direction, with the flange in compression, than in the pull direction, with the flange in tension. From the lateral deformation plot it can be observed that 60 percent of the top end lateral deformations occurred at the midpoint of the wall suggesting that the plastic hinge extended up from the bottom of the wall.
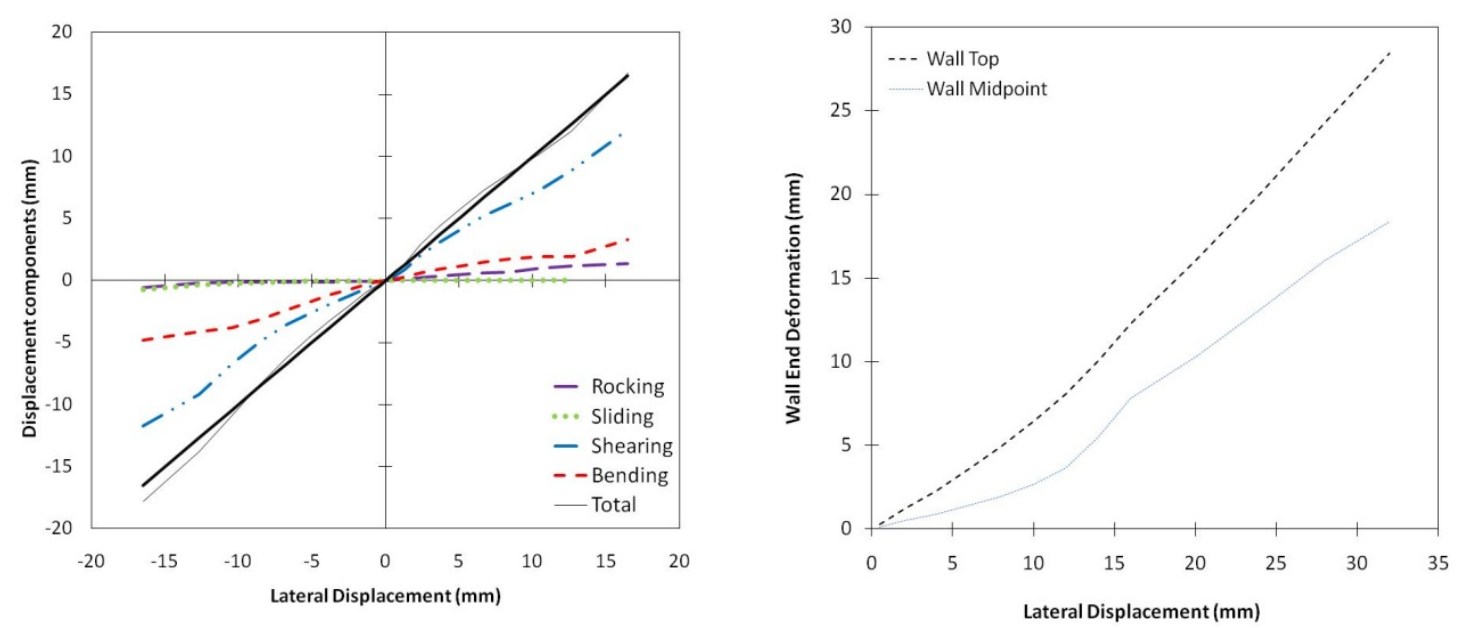

Figure 7-9: W5 deformation components

Table 7-4: Instrument distances for $\mathrm{W} 4$ and $\mathrm{W} 5$ retest

\begin{tabular}{clcc} 
& & $\begin{array}{c}\text { W4 } \\
(\mathrm{mm})\end{array}$ & $\begin{array}{c}\text { W5 retest } \\
(\mathrm{mm})\end{array}$ \\
\hline Instrumented Height & $(h)$ & 800 & 1200 \\
Instrumented Length & $(L)$ & 600 & 1500 \\
Wall Height & $\left(h_{\mathrm{w}}\right)$ & 1800 & 1800 \\
Wall Length & $\left(L_{\mathrm{w}}\right)$ & 900 & 1800 \\
$\begin{array}{c}\text { Distance from top of } \\
\text { wall to instruments }\end{array}$ & $\left(d_{\mathrm{u}}\right)$ & 90 & 550 \\
Diagonal Distance & $(d)$ & 950 & 1920 \\
\hline
\end{tabular}




\subsubsection{W6}

The displacement component of W6 were measured in three different sections, as shown in Table 7-5 and Figure 7-11, then summed together to give the overall displacements, shown in Figure 7-10. From Figure 7-10, it can be observed that in both the push and pull directions the shear and bending deformation components are approximately the same. From the lateral deformation plot, it can be observed that approximately half of the wall top deformation was present at the top of the pier.
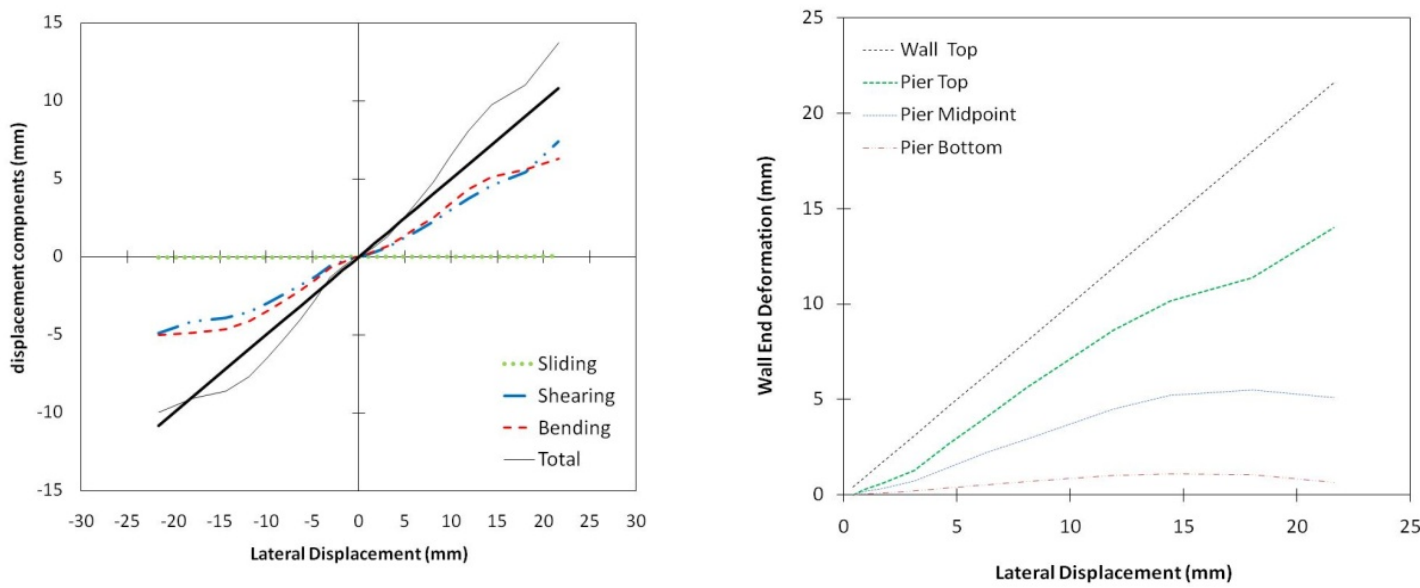

Figure 7-10: W6 deformation components

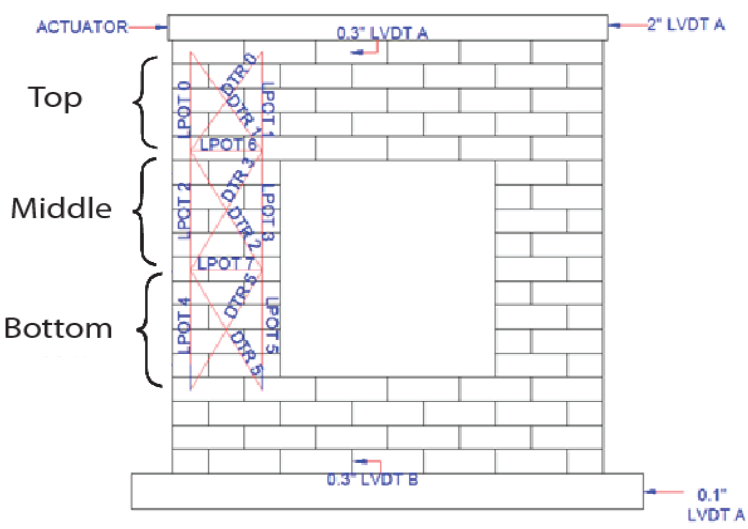

Figure 7-11: W6 shear and bending instrumentation 132 
Table 7-5: Instrument distances for W6

\begin{tabular}{llcccc}
\multicolumn{1}{c}{ Wall 6 } & & $\begin{array}{c}\text { Top } \\
(\mathrm{mm})\end{array}$ & $\begin{array}{c}\text { Middle } \\
(\mathrm{mm})\end{array}$ & $\begin{array}{c}\text { Bottom } \\
(\mathrm{mm})\end{array}$ & $\begin{array}{c}\text { Total } \\
(\mathrm{mm})\end{array}$ \\
\hline $\begin{array}{l}\text { Instrumented Height } \\
\text { Instrumented Length }\end{array}$ & $(h)$ & 400 & 500 & 500 & 1400 \\
$\begin{array}{l}\text { Distance from top of } \\
\text { wall to instruments }\end{array}$ & $\left(d_{\mathrm{u}}\right)$ & 317 & 317 & 317 & 951 \\
Diagonal Distance & $(d)$ & 50 & 0 & 0 & 50 \\
\hline
\end{tabular}

\subsection{Plastic Moment Resistance and Lateral Strength of Specimens}

While each specimen experienced various types of combined failures, including local shear failures, sliding failures, and local crushing failures observed during the tests, all the specimens primarily exhibited flexure dominant behaviors which they were designed for.

The plastic flexure resistance of the cantilever specimens can be derived using the procedure for calculation of the ultimate resistance of reinforced concrete cross-sections, which assumes plane section and strain compatibility, as shown in Figure 7-12. Although this principal relationship is generic, several factors are code based. ACI 530 assumes a uniform distribution of the compression forces resisted by the masonry over a zone where the length is the product of an alpha factor $(\alpha)$ and the distance from the extremely outer masonry fiber to the neutral axis (c). The magnitude of the uniformly distributed compression force is equal to the product of the masonry compressive strength and a beta factor $(\beta)$. ACI 530 defines both $\alpha$ and $\beta$ factors as 0.8 for the masonry compressive block. The tensile force in each steel rebar can be determined by the following equation

$$
f_{\mathrm{si}}=A_{\mathrm{s}} E_{\mathrm{s}} \varepsilon_{\mathrm{si}} \leq A_{\mathrm{s}} f_{\mathrm{y}}
$$


where $A_{\mathrm{s}}$ is the area of the rebar, $E_{\mathrm{s}}$ the modulus of elasticity of steel, and $\varepsilon_{\mathrm{si}}$ is the maximum allowable strain in steel.

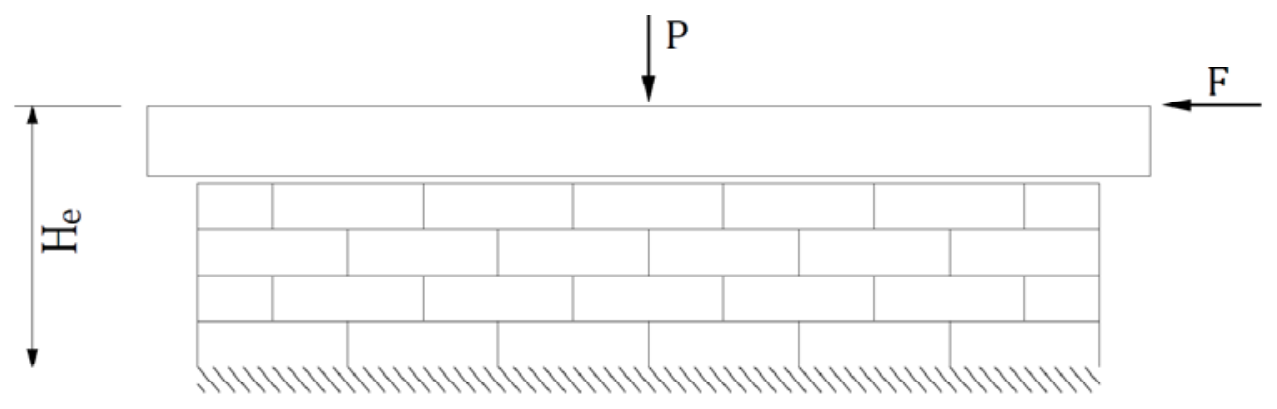

(a) Wall

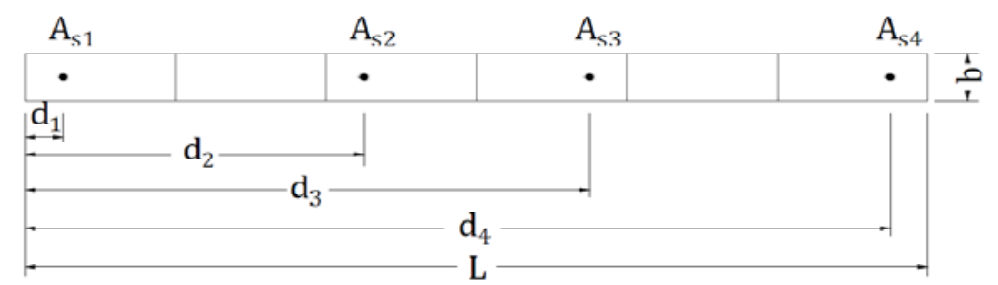

(b) Wall cross-section
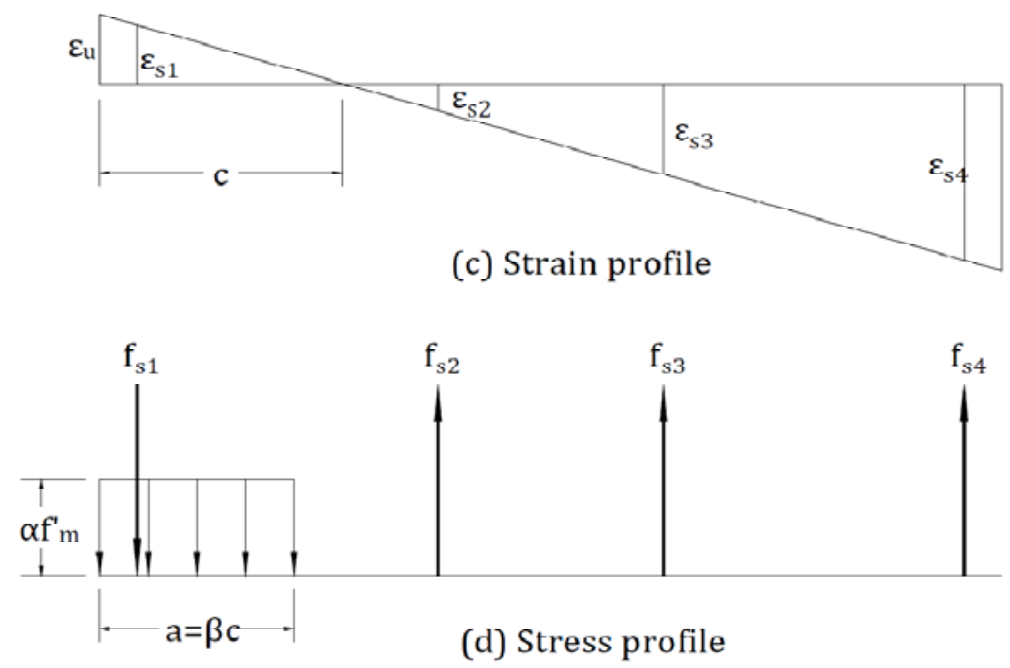

Figure 7-12: Idealized normal stress and strain relations (Bland, 2011)

The equation which defining the plastic moment capacity of the wall, derived from Figure 7-12 with moments taken about the neutral axis of the wall, is: 


$$
M_{p}=C_{m}\left(c-\frac{a}{2}\right)+\sum_{i}^{n} C_{s i}\left(c-d_{i}\right)+\sum_{i}^{n} T_{s i}\left(d_{i}-c\right)+P\left(\frac{L}{2}-c\right)
$$

where $P$ is the applied vertical load, $c$ is the distance from the neutral axis to the extreme outer compression fiber, $L$ represents the length of the wall, and $d_{i}$ is the distance from neutral axis to each respective rebar. $T_{\mathrm{si}}$ and $C_{\mathrm{si}}$ are the compressive and tensile forces in the vertical rebar as determined by strain compatibility, and $C_{\mathrm{m}}$ is the resultant force resisted from the masonry blocks under compression. $T_{\mathrm{si}}$ and $C_{\mathrm{si}}$ are determined by Equation (7-6) and $\mathrm{C}_{\mathrm{m}}$ is determined by Equation (7-7), respectively:

$$
\left\{\begin{array}{l}
T_{s i}=A_{s} f_{s i} \\
C_{s i}=A_{s} f_{s i}
\end{array}\right.
$$

where $\mathrm{A}_{s}$ is the area of a steel bar, $\mathrm{f}_{\mathrm{si}}$ represents the tensile or compression stress in the steel bar and it can be determined based on Equation (7-4) and strain compatibility, following the provisions set forth by ACI-530.

$$
C_{m}=\alpha f^{\prime}{ }_{m} a b=0.8 f^{\prime}{ }_{m}(0.8 c) b=0.64 f^{\prime}{ }_{m} c b
$$

where $a$ is the depth of the compressive block, taken as 0.8 times $c ; f^{\prime}{ }_{m}$ is the compressive strength of the masonry; $\alpha$ is a factor used to convert a nonuniform stress distribution into an equivalent uniform stress, taken as 0.8 according to ACI 530-08; and $b$ is the width of the wall.

For a cantilever structure such as W4 and W5, the lateral force resistance $(F)$ can be found by dividing the plastic moment resistance of the specimen $\left(M_{\mathrm{p}}\right)$, determined from Equation (7-5), by the specimen height $\left(H_{\mathrm{e}}\right)$, as shown by equation

$$
F=\frac{M_{p}}{H_{e}}
$$


For W6, the specimen lateral force resistance can be obtained from the virtual work equation which equating the internal work done by the cross-section plastic moment and the external work done by the lateral load as shown in Equation (7-9)

$$
\sum M_{p i} \cdot \theta=H \cdot \theta \cdot V_{e q}
$$

where $M_{\mathrm{pi}}$ is the plastic moment of the specimen, $H$ is the height of the piers, $V_{\mathrm{eq}}$ is the lateral force at the top of the wall, and $\theta$ is the rotation of each at the location of the plastic moment, as shown in Figure 7-13.

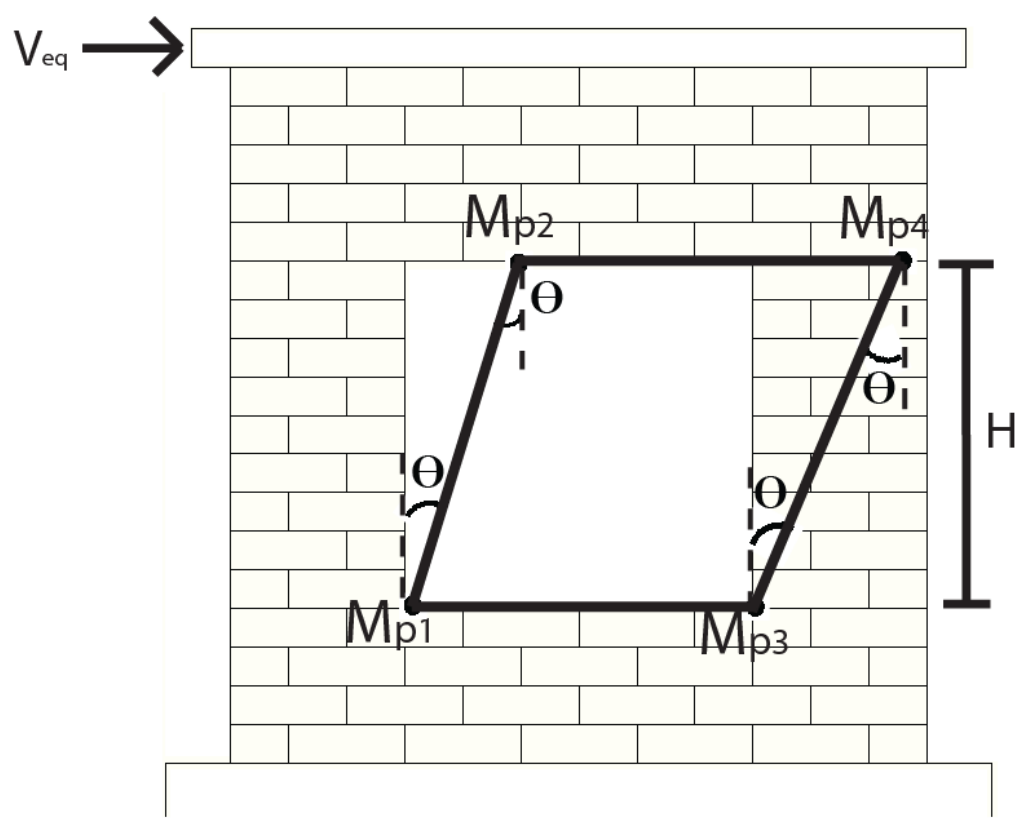

Figure 7-13: Lateral force resistance determination for W6

Figure 7-14 compares the predictions from Equations (7-6) and (7-7) to the testing results. It is recognized that the one of the important parameters controlling lateral strength of the specimens is the rebar yielding strength. The rebar yield strength, obtained from the rebar tests (360 MPa on average, see Appendix A for details) is higher than the 136 
value assumed in specimen design (i.e. $276 \mathrm{MPa}$ ). As such, the actual strength is used for specimen strength calculation. As shown in Figure 7-14, reasonable agreements were observed in W4 and W5.
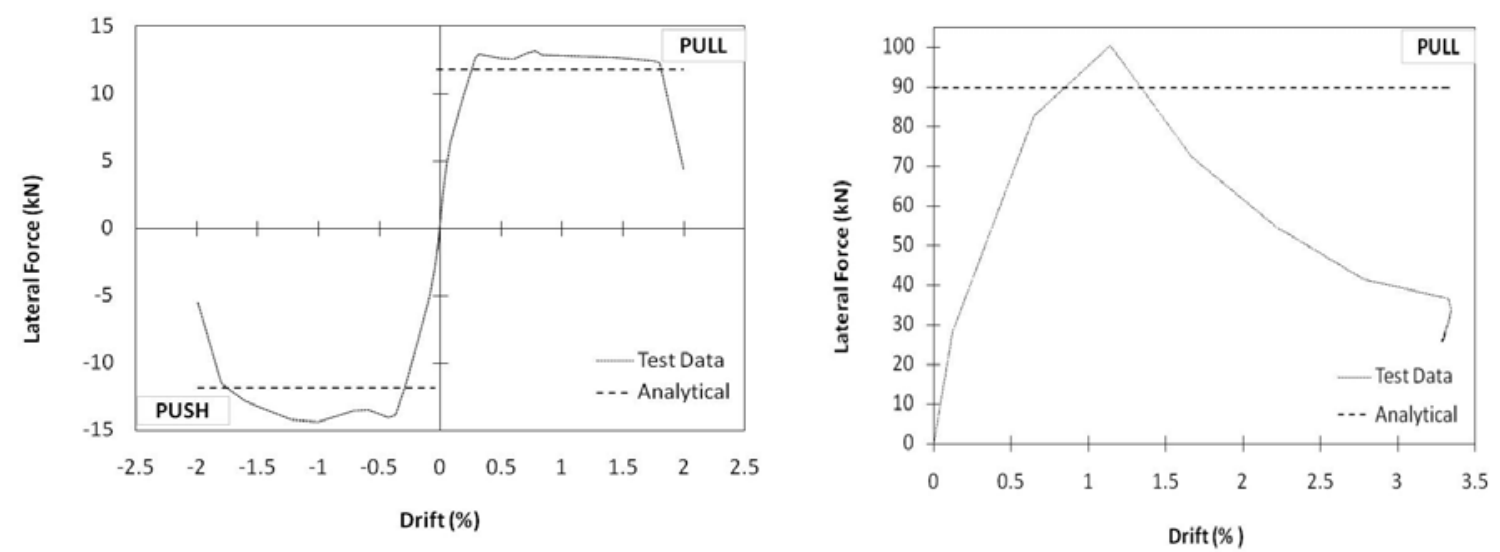

W4

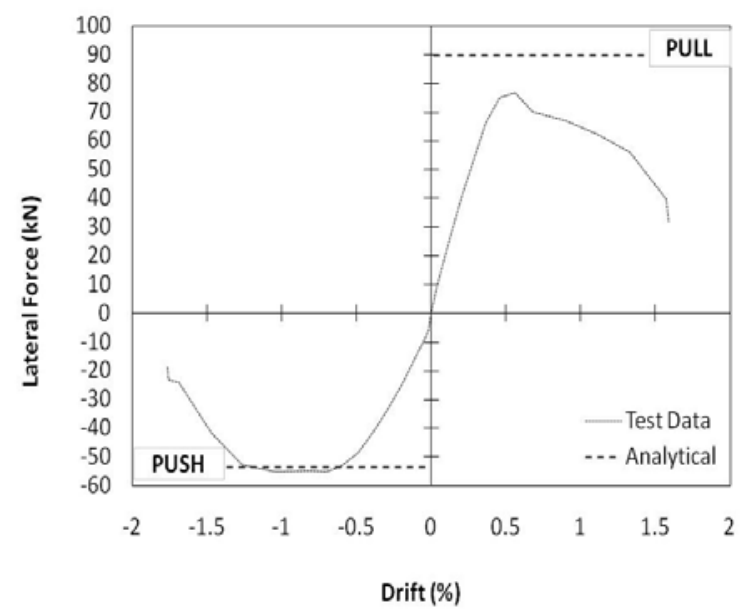

W5- Phase I

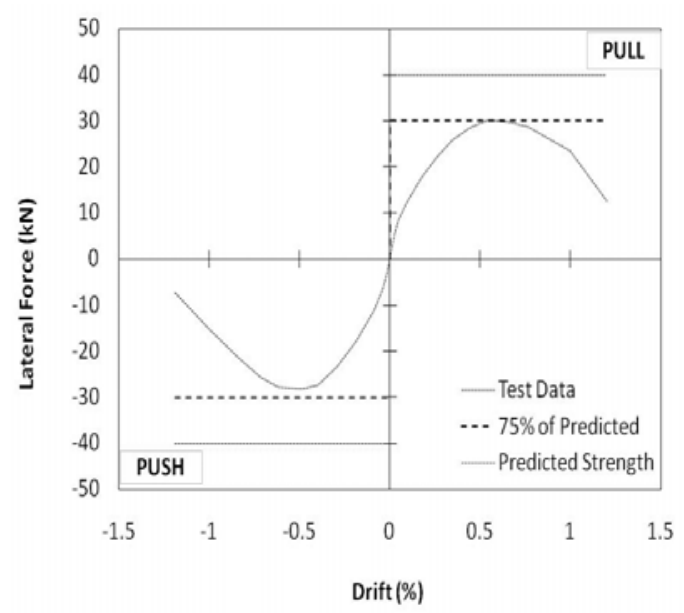

W5- Phase II

W6

Figure 7-14: Lateral force resistance comparisons: Analytical vs. Testing Data

Different from W4 and W5 in which inelastic behavior concentrated at the base of the specimens, W6 had inelastic behavior at each end of the piers. According to equation (7-7), the lateral strength of W6 depends on the number of plastic hinges and strength of these hinges. Ideally, four plastic hinges with $100 \%$ of their nominal strength should form at the ends of the piers. However, for many reasons, such as loss of the hinge moment resistance due to local failures; incomplete development of the plastic moment resistance 
of plastic hinges; increased effective height of the piers; which is used in the calculation of the system lateral resistance; insufficient development length of the rebars in grouted ICEBs, a reduced system strength may be observed. As such, both $100 \%$ and $75 \%$ of the predicted strength from Equation (7-9) were included in Figure 7-14 for comparison purpose.

\subsection{Nonlinear Static Analyses}

In order to check the possibility of incorporating the ultimate strength calculation for ICEB walls into existing structural analysis computer program and further confirm the adequacy of the procedure presented in the previous section, which assumes flexuredominant wall behavior, nonlinear static analyses (also known as pushover analyses) were conducted in SAP 2000.

In the developed models, inelastic behavior of the specimen was captured using a group of frame elements representing the masonry fibers or reinforcing rebars at certain predetermined plastic hinge locations, i.e., modeling the walls with consideration of lumped plasticity. For simplicity, both masonry and steel were modeled as elastic-

perfectly-plastic materials. Compression-only and tension-only properties were assigned to masonry and reinforcing rebars, respectively. To achieve such material properties, each fiber were modeled by connecting one elastic member with tension or compression limit equal to zero to another inelastic member with plastic deformation concentrating at the midpoint. A visual depiction of each fiber is illustrated in Figure 7-15. It is recognized that the above-mentioned simplified material properties overestimate the stiffness of the specimens; however, they provide reasonable estimates of the specimen ultimate strength as shown in Figure 7-16. In order to focus on the flexural behavior of 
the specimen, the shear forces were assumed to be transferred without causing any inelastic behavior at the plastic hinge locations. For the zones outside the plastic hinge locations, isotropic and elastic material properties were assigned. The cross sectional area and number of fibers used in each model is summarized in Table 7-6.

Results for all specimens are summarized in Figure 7-16. For the reasons explained in section 7.5, results associated with 3 and 4 plastic hinges are both provided for W6. In addition, analytical models considering distributed plasticity were developed in the companion thesis (Bland, 2011). For comparison purpose, results from that model were also included for W3. From all cases compared in Figure 7-16, it is consistently observed that results from the computer models match reasonably well with the testing data, indicating the adequacy of these models for practical application. For completeness, Figure 7-17 was generated to compare the nonlinear static analysis to the plastic analysis. Good agreement was found in the result comparison, as shown in Figure 7-17.

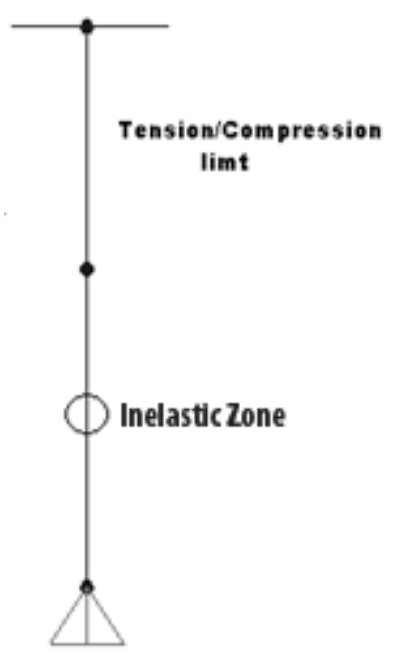

Figure 7-15: Generic Fiber from SAP 2000 model 
Table 7-6: Fiber components of ICEB walls

\begin{tabular}{cccccccc} 
Wall & $\begin{array}{c}\text { Wall } \\
\text { component }\end{array}$ & $\begin{array}{c}\text { Number } \\
\text { of ICEB } \\
\text { fibers }\end{array}$ & $\begin{array}{c}\text { Width of } \\
\text { ICEB fibers } \\
(\mathrm{mm})\end{array}$ & $\begin{array}{c}\text { Depth of } \\
\text { ICEB fibers } \\
(\mathrm{mm})\end{array}$ & $\begin{array}{c}\text { Area each } \\
\text { ICEB } \\
\text { fibers } \\
\left(\mathrm{mm}^{2}\right)\end{array}$ & $\begin{array}{c}\text { Number } \\
\text { of steel } \\
\text { fibers }\end{array}$ & $\begin{array}{c}\text { Area each } \\
\text { steel } \\
\text { fibers } \\
\mathrm{mm}^{2}\end{array}$ \\
\hline W3 & -- & 200 & 9 & 150 & 1350 & 4 & 71 \\
W4 & -- & 100 & 9 & 150 & 1350 & 2 & 71 \\
W5 & Web & 275 & 6 & 150 & 900 & 3 & 71 \\
W5 & Flange & 25 & 6 & 450 & 2700 & 1 & 321 \\
W6 & -- & 180 & 10 & 150 & 1500 & 8 & 71 \\
\hline
\end{tabular}




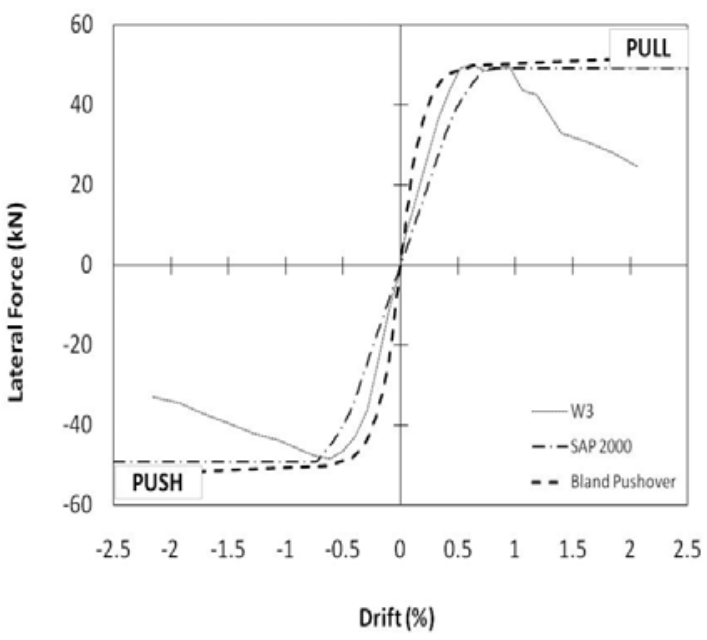

W3

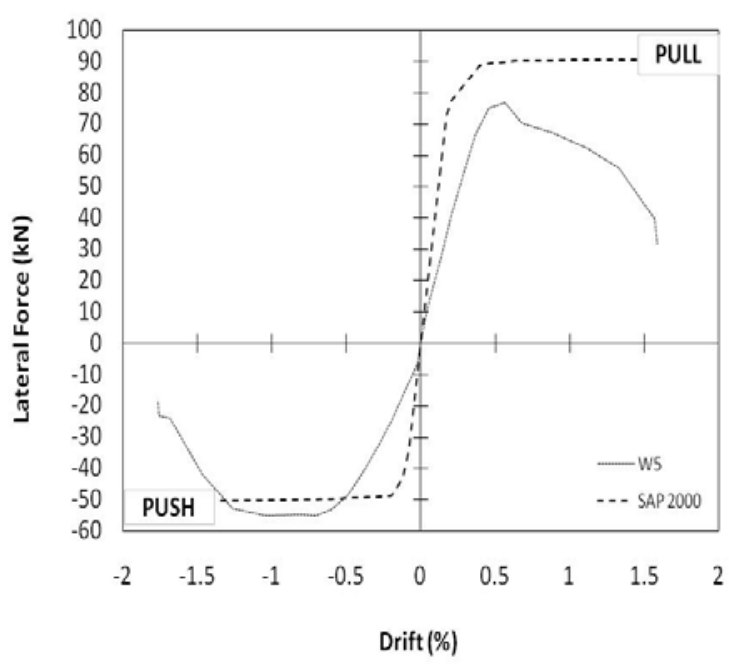

W5- Phase II

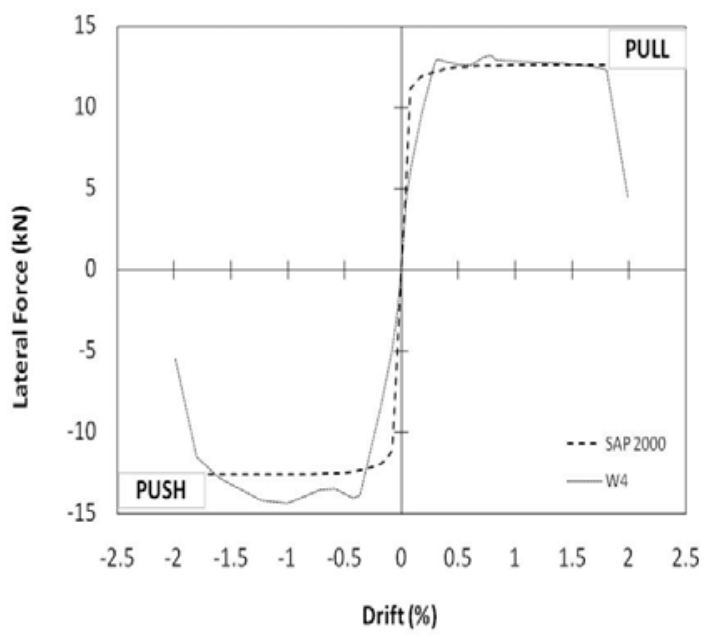

W4

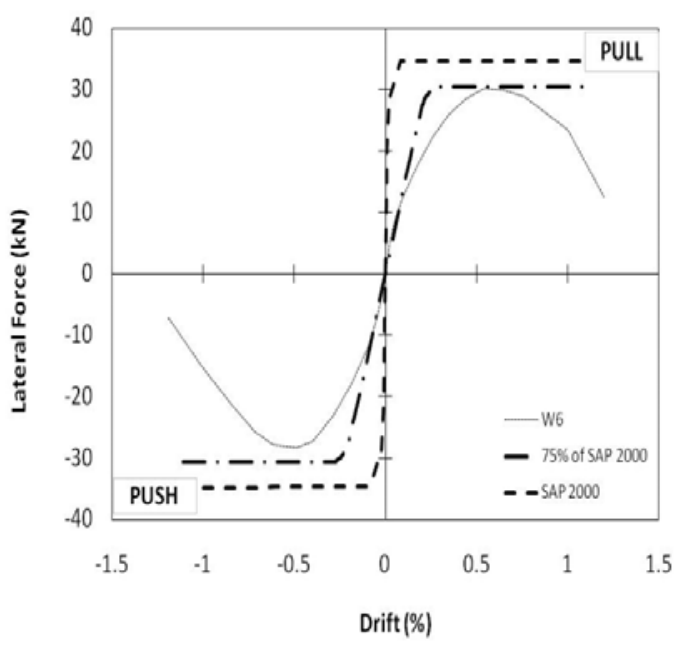

W6

Figure 7-16: Lateral force resistance comparisons: SAP 2000 vs Test Data 


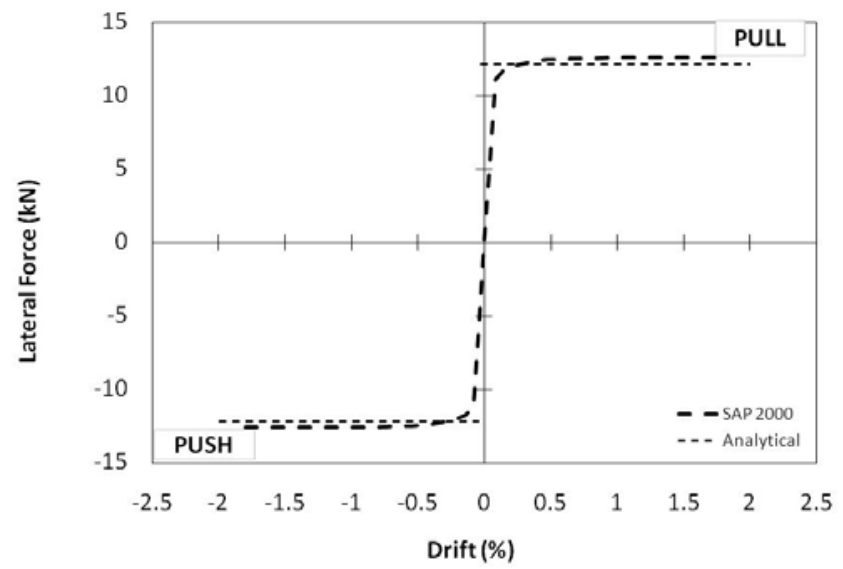

W4

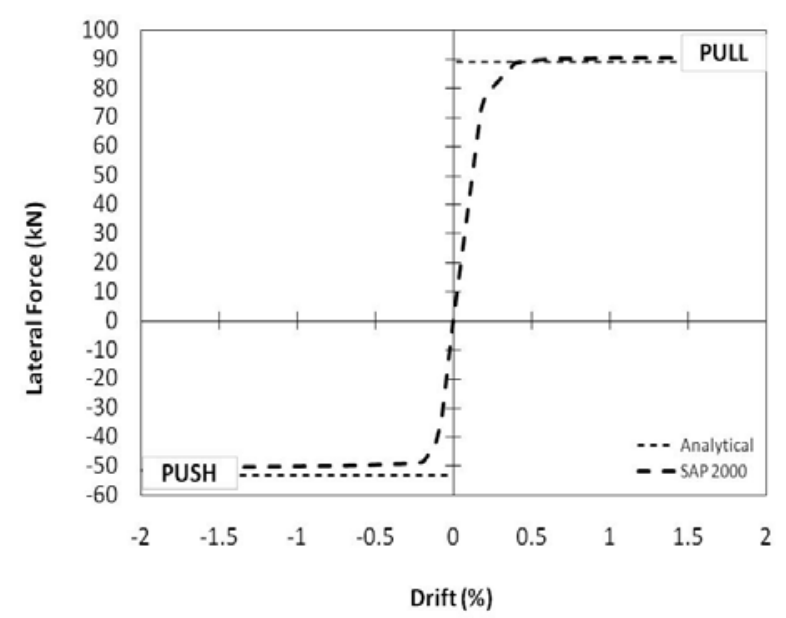

W5

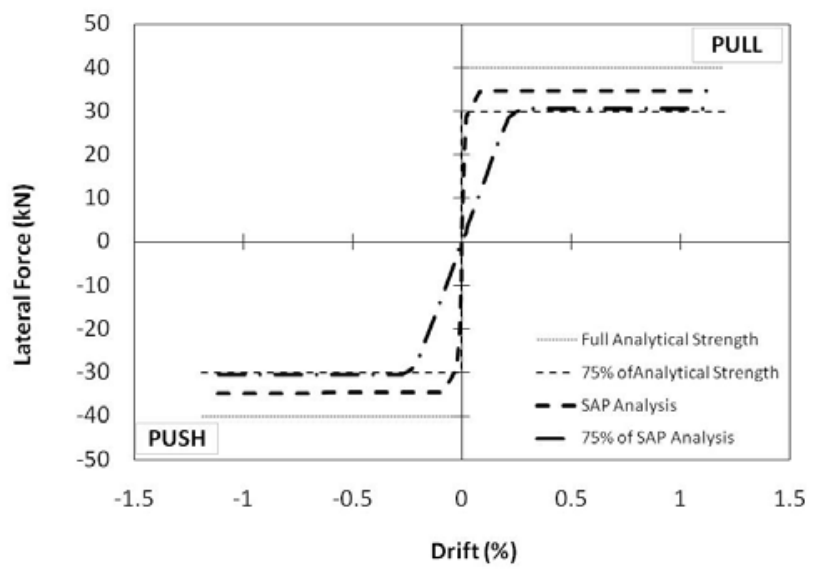

W6

Figure 7-17: Lateral force resistance comparisons: Analytical vs SAP 


\section{SEISMIC PERFORMANCE OF FLEXURE DOMINANT ICEB WALLS}

In order to address the behavior of the flexure dominant walls under earthquake loading, this chapter performed nonlinear time history analysis using the Incremental Dynamic Analysis (IDA) procedure (Vamvatsikos and Cornell, 2002). The following sections summarize the development of the analytical model, description of demonstration buildings, and the results from the analysis.

\subsection{Description and Validation of the Computer Model}

IDARC-2D, commonly referred to as IDARC, is a two dimensional, noncommercial, structural analysis program capable of nonlinear analysis. Created at the State University of New York, Buffalo, IDARC permits both static and dynamic nonlinear analysis (Reinhorn, 2010). This program was used in this thesis for simulating the behavior of ICEB structures.

Considering the scope of this chapter focuses on the flexure dominant wall behavior, W4 was first modeled for validation purpose. Consistent with the actual specimen and testing conditions, W4 was modeled as a cantilever member with distributed plasticity. As discussed in Chapter 3, the masonry behavior is quite similar to that of conventional concrete. The stress-strain curve of unconfined concrete which was modified using the maximum compressive strength from the W4 prism test and the modulus of elasticity identified from the modified Hognestad model, described in section 3.5, was assigned to the masonry in the model. An idealized tri-linear strain-stress relationship with yield strength (410 MPa) and ultimate strength (480 MPa), identified from coupon tests, were assigned to the reinforcing rebars. The general smooth hysteretic model developed by Sivaselvan and Reinhorn (2000) was used in the analysis for 
capturing the deteriorating inelastic behavior of the specimen under unloading and reloading conditions.

The computer model of W4 was analyzed using the same loading protocol used in the shear wall test. Figure 8-1 compares the results from simulation and those from the testing. As shown, reasonable agreement is observed, indicating the adequacy of the developed analytical model.

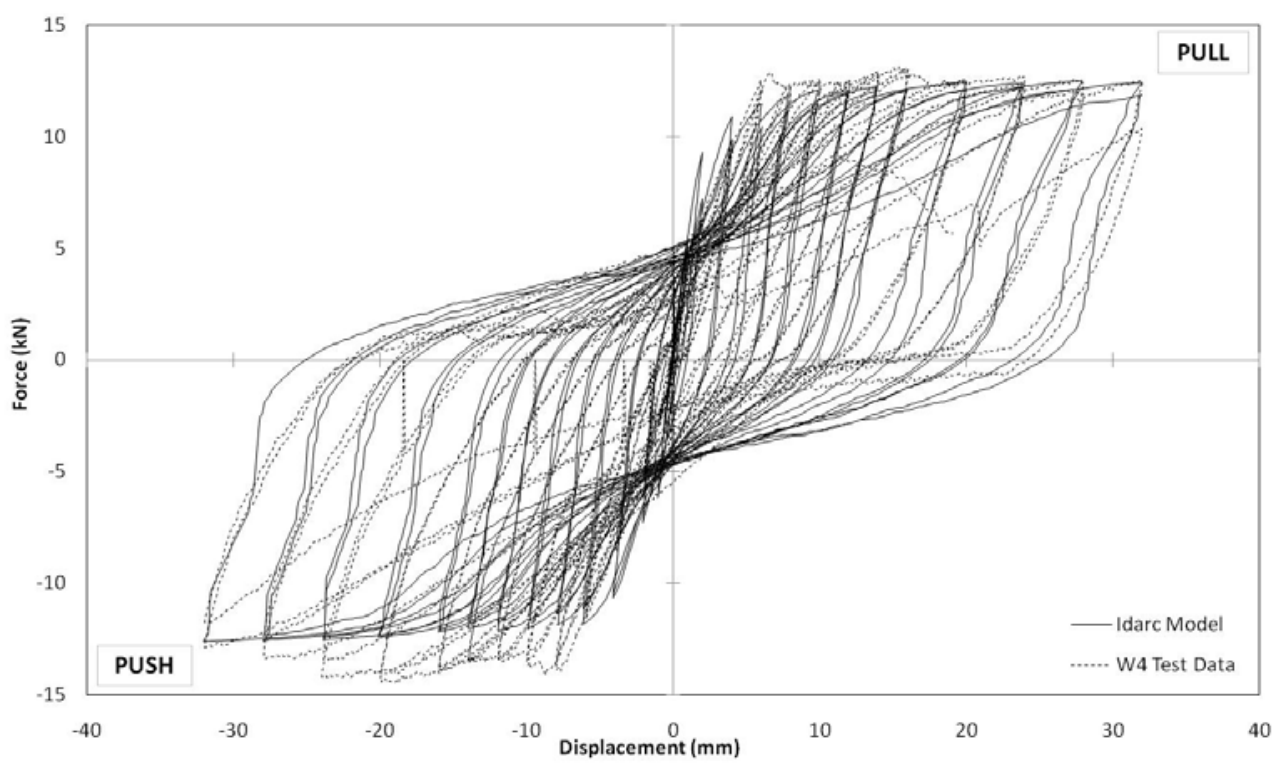

Figure 8-1: Comparison of results from test and IDARC

\subsection{Demonstration Building}

In order to further examine the seismic behavior of flexure dominant ICEB walls, two demonstration buildings were designed for IDA. The following sections describe the geometries, assumed material properties, and determination of the fundamental period of such building examples. 


\subsubsection{Geometries and Materials of the Demonstration Buildings}

As shown in Figure 8-2, the demonstration building includes 20 slim flexure dominant walls, reinforced the same as $\mathrm{W} 4$, as the primary lateral force resisting system along each direction. These two buildings, studied in this thesis, are both single story structure and have the same plan view as shown in Figure 8-2; however, they are different in story height and reactive mass. Such differences allow for investigation of the effects of these parameters on seismic behavior of ICEB buildings.

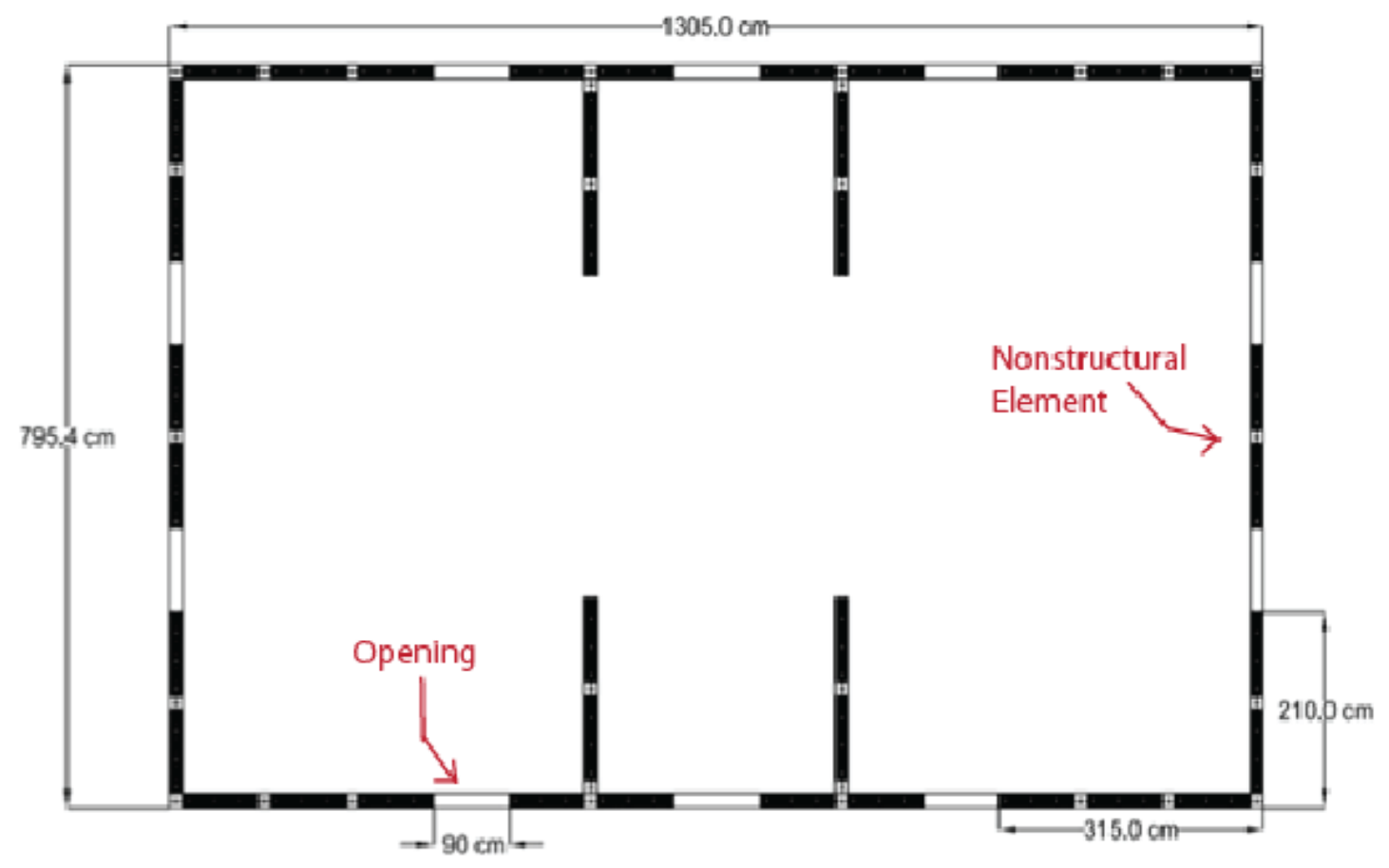

Figure 8-2: Demonstration Building for Nonlinear Dynamic Analysis

Heights of the abovementioned Buildings 1 and 2 were respectively assumed to be $2300 \mathrm{~mm}$ and $3000 \mathrm{~mm}$. These heights were selected to be representative in residential buildings. The openings shown in Figure 8-2 are designed as either doors or windows, with the lintels above the opening and sill's below the opening considered to be nonstructural elements. 
The reactive masses of the building were determined based on three factors: reactive mass of the ICEB walls, reactive mass of the nonstructural elements and the reactive mass from the roof. Equation (8-1) was used to determine the reactive mass of the demonstration buildings.

$$
M=\frac{1}{2} \sum\left(M_{\text {wall }}+M_{\text {NSE }}\right)+M_{\text {roof }}
$$

where $M$ is the mass reactive mass, $M_{\text {wall }}$ is the mass of each shear wall, $M_{\mathrm{NSE}}$ mass of nonstructural elements, and $M_{\text {roof }}$ is the roof mass.

The roof mass was determined based on the vertical load assumed in the shear wall test of $\mathrm{W} 4$, translating to $250 \mathrm{~kg} / \mathrm{m}$ across each shear wall elements. The reactive mass of the shear walls was calculated based on the mass of a fully grouted ICEB and the total number of blocks in each wall. The mass of the nonstructural elements depends on the material which they are constructed from. For the purposes of this thesis, it was considered to be $10 \%$ of the total mass of all ICEB walls. As a result, the reactive masses of Buildings 1 and 2 were determined to be 21,144 kg and 24,408 kg, respectively.

\subsubsection{Determination of Fundamental Period}

The fundamental periods of the demonstration buildings was determined to scale the selected ground motions for further nonlinear time history analysis described in a following section. In addition to the reactive mass described in the previous section, the stiffness of ICEB walls, which can be determined from moment of inertia, and material modulus of elasticity require calculation. A traditional method of transformed sections, found in standard mechanics of materials textbook, allows one to calculate the moment of inertia of a section with two different materials based on the areas and moduli of 
elasticity of the two materials. This method typically assumes isotropic material properties for different materials (i.e. identical properties for both tension and compression), but from the materials testing conducted in this investigation it is understood that ICEBs have negligible tensile strength. As a result, this investigation assumes compression-only material property for ICEBs for moment of inertia calculations. As a result only the masonry within the compression zone, calculated from plastic analysis, was considered to contribute strength.

The Masonry Design Guide (The Masonry Society, 2007), calculates the deflection of a solid cantilever shear wall, subjected to a single point load at the top, as:

$$
\Delta_{c}=P\left(\frac{h^{3}}{3 E_{m} I}+\frac{1.2 h}{E_{v} A}\right)
$$

where $P$ is the applied force, $h$ is the height of the wall, $E_{\mathrm{m}}$ is the modulus of elasticity of the masonry, $E_{\mathrm{v}}$ is the shear modulus of the masonry (taken as $0.4 E_{\mathrm{m}}$ ), and $I$ is the calculated moment of inertia.

Given the fact that the shear deformation associated with the elastic behavior of the wall is negligible and the scope of this thesis focused on the walls with flexure dominate behavior, the shear deformation was neglected in equation (8-2). As a result, the wall elastic stiffness can be calculated according to equation (8-3):

$$
k=\frac{P}{\Delta_{c}}=\left(\frac{3 E_{m} I}{h^{3}}\right)
$$

Figure 8-3 compares the stiffness of W4 determined from the above mentioned procedure and the hysteretic curves of W4 obtained from testing. As shown, the above procedure provides reasonable estimate for the initial stiffness of the specimen. 
With the reactive weights and wall stiffness, the fundamental periods of the demonstration buildings were determined based on the following equation

$$
T=2 \pi \sqrt{\frac{M}{k}}
$$

where $k$ is the stiffness calculated from Equation (8-3) and $M$ is the reactive weight of the structure.

Following Equation (8-4), the fundamental periods of Building 1 and 2 were determined to be 0.18 and 0.29 seconds respectively. Table $8-1$ gives the height, reactive weights, stiffness, and periods associated with each demonstration building.

Table 8-1: Properties of demonstration buildings

\begin{tabular}{ccccc} 
Building & $\begin{array}{c}\text { Height } \\
(\mathrm{mm})\end{array}$ & $\begin{array}{c}\text { Reactive Weight } \\
(\mathrm{kg})\end{array}$ & $\begin{array}{c}\text { Stiffness } \\
(\mathrm{kN} / \mathrm{mm})\end{array}$ & $\begin{array}{c}\text { Period } \\
(\mathrm{s})\end{array}$ \\
\hline 1 & 2300 & 21,144 & 25.44 & 0.18 \\
2 & 3000 & 24,408 & 11.46 & 0.29
\end{tabular}




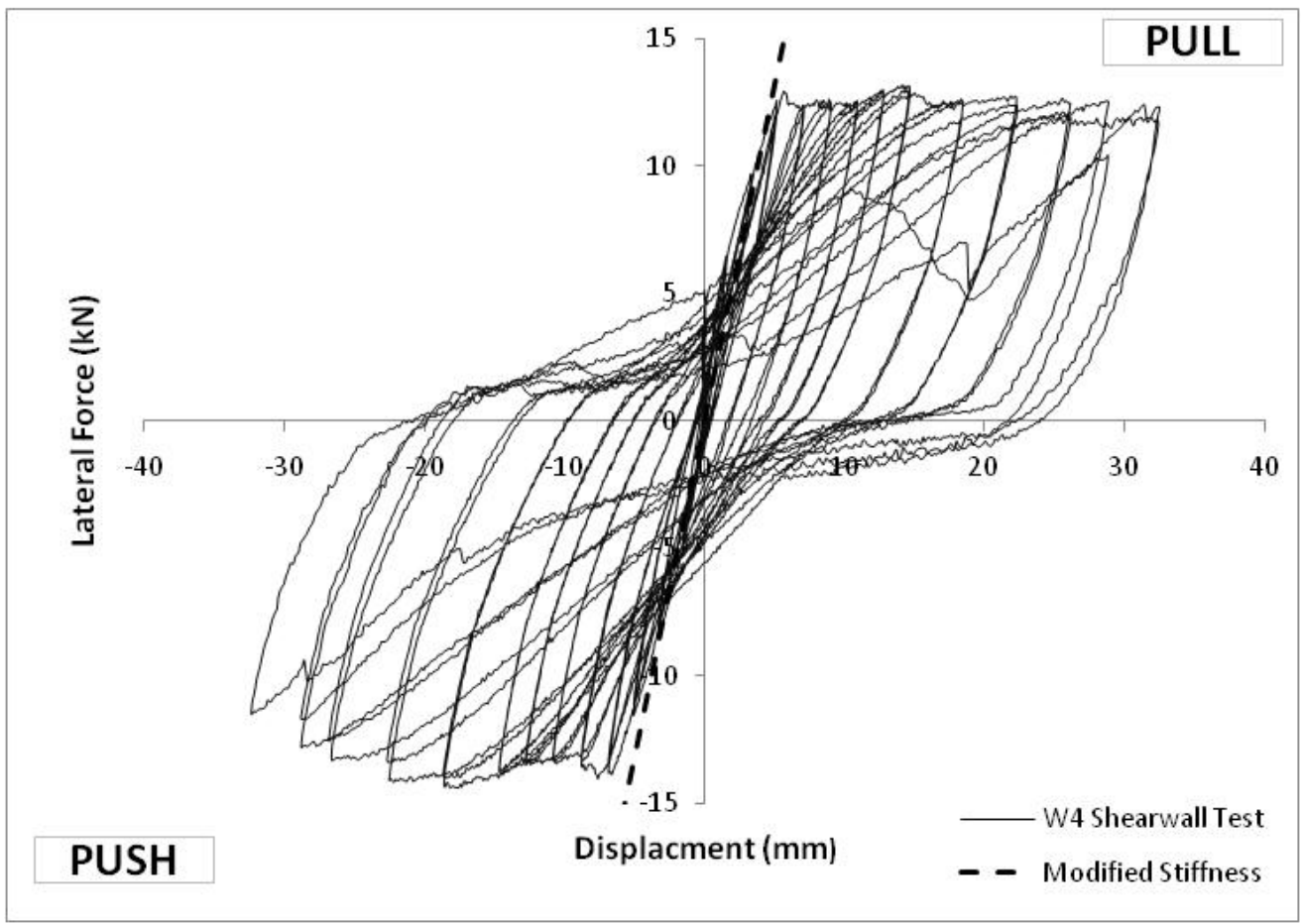

Figure 8-3: Estimated stiffness and hysteretic curves of W4

\subsection{Incremental dynamic analysis}

IDA is a parametric analysis method that has recently emerged in several recent forms to estimate more thoroughly structural performance (in particular collapse level performance) under seismic loads. It typically involves subjecting a structural model to multiple ground motion records scaled to multiple levels of intensity, thus producing curves of response parameterized versus intensity level (Vamvatsikos and Cornell, 2002). In this thesis, based on the structural model validated in Section 8.1, the IDA approach was used to evaluate the collapse performance of the demonstration buildings. The following sections describe the selected ground motions for IDA and quantification of the probability of collapse of the demonstration buildings. 


\subsubsection{Ground Motions}

As a special type of nonlinear time history analysis, the results of IDA highly depend on the ground motion input in the analysis. Conventionally, the ground motion input should be selected from actual earthquake records from different sites to ensure they are not biased. The ground motions used in Quantification of Building Seismic Performance Factors, known as FEMA P695 (FEMA, 2009) were considered in this thesis. The original earthquake sets considered in FEMA P695 includes one set of 22 far field ground motions and one set of 28 near field ground motions (14 records with pulse and the other 14 records without pulse). Considering the availability of these ground motions and their compatibility with IDARC, 19 far field ground motions and 23 near field ground motions were selected. Detailed information about these selected ground motions is presented in Appendix B.

In order to exclude the performance difference of the demonstration buildings caused by magnitude, site conditions, source type, and distance to source of each specific earthquake, the selected ground motions were scaled using the following equation:

$$
P G A_{\text {input }}=\frac{P G A_{\mathrm{MOTION}}}{S a_{\mathrm{T}}} N
$$

where $P G A_{\text {MOTION }}$ is the peak ground acceleration of respective earthquake ground motions, $S a_{\mathrm{T}}$ is the elastic spectral acceleration at the fundamental period of the structure, and $N$ represents the ground motion intensity considered in the analysis. For this thesis, the intensity increment was selected as 0.05 , ranging from 0.05 to 2.5 . 


\subsubsection{Probability of collapse}

Based on the structural models and the selected ground motions, nonlinear time history analyses were conducted for different levels of ground motion intensity (i.e. spectral acceleration values). Results for Buildings 1 and 2 shown in Figure 8-4 form a database for quantification of the probability of collapse.

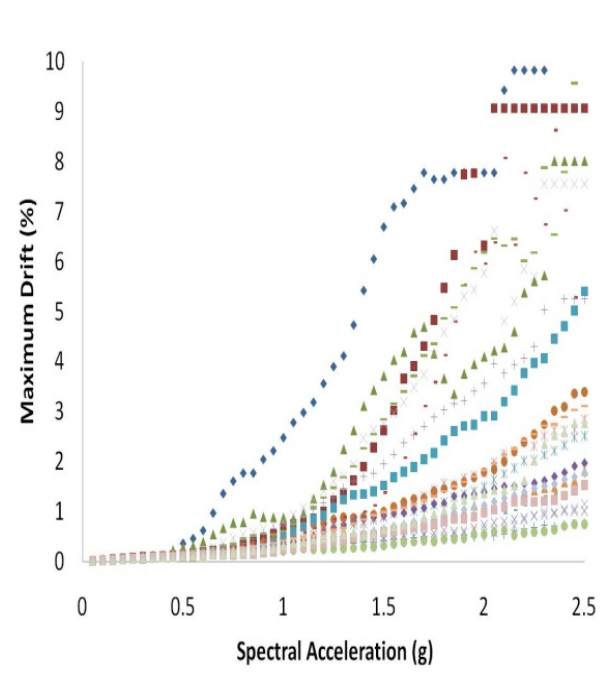

Building 1 under near field earthquakes

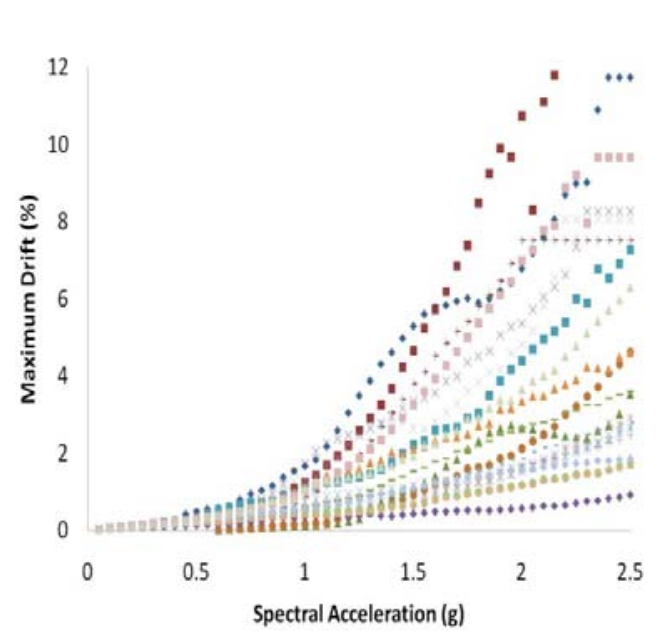

Building 2 under near field earthquakes

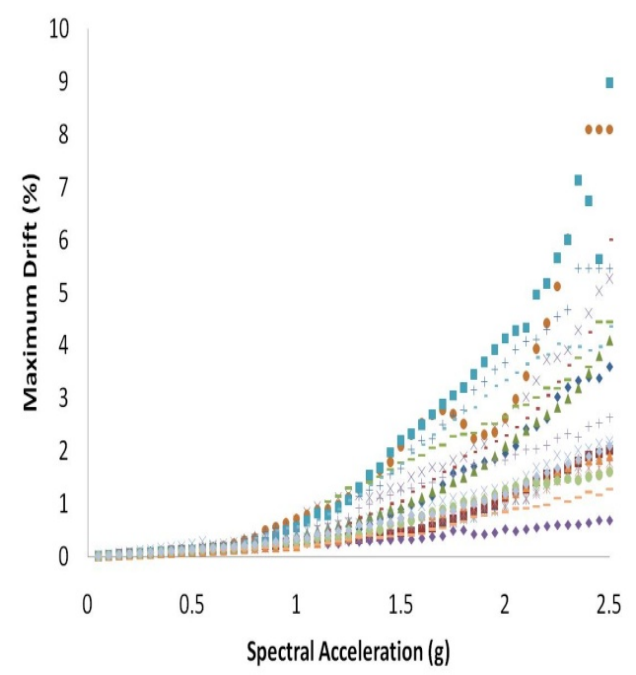

Building 1 under far field earthquakes

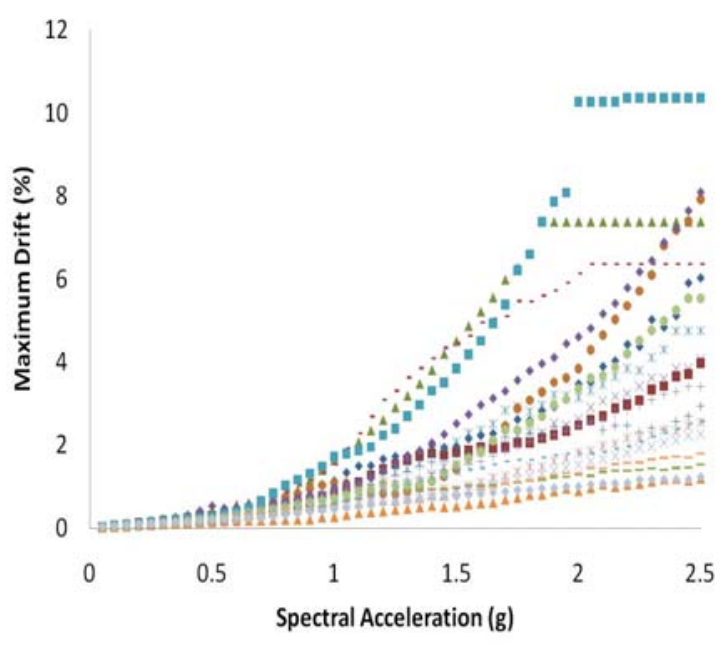

Building 2 under far field earthquakes

Figure 8-4: Results from IDA 
Traditionally, the maximum drift of a structure under a certain level of earthquake intensity is assumed to have a lognormal distribution (FEMA P695, 2009). Therefore, the probability of collapse of the structure at the earthquake intensity level of interest can be calculated as:

$$
P\left(Y>Y_{0} \mid x\right)=1-\Phi\left[\frac{\ln Y_{0}-\theta_{Y}}{\beta}\right]
$$

where $x$ is the earthquake intensity level of interest (i.e. a certain value of spectral acceleration); $Y$ is the random variable representing the maximum story drift of the structure; $Y_{\mathrm{o}}$ is the collapse level drift limit which is defined to be the drift value corresponding to $20 \%$ of strength degradation on the backbone curve shown in Figure 7-2 and was identified to be $1.78 \%$ for flexure dominant walls; $\Phi$ is the cumulative distribution function of standard normal distribution, $\beta$ and $\theta_{\mathrm{Y}}$ are respectively the sample standard deviation and the median of the natural log values of the maximum drifts calculated from the considered ground motions at the intensity level of interest.

Connecting the estimates of the probability of collapse at each earthquake intensity level, one can obtain the fragility curves shown in Figure 8-5 and Figure 8-6. Such graphical representations can be used for quantification of the probability of collapse at the different intensity levels. 


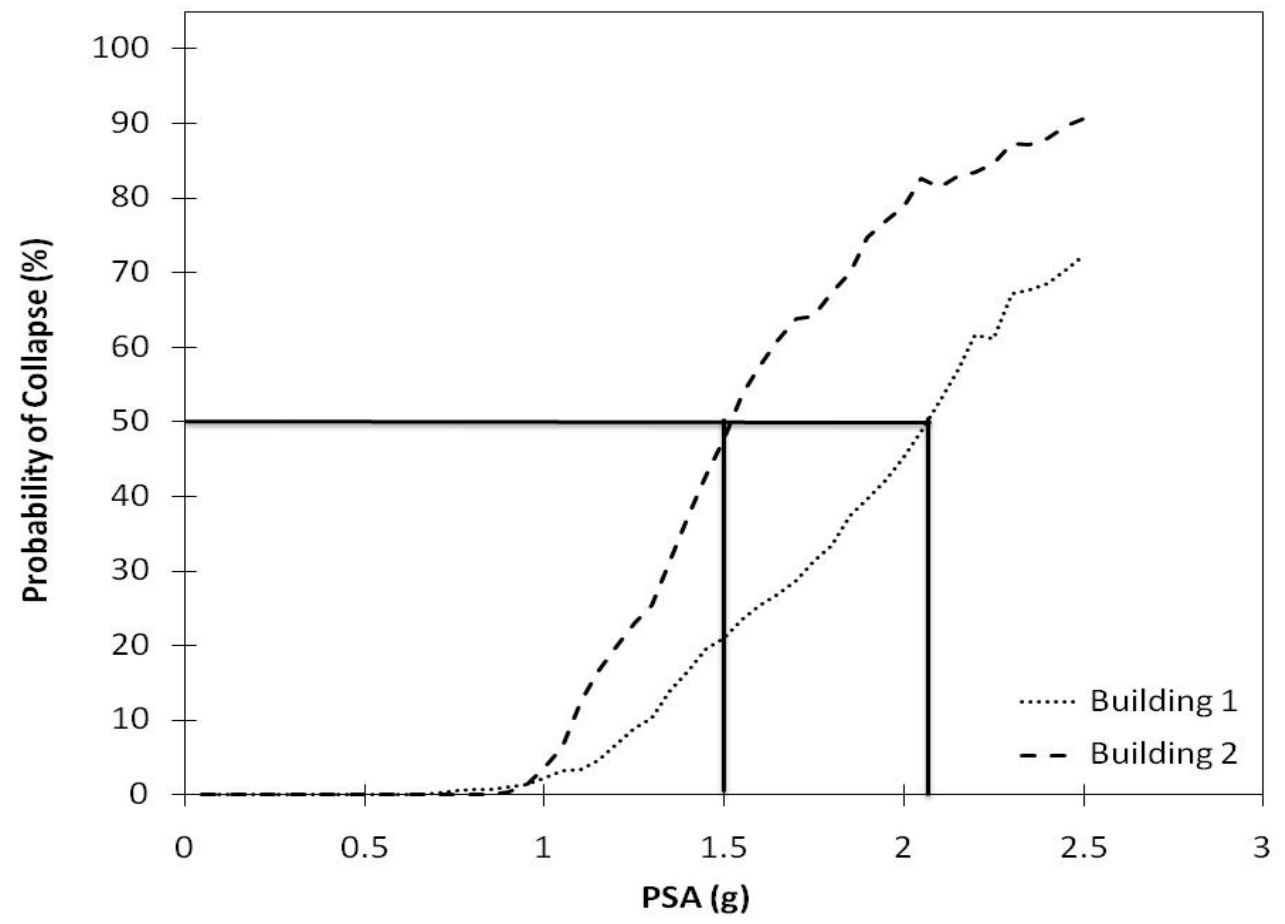

Figure 8-5: Fragility curves of demonstration buildings under near field ground motions

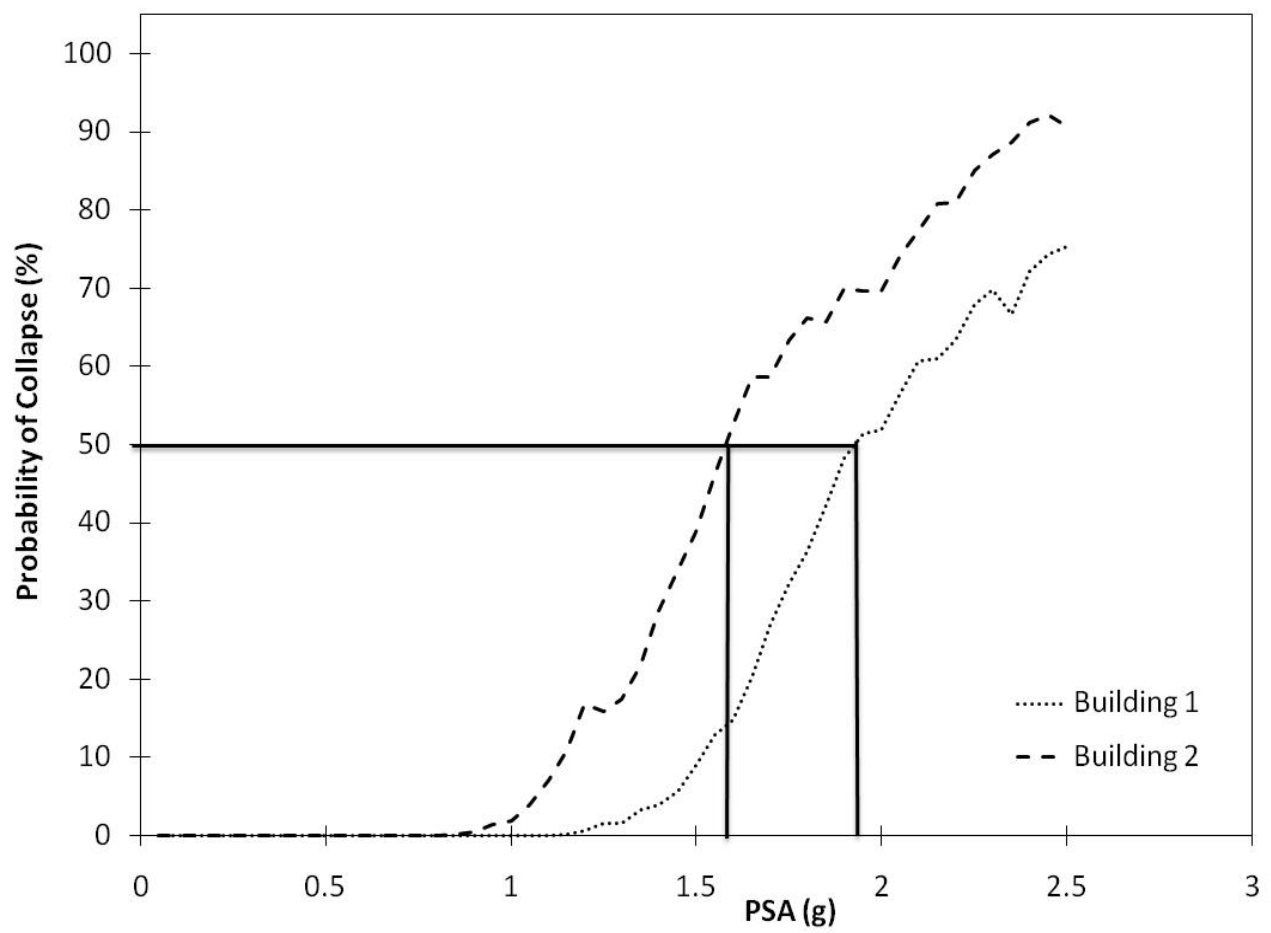

Figure 8-6: Fragility curves of demonstration buildings under far field ground motions 
As discussed in FEMA P695, the spectral acceleration corresponding to a probability of failure equal to 50 percent (denoted as $\mathrm{S}_{\mathrm{CT}}$ ) is used as an index to address the collapse resistance of the structure. From the fragility curves shown in Figure 8-5 and Figure 8-6, the values of $\mathrm{S}_{\mathrm{CT}}$ were identified for Buildings 1 and 2. Results are presented in Table 8-2. As compared, demonstration Building 2, with higher walls and a larger mass, has a smaller value of $\mathrm{S}_{\mathrm{CT}}$ than Building 1 which is shorter and lighter, indicating that larger values of story height and reactive weight may have detrimental effects on the collapse resistance of ICEB walls.

Table 8-2: PSA values for $50 \%$ collapse probability

\begin{tabular}{ccc} 
& $\begin{array}{c}\mathrm{S}_{\mathrm{CT}} \text { for Far Field } \\
(\mathrm{g})\end{array}$ & $\begin{array}{c}\mathrm{S}_{\mathrm{CT}} \text { for Near Field } \\
(\mathrm{g})\end{array}$ \\
\hline Building 1 & 1.93 & 2.07 \\
Building 2 & 1.57 & 1.50
\end{tabular}

\subsection{Discussion of ICEB structures at different sites}

As described in Chapter 1, the ICEB structures are being promoted in developing countries, in particular Asia, where levels of seismicity may vary widely. As such, it would be interesting to address the performance of the demonstration buildings in these countries. This section addresses the suitability of ICEB structures, from the perspective of collapse prevention, based on the fragility curves obtained in the previous section and the seismic hazard identified from the respective seismic design spectra of two Asian countries, i.e., Indonesia and Thailand. These countries have quite different levels of seismicity. For comparison purpose, another site in California (i.e., the Cal Poly campus) was also considered. 
Although different countries recommend different ways for calculating the seismic forces on structures, the equations were presented in the same manner, i.e. multiplying the reactive weight by the elastic spectral acceleration values associated with the design basis earthquakes (DBE). In order to make use of the fragility curves and have a more realistic estimate of the structure collapse performance, the DBE spectral acceleration values were converted to the values associated with the maximum considered earthquakes (MCE). According to FEMA P695, one can multiply the DBE spectral acceleration by 1.5 to obtain the MCE spectral acceleration. With the MCE spectral acceleration, one can identify the corresponding probability of collapse from the fragility curves. Based on this approach, the MCE spectral accelerations were determined for the countries of interest. It is noteworthy that the MCE spectral accelerations should be corresponding to elastic spectra which means that the factors used to modify the seismic force for consideration of inelastic structural performance should not be considered. Appendix $\mathrm{C}$ presents the detailed information about the seismic provisions of Indonesia and Thailand for determination of the DBE spectral accelerations. Table 8-3 lists the corresponding MCE spectral acceleration values. It is recognized that the maximum seismic force is present in zones 2 and 6 zones for Thailand and Indonesia, respectively. Table 8-3 only includes the maximum values (the worst scenarios) for consideration. More complete information about the MCE spectral acceleration values of these zones is also provided in Appendix C.

In order to address the suitability and the ability to avoid collapse failure of the ICEB buildings in the considered countries, the Collapse Margin Ratio (CMR) defined in FEMA P695 (FEMA, 2009) as the ratio of the spectral acceleration associated with 50 
percent collapse probability to the spectral acceleration associated with the MCE event on the site of interest is used as an index for comparison. The higher CMR values indicate a higher level of confidence for preventing structures from collapse. Table 8-4 lists the CMR values for the sites and buildings considered.

\begin{tabular}{lccc}
\multicolumn{3}{c}{ Table 8-3: Maximum DBE and MCE values } \\
& Thailand & Indonesia & California \\
\hline Zone & 2 & 1 & N/A \\
Soil Conditions & Soft Soil & Firm Soil & Class B \\
BDE & 0.045 & 0.52 & 0.84 \\
MCE & 0.0675 & 0.78 & 1.26
\end{tabular}

Table 8-4: CMR ratio

\begin{tabular}{|c|c|c|c|c|c|}
\hline & \multirow{2}{*}{$\begin{array}{c}\text { Demonstration } \\
\text { Building }\end{array}$} & \multirow{2}{*}{$\mathrm{S}_{\mathrm{CT}}$} & \multicolumn{3}{|c|}{ CMR } \\
\hline & & & Thailand & Indonesia & California \\
\hline \multirow{2}{*}{ Near Field } & Building 1 & 2.07 & 30.90 & 2.65 & 1.64 \\
\hline & Building 2 & 1.50 & 22.22 & 1.92 & 1.19 \\
\hline \multirow{2}{*}{ Far Field } & Building 1 & 1.93 & 28.81 & 2.47 & 1.53 \\
\hline & Building 2 & 1.57 & 23.43 & 2.01 & 1.25 \\
\hline
\end{tabular}

Based on the CMR values presented in Table 8-4, it is observed that the two demonstration buildings both exhibit relatively low probabilities (less than 50\%) of collapse during earthquake events, as indicated by the CMR values greater than 1.0. This indicates the ICEB structures with flexure dominant behavior may be suitable for all locations considered from the seismic design perspective. However, this type of construction may be overly conservative for Thailand where relatively low seismicity exists. As shown in Table 8-4, the CMR in Thailand is approximately 10 times and 15 
times larger than Indonesia and the Cal Poly site, respectively. Therefore, future research opportunities exist to develop more cost effective construction detailing (such as partially grouted walls and walls with less steel reinforcement) for the ICEB structures in Thailand. 


\section{CONCLUDING REMARKS AND FUTURE WORK}

\subsection{Summary}

This thesis conducted experimental and analytical investigations on flexural behavior of three commonly constructed ICEB walls. The three walls tested in this research include an $1800 \mathrm{~mm}$ tall and $900 \mathrm{~mm}$ wide slender wall (W4), an $1800 \mathrm{~mm} \times 1800 \mathrm{~mm}$ square wall with a $750 \mathrm{~mm}$ wide flange on one end (W5), and a $1800 \mathrm{~mm}$ square wall with a $900 \mathrm{~mm} \times 900 \mathrm{~mm}$ square opening in the middle (W6). Each wall was constructed from fully grouted ICEBs made on the Cal Poly campus from native soil, sand, and Portland cement. All three walls were tested under displacement controlled cyclic loading. Various instruments were used to capture the shear, bending, rocking, and sliding displacement components for a better understanding of in-plane performance of ICEB shear walls.

Two types of analyses were conducted for calculating the ultimate strength of flexure dominant ICEB walls based on the data collected from shear wall testing: a nonlinear static analysis model assuming lumped plasticity and a plastic analysis model. In addition, incremental dynamic analysis was conducted to address the seismic performance of flexure dominant ICEB buildings. Last, based on the database from the incremental dynamic analysis, the collapse potential of demonstration ICEB buildings were compared for the countries of interest. 


\subsection{Concluding Remarks}

The results of this thesis can be divided into two categories based on the findings from experimental and analytical work, respectively. Both types of results provide insight into the performance of flexure dominant ICEB shear walls.

\subsubsection{Findings from Experimental Results}

- The failure mode of each wall was characterized by tensile yielding of the longitudinal rebar. Compared with the brittle shear failures observed in the companion thesis, the flexure dominant specimens are more ductile and have a more stable energy dissipation capacity.

- A loss of toe confinement which may lead to rebar buckling, characterizes the eventual strength loss of the two cantilever specimens (W4 and W5). Strength loss for the wall with an opening (W6) was characterized by a combination of flexural failure and the diagonal crushing of masonry.

- Shear sliding, observed in the two cantilever specimens, has a significant contribution to the overall deformation of the system.

- A double ring beam was effective in transferring the load from the load beam into the wall.

- Vertical stirrups used in the construction of the lintel, above the opening in W6, were effective in preventing a shear failure of the lintel.

- To help resist buckling the vertical reinforcement, transverse (shear) reinforcement should be hooked 180 degrees, around the vertical reinforcement, despite the narrow width of the channel in the channel ICEB blocks. This is not 
consistent with the minimum bend diameter for reinforcing bars required by the ACI 530-08 provision, but was found effective in W6.

- The ductility of ICEB shear walls can be affected by the aspect ratio, the presences of an opening, and the presences of a flange.

\subsubsection{Findings from Analytical Results}

- A reasonable agreement was found between the ultimate strength observed from testing and that predicted by plastic analysis using the parameters prescribed by ACI 530-08.

- The lumped plasticity model, used in the nonlinear static analysis provides good agreements with the maximum strength observed from testing; however it does not capture the stiffness of ICEB walls due to the simplified material properties.

- Results from the incremental dynamic analysis on single story demonstration buildings suggest that there is a relatively low probability of earthquake-induced collapse for similar single story flexure dominant ICEB constructions in all the three considered countries.

\subsection{Future Research}

- Further investigation of the strengths of lintel is necessary to determine the most effective and efficient manner for designing wall with opening.

- Investigation into the bond strength between reinforcement and grout, and between grout and ICEB would provide better insight into the required length necessary to develop required bond strength. 
- Exploration of various methods of toe confinement could improve the ductility of ICEB walls by preventing premature failure in the compression zone.

- Further cost analysis of ICEB construction is necessary to ensure the widespread acceptance of this system in developing countries. 


\section{REFFERENCES}

ASTM. (2011)."Standard Test Methods and Definitions for Mechanical Testing of Steel Products."West Conshohocken, PA

Bales, C., Donahue, C.; Fisher, M, Mellbom, A., and Pearson, T. (2009). "Interlocking Compressed Earth Blocks: From Soil to Structure." Senior Project, Cal Poly San Luis Obispo, California.

Bei, G., \& Papayianni, I., (2003). "Compressive Strength of Compressed Earth Block Masonry." Structural Studies, Repairs and Maintenance of Heritage Architecture VIII, $15,367-375$.

Bland, D.W. (2011). "In-Plane Cyclic Performance of Interlocking Compressed Earth Block Shear Walls." Masters Thesis. Cal Poly San Luis Obispo, California

Cheah, J.S, Morgan, T.K.K.B \& Ingham, J.M. (2008). "Cyclic Testing of a Full-Size Stabilized, Flax-Fibre Reinforced Earth (uku) Wall System with Openings". Proceedings of the 14th world conference on earthquake engineering Beijing: http://www.iitk.ac.in/nicee/wcee/article/14 08-02-0032.PDF.

Elshafie, H, Hamid, A, \& Nasr, E. (2002). "Strength and Stiffness of Masonry Shear Walls with Openings". The Masonry Society journal, 20(1), 49-60.

Federal Emergency Management Agency (FEMA). (2009). FEMA P695: Quantification of Building Seismic Performance Factors. Applied Technology Council.

Jayasinghe, C, \& Mallawaarachchi, R.S. (2009). "Flexural strength of compressed stabilized earth masonry materials". Materials and Design, (30), Retrieved from www.elsevier.com/locate/matdes

Masonry Standards Joint Committee (MSJC) (2008). "Building Code Requirements for Masonry Structures, " TMS 402-08/ACI 530-08/ASCE5-08, USA

Park, R. (1989). "Evaluation of Ductility of Structures and Structural Assemblages From Testing," Bulletin of The New Zealand Society for Earthquake Engineering,(3)22,155166

Paulay, T, \& Priestley, M.J.N. (1992). Seismic Design of Reinforced Concrete and Masonry Buildings. New York: John Willey \& Sons

Paulay, T, Priestley, M.J.N., \& Synge, A.J. (1982). "Ductility in Earthquake Resisting Squat Shearwalls," ACI Journal, 79(4), 257-269. 
Perera, A., \& Jayasinghe, C. (2003). "Strength Characteristics and Structural Design Methods for Compressed Earth Block Walls,” Masonry International, 16(1), 34-38.

Priestley, M.J, \& Limin, H. (1990). "Seismic Response of T-Section Masonry Shear Walls," The Masonry Society (TMS), 9(1), 10-18.

Proto, C., Sanchez, D., Rowley, K., Thompson, R. (2010). "ICEB: Design and Construction Manual.” Senior Project, Cal Poly San Luis Obispo, California.

Reinhorn A.M., (2010). "IDARC 2D Version 7.0 User's Guide”

Shedid, M.T, Drysdale, G.D, \& Dakhakhni, W.W. (2008). "Behavior of Fully Grouted Reinforced Concrete Masonry Shear Walls Failing in Flexure: Experimental results," Journal of Structural Engineering, 134(11), 1754-1767.

Shedid, M.T, Dakhakhni, W.W, \& Drysdale, R.G. (2009). "Behavior of fully grouted reinforced concrete masonry shear walls failing in flexure: analysis," Engineering Structures, (31), Retrieved from www.elsevvier.com/locate/engstruct

Shedid, M.T, Drysdale, G.D, \& Dakhakhni, W.W. (2010). "Alternative Strategies to Enhance the Seismic Performance of Reinforced Concrete-Block Shear Wall Systems". Journal of Structural Engineering, 136(06), 0733-9445.

Sivaselvan, M.V, \& Reinhorn, A.M. (2000). "Hysteretic Models for Deteriorating Inelastic Structures," Journal of Structural Mechanics, 126(6), 633-639.

The Masonry Society (TMS) (2007). Masonry Designers' Guide. $4^{\text {th }}$ ed. Boulder, CO.

Vamvatsikos, D.,Cornell,C.A. (2002). "Incremental Dynamic Analysis”. Earthquake Engineering and Structural Dynamics.(31),491-514

Voon, K.C. (2007). “In-plane Seismic Design of Concrete Masonry Structures," Ph.D. Thesis, University of Auckland: NZ. Retrieved from http://hdl.handle.net/2292/580

Voon, K.C, \& Ingham, J.M. (2008). "Experimental In-plane Strength Investigation of Reinforced Concrete Masonry Walls with Openings," Journal of Structural Engineering, 134(5), 758-769.

Walker, P. (1999). "Bond Characteristics of Earth Block Masonry," Journal of Materials in Civil Engineering, 11(3), 249-256.

Wheeler, G. (2005). Interlocking Compressed Earth Blocks Volume II. Manual of Construction, Center for Vocational Building Technology, Thailand. 


\section{APPENDIX A RESULTS FROM MATERIAL TESTING}

This appendix presents the material properties obtained from this thesis and the companion thesis. Table A-1 presents the compressive strength obtained from testing of the prism specimens. These specimens tested under the stress-controlled and strain controlled conditions are detonated as $\sigma$ and $\varepsilon$ in Table A-2, and they were respectively loaded at a load rate of $2.0 \mathrm{MPa} / \mathrm{min}$ and a displacement rate of $0.45 \mathrm{~mm} / \mathrm{mm}$ (corresponding to $20 \mu \varepsilon / \mathrm{s}$ ). Table A-2 presents the compressive strength of the ungrouted ICEBs. Table A-3 and Figure A-1 present the tensile strength and strain-stress curves of the reinforcement rebar used in the specimens. Proportions for mortar and grout mixtures, using the in construction of walls are presented in Table A-4. 
Table A-1: ICEB prism compressive strength

\begin{tabular}{|c|c|c|c|c|c|}
\hline Wall & Loading & $\begin{array}{c}\text { Area } \\
\left(\mathrm{mm}^{2}\right)\end{array}$ & $\begin{array}{c}\text { Stress } \\
\mathrm{MPa}\end{array}$ & Mean & St Dev \\
\hline \multicolumn{6}{|c|}{ Partial Grouting } \\
\hline 1 & $\sigma$ & 41,819 & 2.88 & \multirow{2}{*}{3.32} & \multirow{2}{*}{0.615183} \\
\hline 1 & $\sigma$ & 41,819 & 3.75 & & \\
\hline 2 & $\sigma$ & 41,819 & 2.12 & \multirow{3}{*}{2.10} & \multirow{3}{*}{0.047258} \\
\hline 4 & $\varepsilon$ & 45,000 & 2.05 & & \\
\hline 6 & $\varepsilon$ & 41,819 & 2.14 & & \\
\hline \multicolumn{6}{|c|}{ Full Grouting } \\
\hline 1 & $\sigma$ & 45,000 & 4.57 & \multirow{2}{*}{4.12} & \multirow{2}{*}{0.636396} \\
\hline 1 & $\sigma$ & 45,000 & 3.67 & & \\
\hline 2 & $\sigma$ & 45,000 & 4.31 & \multirow{2}{*}{4.20} & \multirow{2}{*}{0.155563} \\
\hline 2 & $\sigma$ & 45,000 & 4.09 & & \\
\hline 3 & $\varepsilon$ & 45,000 & 2.88 & \multirow{2}{*}{3.04} & \multirow{2}{*}{0.219203} \\
\hline 3 & $\varepsilon$ & 45,000 & 3.19 & & \\
\hline 4 & $\varepsilon$ & 45,000 & -- & \multirow{2}{*}{2.77} & \multirow{2}{*}{$\mathrm{N} / \mathrm{A}$} \\
\hline 4 & $\varepsilon$ & 45,000 & 2.77 & & \\
\hline 5 & $\varepsilon$ & 45,000 & 3.16 & \multirow{2}{*}{3.16} & \multirow{2}{*}{ N/A } \\
\hline $5 *$ & $\sigma$ & 45,000 & 4.73 & & \\
\hline 6 & $\varepsilon$ & 45,000 & 2.37 & \multirow{2}{*}{2.26} & \multirow{2}{*}{0.162635} \\
\hline 6 & $\varepsilon$ & 45,000 & 2.14 & & \\
\hline
\end{tabular}

Table A-2: ICEB compressive strength

\begin{tabular}{|c|c|c|c|c|}
\hline Wall & $\begin{array}{c}\text { Area } \\
\left(\mathrm{mm}^{2}\right)\end{array}$ & $\begin{array}{c}\text { Stress } \\
\mathrm{MPa}\end{array}$ & Mean & St Dev \\
\hline 1 & 39,319 & 7.64 & \multirow{8}{*}{7.57} & \multirow{8}{*}{0.662246} \\
\hline 1 & 39,319 & 7.42 & & \\
\hline 2 & 39,319 & 6.96 & & \\
\hline 2 & 39,319 & 7.8 & & \\
\hline- & 39,319 & 7.39 & & \\
\hline- & 39,319 & 7.36 & & \\
\hline- & 39,319 & 9.03 & & \\
\hline- & 39,319 & 6.93 & & \\
\hline
\end{tabular}


Table A-3: Rebar tensile test data

\begin{tabular}{|c|c|c|c|c|c|c|}
\hline Test & ecimen & Area & $\begin{array}{l}\text { Yield Strength } \\
\text { (MPa) }\end{array}$ & $\begin{array}{l}\text { Average Yield } \\
\text { Strength }\end{array}$ & $\begin{array}{l}\text { Ultimate } \\
\text { Strength }\end{array}$ & $\begin{array}{l}\text { Average } \\
\text { Ultimate } \\
\text { Strength }\end{array}$ \\
\hline W/A & Rebar \#1 & 71.00 & 407.42 & 27010 & 574.33 & 54121 \\
\hline VV4 & Rebar \#2 & 71.00 & 348.94 & $3 / 8.18$ & 508.08 & 341.21 \\
\hline & Rebar \#1 & 71.00 & 339.72 & & 574.33 & \\
\hline & Rebar \#2 & 71.00 & 383.90 & & Slipped & \\
\hline$W / 5$ & Rebar \#3 & 71.00 & 354.77 & 36947 & 496.61 & 54212 \\
\hline VVJ & Rebar \#4 & 71.00 & 388.61 & 309.41 & 555.40 & 342.12 \\
\hline & Rebar \#5 & 71.00 & 380.34 & & Slipped & \\
\hline & Rebar \#6 & 71.00 & Slipped & & Slipped & \\
\hline & Rebar \#1 & 71.00 & Slipped & & Slipped & \\
\hline $1 \mathrm{~W} / \mathrm{s}$ & Rebar \#2 & 71.00 & 355.39 & 35605 & 481.38 & 19690 \\
\hline vo & Rebar \#3 & 71.00 & Slipped & נט.טנב & Slipped & 40.57 \\
\hline & Rebar \#4 & 71.00 & 356.71 & & 512.59 & \\
\hline
\end{tabular}




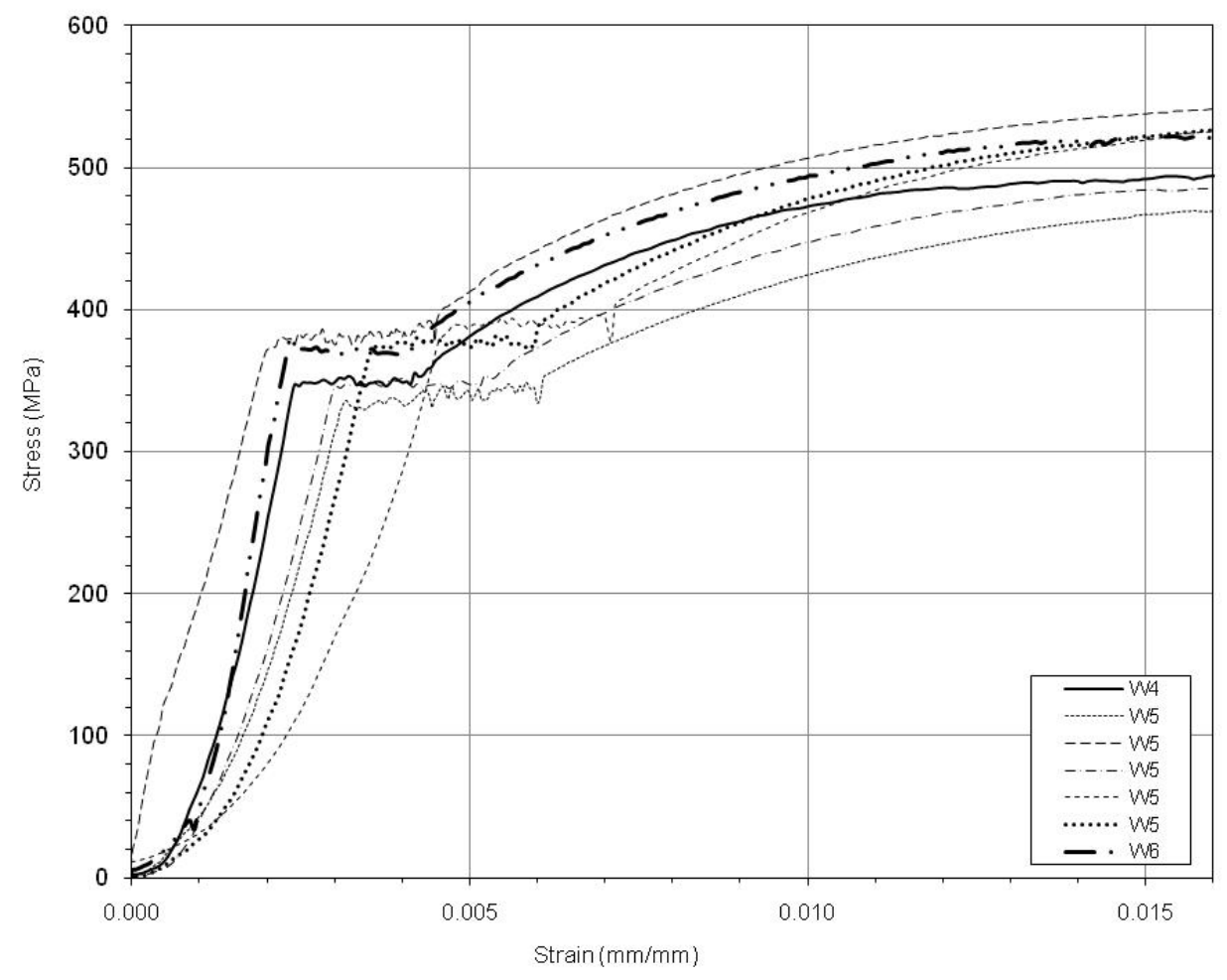

Figure A-1: Stress-Strain data for rebar

Table A-4: Grout and Mortar Proportions

\begin{tabular}{|c|c|c|c|c|}
\hline \multirow{3}{*}{ Ingredients } & \multicolumn{3}{|c|}{ Grout } & \multicolumn{2}{c|}{ Mortar } \\
& $\begin{array}{c}\text { Proportions } \\
\text { (Volume \%) }\end{array}$ & $\begin{array}{c}\text { Mass per Batch } \\
(\mathrm{kg})\end{array}$ & $\begin{array}{c}\text { Proportions } \\
\text { (Volume \%) }\end{array}$ & $\begin{array}{c}\text { Mass per Batch } \\
(\mathrm{kg})\end{array}$ \\
\hline Sand & 75 & 16 & 75 & 14 \\
\hline Cement & 18 & 3.4 & 17 & 2.5 \\
\hline Lime & 7 & 0.5 & 8 & 0.5 \\
\hline
\end{tabular}




\section{APPENDIX B GROUND MOTIONS USED IN SEISMIC PERFORMANCE EVALUATION}

As described in Chapter 8, the IDA approach was used to evaluate the collapse of the demonstration building for a suite of 42 recorded motions selected from the 50 ground motions considered in FEMA P695. The original ground motions in FEMA P695 include 28 near field records (14 with pulse and 14 without pulse) and 22 far field records. Far filed motions are recordings which occur more than $10 \mathrm{~km}$ from the fault rupture, while near field recordings are motions which were recorded within $10 \mathrm{~km}$ of the fault rupture. According to FEMA P695 (FEMA 2009), these original 50 ground motions were selected based on the following criteria:

1. Code (ASCE/SEI 7-05) Consistent - The records should be consistent (to the extent possible) with the ground motion requirements of Section 16.1.3.2 of ASCE/SEI 7-05 Minimum Design Loads for Buildings and Other Structures (ASCE, 2005) for threedimensional analysis of structures.”

2. Very Strong Ground Motions - The records should represent very strong ground motions corresponding to the MCE motion.

3. Large Number of Records - The number of records in the set should be "statistically" sufficient such that the results of collapse evaluations adequately describe both the median value and record-to-record (RTR) variability of collapse capacity.

4. Structure Type Independent - Records should be broadly applicable to collapse evaluation of a variety of structural systems, such as systems that have different dynamic response properties or performance characteristics. Accordingly, records should not depend on period, or other building-specific properties of the structure. 
5. Site Hazard Independent - The records should be broadly applicable to collapse evaluation of structures located at different sites, such as sites with different ground motion hazard functions, site and source conditions. Accordingly, records should not depend on hazard disaggregation, or other site- or hazard-dependent properties

Of the original 50 recorded ground motions, 3 far field and 5 near field motions were not considered in the IDA because they are either not available or not suitable with the IDARC program. Detailed information about the selected far field and near field ground motions are presented in Table B-1 and Table B-2, respectively. 
Table B-1: Far Field Earthquake Records

\begin{tabular}{|c|c|c|c|c|c|}
\hline No. & EQ Location & Record/ Component & Fault Type & Magnitude & PGA (g) \\
\hline 1 & Northridge & NORTHR/MUL279 & Thrust & 6.7 & 0.516 \\
\hline 2 & Northridge & NORTHR/LOS270 & Thrust & 6.7 & 0.482 \\
\hline 3 & Duzce, Turkey & DUZCE/BOL090 & Strike-slip & 7.1 & 0.822 \\
\hline 4 & Hector, Mine & HECTOR/HEC090 & Strike-slip & 7.1 & 0.337 \\
\hline 5 & Imperial Valley & IMPVALL/A-DLT352 & Strike-slip & 6.5 & 0.351 \\
\hline 6 & Imperial Valley & IMPVALL/H-E07140 & Strike-slip & 6.5 & 0.338 \\
\hline 7 & Kobe, Japan & KOBE/NIS000 & Strike-slip & 6.9 & 0.510 \\
\hline 8 & Kobe, Japan & KOBE/SHI000 & Strike-slip & 6.9 & 0.243 \\
\hline 9 & Kocaeli, Turkey & KOCAELI/ARC000 & Strike-slip & 7.5 & 0.358 \\
\hline 10 & Kocaeli, Turkey & KOCAELI/ARC000 & Strike-slip & 7.5 & 0.220 \\
\hline 11 & Landers & LANDERS/YER270 & Strike-slip & 7.3 & 0.245 \\
\hline 12 & Loma Prieta & LOMAP/CAP000 & Strike-slip & 6.9 & 0.450 \\
\hline 13 & Loma Prieta & LOMAP/G03001 & Strike-slip & 6.9 & 0.555 \\
\hline 14 & Manjil, Iran & MANJIL/ABBAR--L & Strike-slip & 7.4 & 0.4964 \\
\hline 15 & Superstition Hills & SUPERST/B-ICC000 & Strike-slip & 6.5 & 0.358 \\
\hline 16 & Superstition Hills & SUPERST/B-POE270 & Strike-slip & 6.5 & 0.446 \\
\hline 17 & Cape Mendocino & CAPEMEND/CPM000 & Thrust & 7 & 0.550 \\
\hline 18 & San Fernando & SFERN/PEL090 & Thrust & 6.6 & 0.209 \\
\hline 19 & Friuli, Italy & FRIULI/A-TMZ000 & Thrust & 6.5 & 0.351 \\
\hline
\end{tabular}


Table B-2: Near Field Earthquake Records

\begin{tabular}{|c|c|c|c|c|c|}
\hline No. & EQ Location & Record/Component & Fault Type & Magnitude & PGA (g) \\
\hline \multicolumn{6}{|c|}{ With Pulse } \\
\hline 1 & Imperial Valley-06 & IMPVALL/H-E06230 & Strike-slip & 6.5 & 0.439 \\
\hline 2 & Imperial Valley-06 & IMPALL/H-E07230 & Strike-slip & 6.5 & 0.463 \\
\hline 3 & Superstition Hills-02 & SUPERST/B-PTS225 & Strike-slip & 6.5 & 0.455 \\
\hline 4 & Loma Prieta & LOMAP/STG090 & Strike-slip & 6.9 & 0.324 \\
\hline 5 & Erzican, Turkey & ERZIKAN/ERZ-EW & Strike-slip & 6.7 & 0.496 \\
\hline 6 & Cape Mendocino & CAPEMEND/PET090 & Thrust & 7 & 0.662 \\
\hline 7 & Landers & LANDERS/LCN000 & Strike-slip & 7.3 & 0.785 \\
\hline 8 & Northridge-01 & NORTHR/RRS228 & Thrust & 6.7 & 0.838 \\
\hline 9 & Northridge-01 & NORTHR/SYL360 & Strike-slip & 6.7 & 0.843 \\
\hline 10 & Kocaeli, Turkey & KOCAELI/IZT090 & Strike-slip & 7.5 & 0.220 \\
\hline 11 & Duzce, Turkey & DUZCE/DZC270 & Strike-slip & 7.1 & 0.535 \\
\hline \multicolumn{6}{|c|}{ Without Pulse } \\
\hline 12 & Gazli, USSR & GAZLI/GAZ090 & Thrust & 6.8 & 0.718 \\
\hline 13 & Imperial Valley-06 & IMPVALL/H-BCR230 & Strike-slip & 6.5 & 0.775 \\
\hline 14 & Imperial Valley-06 & IMPVALL/H-CHI012 & Strike-slip & 6.5 & 0.270 \\
\hline 15 & Nahanni, Canada & NAHANNI/S1280 & Thrust & 6.8 & 1.096 \\
\hline 16 & Nahanni, Canada & NAHANNI/S2240 & Thrust & 6.8 & 0.489 \\
\hline 17 & Loma Prieta & LOMAP/BRN090 & Strike-slip & 6.9 & 0.501 \\
\hline 18 & Loma Prieta & LOMAP/CLSO00 & Strike-slip & 6.9 & 0.644 \\
\hline 19 & Cape Mendocino & CAPEMEND/CPM000 & Thrust & 7 & 1.497 \\
\hline 20 & Northridge-01 & NORTHR/SPV270 & Thrust & 6.7 & 0.753 \\
\hline 21 & Northridge-01 & NORTHR/STC180 & Thrust & 6.7 & 0.477 \\
\hline 22 & Kocaeli, Turkey & KOCAELI/YPT330 & Strike-slip & 7.5 & 0.349 \\
\hline
\end{tabular}




\section{APPENDIX C \\ SEISMIC DESIGN SPECTRA IN THE CONSIDERED COUNTRIES}

As discussed in Chapter 8, the seismic design spectra of Indonesia, Thailand and California were used to determine the spectral accelerations for quantification of the CMR values to evaluate the collapse performance of the demonstration ICEB buildings. The following sections describe the detailed information of these spectra. It should be noted that the provisions for generating these spectra presented in this appendix are taken from the website of the International Institute of Seismography and Earthquake Engineering (IISEE) in Japan:

http://iisee.kenken.go.jp/net/seismic_design_code/index.htm

\section{C.1 Thailand}

Ministry regulation code No. 48, set forth by the Thailand ministry of the interior, defines horizontal seismic base shear according equation (C-1) with the corresponding variables defined in Table C-1.

$$
V=C_{d} * W
$$

C-1 


\section{Table C-1: Thailand Seismic Design Factors}

\begin{tabular}{|c|c|c|}
\hline Variable & Definition & Value \\
\hline W & Effective weight of the structure & $\begin{array}{l}\text { Total dead load and at least one- } \\
\text { fourth of the design live load }\end{array}$ \\
\hline $\mathrm{C}_{\mathrm{d}}$ & Spectral Design value & $Z * K * C * S * I$ \\
\hline $\mathrm{Z}$ & seismic zone factor & Table C-2 and Figure C-1 \\
\hline $\mathrm{K}$ & Structural Factor & Table C-3 \\
\hline $\mathrm{C}$ & Dynamic Factor & $C=\frac{1}{15 \sqrt{T}} \leq 0.12$ \\
\hline $\mathrm{T}$ & $\begin{array}{l}\text { Fundamental Natural period of the } \\
\text { structure }\end{array}$ & \\
\hline S & Site-structure resonance coefficient & Table C-4 \\
\hline I & Importance factor & Table C-5 \\
\hline
\end{tabular}

Table C-2: Seismic Factor for each Zone

\begin{tabular}{|c|c|}
\hline Zone & Seismic Factor $(\mathbf{Z})$ \\
\hline 0 & No need of seismic design \\
\hline 1 & 0.15 \\
\hline 2 & 0.25 \\
\hline
\end{tabular}

Table C-3: Structural Factor for Different Type Buildings

\begin{tabular}{|c|c|}
\hline Description & Structural Factor (K) \\
\hline steel structures & 0.67 \\
\hline other structures & 1 \\
\hline
\end{tabular}

C-2 
Table C-4: Resonance Coefficient as a function of Soil Type

\begin{tabular}{|c|c|}
\hline description & $\boldsymbol{S}$ \\
\hline soft soil & 1.5 \\
\hline stiffer soil type & 1 \\
\hline
\end{tabular}

Table C-5: Seismic Importance factor based on Structure use

\begin{tabular}{|l|c|}
\hline \multicolumn{1}{|c|}{ description } & I \\
\hline $\begin{array}{l}\text { Buildings essential to the public use, e.g., } \\
\text { schools, hospitals, fire stations, disaster } \\
\text { mitigation centers, railway stations, airports }\end{array}$ & 1.5 \\
\hline $\begin{array}{l}\text { Buildings that can assemble more than 300 } \\
\text { persons in one room at one time, or buildings } \\
\text { with more than 5 stories }\end{array}$ & 1.25 \\
\hline $\begin{array}{l}\text { Any other buildings than above mentioned } \\
\text { ones }\end{array}$ & 1 \\
\hline
\end{tabular}

C-3 


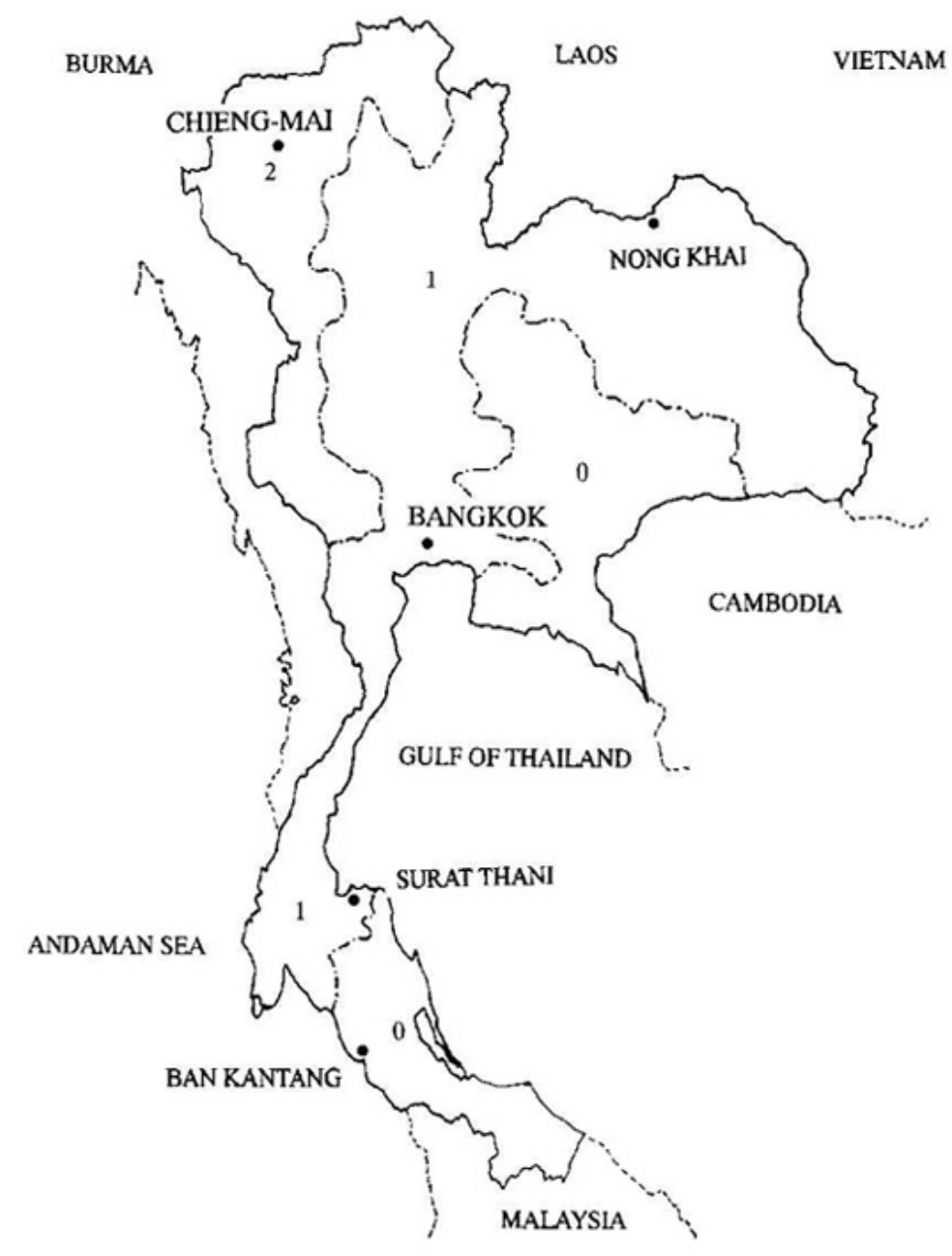

Figure C-1: Thailand Seismic Regions (from IISEE)

Excluding consideration of the effects of structure nonlinear performance and difference caused by the occupancy category, i.e. setting $\mathrm{K}$ and I equal to 1.0 according to Table C-3 and Table C-4, the Dynamic factor (C) has a value of 0.12 based on the fundamental period of the structure. $C_{\mathrm{d}}$ determined from Table C-1, is the estimate of DBE spectral acceleration. The MCE spectral acceleration values for all the seismic zones in Thailand and other factors used in the calculation are provided in Table C-6. 
Table C-6: Summary of Spectral Acceleration values of the sites in Thailand

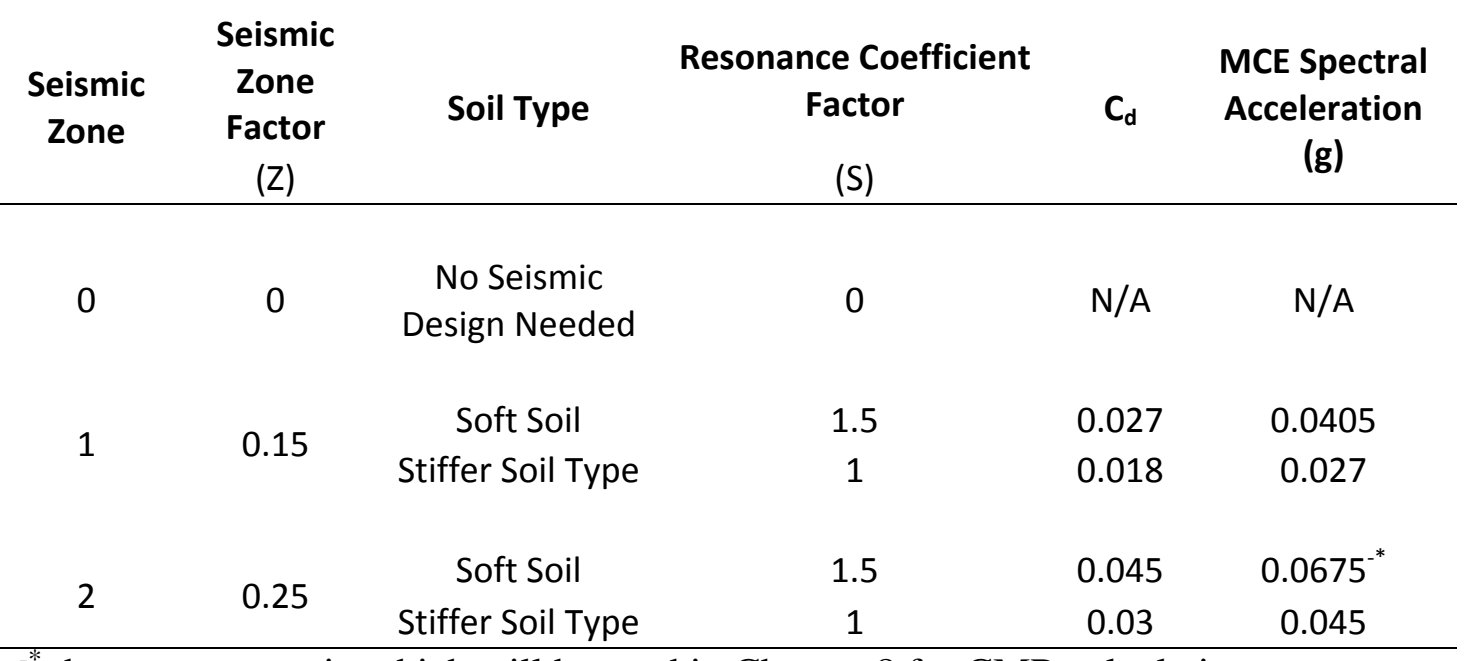

${ }^{-*}$ the worst scenario which will be used in Chapter 8 for CMR calculation

\section{C.2 Indonesia}

The Ministry of Public Works for Indonesia set forth the Indonesian Earthquake Code, which defines horizontal seismic base shear according to equation (C-2) with the corresponding variables defined in Table C-7.

$$
V=C_{d} * W_{t}
$$


Table C-7: Indonesia Seismic Design Factors

Variable Definition

Value

\begin{tabular}{ccc}
\hline $\mathrm{W}_{\mathrm{t}}$ & Effective weight of Structure & $\begin{array}{l}\text { Combination of the total vertical } \\
\text { dead load and the reduced vertical } \\
\text { live load }\end{array}$ \\
$\mathrm{C}_{\mathrm{d}}$ & Spectral Design Value & $C^{*} K^{*} I$ \\
$\mathrm{C}$ & Basic seismic coefficient & Figure C-2 and Figure C-3 \\
$\mathrm{I}$ & Importance factor & Table C-8 \\
$\mathrm{K}$ & Structural Factor & Table C-9 \\
\hline
\end{tabular}

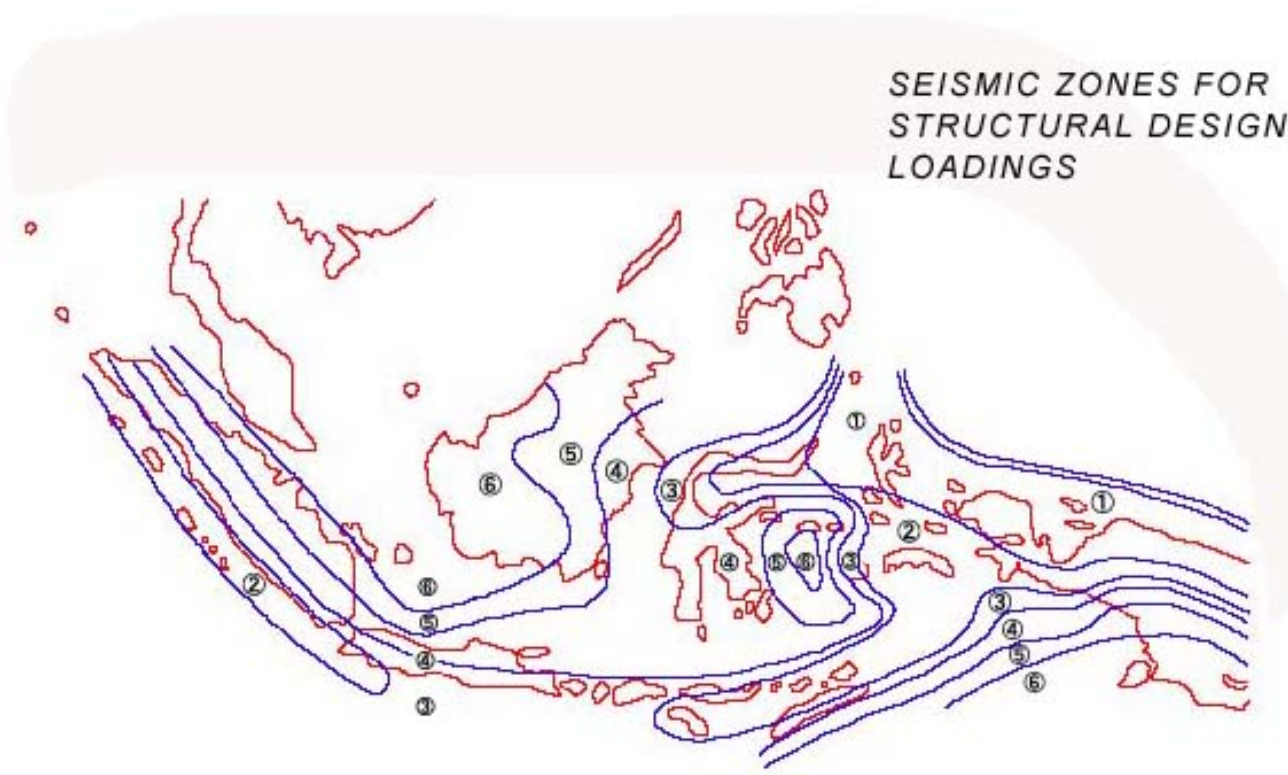

Figure C-2: Seismic Zones for Indonesia

C-6 

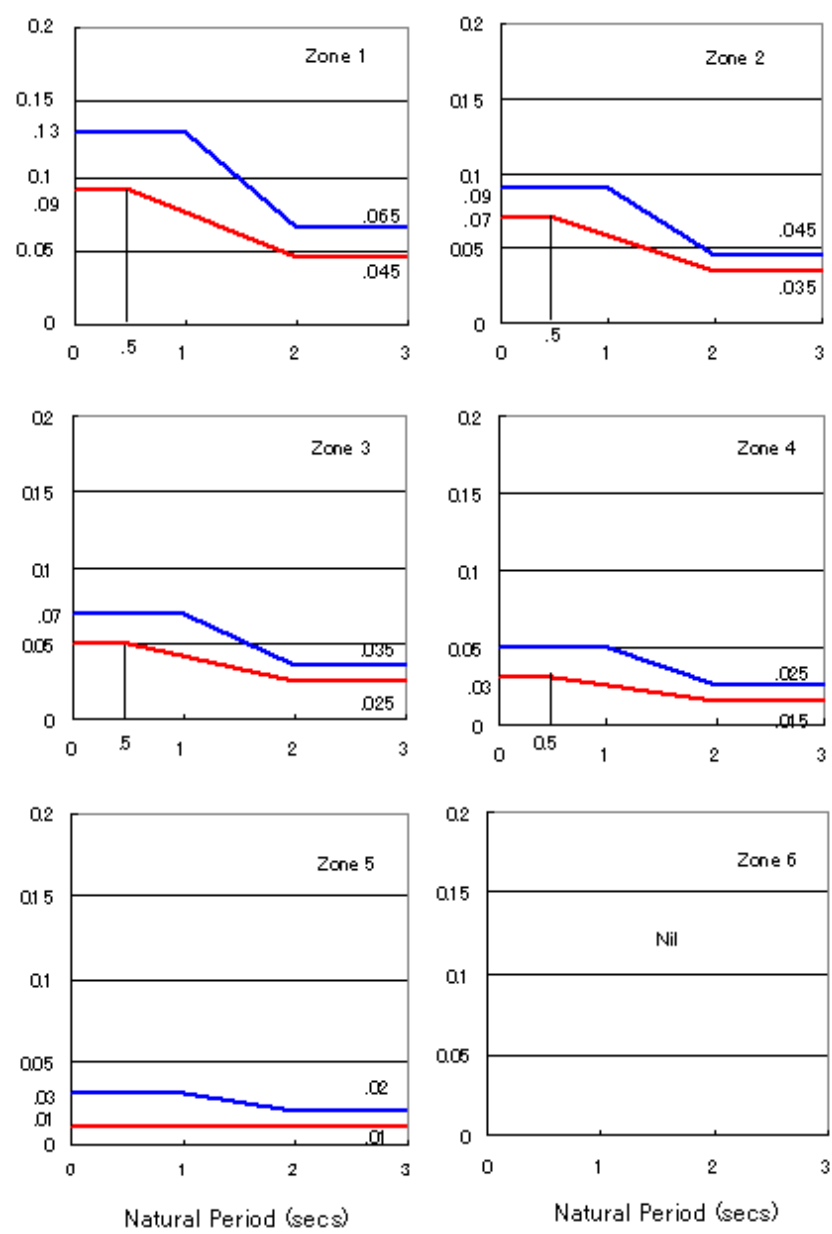

Figure C-3: Indonesia zone based Seismic Design Spectra

Table C-8: Importance factors for Buildings in Indonesia

IMPORTANCE FACTOR I

\begin{tabular}{|lc}
\hline a. Monumental Buildings & 1.5 \\
\hline $\begin{array}{l}\text { b. Essential facilities that should remain functional after an } \\
\text { earthquake }\end{array}$ & 1.5 \\
$\begin{array}{l}\text { c. Distribution facilities for gas or petroleum products in urban } \\
\text { areas }\end{array}$ & 2 \\
$\begin{array}{l}\text { d. Structures for the support or containment of dangerous } \\
\text { substances (such as acids, toxic substances etc) }\end{array}$ & 2 \\
\hline e. Other structures & 1 \\
\hline
\end{tabular}

C-7 
Table C-9: Structural factor for Indonesian Building

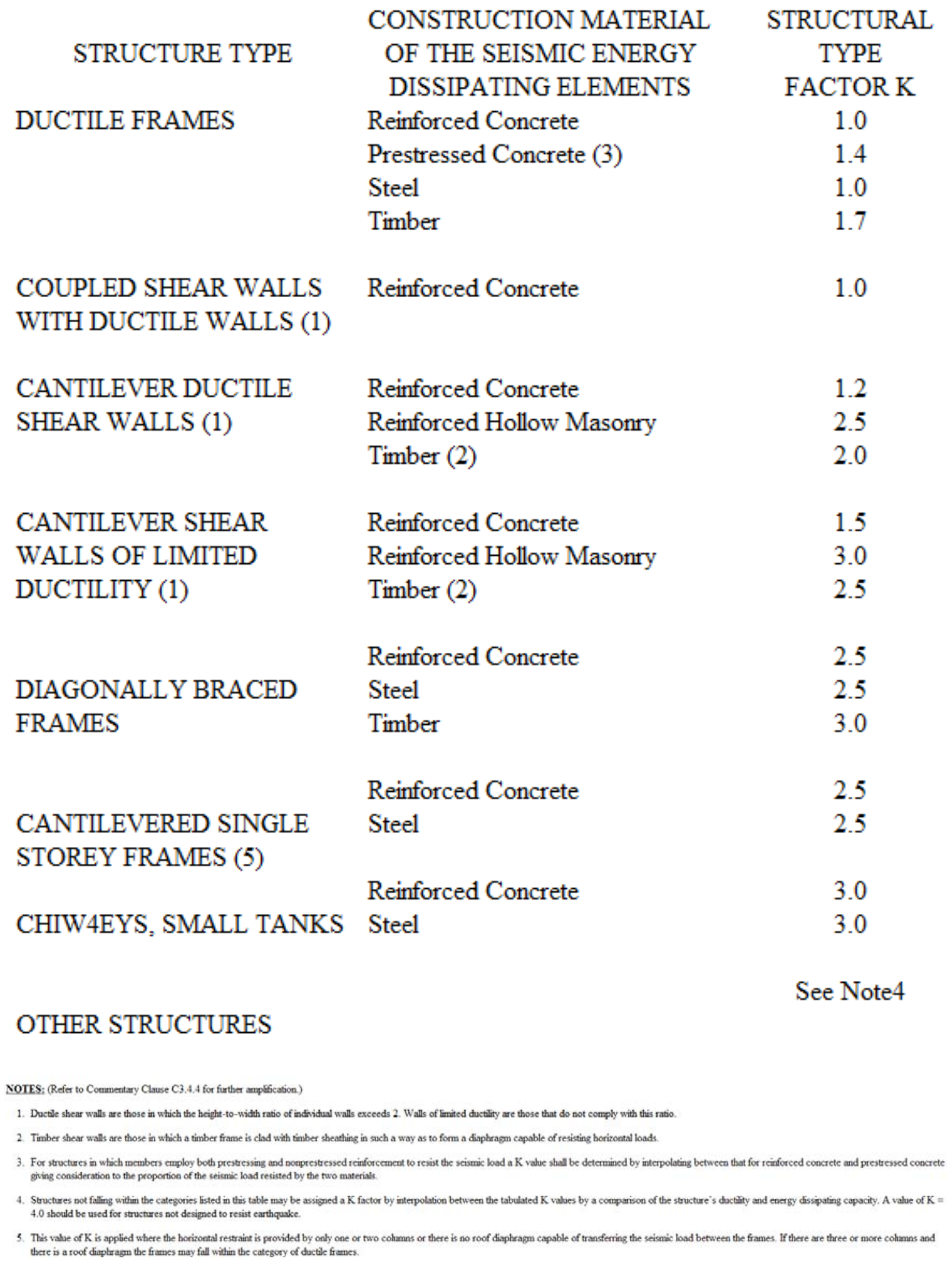

C-8 
Excluding the considerations of structure nonlinear performance and difference caused by the occupancy category, i.e. setting $\mathrm{K}$ and I equal to 4.0 and 1.0 according to Table C-8 and Table C-9, the value of $\mathrm{C}_{\mathrm{d}}$ obtained from Table C-7 is the estimate of DBE spectral acceleration. The MCE spectral acceleration values for all the seismic zones in Indonesia and other factors used in the calculation are provided in Table C-10.

Table C-10: Location based design factors

\begin{tabular}{|c|c|c|c|c|c|c|}
\hline \multirow{2}{*}{ Zone } & \multicolumn{2}{|c|}{ Base Seismic Coefficient C } & \multicolumn{2}{c|}{ C $_{d}$ Factor } & \multicolumn{2}{c|}{ MCE } \\
\cline { 2 - 7 } & Soft Ground & Firm Ground & Soft Ground & Firm Ground & Soft Ground & Firm Ground \\
\hline Zone 1 & 0.13 & 0.09 & 0.52 & 0.36 & $0.78^{-*}$ & 0.54 \\
\hline Zone 2 & 0.09 & 0.07 & 0.36 & 0.28 & 0.54 & 0.42 \\
\hline Zone 3 & 0.07 & 0.05 & 0.28 & 0.2 & 0.42 & 0.3 \\
\hline Zone 4 & 0.05 & 0.03 & 0.2 & 0.12 & 0.3 & 0.18 \\
\hline Zone 5 & 0.03 & 0.01 & 0.12 & 0.04 & 0.18 & 0.06 \\
\hline Zone 6 & N/A & N/A & N/A & N/A & N/A & N/A \\
\hline
\end{tabular}

${ }^{*}$ the worst scenario which will be used in Chapter 8 for CMR calculation

\section{United States- Cal Poly Site}

For the Cal Poly Site, the design spectrum shown in Figure C-4, which was generated by the procedure recommended by ASCE 7 based on the spectral coefficient provided by the (USGS), was used for determining the spectral acceleration. Excluding the consideration of structure nonlinear performance and difference caused by the occupancy category, the DBE and MCE spectral acceleration values are determined to be $0.84 \mathrm{~g}$ and $1.26 \mathrm{~g}$ respectively. 


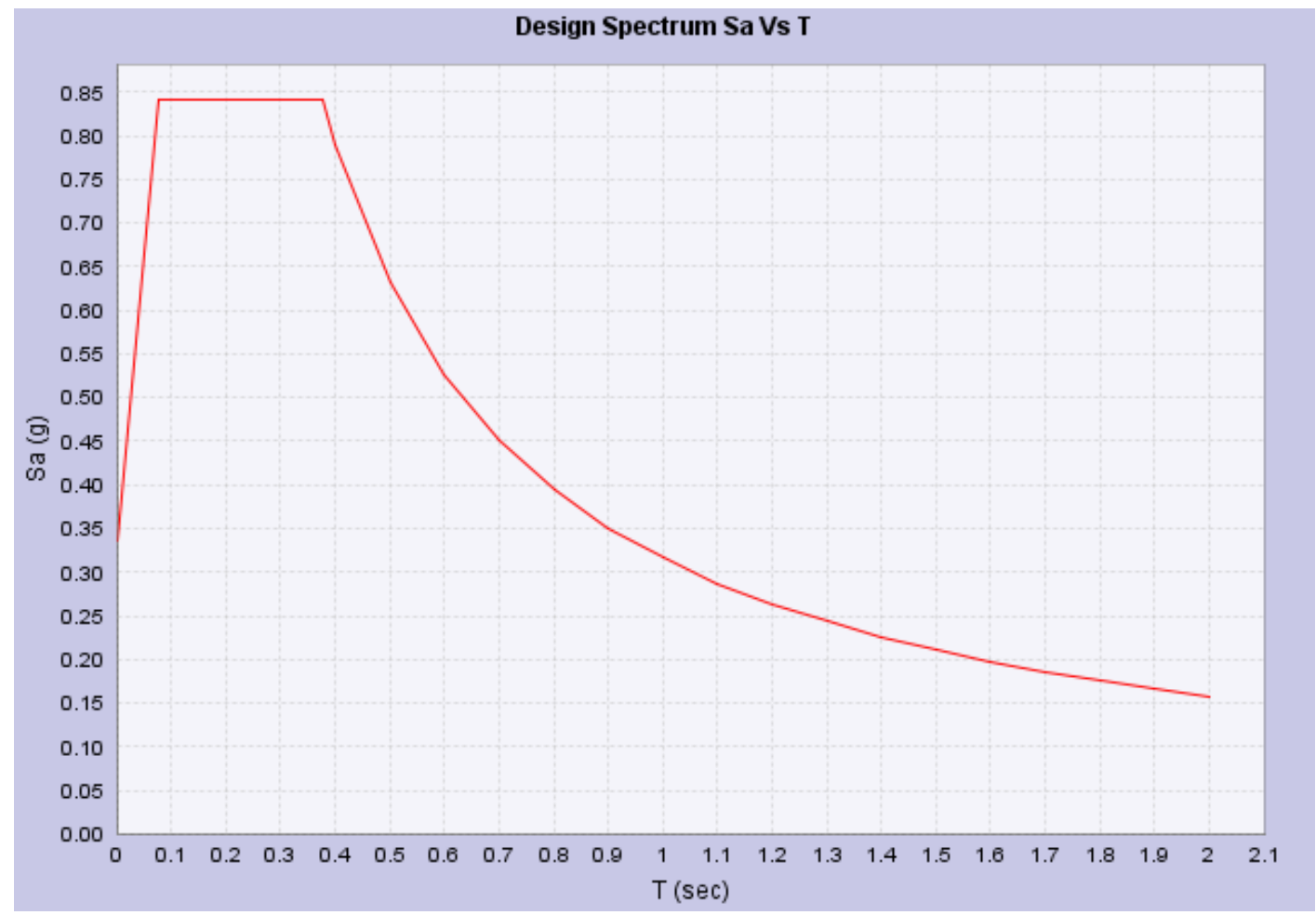

Figure C-4: Design Spectra for Cal Poly assuming site class B 